


\section{Epistemic Duties}

There are arguably moral, legal, and prudential constraints on behavior. But are there epistemic constraints on belief? Are there any requirements arising from intellectual considerations alone? This volume includes original essays written by top epistemologists that address this and closely related questions from a variety of new, sometimes unexpected, angles. It features a wide variety of positions, ranging from arguments for and against the existence of purely epistemic requirements, reductions of epistemic requirements to moral or prudential requirements, the biological foundations of epistemic requirements, extensions of the scope of epistemic requirements to include such things as open-mindedness, eradication of implicit bias and interpersonal duties to object, to new applications such as epistemic requirements pertaining to storytelling, testimony, and fundamentalist beliefs. Anyone interested in the nature of responsibility, belief, or epistemic normativity will find a range of useful arguments and fresh ideas in this cutting-edge anthology.

Kevin McCain is Associate Professor of Philosophy at the University of Alabama at Birmingham. His published works include: Evidentialism and Epistemic Justification (Routledge, 2014), The Nature of Scientific Knowledge: An Explanatory Approach (2016), and with Kostas Kampourakis Uncertainty: How It Makes Science Advance (2019).

Scott Stapleford is Professor of Philosophy at St. Thomas University, Fredericton. $\mathrm{He}$ is the author of Kant's Transcendental Arguments: Disciplining Pure Reason (2008), coauthor (with Tyron Goldschmidt) of Berkeley's Principles: Expanded and Explained (Routledge, 2016) and Hume's Enquiry: Expanded and Explained (Routledge, forthcoming), and coauthor (with Lorne Falkenstein and Molly Kao) of Logic Works: A Rigorous Introduction to Formal Logic (Routledge, forthcoming). 


\section{Routledge Studies in Epistemology}

Edited by Kevin McCain, University of Alabama at Birmingham, USA and Scott Stapleford, St. Thomas University, Canada

New Issues in Epistemological Disjunctivism

Edited by Casey Doyle, Joseph Milburn, and Duncan Pritchard

Knowing and Checking

An Epistemological Investigation

Guido Melchior

Well-Founded Belief

New Essays on the Epistemic Basing Relation

Edited by J. Adam Carter and Patrick Bondy

Higher-Order Evidence and Moral Epistemology

Edited by Michael Klenk

Social Epistemology and Relativsm

Edited by Natalie Alana Ashton, Martin Kusch, Robin McKenna and

Katharina Anna Sodoma

Epistemic Duties

New Arguments, New Angles

Edited by Kevin McCain and Scott Stapleford

The Ethics of Belief and Beyond

Understanding Mental Normativity

Edited by Sebastian Schmidt and Gerhard Ernst

Ethno-Epistemology

New Directions for Global Epistemology

Edited by Masaharu Mizumoto, Jonardon Ganeri, and Cliff Goddard

The Dispositional Architecture of Epistemic Reasons

Hamid Vabid

For more information about this series, please visit: www.routledge.com/ Routledge-Studies-in-Epistemology/book-series/RSIE 


\section{Epistemic Duties \\ New Arguments, New Angles}

\section{Edited by Kevin McCain and Scott Stapleford}


First published 2021

by Routledge

52 Vanderbilt Avenue, New York, NY 10017

and by Routledge

2 Park Square, Milton Park, Abingdon, Oxon OX14 4RN

Routledge is an imprint of the Taylor \& Francis Group, an informa business

(C) 2021 Taylor \& Francis

The right of the editors to be identified as the authors of the editorial material, and of the authors for their individual chapters, has been asserted in accordance with sections 77 and 78 of the Copyright, Designs and Patents Act 1988.

With the exception of Chapter 14, no part of this book may be reprinted or reproduced or utilised in any form or by any electronic, mechanical, or other means, now known or hereafter invented, including photocopying and recording, or in any information storage or retrieval system, without permission in writing from the publishers.

Chapter 14 of this book is available for free in PDF format as Open Access from the individual product page at www.routledge.com. It has been made available under a Creative Commons Attribution-Non Commercial-No Derivatives 4.0 license.

Trademark notice: Product or corporate names may be trademarks or registered trademarks, and are used only for identification and explanation without intent to infringe.

Library of Congress Cataloging in Publication Data

Names: McCain, Kevin, 1980- editor. I Stapleford, Scott, 1973- editor.

Title: Epistemic duties: new arguments, new angles /

edited by Kevin McCain and Scott Stapleford.

Description: New York: Routledge, 2020. I

Series: Routledge studies in epistemology I

Includes bibliographical references and index.

Identifiers: LCCN 2019059792 (print) I LCCN 2019059793 (ebook) I

ISBN 9780367141103 (hbk) I ISBN 9780429030215 (ebk)

Subjects: LCSH: Knowledge, Theory of. I Ethics. I Duty.

Classification: LCC BD176.E65 2020 (print) I

LCC BD176 (ebook) I DDC 121/.6-dc23

LC record available at https://lccn.loc.gov/2019059792

LC ebook record available at https://lccn.loc.gov/2019059793

ISBN: 978-0-367-14110-3 (hbk)

ISBN: 978-0-429-03021-5 (ebk)

Typeset in Sabon

by Newgen Publishing UK 
For those who believe as they should 
$\because$ Taylor \& Francis Taylor \& Francis Group

http://taylorandfrancis.com 


\section{Contents}

List of Contributors

Acknowledgments

Introductory Note

KEVIN MCCAIN AND SCOTT STAPLEFORD

\section{PART I}

The Nature of Epistemic Duty 5

1 Epistemic Duty, Justified Belief, and Voluntary Control 7 MATTHIAS STEUP

2 Believing Badly: Doxastic Duties Are Not Epistemic Duties MIRIAM SCHLEIFER MCCORMICK

3 Evading the Doxastic Puzzle by Deflating Epistemic Normativity

LUIS OLIVEIRA

4 Epistemic Tension and Epistemic Duty: A Rossian Account MARK T. NELSON

5 Intellectual Responsibility and the Scope of the Will ROBERT AUDI

6 We are Like American Robins 
viii Contents

PART II

Epistemic Duties of Individuals

7 Bound by the Evidence

SCOTT STAPLEFORD AND KEVIN MCCAIN

8 Epistemic Duty and Implicit Bias

LINDSAY RETTLER AND BRADLEY RETTLER

9 Robust Justification

JONATHAN MATHESON

10 Ought to Believe vs. Ought to Reflect ANTHONY ROBERT BOOTH

11 Wisdom, Open-Mindedness, and Epistemic Duty SHARON RYAN

12 On What We Should Believe (and When (and Why) We Should Believe What We Know We Should Not Believe) CLAYTON LITTLEJOHN

13 The Normative Ground of the Evidential Ought 208 ANNE MEYLAN

\section{PART III}

Social Epistemic Duties

14 Responsibility for Fundamentalist Belief RIK PEELS

15 Trust, Testimony, and Reasons for Belief REBECCA WALLBANK AND ANDREW REISNER

16 When the Personal Becomes Political: How do We Fulfil Our Epistemic Duties Relative to the Use of Autobiographical Stories in Public Debates? 
17 Dialectical Responsibility and Regress Skepticism 268 SCOTT AIKIN

18 Epistemic Duties Regarding Others 281 JENNIFER LACKEY

Index 296 


\section{Contributors}

Scott Aikin-Vanderbilt University

Robert Audi-University of Notre Dame

Anthony Robert Booth-University of Sussex

Lisa Bortolotti-University of Birmingham

Jennifer Lackey- Northwestern University

Clayton Littlejohn-King's College London

Jonathan Matheson-University of North Florida

Kevin McCain-University of Alabama at Birmingham

Miriam Schleifer McCormick-University of Richmond

Anne Meylan-University of Zurich

Mark T. Nelson-Westmont College

Luis Oliveira-University of Houston

Rik Peels-Vrije Universiteit Amsterdam

Andrew Reisner-Uppsala University

Bradley Rettler-University of Wyoming

Lindsay Rettler-University of Wyoming

Sharon Ryan-West Virginia University

Sophie Stammers-University of Birmingham

Scott Stapleford-St. Thomas University

Matthias Steup-University of Colorado-Boulder

Ema Sullivan-Bissett-University of Birmingham

Rebecca Wallbank-Uppsala University 


\section{Acknowledgments}

We are grateful to Andrew Weckenmann and Allie Simmons at Routledge for their support and help in moving this project from an idea to the present volume. And we are grateful to each of the volume contributors for providing the excellent essays that make this volume what it is. 
$\because$ Taylor \& Francis Taylor \& Francis Group

http://taylorandfrancis.com 


\title{
Introductory Note
}

\author{
Kevin McCain and Scott Stapleford
}

The language of duty and obligation has deep roots in epistemology. Descartes (1596-1650) maintained that in the search for truth "[w]hat is doubtful should even be considered as false" (1644/1989, 160, emphasis added). John Locke (1632-1704) claimed that if a person has insufficient reasons for the things he believes, then he "neither seeks truth as he ought, nor pays the obedience due his maker" (1690/1959, 413-414, emphasis added). And most famously, of course-perhaps even infamously-William K. Clifford (1845-1879) asserted that "it is wrong always, everywhere, and for anyone, to believe anything upon insufficient evidence" (1879, 183, emphasis added).

While many reject this tradition, there's something undeniably bad about forming beliefs in irrational ways. Believing poorly is undesirable from a practical point of view, if nothing else. After all, doing so is liable to frustrate the attempt to achieve one's aims. And some might agree with Clifford that we are morally required to believe in accordance with the evidence. But there are other questions to ask. May we believe whatever we want? Do we have duties that are purely epistemic? Is there something epistemically wrong with forming beliefs ahead of the evidence? There is a sizeable literature on the ethics of belief dealing with these and related matters. Despite the vigorous debates, certain angles have not been considered. The essays collected here are the cutting edge in the field. They offer new arguments for a variety of positions, and new angles for contemplation.

The volume is divided into three parts. The essays in Part I explore the nature of epistemic duty. Matthias Steup takes on William Alston in Chapter 1, arguing that his case against construing epistemic justification in terms of epistemic duties is unsuccessful. Additionally, Steup provides an analysis of various evidentialist conceptions of our epistemic duty, settling on one in which our epistemic duty is to avoid believing what our evidence doesn't support and to believe no more, but also no less, informational content than our considered evidence supports. In Chapter 2, Miriam Schleifer McCormick argues that any duties we have to believe are not purely epistemic. In fact, McCormick maintains that when we fall short as believers it is because we have failed to meet the appropriate expectations of other people. Next, in Chapter 3, Luis Oliveira explores what he calls the "evasive strategy" for responding to Alston's puzzle for reconciling the most natural way of understanding epistemic 


\section{Kevin McCain and Scott Stapleford}

justification talk with our limited control over the beliefs we form. Ultimately, Oliveira argues that this strategy leads us to a deflationary picture of epistemic normativity, but that such a picture is actually a good thing. In Chapter 4, Mark T. Nelson examines the phenomenon of epistemic tension-the feeling of being pulled between two incompatible, yet equally plausible ideas. Nelson argues that there is no epistemic duty to relieve such tension as quickly as possible because epistemic tension can teach us something about the nature of epistemic justification. In Chapter 5, Robert Audi develops a conceptual and psychological framework for thinking about intellectual responsibility. This framework allows Audi to distinguish five kinds of standards governing our intellectual responsibilities. Ema Sullivan-Bissett wraps up this part of the book by arguing that there are no distinctively epistemic duties in Chapter 6. Rather, she argues, the only sense in which we ought to do something epistemically is the sense in which an American robin ought to build a nest.

Part II contains essays focused on epistemic duties for individual agents. In the first (Chapter 7), Scott Stapleford and Kevin McCain push back against extreme views of epistemic obligation. More specifically, they argue that while we are not required on epistemic grounds to conduct inquiry or gather evidence, we do have an epistemic duty to get our beliefs into line with our evidence through reflection. Lindsay Rettler and Bradley Rettler argue, in Chapter 8, that we have an epistemic duty to eradicate implicit biases that have negative epistemic impacts. They acknowledge that we have this duty only if we also have adequate control over our implicit biases. But once we properly understand the nature of the requisite control, they say, we'll find empirical evidence that we have it. Jonathan Matheson supplements evidentialism with a new conception of robust justification in Chapter 9. According to Matheson, to be robustly justified in believing $p$ at $t$, the subject's evidence must support $p$ at $t$ (the standard evidentialist requirement), and the body of evidence must have been acquired through a process of responsible inquiry (the supplement). Next, in Chapter 10, Anthony Robert Booth argues that our duties with respect to belief are exhausted by the duty to reflect. In particular, Booth claims that, once you have met your obligation to reflect, it is impossible to fail to meet your doxastic obligations. Sharon Ryan asks, in Chapter 11, whether we have an epistemic duty to be open-minded. She argues that while there are varieties of open-mindedness that are not virtuous, there is a type of open-mindedness that is both virtuous and a necessary condition of wisdom. In Chapter 12, Clayton Littlejohn seeks to connect two parts of epistemology: the nature and extent of knowledge and what we ought to believe. Though his own proposal is that what we ought to believe is connected to facts about what we can know, Littlejohn's main goal in the chapter is to offer a general framework from which to address questions concerning what we ought to believe. Anne Meylan concludes this part of the volume with a look at the normative ground of the evidential ought in Chapter 13. She distinguishes instrumentalism from intrinsicalism and argues that there is only one viable way of being an intrinsicalist - the constitutive version holds up, while the intrinsic version does not. 
Part III of the volume moves beyond individual epistemic duties to the social dimensions of epistemic normativity. It begins with Rik Peels' consideration of the nature of fundamentalist belief and how people can be responsible for holding such beliefs in Chapter 14. He argues that the existing models of fundamentalist belief are lacking, and that an empirically informed philosophical model of fundamentalist belief is required. Rebecca Wallbank and Andrew Reisner discuss two distinct kinds of testimonial trust-evidential and nonevidential-in Chapter 15. They argue that neither kind of trust provides an evidential reason for belief, but it may be that non-evidential testimonial trust can provide a novel sort of epistemic reason. Next, in Chapter 16, Sophie Stammers and Lisa Bortolotti discuss how autobiographical stories are used as evidence in political debates. Although they argue that such stories may offer insights into the perspectives of those involved in such debates, the stories themselves are unlikely to provide support for their target claims without being supplemented by additional evidence. In Chapter 17, Scott Aikin examines the regress problem for epistemic justification through the lens of dialectical responsibility. In the end, he concludes that dialectical forms of foundationalism capable of solving the regress problem face a dilemma concerning how one can responsibly terminate the regress of reasons. Jennifer Lackey closes the volume by arguing that we have other-regarding epistemic duties towards both individuals and communities in Chapter 18. She maintains that epistemology has deep similarities to ethics and is much more social than has been previously appreciated.

\section{References}

Clifford, W. K. 1879. Lectures and Essays. London: Macmillan.

Descartes, Rene. 1989. Descartes: Selected Philosophical Writings, ed./tr. John Cottingham, tr. Robert Stoothoff and Dugald Murdoch. Cambridge: Cambridge University Press.

Locke, John. 1690. An Essay Concerning Human Understanding, ed. A. C. Fraser. New York: Dover Publishing. 
$\because$ Taylor \& Francis Taylor \& Francis Group

http://taylorandfrancis.com 


\section{Part I}

\section{The Nature of Epistemic Duty}


$\because$ Taylor \& Francis Taylor \& Francis Group

http://taylorandfrancis.com 


\title{
1 Epistemic Duty, Justified Belief, and Voluntary Control
}

\author{
Matthias Steup
}

\section{Deontological vs. Non-Deontological Justification}

In his seminal paper "Concepts of Epistemic Justification," William Alston distinguishes between a deontological and a non-deontological concept. ${ }^{1}$ According to the deontological concept, $\mathrm{J}_{\mathrm{d}}$, justification is a matter of duty fulfillment. A belief that $p, \mathrm{~B} p$, is deontologically justified, $\mathrm{J}_{\mathrm{d}}$, iff $\sim \mathrm{O}(\sim \mathrm{B} p)$, that is, iff one doesn't have an epistemic obligation to refrain from believing $p .^{2}$ Alternative definitions are on offer, made available by more or less plausible synonymy relations between various deontic terms. For example, a synonymous alternative definition of $\mathrm{J}_{\mathrm{d}}$ is this: $\mathrm{B} p$ is $\mathrm{J}_{\mathrm{d}}$ iff $\mathrm{B} p$ is permissible. The definition Alston settles on is this one: $\mathrm{B} p$ is $\mathrm{J}_{\mathrm{d}}$ iff $\mathrm{B} p$ is epistemically blameless. While the synonymy of 'permissible' and 'not obligatory' is unproblematic, identifying permissibility with blamelessness is not. I'll return to this point further below.

Alston thinks that $\mathrm{J}_{\mathrm{d}}$ is not the same as genuine epistemic justification, $\mathrm{J}_{\mathrm{e}}$. He takes it that only a non-deontological concept captures what we have in mind when we classify a belief as epistemically justified. But what would it be for a belief to be non-deontologically justified? According to Alston, a belief is non-deontologically justified, $\mathrm{J}_{\text {nd }}$, if having that belief is a good thing from the epistemic point of view, where the goodness in question has nothing to do with the fulfillment of any epistemic duties. ${ }^{3}$ This formula doesn't say much unless we are told what it is for a belief to be a 'good' belief from the epistemic point of view. Alston proposes a teleological understanding of epistemic goodness. The basic idea is that the kind of goodness that renders beliefs epistemically justified is a species of ends-means rationality. Forming beliefs that are epistemically good is the means to achieve the cognitive goal of maximizing truth and minimizing falsehood in a large system of beliefs. ${ }^{4}$ On this approach, a belief is $\mathrm{J}_{\mathrm{e}}$ iff it is formed in a truth-conducive way: in a way that is conducive to achieving the cognitive goal just mentioned.

Alston rejects $J_{d}$ on the basis of two arguments. According to the first, beliefs in particular and propositional attitudes in general are unsuitable for deontological evaluation because we don't have voluntary control over them. According to the second, $\mathrm{J}_{\mathrm{d}}$ fails to secure truth-conducive belief formation and thus falls short of being genuine epistemic justification. It doesn't deliver the goods when it comes to the goal of maximizing truth in a large belief system. 


\section{Matthias Steup}

I will argue that Alston's arguments against identifying $\mathrm{J}_{\mathrm{e}}$ with $\mathrm{J}_{\mathrm{d}}$ fail. First, however, I will focus on the concept of epistemic duty and explore exactly what our epistemic obligations are.

\section{Unconstrained Evidentialism}

It is undeniable that $\mathrm{J}_{\mathrm{e}}$ is intimately tied up with the notion of truth. Since, as a purely conceptual matter, evidence is evidence of truth, it's natural to link $\mathrm{J}_{\mathrm{e}}$ to the possession of evidence. Let 'Ep' stand for 'your total evidence supports $p$ '. To say that your total evidence supports $p$ is to say that your total evidence makes it likely that $p$ is true. Likelihood of truth-that is what evidence is all about. Starting out with this thought, there is a straightforward way of fixing what our epistemic duty is: it is to believe in accord with our evidence. According to what we might call Unconstrained Evidentialism, this duty breaks down into two sub-duties:

$$
\begin{aligned}
& \mathrm{D} 1 \sim \mathrm{O}(\sim \mathrm{B} p) \rightarrow \mathrm{E} p \\
& \text { D2 } \mathrm{E} p \rightarrow \mathrm{O}(\mathrm{B} p) .
\end{aligned}
$$

According to $\mathrm{D} 1, \mathrm{E} p$ is necessary for $\mathrm{B} p$ to be permissible. According to $\mathrm{D} 2, \mathrm{E} p$ is sufficient for $\mathrm{B} p$ to be obligatory. Each of these duties is surprisingly problematic. Though evidentialists are unlikely to reject D1 as false, they might disagree about the nature of the ought D1 is about. That is, they might have different views on the kind of normativity the antecedent of D1 is about. There are three options: the ought in question is (i) sui generis, constituting an independent and irreducible domain of normativity; (ii) it is the ought of prudential rationality; (iii) it is the ought of morality. ${ }^{5}$ While option (i) would secure an epistemically pure version of evidentialism, it is not clear to me that (ii) and (iii) pose a threat to evidentialism. Consider (ii). If epistemic normativity is a species of prudential normativity, there will then be two different types of prudential oughts: epistemic and non-epistemic prudential oughts. Here is an analogy: dogs are not a sui generis genus of animal. Rather, they are mammals. But within the genus mammal, dogs constitute their own distinctive species. Likewise with epistemic normativity. Even if epistemic normativity is ultimately prudential, epistemic and non-epistemic oughts will nevertheless be distinctive species, just like dogs and cats are distinctive species of mammals. Analogous reasoning applies to option (iii). Here, I will not argue for or against any of these three options.

\section{The Infinity Problem}

The worry about D2 is that it is excessively demanding. If you have evidence for $p$, you thereby have evidence for all obvious deductive consequences of $p$. For example, $p$ entails an infinite number of disjunctions: $p \mathrm{v} q, p \mathrm{v} r$, etc. Hence, if you have evidence for $p$, then you have evidence for an infinite number of disjunctions. D2 says you ought to believe $p$ if you have evidence for $p$. So, D2 generates an epistemic duty to believe an infinite number of disjunctions. ${ }^{6}$ 
That's problematic. Since we cannot believe an infinite number of disjunctions, D2 generates an epistemic duty we cannot meet. As a result, D2 makes epistemic sin inescapable. No matter how epistemically virtuous you are, you cannot help failing massively in the attempt to live up to epistemic duty. A normative theory with such consequences, it seems to me, is highly suspect.

The epistemic duty to believe an infinite number of deductive consequences can be avoided by limiting the antecedent of D2. We could say that you have a duty to believe $p$ if you have evidence for $p$ and you consider $p$. This gives us:

$$
\mathrm{D} 2 *(\mathrm{E} p+\mathrm{C} p) \rightarrow \mathrm{O}(\mathrm{B} p) .
$$

According to D2*, it's only your considered evidence that determines what you ought to believe. Let's call this view C-Constrained Evidentialism. Since you cannot consider an infinite number of propositions, this version of evidentialism does not generate a duty to believe an infinite number of deductive consequences. Alas, C-Constrained Evidentialism runs into another problem.

\section{The Epistemic Felicity Problem}

Suppose the following is true of me:

(1) I'm hungry.

Unless something weird is going on, we can go from (1) to:

(2) E(I'm hungry).

Since (1) obviously entails a trivial and utterly uninformative disjunction such as

(3) I'm hungry or Napoleon is hungry,

we have as well:

(4) $\mathrm{E}$ (I'm hungry or Napoleon is hungry).

Suppose I consider (3). D2* tells us that I ought to believe (3). Is this plausible? An epistemic duty to believe a disjunction need not be objectionable. Suppose Sherlock Holmes has two strong pieces of evidence. The first suggests that the butler did it, the second that the gardener did it. It's plausible to say Holmes ought to believe:

(5) The butler did it or the gardener did it.

It seems to me, however, that there is a significant difference between Holmes believing (5) and me believing (3). Here is a Gricean rule of felicitous 
conversation: "Make your contribution as informative as is required (for the current purposes of the exchange)." S Suppose Watson were to ask Holmes: "Whom do you suspect?" If Holmes asserted (5), he would not be violating this Gricean rule. However, if someone asked me whether I was hungry and I replied by asserting (3), I clearly would. Could it be that, whereas asserting (3) would be conversationally infelicitous, adding (3) to my belief system would be epistemically felicitous? Let's see whether saying 'no' can be defended.

Here is a suggestion I will briefly explore: we should distinguish between evidential support and epistemic felicity. $\mathrm{E} p$ supports $\mathrm{B} p$ iff $\mathrm{E} p$ raises the probability of $p$ above $0.5 . \mathrm{B} p$ is epistemically felicitous iff $\mathrm{B} p$ fits your evidence. Evidential support is a necessary condition of evidential fit. But evidential support is not sufficient for evidential fit. Thus, we get the following possible situation: although your total evidence supports believing $p$, believing $p$ would be epistemically infelicitous.

According to evidentialism, it's our duty to follow our evidence. Arguably, that doesn't mean that, according to evidentialism, it's our duty to believe everything our total evidence supports. Rather, evidentialism, properly construed, tells us that we ought to proportion our beliefs to our evidence. If we do that, our beliefs fit our evidence. ${ }^{8}$ To proportion our beliefs to our evidence, we must, as a first approximation, do two things: not believe more, and not believe less, than our considered evidence supports. ${ }^{9}$ For example, when I am hungry and I believe (3) instead of (1), then I believe less than my evidence supports. Therefore, if I believe (3) but not (1), I don't proportion my belief to my evidence. This makes my believing (3) epistemically infelicitous.

But what about believing (1) and (3)? Suppose I consider both (1) and (3). Let E1 be my awareness of my being hungry. Let E2 be my recognition that that (1) entails (3). E1 supports believing (1). E2 supports believing (3). E1 and E2 jointly support believing (1) and believing (3). If I acquire both beliefs, I believe (3) in addition to (1). Now I no longer believe less than my evidence supports. Nor do I believe more than my evidence supports.

According to evidentialism, do E1 and E2 make it the case that I ought to believe both (1) and (3)? I would prefer to say 'no'. The proposal I'm exploring defends saying 'no' on the ground that having both beliefs would not be epistemically felicitous. For this move to work, epistemic felicity would have to involve more than believing no more and no less than one's evidence supports. Perhaps we could say that epistemic felicity is to believe no more and no less than one's evidence informationally supports. Compare:

(1) I'm hungry.

(3) I'm hungry or Napoleon is hungry.

(7) I'm hungry and Napoleon is hungry.

It's plausible to say that (3) is weaker than (1) and (7) is stronger than (1). (3) carries less, and (7) carries more, information than (1) does. This appeal to informational strength calls for elaboration. Here, I will deploy the concept 
of informational strength without offering anything in the way of an analysis of that concept. I merely want to suggest that the following claim might be defensible: believing $p$ is epistemically felicitous iff believing $p$ fits the informational content of my evidence.

So, given E1 and E2, what ought I to believe? According to the proposal under consideration, while I ought to believe (1), it's not the case that I ought to believe (3). Believing (3) in addition to (1) does not add informational content to my belief system. Therefore, believing (3) does not fit the informational content of my evidence. So, believing (3) would be an instance of epistemic infelicity. This secures the outcome that, according to the proposal under consideration, my having evidence E1 and E2 does not make it the case that I ought to believe (3). ${ }^{10}$

It could be objected that, surely, I ought to take (3) to be true. And if it's my epistemic duty to take (3) to be true, doesn't that mean I ought to believe (3)? My reply is that taking a proposition to be true is one thing, adding that proposition to one's belief system is another. I recognize that (3) is a logical consequence of my belief that I'm hungry. Thus, there is a further proposition I ought to believe, namely

(8) (3) is a logical consequence of (1).

And since I take (1) to be true, I ought to take (3) to be true. But, it seems to me, from the fact that I ought to believe (8) and take (3) to be true, it doesn't follow that I ought to add (3) to my belief system.

According to this proposal, a proper articulation of evidentialism calls for a fine-grained account of our propositional attitudes. It seems to me that, if we wish to avoid an epistemic duty to believe vacuous disjunctions, such a finegrained account is necessary.

\section{Moderate Evidentialism and Doxastic Omission}

With the idea of epistemic felicity in place, we can now replace D2* with:

$$
\mathrm{D} 2 * * \quad[\mathrm{E} p+\mathrm{C} p+\mathrm{F}(\mathrm{B} p)] \rightarrow \mathrm{O}(\mathrm{B} p) \cdot{ }^{11}
$$

If we conjoin D1 with D2**, we arrive at a version of evidentialism that is constrained along two parameters: what determines epistemic duty is the informational strength of your considered evidence. Let's call this view CFConstrained Evidentialism. Like the earlier, less constrained versions of evidentialism, the CF-Constrained version says that $\mathrm{B} p$ is permissible only if Ep. Unlike the unconstrained view, CF-Constrained Evidentialism requires $\mathrm{B} p$ only when your total evidence supports a proposition you consider and believing that proposition is epistemically felicitous. What motivates the step from $\mathrm{D} 2 *$ to $\mathrm{D} 2 * *$ is the thought that one has an epistemic obligation to believe $p$ only if believing $p$ would be epistemically felicitious: $\mathrm{O}(\mathrm{B} p) \rightarrow \mathrm{F}(\mathrm{B} p)$. 


\section{Matthias Steup}

Hence, according to D2**, if believing a proposition your evidence supports is epistemically infelicitous, then believing this proposition is not required: $\sim \mathrm{F}(\mathrm{B} p) \rightarrow \sim \mathrm{O}(\mathrm{B} p) .^{12}$

Let's focus a bit more on a situation like this: $\mathrm{E} p+\mathrm{C} p+\sim \mathrm{F}(\mathrm{B} p)$. Consider again:

(3) I'm hungry or Napoleon is hungry.

Given E(I'm hungry) and thus E(I'm hungry or Napoleon is hungry), disbelieving (3) and suspending judgment about (3) are impermissible. However, given that believing (3) would be epistemically infelicitous, believing (3) is also impermissible. Hence, we have:

I ought not disbelieve (3) + I ought not suspend judgment about (3) + I ought not believe (3).

Suppose I adjust my propositional attitudes accordingly. If I do that, my attitude cannot be identified with either believing (3), disbelieving (3), or suspending judgment about (3). Rather, it would be a fourth propositional attitude, namely doxastic omission: the attitude of neither believing (3), nor disbelieving (3), nor suspending judgment about (3).

The attitude of doxastic omission is a bit odd. I omit believing (3), but at the same time I take (3) to be true. The oddness of doxastic omission notwithstanding, it seems allowing for this attitude is inescapable if we agree that believing (3) would be no less infelicitous than asserting (3). Perhaps the attitude's oddity is outweighed by the benefit of suitably constraining the scope of epistemic duty. That is, if we allow for doxastic omission, we can say it isn't your epistemic duty to believe an utterly trivial disjunction such as (3).

Once again, we see that, if we wish to avoid an epistemic duty to believe vacuous disjunctions, we need a fine-grained account of propositional attitudes, that is, an account to goes beyond the traditional approach of identifying the primary, reflective propositional attitudes with belief, disbelief, and suspension of judgment. ${ }^{13}$

\section{Practical Interest Permissivism}

While CF-Constrained (Moderate) Evidentialism avoids an implausibly excessive scope of epistemic duty, it nevertheless ratifies a strong epistemic ought. If your total evidence supports $p$ and believing $p$ is epistemically felicitous, then, upon considering $p$, you ought to believe $p$. That's a positive epistemic duty. Mark Nelson has argued that such duties don't exist. ${ }^{14}$ Suppose you somehow stumble upon the information that

(1) Sergei Rachmaninov was born on April 1, 1873.

But you couldn't care less about when Rachmaninov was born. You have zero interest in this proposition. Since $p$ is now under your consideration, and 
since you have evidence for $p$, and since $p$ is not informationally vacuous, and since believing $p$ would therefore not be epistemically infelicitous, Moderate Evidentialism says you ought to add it to your belief system. Nelson finds such an ought implausible. According to him, your evidence for (1) has sufficient normative force to generate an epistemic ought only when paired with interest in (1). If (1) were to matter to you, then your evidence would make it epistemically obligatory for you to believe $p$. Since you couldn't care less about (1), it doesn't. Let's call this view Practical Interest Permissivism, or Permissivism for short. ${ }^{15}$ Permissivism differs from Moderate Evidentialism by replacing D** with:

$$
\mathrm{D} * * *[\mathrm{E} p+\mathrm{C} p+p \text { is interesting }] \rightarrow \mathrm{O}(\mathrm{B} p) \text {. }
$$

By making the epistemic ought dependent on practical interest, permissivism offers an attractive solution to the problem of vacuous disjunctions. Evidential purists, however, would want to reject the idea that the normative force of one's evidence is constrained by practical interests. They could object to $\mathrm{D}^{* * *}$ with the following argument.

\section{The Argument from Suspension}

Suppose again your total evidence supports the proposition

$$
p=\text { Sergei Rachmaninov was born on April 1, } 1873 .
$$

Alas, you have zero interest in $p$. Let ' $S p$ ' stand for 'suspending judgment about $p$ '. The argument begins with the following two premises:

(1) (Permissivism is true) $\rightarrow(\sim \mathrm{B} p$ is permissible for you)

(2) ( $\sim \mathrm{B} p$ is permissible for you $) \rightarrow(\mathrm{S} p$ is permissible for you).

The next premise tells us what it is to suspend judgment about $p$ : it is to judge that your total evidence fails to support $p$.

(3) $\mathrm{S} p=$ judging that $\sim \mathrm{E} p$.

However, we have stipulated that your total evidence supports $p$. We are considering an $\mathrm{E} p$ case, not a $\sim \mathrm{E} p$ case. Hence:

(4) $S p$ is not permissible for you.

Assuming there are exactly three propositional attitudes—belief, disbelief, and suspension-it then follows that not believing $p$ is not permissible for you because, given $\mathrm{E} p$, both $\mathrm{S} p$ and $\mathrm{B} \sim p$ are impermissible for you:

(5) $\sim(\sim \mathrm{B} p$ is permissible for you $)$.

And thus we arrive at the conclusion that: 


\section{Matthias Steup}

(6) Permissivism is false.

Nelson considers this argument and denies the second premise. According to him, the permissibility of $\sim \mathrm{B} p$ does not entail the permissibility of $S p$. Given lack of interest in $p, \sim \mathrm{B} p$ is permissible for you. But, given $\mathrm{E} p$, suspending judgment about $p$ is impermissible. In effect, this reply introduces doxastic omission as a fourth propositional attitude. Since advocates of CF-Constrained Evidentialism do so as well, they are hardly in a position to object to Nelson's denial of the second premise. They might, however, deploy a different argument against permissivism.

\section{The Pandora's Box Argument}

The basic idea of permissivism is that, if you have zero interest in $p$, then $\mathrm{E} p$ does not generate a positive duty to believe $p$. According to Limited Permissivismto be contrasted with Unbridled Permissivism-what's permissible in such a situation is believing $p$ and not believing $p$. Disbelieving and suspending judgment are impermissible. So, according to Limited Permissivism, given E $p$ and zero interest in $p$, the following holds about zero interest cases:

(1) $\mathrm{O}(\sim S p)$ : suspending judgment about $p$ is impermissible;

(2) $\mathrm{O}(\sim \mathrm{B} \sim p)$ : disbelieving $p$ is impermissible;

(3) $\sim \mathrm{O}(\sim \mathrm{B} p)$ : believing $p$ is permissible;

(4) $\sim \mathrm{O}(\mathrm{B} p)$ : not believing $p$ is permissible;

(3) and (4) respect practical interest, or, more precisely, your lack of practical interest in $p$. (1) and (2) respect the evidence, your lack of practical interest notwithstanding. While combining respect for practical interest with respect for the evidence in this compromising fashion comes with an initial air of plausibility, we may wonder what motivates the compromise. Assume that $p$ is indeed of zero practical significance to you. Neither the truth nor the falsehood of $p$ will affect you one way or another. Believing $p$ gives you zero benefit. ${ }^{16}$ Hence, permissivists say, $\sim \mathrm{B} p$ is permissible. However, disbelieving $p$ causes you zero harm. Why, then, should they not go further and say that $\mathrm{B} \sim p$ is permissible, too? If practical insignificance can constrain the normative force of $\mathrm{E} p$, why shouldn't we conclude that, in the extreme case of zero significance, it reduces the normative force of the evidence sufficiently to make both $\sim \mathrm{B} p$ and $\mathrm{B} \sim p$ permissible options?

Suppose permissivists agree that, if practical insignificance can make $\sim \mathrm{B} p$ permissible notwithstanding $\mathrm{E} p$, it can also make $\mathrm{B} \sim p$ permissible notwithstanding Ep. They will then accept the following principle:

\section{Radical Permissibility}

In cases in which $p$ has zero practical significance, $\sim \mathrm{B} p$ and $\mathrm{B} \sim p$ are both permissible even given $\mathrm{E} p$, and $\sim \mathrm{B} \sim p$ and $\mathrm{B} p$ are both permissible even given $\mathrm{E} \sim p$. 
Radical permissibility does not challenge (1). It doesn't because to suspend judgment about $p$ is to judge that one's total evidence supports neither $\mathrm{B} p$ nor $\mathrm{B} \sim p$, that is, to reject both $\mathrm{E} p$ and $\mathrm{E} \sim p$. Therefore, for $\mathrm{E} p$ cases, Radical Permissibility doesn't say that suspending judgment is permissible. ${ }^{17}$ Hence, (1) still holds. But, given E $p$ and zero interest in $p$, Radical Permissibility says that disbelieving $p$ is permissible. (2) does not hold. Instead, we have:

$(\sim 2) \sim \mathrm{O}(\sim \mathrm{B} \sim p)$ : disbelieving $p$ is permissible.

If Radical Permissibility is true, permissivism becomes unbridled. According to Unbridled Permissivism, E $p$ cases in which $p$ is of zero practical significance are cases in which believing $p$ and disbelieving $p$ are both permissible.

Radical permissibility isn't plausible, as I will argue in the next section. We may wonder, therefore, whether it's possible to reject Unbridled Permissivism while endorsing Limited Permissivism. I'm skeptical about that. It seems to me we are looking at a case of Pandora's Box. Once the spirit of permissivism is set free, it asserts itself with unbridled force. For once we agree that zero practical significance makes $\sim \mathrm{B} p$ permissible $\mathrm{E} p$ notwithstanding, it remains unclear why it doesn't make B $\sim p$ permissible as well. It's not easy to see how advocates of permissivism can succeed in avoiding this outcome.

Permissivists, then, face a challenge: how to avoid the outcome of radical permissibility? This challenge arises with strengthened force when we consider cases of a different kind: $\mathrm{E} p$ and $\sim \mathrm{B} \sim p$ will harm you. If we buy the basic permissivist idea and allow that practical interest can mess with the normative force of the evidence, we are now looking at an even more compelling case in which disbelieving $p$ will be permissible for you although your total evidence supports $p .{ }^{18} \mathrm{~A}$ standard example is that of a cancer patient. Let $p$ be: "I'm going to die within the next six months." $\sim \mathrm{B} \sim p$ will harm the patient. It is unclear to me on what principled grounds permissivists can avoid the outcome that, although the patient's evidence strongly supports $p$, the patient is epistemically permitted to disbelieve $p$. It would seem that, once the permissivist train starts rolling, it is headed towards the destination of maximal permissibility. As I will argue next, that destination is not a comfortable place.

\section{The Unjustified Belief Argument}

Unbridled Permissivism produces a bad outcome when we consider what the view implies about epistemic justification. Assume you receive a bad cancer diagnosis, and let $p$ stand for "I'm going to survive this illness." Your total evidence indicates that $p$ is false. Disbelieving $p$ will harm you. Failure to believe $p$ will also harm you. Unbridled permissivism says that, factoring in what's good for you, it's permissible for you to believe $p$. That's the thought the Unjustified Belief Argument starts out with:

(1) (Unbridled Permissivism is true) $\rightarrow \sim \mathrm{O}(\sim \mathrm{B} p)$ 


\section{Matthias Steup}

The second premise defines epistemic justification as epistemic permission. That's the very deontological concept Alston rejects. In due time, I'll argue that Alston's argument against $\mathrm{J}_{\mathrm{e}}=\mathrm{J}_{\mathrm{d}}$ fails. For now, let us set Alston's arguments aside and proceed with:

(2) $\mathrm{J}(\mathrm{B} p)=_{\mathrm{df}} \sim \mathrm{O}(\sim \mathrm{B} p)$.

Premises (1) and (2) give us:

(3) (Unbridled Permissivism is true) $\rightarrow \mathrm{J}(\mathrm{B} p)$

But we have stipulated that your total evidence indicates that $p$ is false. It is hard to imagine an evidentialist who is willing to agree that, given that your total evidence supports $\sim p, \mathrm{~J}(\mathrm{~B} p)$ enjoys any degree of plausibility. Rather, given $\mathrm{E} \sim p$, we have:

(4) $\sim \mathrm{J}(\mathrm{B} p)$.

And thus we arrive at the conclusion that:

(5) Unbridled Permissivism is false.

Permissivists might argue that the Unjustified Belief Argument is fatal against Unbridled Permissivism but fails to dispose of Limited Permissivism. For Limited Permissivism doesn't say that $\mathrm{B} p$ is permissible. It merely says that $\sim \mathrm{B} p$ is permissible. According to the Pandora's Box Argument, for permissivists to succeed with this defense, they must find a way to block the transition from Limited to Unbridled Permissivism. Unless they find a way to succeed with this endeavor, Limited Permissivism inherits the implausibility of Unbridled Permissivism.

\section{Commensurability Permissivism}

According to Richard Feldman, the epistemic ought and the practical ought are incommensurable. ${ }^{19}$ Consider again the case in which you receive a bad cancer diagnosis, and let $p$ again stand for the proposition "I'm going to survive this illness." Positive thinking raises the chance of survival. Given your evidence, you should not believe $p$. Given practical interest, you should believe $p$. Feldman thinks that's all there is to be said about the case. Epistemic and practical reasons pull in different directions, and that's the end of it. There is no domain-crossing, higher-order all-things-considered ought that settles what the patient ought to believe. ${ }^{20}$ The contrary view is that there is such an ought. Presumably it will tell us that your interest in survival trumps the normative force of your evidence. ${ }^{21}$ Given what's at stake, you ought to be optimistic and believe $p .{ }^{22}$ Call this type of permissivism Commensurability Permissivism (C-Permissivism for short).

Against C-Permissivism, the Unjustified Belief Argument is not effective. The argument's first premise must now make it explicit that the ought at work in 
the consequent is not a first-order epistemic ought, but instead a higher-order all-things-considered ought. Thus, what we have is this:

$(1 *)$ (C-Permissivism is true) $\rightarrow \sim \mathrm{O}_{\text {atc }}(\sim \mathrm{B} p)$,

where the consequent is to be read as follows: all epistemic and practical things considered, it's not the case that you ought to refrain from believing $p$. Similarly, C-Permissivism doesn't tell us that atc-permission is to be identified with epistemic justification. Rather, it is to be identified with a higher-order type atc-justification. Thus:

(2) $\mathrm{J}_{\mathrm{atc}}(\mathrm{B} p)=_{\mathrm{df}} \sim \mathrm{O}_{\mathrm{atc}}(\sim \mathrm{B} p)$

What follows is that, in the case at hand, if C-Permissivism is true, then you are atc-justified in believing $p$ :

(3) (C-Permissivism is true) $\rightarrow \mathrm{J}_{\text {atc }}(\mathrm{B} p)$.

Unlike before, we now cannot assert, solely because your evidence supports $\sim p$, that:

(4) $\sim \mathrm{J}_{\text {atc }}(\mathrm{B} \sim p)$

Doing so would ignore the point that, according C-Permissivism, practical interest trumps the normative force of your evidence. The Unjustified Belief Argument against permissivism, then, is effective as long as permissivism makes a claim about what is epistemically permissible. It is not effective against CPermissivism. Let us be clear on what the view says. Since the view is not a form of epistemic permissivism, it doesn't say that, in the case under consideration, it's epistemically permissible for you to believe $p$. Rather, it says that believing $p$ is all-things-considered permissible for you because the practical badness of not believing $p$ overrides the epistemic requirement of not believing $p$. This is for sure a controversial view. The Unjustified Belief Argument, however, does not challenge it.

\section{Evidentialism, Commensurability, and Supervenience}

Richard Feldman, arch evidentialist, thinks that epistemic reasons and practical reasons are incommensurable. ${ }^{23}$ There is no higher-level, just plain ought that tells us what to believe when epistemic reasons and practical reasons clash. Let's assume he were to change his mind about that. Would that mean he'd have to cancel his membership in the evidentialist club? Not necessarily, it seems to me.

Consider the following claim:

(E) Beliefs that don't fit one's evidence are never epistemically justified. 
(E) sounds like a hefty version of evidentialism to me. C-Permissivism does not threaten (E), for C-Permissivism merely asserts this: a belief that doesn't fit one's evidence might, in a domain-crossing, non-epistemic sense, be all-things-considered justified. That's compatible with the belief's being epistemically unjustified. And (E) doesn't say that beliefs that don't fit one's evidence are never justified in this non-epistemic, domain-crossing sense of all-things-considered justification. That claim would conflict with CPermissivism. But it is not, it seems to me, a claim that evidentialism must endorse.

Feldman, though, might be right about the incommensurability of epistemic and non-epistemic reasons. It is commonly accepted that evaluative status supervenes on non-evaluate facts. Necessarily, if two things, A and B, are factually alike, then they are evaluatively alike. Consider Al and Ben. They are about to take the LSAT. Unfortunately, they are ill-prepared, and they know this. Their evidence suggests they will do poorly. Believing they will do well will be a performance-enhancing confidence booster. Let $p$ be the proposition "I will do well." Prudence requires B $p$. The evidence requires B $\sim p$. Suppose Al and Ben are factually alike in all relevant respects. Thus, if there is a higherlevel, domain-crossing plain ought, that ought applies to each of them. Suppose it so happens that, while $\mathrm{Al}$ believes $p$, Ben believes $\sim p$. If there is a higherlevel, plain ought, one of them is irrational. Which one, however? Arguably, neither one is. What we have here, it might be argued, is a permissive situation. The permissiveness in question would not be epistemic. Rather, it would an all-things-considered - that is, all epistemic and practical things consideredhigher-level type of permissiveness. If the situation is permissive in this way, neither Al nor Ben can justly be accused of irrationality. Its name notwithstanding, C-Permissivism does not allow for such permissiveness. In situations in which there is a higher-order ought telling agents what to believe all things considered, it is then not rationally permissible for them to believe contrary to this atc ought. ${ }^{24}$ So either $\mathrm{Al}$ or Ben is irrational. And that, it might be argued, is not a plausible outcome. ${ }^{25}$

\section{Teleology and Epistemic Rationality}

CF-Constrained Evidentialism says: $[\mathrm{E} p+\mathrm{C} p+\mathrm{F}(\mathrm{B} p)] \rightarrow \mathrm{O}(\mathrm{B} p)$. If epistemic normativity is teleological or instrumentalist, this ought is dependent on a suitable telos, typically taken to be that of believing what's true and not believing what's false. If epistemic normativity is categorical, then the ought in Moderate Evidentialism is not dependent on any truth goal.

Thomas Kelly has argued that teleological conceptions of epistemic rationality are mistaken. He says:

What one has reason to believe does not seem to depend on the content of his or her goals in the way that one would expect if the instrumentalist conception were correct. ${ }^{26}$ 
This seems right to me. Whether it's epistemically rational for you to believe $p$-that is, whether your total evidence favors $p$ - does not depend on whether you have any truth goal. Instead, it depends on whether you have experiencesperceptual, memorial, intuitional, or introspective-that raise the probability of $p$ 's being true above 0.5 . When a testifier whom you know to be reliable tells you that $p$, you then have a reason to believe $p$ whether or not you have a truth goal for $p$. When you clearly perceive that it's raining, then you have a perceptual reason to believe that it's raining whether or not the truth of the matter is something you care about.

Of course, it's one thing for one's total evidence to make it likely that $p$ is true. Having an epistemic duty to believe $p$ is another. It might be that, whereas Kelly is right about what one has reason to believe, his argument does not extend to the epistemic ought: what one is epistemically required to believe. It seems to me, however, that the Unjustified Belief Argument, deployed above against Permissivism, is also effective against teleology about epistemic duty. Both views-Permissivism and Teleology about Epistemic Duty-allow for cases in which believing that $p$ is permissible for you although your total evidence indicates that $p$ is false. Hence, assuming justified belief is permissible belief, both views allow for cases in which you are justified in believing what your evidence contradicts. That's not a plausible consequence.

\section{Evidentialism and Epistemic Duty}

We have considered five views about epistemic duty. According to them, it is your epistemic duty to believe $p$ :

1. Unconstrained Evidentialism: if your evidence supports $p$;

2. C-Constrained Evidentialism: if your considered evidence supports $p$;

3. F-Constrained Evidentialism: if believing $p$ fits the informational strength of your considered evidence;

4. Permissivism: if $p$ is interesting to you and your considered evidence supports $p$.

In addition, we have considered a fifth view: Commensurability Permissivism. According to one variant of this view, you have an all-things-considered higherorder duty to believe $p$ if your considered evidence supports $p$ and believing $p$ does not conflict with your practical interests. ${ }^{27}$ According to each of these views, your evidence is a primary factor that determines what you ought to believe. Therefore, on an ecumenical construal of evidentialism, each of them may be considered a version of evidentialist deontology. If the concept of justification can be defined in terms of duty, each of them gives us a deontological account of justified belief. As I mentioned at the outset, Alston rejects the idea that epistemic justification bears an essential connection to epistemic duty. Next, I will discuss the two arguments that motivate Alston's rejection of this idea. 


\section{Deontological vs. Non-Deontological Justification}

Alston distinguishes between $\mathrm{J}_{\mathrm{d}}$ and $\mathrm{J}_{\mathrm{nd}}$ and defines the two notions as follows:

$\mathrm{J}_{\mathrm{d}}(\mathrm{B} p)$ iff $\mathrm{B} p$ is not epistemically blameworthy.

$\mathrm{J}_{\mathrm{nd}}(\mathrm{B} p)$ iff $\mathrm{B} p$ is a good thing relative to the goal of maximizing truth in a large belief system.

As he defines it, Alston's non-deontological concept is teleological and therefore vulnerable to the objections I discussed above. However, that feature is not essential to Alston's concept of $\mathrm{J}_{\mathrm{nd}}$. The account of justification he eventually settles on makes a teleological construal merely optional. To avoid any essential link between $\mathrm{J}_{\mathrm{nd}}$ and teleology, let us replace Alston's initial definition of Jn with:

$\mathrm{J}_{\mathrm{nd}}(\mathrm{B} p)$ iff $\mathrm{B} p$ is based on a truth-conducive ground..$^{28}$

According to Alston, what makes this concept non-deontological is this: doing your epistemic duty doesn't necessarily connect you with your evidence. It's possible for $\mathrm{B} p$ to be an instance of $\sim \mathrm{O}(\mathrm{B} \sim p)$ although $\mathrm{B} p$ is not based on a truth-conducive ground. Next, I'll argue that Alston is wrong about that.

\section{Justification and Epistemic Blame}

Alston identifies $\mathrm{J}_{\mathrm{d}}$ with freedom from epistemic blame. He says:

$\mathrm{J}_{\mathrm{d}}$ is, most centrally, a concept of freedom from blameworthiness, a concept of being "in the clear" so far as one's intellectual obligations are concerned. ${ }^{29}$

He rejects $J_{d}$ because "it does not give us what we expect of epistemic justification. The most serious defect is that it does not hook up with an adequate, truth-conducive ground." ${ }^{30} \mathrm{He}$ then proceeds to describe the following case of cultural isolation:

If I have grown up in an isolated community in which everyone unhesitatingly accepts the traditions of the tribe as authoritative, then I have never encountered anything that seems to cast doubt on the traditions and have never thought to question them, I can hardly be blamed for taking them as authoritative. There is nothing I could reasonably be expected to do that would alter that belief-forming tendency. And there is nothing I could be expected to do that would render me more exposed to counter-evidence. ${ }^{31}$

The punch-line is that, under circumstances like that, I will have many beliefs that are $\mathrm{J}_{\mathrm{d}}$ but are not $\mathrm{J}_{\mathrm{e}}$. These beliefs are $\mathrm{J}_{\mathrm{d}}$ because I'm in a culturally isolated 
community, and they are not $\mathrm{J}_{\mathrm{e}}$ because they are not based on a truth-conducive ground. To assess this argument, let's fill in some details. Ragnar is a member of a tribe of Vikings in the 8th century. On the eve of an important battle, Ragnar forms the belief "We will be victorious" on the basis of a drug-induced vision. Alston would say Ragnar's belief is not $\mathrm{J}_{\mathrm{e}}$ because a drug-induced vision is obviously not a truth-conducive ground. But, given that his tribe has never been in contact with a community in which drug-induced visions are considered an unreliable method of predicting the outcome of a battle, he cannot be blamed for taking such visions to be epistemically authoritative. So, Ragnar's belief is $\mathrm{J}_{\mathrm{d}}$ without being $\mathrm{J}_{\mathrm{e}}$.

Alston's argument fails because the word 'blame' is ambiguous between a narrow, theoretical sense and a broad, social sense. Suppose you do something morally wrong. Let's say you punch someone in the nose. Since what you did is wrong, it is morally criticizable. You shouldn't have done that. And that's just to say that what you did was blameworthy. At the same time, however, it's not yet settled whether you should be blamed. If the blow to the nose was gratuitous and vicious, then a severe chastising, a stern moral reprimand, and indeed suitable punishment are in order. If, on the other hand, you were gratuitously provoked, then you would have an excuse. In that case, the blow to the nose, though still morally wrong and thus blameworthy, is understandable. Therefore, a severe reprimand-"How could you have done that?" uttered with a stern tone of moral disapproval—would not be in order. This example indicates that we should distinguish between two ways in which an agent might deserve blame. First, there is theoretical blameworthiness. Whenever an act is morally wrong, what the agent did is blameworthy. Second, there is blaming as a social activity by bestowing a reprimand or chastisement. An act's being theoretically blameworthy does not entail that the agent deserves to be reprimanded for the act, for the agent may have an excuse. Theoretical blameworthiness, then, calls for a social act of blaming only when the agent does not have an excuse.

An analogous distinction applies to epistemic blame. Ragnar has an excuse for his belief: his tribe is culturally isolated. Therefore, it would be unfair to chastise him for the way he has formed his belief about the outcome of tomorrow's battle. But, from the inappropriateness of a social act of blaming, it doesn't follow that Ragnar's belief is blameless in the theoretical sense. Since drug-induced visions are not truth-conducive, there is a fair criticism of Ragnar's belief. And that's just to say that his belief is epistemically blameworthy. At the same time, Ragnar oughtn't be chastised or reprimanded for his belief. Doing that would not be fair because he has an excuse.

Here is the rub. When advocates of $\mathrm{J}_{\mathrm{d}}$ identify $\sim \mathrm{O}(\sim \mathrm{B} p)$ with epistemic blamelessness, they have in mind the thin, theoretical sense, not the thick, social activity sense of 'blame'. In response to the proposed counterexample, they will therefore say that Ragnar's belief is neither $\mathrm{J}_{\mathrm{e}}$ nor $\mathrm{J}_{\mathrm{d}}$.

Could the possibility of $\mathrm{J}_{\mathrm{d}}$ without $\mathrm{J}_{\mathrm{e}}$ be defended by describing alternative cases? I don't think so. Beliefs lacking $J_{e}$ will always have a defect that grounds a fair epistemic criticism. ${ }^{32}$ Typically, unjustified beliefs are the result of epistemic 


\section{Matthias Steup}

flaws like wishful thinking, jumping to conclusions, careless reasoning, or ignoring relevant evidence. In all such cases, there is a fair criticism of the resulting beliefs, namely: they are not supported by evidence and thus unlikely to be true. Unjustified beliefs are therefore bound to be epistemically blameworthy even if the subject has an excuse that renders the dispensation of social blame inappropriate.

\section{Belief and Intentionality}

Next, I will complete my defense of $\mathrm{J}_{\mathrm{d}}$ by responding to Alston's other objection: the argument from doxastic involuntarism. It says that $\mathrm{J}_{\mathrm{d}}$ must be rejected because what's suitable for deontological evaluation must be something over which we have voluntary control. But beliefs are not the sort of thing over which we have voluntary control. Beliefs just happen to us, in the same way cell metabolism and the secretion of gastric juices just happen to us. ${ }^{33}$ Therefore, beliefs are not suitable for being evaluated deontologically.

Doxastic involuntarism - the thesis that, unlike actions, beliefs are not under our voluntary control-is near orthodoxy among today's epistemologists. In a series of papers, I have argued that belief is no less under our voluntary control than our actions are. ${ }^{34}$ It would appear the aforementioned orthodoxy continues unabated. ${ }^{35}$ I will conclude this paper with another, most likely futile, attempt to correct this situation.

Involuntarists are convinced that belief cannot be intentional. ${ }^{36}$ I claim they are mistaken about that. Let's distinguish between:

Explicit intentionality:

Implicit intentionality:

Unintentional behavior:
In $\phi$-ing, one carries out an antecedently formed intention to $\phi$. Example: taking a walk after deliberating about whether to do that or not. $\phi$-ing without carrying out an antecedently formed intention to $\phi$. Nevertheless, one is $\phi$-ing intentionally because one means to be $\phi$-ing. When asked, "Did you mean to $\phi$ ?" one wouldn't respond by saying "no". Examples: stepping on the brakes when approaching a red traffic light; pressing the gas pedal when the light turns to green.

Things one does without meaning to. Examples: knocking over a cup of tea, slipping on ice, accidentally dropping an object.

Propositional attitudes acquired after deliberation are examples of explicit intentionality. Suppose you are on a jury. You weigh the reasons for and against the defendant's guilt. You conclude the former are stronger. You form the belief that the defendant is guilty because you decided to believe this. A belief acquired in this way is no less intentional than a walk that's undertaken after deciding that's what you want to or should do.

Spontaneous perceptual beliefs exhibit implicit intentionality. Though not the outcome of antecedent deliberation, they are nevertheless intentional in 
just the same way braking is when you approach a red traffic light. Consider your belief that it's raining when you see and hear the rain. It would be absurd to say that belief just happens to you in the way a fall on a slippery surface just happens to you, or that that belief is akin to accidentally knocking over a cup of tea. These are not things you meant to do. But when asked why you believe it's raining, you wouldn't respond by saying that that is not what you meant to believe, or that your belief is one that, after reflection, you don't want to have. Given your evidence, that it's raining is exactly what you want to believe.

Unintentional beliefs are rare. Examples are beliefs resulting from manipulation, brainwashing, neurological defects, or mental illness. For example, a mysophobe might believe there are dangerous germs on his hands although he just washed them five minutes ago. This is a belief the subject can't help having. It is a belief that is immune to rational deliberation and consideration of the relevant evidence.

In sum, when involuntarists claim that belief is in general unintentional, they are in effect saying that belief is on a par-relevantly similar to-paradigm examples of unintentional behavior. I don't think that's plausible at all. When you do something unintentionally, like dropping an object, slipping on ice, or knocking over a teacup, it's an accident. Beliefs are not accidents. Typically, they are rational responses to our evidence and therefore intentional. ${ }^{37}$

\section{Belief and Voluntary Control}

Once it is agreed that belief is no less intentional than action is, the question of whether we have voluntary control over our beliefs becomes a question of metaphysics. Belief, like action, is under our control if, and only if, our will is free and we are free to do what we will. Let's focus on what, in contemporary philosophy, qualifies as the dominant approach to the question of whether the will is free: compatibilism. According to compatibilism, when assessing whether and agent is $\phi$-ing freely, what matters is not whether the agent's $\phi$-ing is caused but how it is caused. If caused in a good way, it is free; if caused in a bad way, it's unfree.

How are we to conceive of the difference between good and bad causation? There are various accounts of how to do that. No matter which account is chosen, once involuntarists reveal allegiance to compatibilism, the game is up for them. An influential version of compatibilism identifies good causation with reason-responsiveness. This approach nicely illustrates why compatibilists can't be involuntarists. The key point is that propositional attitudes are no less reason-responsive than actions are. In fact, the very point that according to Alston and his involuntarist followers establishes involuntarism, namely that your evidence irresistibly dictates what we believe, is grist to the compatibilist's mill. Alston's point is that our beliefs are unfree because they are caused by our evidence. Yet, according to the reason-responsiveness variety of compatibilism, being caused by the evidence is exactly what makes our beliefs free.

Next consider free will skepticism. ${ }^{38}$ That's not a good option for involuntarists. If free will skepticism is true, belief and action are equally 


\section{Matthias Steup}

unfree. That's not what involuntarists want to say. They think that, although belief is unfree and thus unsuitable for deontological evaluation, action is not. Involuntarists, therefore, fare best if they endorse libertarianism. But that option has two downsides. First, libertarianism is highly problematic because it's unclear how an indeterministic decision can be a form of agency. Clearly, if involuntarism rests on the premise that libertarianism is true, the view will lose its luster for those who consider libertarianism implausible. Second, it's unclear how involuntarism could be defended on libertarian grounds. If libertarianism is true, indeterministic decisions instantiate agency because of a certain feature F. If involuntarism is paired with libertarianism, the claim would have to be that, whereas practical deliberation can instantiate feature F, epistemic deliberation cannot. I don't think the prospects for defending this claim look very good.

In sum, if we view the problem of free belief as a metaphysical issue akin to the problem of free action, it's difficult to see how any particular approach to these problems will plausibly yield one outcome for action and another one for belief.

\section{Alston's Test of Voluntary Control}

According to Alston, the truth of doxastic involuntarism can be established by performing a quick and easy test. Can you stop believing it's raining when you clearly perceive it is? Clearly, you cannot. Alston thinks this shows that your belief is not under our voluntary control. ${ }^{39}$ In the literature on the issue, this type of argument is rolled out again and again as a quick and allegedly decisive demonstration of doxastic involuntarism. Yet it is an extraordinarily poor argument. It massively backfires when applied to action. Can you cross the street when you clearly perceive SUVs and trucks approaching from both directions at high speeds? Clearly, you cannot. By parity of argument, we must now conclude that crossing the street is not the sort of thing over which you have voluntary control. That's not what involuntarists want to say.

Notice the standard of voluntary control Alston's test silently assumes: voluntary control over whether to $\phi$ requires that you can $\phi$ even if reason decisively dictates not to $\phi$. Some libertarians might be amenable to endorsing this standard. They would have to agree with Alston that you are not free to cross the street when doing so would clearly be fatal. ${ }^{40}$ But compatibilists, surely, should reject Alston's standard of voluntary control. On compatibilist reasoning, not crossing the street in the envisioned circumstances is a paradigmatic case of free, reason-responsive behavior. Likewise, on compatibilist reasoning, believing it's raining when you clearly perceive it is should be viewed as a paradigmatic case of free, evidence-responsive doxastic conduct.

In sum, Alston's test fails. To assess whether a particular propositional attitude is under the agent's voluntary control, a different method is needed. If we are compatibilists, we need to investigate the attitude's causal history. If reason doesn't play a suitable role in it, a good case can be made that the attitude is not under the agent's control. If we are libertarians, we must find out whether 
the attitude is indeterministic, or at least has its origin in an indeterministic event. Whichever way we go, demonstrating involuntariness isn't as easy as Alston's ill-conceived test suggests.

\section{Conclusion}

Alston's argument from doxastic involuntarism fails. Belief is no less under our voluntary control than action is. This makes belief eligible for evaluation in terms of epistemic duty. Alston has argued that such evaluation fails to hook up with what epistemic justification requires: a truth-conducive ground. This argument is based on a thick, social sense of epistemic blame. If $\mathrm{J}_{\mathrm{e}}$ is identified with $\mathrm{J}_{\mathrm{d}}$ and $\mathrm{J}_{\mathrm{d}}$ is explicated in terms of a thin, theoretical sense of epistemic blame, Alston's objection is effectively rebutted. The path is cleared towards thinking of epistemic justification in terms of epistemic duty. Exactly what, however, is our epistemic duty? I have proposed the following. Negatively, our epistemic duty is not to believe what our evidence doesn't support. Positively, it is to proportion our beliefs to our evidence: to believe no more and no less informational content than our considered evidence warrants. ${ }^{41}$

\section{Notes}

1 Alston 1985.

2 Let ' $\mathrm{O}(\mathrm{B} p)$ ' stand for 'believing $p$ is epistemically obligatory', or 'you ought to believe $p$ ' in a specifically epistemic sense of 'ought'.

3 See Alston 1985, 69.

4 See ibid., pp. 59-60.

5 Feldman 2000 defends (i), Nelson 2010 defends (ii), and Wrenn 2007 defends (iii). For a response to Nelson, see Stapleford 2013, and for a response to Wrenn, see Stapleford 2015a.

6 For a nice and somewhat different presentation of the infinity problem, see Nelson 2010.

7 See Grice 1975. Grice subsumes the maxim in question under the category of 'Quantity'.

8 Thus the kind of evidentialism proposed in Conee and Feldman 1985, articulated in terms of evidential fit, captures the idea that it's our epistemic duty to proportion our beliefs to the evidence.

9 The restriction to considered evidence is needed to avoid the infinity problem discussed above.

10 It looks like a stronger conclusion might be warranted: I ought to refrain from believing (3).

11 Let " $\mathrm{F}(\mathrm{B} p)$ " stand for "believing $p$ is epistemically felicitous."

12 We might even want to go all the way to the following, stronger claim: $\sim \mathrm{F}(\mathrm{B} p) \rightarrow$ $\mathrm{O}(\sim \mathrm{B} p)$. We would then have to say that I would be unjustified in believing (3). Surely, it might be objected, this is going too far. However, what I'm suggesting is the following. If we wish to avoid the outcome that our evidence requires of us to believe vacuous propositions, we must develop a fine-grained account of propositional attitudes. On such an account, we could say that, while I'm of course justified in taking (3) to be true, I would be not justified in adding (3) to my belief system. 


\section{Matthias Steup}

13 I refer to belief, disbelief, and suspension as the primary attitudes because there are also attitudes such as suspecting that $p$, hoping that $p$, and fearing that $p$. And I am talking of reflective attitudes because, if one neither believes nor disbelieves $p$, there are two possibilities: one never considered $p$ and thus simply has no attitude at all toward $p$, or one reflects on $p$ and judges that one's evidence supports neither believing nor disbelieving $p$.

14 See Nelson 2010.

15 There are, of course, other versions of permissivism. See, for example, Kelly 2014. For a contrary view, denying permissibility, see White 2014.

16 This view assumes that the following is not the case: believing true propositions is intrinsically valuable and thus, even in zero interest cases, comes with some benefit to the believer.

17 It might be objected that, when, given zero practical significance, one judges that $\mathrm{E} p$ fails to be an indication of $p$ 's truth. This is why one is then free to refrain from believing $p$. Here is my reply: that's not the permissivist view under consideration. According to the kind of permissivism I'm discussing, $p$ 's being practically insignificant does not have the effect of blocking Ep from indicating that $p$ is true. Rather, it blocks E $p$ from having normative force with regard to what attitude I should take towards $p$.

18 The kind of permissivism under consideration here should not be misunderstood. The view does not say that, given that $\sim \mathrm{B} \sim p$ will harm you, $\mathrm{B} \sim p$ is practically permissible for you although your evidence makes $\mathrm{B} \sim p$ epistemically impermissible for you. Rather, the view says that, given that $\sim \mathrm{B} \sim p$ will harm you, your evidence fails to make $\mathrm{B} \sim p$ impermissible for you. In other words, given that $\sim \mathrm{B} \sim p$ will harm you, $\mathrm{B} \sim p$ is indeed epistemically permissible for you. That is, the type of normativity under consideration here is specifically epistemic normativity.

19 See Feldman 2000, 691-694.

20 Note that we must distinguish between two different types of all-things-considered ought. First, there is the domain-specific ought of all evidential things considered. That ought tells you what you should believe given your total evidence. Second, there is, at least according to some, the domain-crossing ought of all evidential, prudential, and moral reasons considered. That ought tells you what you should believe given the totality of all of your reasons, with no restriction to any specific domain of reasons.

21 The mere assertion that there is a domain-crossing all-things-considered ought doesn't tell us how to calculate this ought. The thought that practical considerations sometimes outweigh evidential considerations will be resisted by some. A Cliffordian evidentialist might argue that believing contrary to the evidence is never permissible. On such a view, there is a strict domain-crossing higher-order ought: it tells us that we should never believe contrary to the evidence, no matter what our practical interests are.

22 Booth 2012, McCormick 2015, Rinard 2017, and Maguire and Woods forthcoming defend theories that presuppose commensurability. For a response to Booth 2012, see Stapleford 2015b.

23 Some evidentialists deny that there are practical reasons for belief. Kelly 2003 argues that practical considerations cannot rationalize a belief. In his 2017, Stapleford says: "The standard evidentialist angle is that practical reasons are never reasons for belief: the norms governing belief are exclusively evidential.” But that would make Feldman-style evidentialism non-standard. After all, Feldman doesn't argue that there are no practical reasons for belief. His point is rather that epistemic and practical reasons for belief are not commensurable, and thus don't yield a higherorder, plain "ought to believe." 
24 C-Permissivists could allow for situations in which, with regard to $p$, epistemic reasons and practical reasons of equal weight oppose each other. Arguably, that's a situation in which an agent is free to choose between $\mathrm{B} p$ and $\sim \mathrm{B} p$.

25 It could be objected that, if Al believes $p$ but Ben believes $\sim p$, the explanation is most likely that they put different weights on the two conflicting considerations: believing what the evidence supports vs. believing what helps performing well. And, if that were the case, they would not be factually alike, in which case their beliefs might be equally rational. Suppose, however, they do attach the same weights to the conflicting considerations and yet differ in their beliefs as described. We then get again the outcome that one of them would have to be irrational. As before, it is not clear that this outcome is plausible.

26 Kelly 2003, 621.

27 Commensurability Permissivism says that, if your evidence supports $\mathrm{B} p$ but $\mathrm{B} p$ conflicts with your practical interests, $\sim \mathrm{B} p$ will be atc-permissible or even atc-required for you. But what does the view say about what your atc-attitude towards $p$ ought to be in cases in which your evidence supports $\mathrm{B} p$ and $\mathrm{B} p$ does not conflict with your practical interests? Here, the options are exactly the ones associated with the first four views.

28 In fact, Alston's truth-conducive-ground approach to analyzing J reinforces Kelly's point: whether a belief's ground is truth-conducive surely does not depend on whether the subject has a truth goal for that belief.

29 Alston 1985, 63.

30 Alston 1985, 67.

31 Alston 1985, 67-68.

32 Of course, this claim presupposes internalism. On reliabilism, BIVs have unjustified beliefs, but there is no fair criticism of them. However, cases involving undetectable deception are a huge problem for reliabilism (the New Evil Demon Problem, as it is sometimes called), and thus reinforce the claim in question.

33 See Alston 1988, 263.

34 Steup 2000, 2008, 2012, 2017.

35 For authors who have resisted the orthodox approach to the problem, see Ryan 2003, Flowerree 2017, and Roeber forthcoming.

36 For example, Alston 1988, 277, says: "I conclude that we do not generally have the power to carry out an intention to take up a certain propositional attitude ... The inauguration of propositional attitudes simply does not work like intentional action.”

37 For further elaboration, see Steup 2012 and 2017.

38 See, for example, Pereboom 2001.

39 See Alston 1988, 270.

40 Some hyper-optimistic libertarians might demur. They might say that reason never dictates what to do. You are free to cross the street even when you can clearly foresee that doing so would be fatal.

41 An earlier version of this was presented at the Epistemic Duty Conference in Fredericton, May 29-31, 2019, organized by Scott Stapleford and Kevin McCain. For valuable comments and discussion, I wish to thank Cheryl Abbate, Kevin McCain, Mark Nelson, Scott Stapleford, Sharon Ryan, Brian Talbot, and Jonathyn Zapf.

\section{References}

Alston, William. 1985. “Concepts of Epistemic Justification.” The Monist 68: 57-89. Alston, William. 1988. “The Deontological Conception of Epistemic Justification." Philosophical Perspectives 2: 257-299. 


\section{Matthias Steup}

Booth, Anthony. 2012. “All Things Considered Duties to Believe.” Synthese 187: 509-517.

Conee, Earl, and Feldman, Richard. 1985. "Evidentialism.” Philosophical Studies 15-34.

Feldman, Richard. 2000. "The Ethics of Belief." Philosophy and Phenomenological Research 90: 667-695.

Flowerree, A. K. 2017. “Agency of Belief and Intention.” Synthese 194: 2763-2784.

Grice, Paul. 1975. “Logic and Conversation.” In G. Harman and D. Davidson (eds), The Logic of Grammar. Encino, CA: Dickenson, pp. 64-75.

Harman, Gilbert. 1986. Change in View. Cambridge, MA: MIT Press.

Kelly, Thomas. 2003. "Epistemic Rationality as Instrumental Rationality: A Critique." Philosophy and Phenomenological Research 66 (3): 612-640.

Kelly, Thomas. 2014. "Evidence Can Be Permissive.” In M. Steup, J. Turri and E. Sosa (eds), Contemporary Debates in Epistemology. Malden, MA: Blackwell Wiley: 298-312.

Maguire, Barry, and Woods, Jack. 2019. “The Game of Belief.” Philosophical Review, 129 (2): 211-249.

McCormick, Miriam Schleifer. 2015. Believing Against the Evidence: Agency and the Ethics of Belief. Abingdon, Oxon: Routledge.

Nelson, Mark T. 2010. “We Have No Positive Epistemic Duties.” Mind 119: 84-102.

Pereboom, Derk. 2001. Living without Free Will. Cambridge: Cambridge University Press.

Rinard, Susanna. 2017. "No Exception for Belief." Philosophy and Phenomenological Research 94: 121-143.

Roeber, Blake. Forthcoming. "Evidence, Judgment, and Belief at Will.” Mind.

Ryan, Sharon. 2003. "Doxastic Compatibilism and the Ethics of Belief." Philosophical Studies 114: 47-79.

Stapleford, Scott. 2013. "Imperfect Epistemic Duties and the Justificational Fecundity of Evidence." Synthese 190: 4065-4075.

Stapleford, Scott. 2015a. "Why There May Be Epistemic Duties." Dialogue 54: 63-89.

Stapleford, Scott. 2015b. "Epistemic Versus All Things Considered Requirements." Synthese 192: 1861-1881.

Stapleford, Scott. 2017. "Review of Miriam Schleifer McCormick: Believing Against the Evidence: Agency and the Ethics of Belief.” Philosophical Review: 551-554.

Steup, Matthias. 2000. "Doxastic Voluntarism and Epistemic Deontology." Acta Analytica 15 (1): 25-56.

Steup, Matthias. 2008. “Doxastic Freedom.” Synthese 161: 375-392.

Steup, Matthias. 2012. "Belief Control and Intentionality." Synthese 188: 145-163.

Steup, Matthias. 2017. "Believing Intentionally," Synthese 194: 2673-2694.

White, Roger. 2014. "Evidence Cannot Be Permissive.” In M. Steup, J. Turri and E. Sosa (eds), Contemporary Debates in Epistemology. Malden, MA: Blackwell Wiley: 312-23.

Wrenn, Chase. 2007. “Why There Are No Epistemic Duties.” Dialogue 46: 115-36. 


\title{
2 Believing Badly \\ Doxastic Duties Are Not \\ Epistemic Duties
}

\author{
Miriam Schleifer McCormick
}

\section{Introduction}

This chapter has two main aims. The first is to establish that if the normative domain termed "epistemic" is taken to be autonomous (i.e. independent of the ethical domain) then what are called "epistemic duties" do not help us understand what it is to believe badly. If we do have duties to believe (i.e. doxastic duties) then they are not purely epistemic ones. Second, I will suggest that the language of duty and obligation does not best capture the ways we fall short as believers. What is central to cases of believing badly is that the believer exhibits a lack of care, and in so doing, fails to meet appropriate expectations we have of each other. This second conclusion is suggestive because I won't have the space here to fully develop the alternative account.

What I mean by "believing badly" is when someone believes in such a way that a negative reaction attitude-blame, or something very blame-like-is appropriate. Many common reactions to each other's beliefs exhibit attitudes that display negative judgments and emotions; someone's belief can elicit what Peter Strawson referred to as "reactive attitudes" such as anger and contempt. We ask in an incredulous tone, "How can you believe that?" or exclaim, "What a ridiculous thing to believe!" I am sure we have all seen a look of disgust on someone at a philosophy talk elicited by what is taken to be the deeply mistaken belief being expressed by the speaker.

It has been noted by many that this feature of our doxastic practice is puzzling given how little direct control we have over what we believe. I am not here centrally concerned with this puzzle, namely the puzzle of how to make sense of the doxastic responsibility that these attitudes seem to assume, though what I say will have some bearing on it. I am interested, rather, in the different ways that one can believe badly, the different kinds of flaws that one can exhibit in believing as one does, and the different kinds of criticisms, and attitudes that such doxastic flaws generate. We criticize beliefs for different reasons and in different ways and our attitudes differ depending on the ways in which we find people falling short or being defective in their belief maintenance practices. I will argue that if the flaw is a purely epistemic, then blame is not appropriate. If this is so then epistemic duties are only duties in a deflated 
sense; they are like the duties of etiquette-conventional and contingent. My argument can be summarized as follows:

(1) If, by $\varphi$-ing, $S$ violates a duty, then $S$ is subject to blame.

(2) If the doxastic flaw with S's $\varphi$-ing is purely epistemic, then $S$ is not subject to blame.

C So if the doxastic flaw with S's $\varphi$-ing is purely epistemic, then, by $\varphi$ ing, $S$ has not violated a duty.

The first premise may seem too strong as some may allow for cases of blameless violations of duties. It could be, for example, that if one violates a duty with a good excuse then blame ceases to be appropriate. So, perhaps, something like prima facie should be inserted before "subject to blame." Though, in the moral context, most will say that if one is really excused then the duty disappears. Others will say that you are still subject to blame but that the expression of blame should be mitigated because of the excuse. ${ }^{1}$ How best to think of these matters won't matter for my purposes because I will argue that, when it comes to believing, if the flaw is purely epistemic, then one isn't subject to blame in any sense. In the context of believing, blame is only appropriate, when the flaw extends into the broadly practical domain. And so, I will be mostly concerned with providing reasons to accept (2). I will do this, mostly, by reflecting on cases. I will begin (in section 1) by clarifying what a purported purely epistemic duty is and I will argue that these can be violated-even when the violation is not excused or justified-without believing badly; the criticism registers a flaw but does not appropriately warrant reactive attitudes like blame or indignation. These blameless norm violations show that many violations of such norms are not best thought of as violation of duties, and if this is so then violation of these purported duties is not sufficient for believing badly. I will then consider cases (in sections 2 and 3) where blame is appropriate. Some of these are cases where no epistemic norms are violated. If there are such cases, this shows that one could fulfill all one's supposed epistemic duties and still fail to believe as one ought: the ideal epistemic agent and the ideal doxastic agent diverge. Finally, I will consider cases where epistemic norms are violated and such attitudes do seem appropriate. I will argue that these are distinguished from the first kind of cases in that the flaw or defect being targeted is not purely epistemic. I don't think, however, these cases are all best understood as a violation of duties. The kind of reproach appropriate in the doxastic realm does not usually stem from a violation of duties, epistemic or otherwise. Rather, doxastic flaws point to different kinds of flaws of agency and to a lack of certain virtues. I will end (in section 4) by considering some objections.

I would like to forestall one worry at the outset. I have said that I am skeptical that there are any epistemic duties that are more robust than, for example, duties of etiquette. But one may wonder if this would be a problem for those who think there are epistemic duties; does anyone think of them as normatively on par with moral duties? I will return to this question when considering objections, but there is much in the literature which suggests that such duties 
are often taken to be substantially normative. Most discussion of epistemic duties assumes that it is an unproblematic category and then the questions turn on figuring out some specifics about them. Is there a duty to seek more evidence? Is there a duty to alter one's doxastic state in the face of peer disagreement? Are there only negative ones? When and why can one be blameless in violating one? What is the difference between justification and excuses when it comes to such violations? ${ }^{2}$ The debate between whether one is justified or only excused if the beliefs are false but the result of proper cognitive functioning shows that this kind of language is often thought of as robustly normative. In arguing that this debate is not "merely verbal," Daniel Greco says that whether one is merely excused in such context matters:

to label reasonable false beliefs as merely excused is to damn them with faint praise; excused beliefs you form because you're a child, or insane, or drugged. To lump ... beliefs that are the product of impeccable reasoninginto such a category seems indiscriminating.

Talk of duties and "oughts" sounds like it should offer guidance for someone seeking to be a good doxastic agent, who wants to avoid believing badly. But if we want to hold on to the idea of there being ways of believing badly that consist in a violation of duties, they cannot be merely or purely epistemic. Those kinds of reactions are always pointing to something in the agent beyond a violation of a purely epistemic duty.

\section{Violations of Epistemic Duties without Believing Badly}

One kind of doxastic flaw arises from violating what some call epistemic duties. While the term "epistemic" is usually left undefined, it is often taken to mean pertaining to truth, evidence, or knowledge. Epistemic duties are duties grounded in purely epistemic considerations, namely those duties which one must fulfill to gain truth or knowledge. It is further often assumed that whatever duties we have regarding belief, that is, what we are obligated to believe or to not believe, are epistemic. According to Richard Feldman "our epistemological duty is to believe as the evidence we have dictates" (Feldman 2002, 364).

Here are some other possible candidate epistemic duties:

Do not believe falsehoods.

Only believe truths.

Only believe when you have sufficient evidence.

Only believe when you are in a position to know.

If you are in a position to know then believe.

Do not believe if you lack justification.

Do not believe without good reasons.

Depending on one's view about the norms of belief some of these imperatives might be expressing the same view. So, for example, an evidentialist about 
justification would say that the duty to believe in accordance with evidence (and to only believe when one's evidence is sufficient) is tantamount to saying do not believe when you lack justification. For those who think that some beliefs, such as non-inferential ones, can be justified without evidence, then these would come apart. ${ }^{3}$

Despite different views about the norm or norms of belief, all agree that having an ill-founded false belief violates an epistemic norm, but all would also agree that such violations are often blameless. Even those who want to say one can never be justified in believing falsehoods but only excused, think being so excused gets you off the hook for blame. Now one might take the fact that there is an extensive debate about what makes a belief that violates an epistemic norm "blameless" to show that most (or many) cases of such violations provide examples of blameworthy beliefs. I will argue that, according to all the different views of what constitutes blame, where blame goes beyond pointing to the cause such as when we say the hurricane is to blame for the city's destruction, to say such violations of purely epistemic norms are worthy of blame is misguided. In discussions about when violating certain epistemic norms is "blameless" (whether such believing is justified or only excused) what is being asked is whether there is something about the situation which gets the believer off the hook from any kind of reproach. But in the cases where the fault is being viewed only as a violation of an epistemic norm (and such norms are viewed as entirely distinct from moral ones) to think of the kind of criticism as including an attitude of blame would force us to widen the concept of blame far beyond its usual boundaries. ${ }^{4}$

Think about the huge number of ill-founded false beliefs we all hold. Perhaps these can be minimized to some degree if one has a view that full beliefs require a very high credence. But one of our ordinary ways of attributing beliefs is by looking at what one asserts (or would be willing to assert), and by this measure we hold many false beliefs. The previous sentence I asserted, for example, may be expressing a false belief. In non-philosophical contexts they are ubiquitous: beliefs about directions, beliefs about the weather, beliefs about the precise time that your friend's plane arrives or the movie starts. Now some of these false beliefs may be held fleetingly and are easily corrected. For example, you believe, based on your memory, that your friend's plane arrives at 1:00. You check the calendar on your phone and see she arrives at 1:30 (1:00 was the time you need to leave your house so that's what stuck in your mind). If one thinks that one is blameworthy if one violates an epistemic norm if there are no mitigating factors to excuse or justify such violations then each instance of believing an ill-founded falsehood when there are no mitigating factors to excuse or justify so believing warrants blame. ${ }^{5}$

One may respond to these cases by saying all I have shown is that "don't believe falsehoods" is not a good candidate as an epistemic duty, and so not all epistemic norms are epistemic duties. But take any candidate epistemic norm and we will find our violations ubiquitous. Violating these norms does show our beliefs are defective according to a particular standard but blame is only appropriate once more context is provided. 
While I cannot here do justice to the extensive literature on the meaning and purpose of blame, if we take a moment to canvass some of the central ideas connected with blame, it reveals how misguided it would be to say that your false belief about your friend's arrival time is blameworthy. ${ }^{6}$ Blame carries with it some normative force that seems to require that it includes a negative evaluative judgment of the person being blamed. Yet, it seems wrong to think of blame as a purely cognitive attitude because when we blame others negative emotions are often included in the blaming. While there is dispute among theorists of blame whether any particular emotions are necessary, the challenge for those who deny any are required is to explain the special force that blame has. All agree that to blame someone goes beyond mere description; it is not simply to register that someone has failed to meet a particular standard. I can describe you as flawed in a certain way without blaming you or judging you blameworthy. Imagine I am on your team playing a casual pick-up soccer game. You know I am not very good at soccer but I enjoy it; it's a fun way to get some exercise and I can run pretty fast so sometimes I manage to get to the ball before our opponents and can get it to someone who can actually help us score. When I miss an easy pass and the other team scores, you are accurate in evaluating my soccer-playing as deeply flawed, in judging my playing as very poor, but you would not blame me, or if you did it would not be appropriate.

Similarly in the epistemic realm I can point to a flaw in your reasoning; I can accurately describe you as having a flawed belief but the fact that an epistemic norm has been violated without excuse or justification does not settle the question of whether blame is appropriate. Here we begin to see that thinking about these violations as violations of duties is misleading. An unexcused and not overridden violation of a moral duty always warrants blame while an unexcused and not overridden violation of a purely epistemic "duty" does not. We will see that when such a violation does warrant blame, it is because it matters ethically. Your particular context or role reveals that your believing as you do is flawed in a way that is not merely epistemic. I will turn now to thinking about when blame does seem appropriate in the doxastic realm, and we will see that these cases are all morally tinged.

\section{Believing Badly without Violation of "Epistemic Duties"}

There has a been a recent proliferation of discussion focused on cases where, despite one's belief being epistemically flawless, agents are still failing to believe as they ought. Many of these concern examples of what is called "moral encroachment," which is the idea that how to respond to the evidence varies as the moral stakes increase. In a recent discussion, Georgi Gardiner defines the view as stating "What is epistemically rational for a person to believe can, in some cases, be affected by moral factors" $(2018,173)$. In a number of recent articles, Rima Basu has explored the idea that beliefs that wrong, like racist beliefs, are unjustified even if they do not violate any standard evidential norms for, as she puts it, "living in an unjust world will provide evidence for unjust beliefs" (Basu 2019). While I think these examples do support my view 
that being a good believer goes beyond attending to purely epistemic considerations, given the resistance to viewing these beliefs as epistemically flawless I will, instead, begin by considering an example where there is no question that one had been a dutiful epistemic agent and, yet, it makes a lot of sense to say one ought not to believe what one does.

Imagine that I know (and so believe) my teenage daughter has a crush on our neighbor, and I know this because I found her well-hidden diary where she writes down all her private thoughts and read it. I have excellent evidence for this belief, but there is a clear sense in which I can blamed for having it. As David Hunter says about a similar case of someone violating privacy rights by reading confidential medical files, "it would be irrational for him not to believe that she has cancer. Still, it is not the case that he ought to believe it. In fact, he positively ought not to believe it. The right to privacy would not amount to much if we could override it simply by learning the private fact!" (Hunter 2018). ${ }^{7}$

Another kind of case where it seems one can believe badly even when no epistemic norm is violated is in the domain of friendship and trust. While these examples are controversial, it has seemed to many that if I form beliefs about a friend or a loved one just as I would someone to whom I had no partiality, I am believing badly. Sarah Stroud's discussion of this kind of case was one of the first to highlight this problem and she put it in terms of the demands of friendship conflicting with the demands of epistemic rationality. She asks you to consider how you should respond to evidence that seems to impugn your good friend's character and argues that it would be wrong in such a case to weigh the evidence as you would in any other situation. She suggests that you should interpret what you hear in a less-damaging way than would a stranger, looking for alternative interpretations to the obvious, and damning, ones. Just as a certain way of behaving concurs with our ideas of what a good friend would do, so, she argues, does a corresponding manner of believing. She says, "the good friend seems eminently subject to epistemic criticism ... We thus have a genuine clash between the demands of friendship and the demands of epistemology ... friendship requires epistemic irrationality" (Stroud 2006). This kind of example again points to the limitation in thinking about purely epistemic duties when identifying cases of blameworthy beliefs.

In a recent discussion, Berislav Marušić and Steven White worry that in cases of testimonial injustice, focusing only on epistemic considerations in thinking about the flaw in the belief fails to adequately explain the wrong being done to the person being dismissed. While disregarding someone's testimonial evidence, if legitimate, will be an epistemic flaw, it is different from other kinds of failure to attend to evidence such as the failure of the detective to attend to the blood stain as evidence that the butler did it. In critiquing Miranda Fricker's view of what is wrong when someone (here Herbert) dismisses someone's testimony (here Marge) because that person is a member of a group (here women) who the hearer thinks of as not warranted being listened to, Marušić and White say the following:

[I]n determining what, say, Herbert should believe, all the work is done by epistemic considerations whose rational role seems to have little to do with what Marge might be owed, morally speaking ... the relevant epistemic 
considerations, and the nature of the warrant they provide, seem too far removed from Marge herself, and her value as a person, to serve as a basis for a claim of justice on her part ... Fricker's account takes the relevant testimonial wrong to be found in the way that prejudice can distort the hearer's responsiveness to evidence for attributing credibility to a speaker, and thus distort the hearer's doxastic response to the speaker's contribution. It's not clear, though, that this locates the wrong in the right place.

(2018, 103-104)

In a similar vein, Basu argues one will fail to understand how a racist belief wrongs if one attends only to the strictly epistemic factors involved. She argues that it is important to consider the possibility of a "supposedly rational racist." She imagines such a person, who she calls Spencer, saying the following:

Although it might be 'unpopular' or 'politically incorrect' to say this, I'm tired of constantly being called a racist whenever I believe of a black diner in my section that they will tip worse than the white diners in my section." Spencer argues that the facts don't lie; he cites studies that show that on average black diners tip substantially less than white diners. The facts, he insists, aren't racist. If you were to deny his claims and were to believe otherwise, it would be you who was engaging in wishful thinking. It would be you who believed against the evidence. It would be you, not Spencer, who was epistemically irrational.

As mentioned above, a common reaction to a case like this is to locate an epistemic flaw in his thinking, such as misusing statistical evidence (Gardiner 2018, 176-178). But Basu claims, and I think rightly, that it is not such failures of reasoning that are at the core of what is wrong with such beliefs. Instead, she says, "anger or dismay is an appropriate reaction to the beliefs in question because these beliefs express or betray moral indifference or insufficient regard" (2019).

\section{Believing Badly When "Epistemic Duties" are Violated}

In my first section I considered examples of epistemically faulty beliefs that are blameless. In the second section I considered cases of believing badly where one's beliefs are epistemically faultless. Other examples, however, of believing badly do seem to focus on the violation of epistemic norms or duties. W. K. Clifford says that the ship owner who ignores the evidence that a ship is not sea-worthy is blameworthy for not believing in accord with the evidence, even if the ship managed to sail without anyone being harmed. Here the blame is being attached to violation of an epistemic duty. But Clifford is clear that believing this way is a moral fault:

It is wrong always, everywhere, and for any one, to believe anything on insufficient evidence ... Belief, that sacred faculty which prompts the decisions of our will, and knits into harmonious working all the compacted 
energies of our being, is ours not for ourselves, but for humanity ... No simplicity of mind, no obscurity of station, can escape the universal duty of questioning all that we believe.

Contemporary epistemologists, however, do not want to collapse epistemic flaws into moral ones. For example, in thinking about when and why people are blameworthy for failing to know what "they should have known," Sandy Goldberg says that he is interested in when such an accusation "alleges a distinctively epistemic shortcoming" $(2017,2864)$. But the examples given to help illustrate when such an accusation is appropriate and blame along with it are ones that reference one's professional duties; the doctor should have known to consult her colleagues, the day care worker should have known to read the allergy report before giving food to a child in their care. And Goldberg's analysis of what grounds the appropriateness of such allegations centers on the nature of participation in a social practice. When these practices are legitimate, we are entitled to expect one another to perform according to the standards of the practice, and some of these expectations include that we believe or know certain things. But once Goldberg explicates the "should have known" phenomenon in terms of practice-generating entitlements it ceases to be clear that the fault is a purely epistemic fault. When the expectations I have of my doctor or my child's day care worker are not met, the fault is a moral one. These people can be appropriately blamed but only once the wider context of the distinctive role they play is specified.

What about our doxastic practice in general? Does it generate entitled expectations? Goldberg argues that there are "basic ... epistemic expectations that we have of any and all epistemic subjects (no matter our relation to them, or their professional status or institutional roles), [and] that we are entitled to these expectations" (2017, 2875).

The example he provides is of one where one fails to read carefully and draws a hasty conclusion. Goldberg thinks that abstracting from any professional or institutional role we can appropriately say of any competent adult that they should have known to read more carefully. One can do so "in virtue of the mutual recognition of his status as a mature, literate epistemic subject on whom others were appropriately relying in deliberation and coordinated activity" (2017, 2875). But again, what kind of expectation is this and what sort of flaw is being pointed to? It doesn't seem that far from Clifford's view. We rely on one another's beliefs and the way we form and maintain beliefs affects one another. Once epistemic expectations are tied to social ones, the purity and exclusivity of the epistemic realm is called into question.

In thinking about when believing badly warrants strong reactive attitudes, when, for example indignation is appropriate, sometimes these beliefs can be explicated in terms of violating duties, but this language can obscure the nature of the defect. Many of the accounts trying to make sense of ways that beliefs can be morally wrong or of how one's doxastic attitudes can wrong others point, as Goldberg does, to the expectations we have of each other, and the way 
we relate to each other. We have seen this is central to Basu's diagnosis of the wrongs of certain racist beliefs. And Marušić and White say "we expect other to regard us in certain ways-which includes believing certain things of usand these expectations are the grounds for our reactive attitudes" $(2018,110)$.

These thoughts lead to the idea that the ideal doxastic agent will exhibit intellectual virtues such as open-mindedness, inquisitiveness, and diligence but will also recognize that this is not all that matters. One must also take care to respect others' rational capacities and status as persons when figuring out what to believe. So an ideal doxastic agent would also exhibit the traditionally moral virtues such as benevolence and generosity. This also reminds us of the inextricably social aspect of our doxastic practices. The ideal doxastic agent will thus exhibit care in the beliefs they maintain, and will recognize the need to engage with others in the shared activity of reasoning. This recognition will reinforce the need to cultivate a carefulness and humility. Considering all the ways that one can believe badly, one of the most common defects, I submit, is a lack of care. Carelessness takes a number of forms. It can be exhibited in the hastiness of drawing conclusions, which can be often be benign but in certain contexts and when on a greater scale can be catastrophic. Other kinds of believing badly exhibit a lack of care due to persons as such.

\section{Objections}

Those who are interested in figuring out the nature of epistemic duties may find my discussion orthogonal to their concerns. One might be interested, for example, in the question of whether one is required to alter one's belief based on good first-order evidence if one has higher-order evidence that leads one to question the belief-for example that an epistemic peer disagrees with you. For me to say that these kinds of norms do not generate duties because violating them does not warrant blame may seem beside the point since no one was purporting to use duty or blame in a way that is anything like the moral sense. For me to say these are not really duties and this isn't real blame may seem to beg the question. If I assume that the concepts of duty and blame are essentially moral then it will follow that they are being misapplied if they are being used in a non-moral sense. But it may seem I am being too stringent in what counts as a duty or blame, and that there are obviously contexts in which we can think about duties and blame in a non-moral sense.

First, I will clarify what I take my discussion to have shown. I have argued that in all the clear cases of believing badly, that is where blame is appropriate, the kind of fault is not a strictly epistemic one. I have done this by reflection on different kinds of cases. And so if some of these cases are understood in terms of violating duties to believe a certain way (i.e. doxastic duties) then one cannot equate doxastic duties with epistemic ones. Given that my conclusion is based on thinking about cases, I have not established that it is conceptually impossible for blame to be appropriate for a purely epistemic fault, but it does seem that all purported examples are forced and stem from a theoretical commitment to there being such cases. 
I will now turn to thinking about other kinds of non-moral duties to see what would be the implications of thinking of epistemic duties as analogous to these. I will end by considering the possibility of thinking about blame in a non-moral sense, something which I am skeptical there is room for beyond the purely causal sense of blame.

\subsection{Not All Duties are Moral Duties}

The most obvious example of a non-moral duty is a legal one. That I have violated a legal duty does not settle the question of whether I have violated a moral one or if I am blameworthy. If we think of requirements and duties as synonymous, as some who talk about epistemic duties seem to (though not all), then we can think about a host of other non-epistemic duties. So the custodian is required to empty the trash, the Nazi prison guard to shoot the escaping prisoner. According to the rules of etiquette, I am required to use my fork furthest on the left from my dinner plate first, and according to the rules of the country club to wear a white shirt when playing tennis. Such "duties" are entirely conventional and they are conditional on your "buying into" the normative domain that they generate.

Are we supposed to think about epistemic duties and requirements in this conditional sense? Are they like rules of the epistemic club that you are required to follow as a member? But what marks out membership of this club; can I choose whether I am in or out? I think debates about the ultimate aims or norms of belief are sometimes best seen as attempts to answer this kind of territorial question, namely the question as to what is the mark of the epistemic domain. So if the purpose of the "club" is to gain as much truth as possible, then this would delineate one set of requirements that may differ if the club is seen more as an "achieving knowledge" club.

Let's take it that this kind of debate is settled and we say, for example, that epistemic requirements refer to whatever is needed to attain knowledge. The discussion then becomes about what is required for knowledge and at this point the talk of duties becomes even more obscuring. For if there is anything uncontroversial we can say about duty, it is that it applies to agents. I can talk about what is required for knowledge or justification without talking about agents at all. I take it that the discussion of duties, blamelessness, and excuses is attempting to shift the focus away from the belief and what is needed for it to count as knowledge or to be justified on to the agent: how ought I form and maintain my beliefs? But, once this is the question being asked then, as we have seen, we have taken a step beyond the purely epistemic.

Richard Feldman was clear about the limitations of what supposedly epistemic duties can tell us about how we ought to believe. One of the main conclusions in his discussion of "the ethics of belief" is that the epistemic "ought" is entirely distinct from the moral or practical. He contends that for each "ought" there is an associated value and we "ought, in the relevant sense, [to] do the thing that maximizes, or perhaps something that does well enough 
in achieving that kind the value." But if these "oughts" conflict, there is no way to adjudicate between them, no meaningful question about what I ought to do or believe all things considered. He says: "We've disambiguated 'ought' and we can't put the various senses back together again" $(2000,694)$.

Others may want to maintain the distinctness of these categories but say we can adjudicate between them and, in the cases I have pointed to, moral duties override the epistemic ones. The problem with this response is that they always do-just as they override duties of etiquette or the duties of the Nazi guard. Again this may not seem to be a problem if one is not claiming that epistemic duties are any different than these conventional ones.

While moral duties can override legal duties as well, there is supposed to be a connection between law and morality; many think, for example, there is a moral duty to obey the law, in which case the conflict between a legal and a moral duty would be a conflict between two moral duties. Perhaps one can view epistemic duties as analogous to legal duties in this sense. Doing so may well offer a way of introducing some more substantial normativity. For Cliffordian reasons we might have a moral duty to cultivate doxastic practices that get us truth and knowledge but, just as we need to be on the look-out for unjust laws and professional duties in figuring out how best to act, we also need to recognize the limits of the purely epistemic duties in figuring out what to believe. This idea is something I have explored at length elsewhere but if one goes this route then one must expect that the norms of belief as well as reasons to believe are not merely epistemic. ${ }^{8}$

Scott Stapleford argues that we do have purely epistemic duties, but that they are best thought of as imperfect duties. We must set evidential proportion as "an ideal limit on rationality and aim for it. How much deliberation is required, and on which propositions is a matter of judgement ... we have a sort of policy obligation - an imperfect epistemic duty-to adopt the end of believing in accordance with the evidence. We are to blame, on purely epistemic grounds, if we make a habit of ignoring our evidence" (2015a,1869-1870). Thinking of epistemic duties this way squares well with our actual practice. It is true that we don't blame a person for each false or unjustified belief they have, or every inference they fail to draw, but we do "blame people for inveterate irrationality, for relying on their guts and their creeds and neglecting to think things through" (Stapleford 2015a, 1870). Elsewhere he puts it this way: "we blame people for habitual irrationality or failing to reflect with sufficient care or frequency on the grounds of their beliefs. 'He's overly emotional and ignores the evidence' and 'She rarely thinks about what she believes' give natural expression to a common concern-that someone is managing their belief system poorly" (2015b, 22).

I agree that we make these kinds of normative assessments but if we think about why we reproach each other for these failings we are led back to the Cliffordian idea that we count on each other, and that bad belief-forming habits risk doing serious damage. We are currently seeing vivid effects of how this is so. Here are just a few examples: (i) the recent measles outbreak, (ii) the suspicion 
that the doctors trying to fight Ebola are spreading it, (iii) the scientists trying to combat the olive tree disease in Italy being accused of causing it, (iv) the reluctance to seriously consider the evidence of the effects of climate change. ${ }^{9}$ Stapleford is right that these negative evaluations "needn't make any reference to the moral ... ramifications of transient or chronic irrationality" but that they need not be referenced does not show that they "stem from epistemic considerations alone" (2015b, 22). When I say "you are so wrapped up in your work, you are constantly ignoring my emotional needs" I am not referencing the moral ramifications of your lack of care. Yet, they are clearly present.

\subsection{Not All Blame is Moral Blame}

I have argued that blame is not appropriate when one's fault is purely epistemic and, if this is so, that purely epistemic duties are akin to these more conventional and conditional ones. But perhaps the kind of blame being referred to in discussions of which beliefs are blameworthy is a different kind of blame. I think that sometimes what is in question is the purely causal sense of blame which is no different from the causal sense of responsibility; we blame the wind for blowing over the tent. When one looks to cases where blame is attributed in a non-moral sense, it is this causal sense that is usually being employed. If one does a google search, one can find many stories discussing whether Billy Buckner is "to blame" for losing game 6 of the World Series to the Mets, as well as the series itself. Other factors beyond his error will be pointed to when someone is arguing that he is not to blame. Here the question seems to be one of where best to locate the cause of the loss.

But sometimes when it is clear that a professional athlete was the cause of an important loss, fans will feel angry, betrayed, and blame the athlete in a much stronger sense- even to the point of issuing death threats. Is this a case of non-moral blame? I don't think so. I think it is a case of inappropriate moral blame. It again has to do with a failure of expectations, but it is much harder to make sense of how the athlete's failure generates any kind of entitlement. But the fan feels like it does because it feels like they are participating in a social practice together and so the reasons grounding the reaction are the same kind as in the case of the doctor or child care worker but the fan is mistaken in their description of the relationship.

Jessica Brown offers one of the few accounts of epistemic blame which she sees as related but distinct from moral blame. She models her view on George Sher's account of moral blame. Now Sher's account is controversial and in some ways requires a lot less than other accounts of blame. But even on this more minimal view I don't think we can make sense of blaming people for their purely epistemic faults. On Sher's view we should understand blame as constituted by a belief-desire pair, namely the belief that an agent has acted wrongly and the desire that the person had not performed this bad act, where the desire issues from blamer's general commitment to morality. In adapting Sher's view to the epistemic case, Brown's analogy to acting wrongly is "believing badly" which she equates with violating an epistemic norm without 
excuse or justification. So "in the case of epistemic blame the relevant belief is that the agent believed badly and the relevant desire is that the agent hadn't believed badly" $(2018,11)$.

But while we can often have the requisite belief, when do we have the corresponding desire "that the believer appreciate the relevant epistemic reasons that she previously ignored and flouted"? Brown doesn't specify when and why some cases elicit such a desire. I think we have this desire when the ignoring and flouting matters or when we view it as mattering. Brown notes that she is not claiming that we have the general desire that no one believes badly and she says this is a "happy result" since "it seems part of the phenomena to be explained that blaming people for their beliefs is less common and often takes a less strong form than blaming people for their bad actions" $(2018,13-14)$. I agree and think that the instances which give rise to the blame in the doxastic realm are times where the faults display some kind of disregard for something we care about that goes beyond the unexcused violation of an epistemic norm. ${ }^{10}$

\section{Notes}

1 For an illuminating discussion of why overridden duties no longer count as duties see Herman (1993). For arguments for why someone can be blameworthy but actually blaming would not be appropriate see Pickard (2011) and Westlund (2018).

2 For a discussion of different ways of thinking about blameless norm violations see Brown (2017).

3 See, for example, Littlejohn (2018).

4 Sometimes the question is put in terms of whether the believer is responsible for the belief. There may well be notions of responsibility where one can be responsible but not blameworthy (see Pickard 2011, Westlund 2018). I can allow for this divergence; there are many times when one is responsible without violating a duty. I am claiming that holding on to this strong deontological language commits one to saying the believer is subject to blame.

5 One may think that the evidentialist norm that says one should only believe on sufficient evidence, or that says "If $S$ adopts a doxastic attitude toward $\mathrm{p}, \mathrm{S}$ ought to adopt the doxastic attitude that fits her evidence" is not violated in this case. Your belief is based on your memory so that is some evidence in support of the it. By positing that the belief is not well-founded, I have built in to the case the idea that this memory-evidence is not sufficient. We can even add that you are aware that you often make mistakes when you rely only on your memory. Still, when such a belief is so easily corrected, and has no negative results, to say that it is a violation of an obligation and you are subject to blame is misguided.

6 See Tognazzini and Coates (2018) for a very helpful overview.

7 One may object that is not the belief that is blameworthy but, rather the way the information was gathered. One may think that is it isn't that I should not have the belief but, rather, that I should not have read the diary. It is true that I should not have read the diary. but why? Because I should not know what it says. The order of explanation goes from what I ought to know (or not know) to what I ought to investigate (or not investigate). To see this, notice how odd it would be to say that while it is wrong for me to read the diary it is perfectly OK for me to know what it says. 
8 See Schleifer McCormick (2015), especially chapters 2 and 3.

9 www.nbcnews.com/news/world/congo-s-ebola-response-threatened-conspiracytheories-rumors-n994156; www.cbc.ca/radio/asithappens/as-it-happens-thursdayedition-1.5155786/charges-against-scientists-dropped-in-italian-olive-treedevastation-1.5155817. When I first wrote this paper I could not envision how such bad belief forming habits would lead to thousands of preventable deaths from Covid-19.

10 Earlier versions of this paper were presented at the University of Richmond, the University of Virginia, the Epistemic Duty Workshop at St. Thomas University, the Dimensions of Rationality Workshop at Goethe University Frankfurt, and a Pacific Division meeting of the American Philosophical Association. I am grateful to the audiences present on these occasions. I am especially grateful to Scott Forrest Aikin and Luis Oliveira for their comments at the APA, and to Kevin McCain for his written comments.

\section{References}

Basu, Rima. 2019. “What We Epistemically Owe Each Other.” Philosophical Studies 176 (4): 915-931.

Basu, Rima. 2019. “The Wrongs of Racist Belief.” Philosophical Studies 176: 2497-2515.

Brown, Jessica. 2017. "Blame and Wrongdoing.” Episteme 14 (3): 2-22.

Brown, Jessica. 2018. "What is Epistemic Blame?” Nô̂s 54: 1-19.

Clifford, William K. 1987. "The Ethics of Belief.” In Gerald D. McCarthy (ed.), The Ethics of Belief Debate. Atlanta, GA: Scholars Press, 19-36.

Feldman, Richard. 2002. "Epistemological Duties” In P. K. Moser (ed.), The Oxford Handbook of Epistemology. Oxford: Oxford University Press, 352-383.

Feldman, Richard. 2000. "The Ethics of Belief." Philosophy and Phenomenological Research 60 (3): 667-695.

Gardiner, Georgi, 2018. "Evidentialism and Moral Encroachment.” In K. McCain (ed.), Believing in Accordance with the Evidence: New Essays on Evidentialism. Cham: Springer, 169-195.

Goldberg, Sanford. 2017. "Should Have Known.” Synthese 194: 2863-2894.

Greco, Daniel. 2019. "Justifications and Excuses in Epistemology” Nô̂s.

Herman, Barbara. 1993. “Obligation and Performance.” In Practice of Moral Judgment. Cambridge, MA: Harvard University Press, 159-183.

Hunter, David. 2018. "Directives for Knowledge and Belief." In Conor McHugh, Jonathan Way and Daniel Whiting (eds), Normativity: Epistemic and Practical. Oxford: Oxford University Press, 68-88.

Littlejohn, Clayton. 2018. “Evidence and its Limits.” In Conor McHugh, Jonathan Way and Daniel Whiting (eds), Normativity: Epistemic and Practical. Oxford: Oxford University Press, 115-136.

Marušić, Berislav, and White, Stephen. 2018. "How Can Beliefs Wrong? A Strawsonian Epistemology." Philosophical Topics 46 (1): 97-114.

Pickard, Hannah. 2011. "Responsibility without Blame: Empathy and the Effective Treatment of Personality Disorder." Philosophy, Psychiatry, and Psychology 13 (3): 209-224.

Schleifer McCormick, Miriam. 2015. Believing Against the Evidence: Agency and the Ethics of Belief, Abingdon, Oxon: Routledge. 
Stapleford, Scott. 2013. "Imperfect Epistemic Duties and the Justificational Fecundity of Evidence.” Synthese 190 (118): 4065-4075.

Stapleford, Scott. 2015a. "Epistemic Versus All Things Considered Requirements." Synthese 192 (6): 1861-1881.

Stapleford, Scott. 2015b. "Why There May Be Epistemic Duties." Dialogue 54 (1): 63-89.

Stroud, S. 2006. “Epistemic Partiality in Friendship.” Ethics 116: 498-524.

Tognazzini, Neil and Coates, Justin. 2018. "Blame." Stanford Encyclopedia of Philosophy.

Westlund, Andrea. 2018. “Answerability without Blame?” In Katrina Hutchison, Catriona Mackenzie, and Marina Oshana (eds), Social Dimensions of Moral Responsibility. Oxford: Oxford University Press, 253-274. 


\title{
3 Evading the Doxastic Puzzle by Deflating Epistemic Normativity
}

\author{
Luis Oliveira
}

\section{Introduction}

About 30 years ago, William Alston (1988) penned the locus classicus for a puzzle that is at the heart of contemporary debates on epistemic normativity. Alston's puzzle, in short, comes from realizing that the most natural way of understanding talk of epistemic justification seems to be in tension with the limited control we have over our belief formation. ${ }^{1}$ In this chapter, I want to clarify and expand this puzzle, as well as examine the nature and full consequences of a deflationary approach to its resolution.

I begin by abstracting from Alston's discussion in three ways. First, I will shift from his narrow focus on epistemic justification and will focus instead on the broader notion of a doxastic obligation: an obligation regarding what one believes, disbelieves, and suspends judgment about. ${ }^{2}$ Alston clearly thinks of the deontological conception of justification as depending on more fundamental facts about our obligations to believe, so the shift in focus I am proposing is not at all a departure from Alston's own way of thinking about this issue. Next, I will shift from a narrow focus on belief and speak instead of our alleged obligations to have various doxastic attitudes: belief, disbelief, and suspension. ${ }^{3}$ This too is in line with Alston's own way of thinking, despite his surface focus on belief. Finally, and still following Alston, I take a cue from the common language typically used to express ideas related to my target notion:

There are many locutions that encourage us to think of believing as subject to requirement, prohibition, and permission. We say "You shouldn't have supposed so readily that he wouldn't come through", "You have no right to assume that", "I had every right to think that she was honest", "I ought to have given him the benefit of the doubt", and "You shouldn't jump to conclusions".

(Alston 1988, 119)

However, I will once again abstract away from these particular claims and focus instead on what I will call general doxastic ought-claims: claims whose propositional content is equivalent to " $\mathrm{S}$ ought to have doxastic attitude $\mathrm{D}$ towards $\mathrm{p}$ at t." My guiding presumption is that the truth of some such claim 
is behind the truth of the ones in Alston's examples. More importantly, my guiding presumption is that the truth of some such claim is behind the truth of most epistemic norms: $\mathrm{S}$ ought to believe that $\mathrm{p}$ in accordance with $\mathrm{S}$ 's evidence; $S$ 's credence in $\mathrm{p}$ ought to conform to the axioms of the theory of probability; $S$ ought not to have contradictory beliefs; etc. If the truth of general doxastic ought-claims is problematic, then so is the truth of all these norms.

With these three modifications in mind, I will call what follows the Doxastic Puzzle, or the puzzle for short:

\section{The Doxastic Puzzle}

Each of these claims seems true, but at least one must be false:

Doxastic Deontology (D): Claims of the form "S ought to have doxastic attitude $\mathrm{D}$ towards $\mathrm{p}$ at $\mathrm{t}$ " are sometimes true at $\mathrm{t}$.

Ought-Implies-Can (OIC): If $\Phi$-ing at $\mathrm{t}$ is not within $S$ 's effective control at $\mathrm{t}$, then it is false, at $\mathrm{t}$, that " $\mathrm{S}$ ought to $\Phi$ at $\mathrm{t}$ ".

Doxastic Involuntarism (I): For all S, p, and t, having doxastic attitude D towards $\mathrm{p}$ at $\mathrm{t}$ is not within S's effective control at $\mathrm{t}$.

If (D) is true, then the consequent of (OIC) sometimes is false when $\Phi$-ing stands for having doxastic attitude $D$ towards $p$. And if (I) is true, then the antecedent of (OIC) is always true when $\Phi$-ing stands for having doxastic attitude $D$ towards $p$. Yet (OIC) cannot be true if its antecedent is always true, and its consequent is sometimes false, for the same interpretation of $\Phi$-ing. Alstonian exegesis aside, this broader characterization of the doxastic puzzle is my true concern in this chapter.

All three natural replies to the puzzle have been pursued. Some have claimed that doxastic attitudes like believing that $\mathrm{p}$ are, in fact, within our effective control, or sufficiently so. Others have claimed that doxastic ought-claims, strictly speaking, are always false. And some have denied that effective control is required for the adequacy of doxastic ought-claims in general. ${ }^{4}$ What all of these different reactions to the puzzle have in common, however, is that they are attempts to dispel it: they solve the puzzle by eliminating one of its constitutive claims. Yet given the initial and resilient plausibility of these three claims, none of the various resulting views is theoretically inexpensive: each denial requires either silencing strong intuitions or modifying central aspects of one's epistemology and/or one's general normative outlook. Each view accepts a claim that is denied by another, after all, and each also denies a claim that is accepted by the other two. I myself am initially inclined to accept all three claims and am resistant to rejecting any of them, despite the extant arguments, upon reflection. So perhaps there is room in this dialectic for a more diplomatic resolution.

In the first part of this chapter, then, I propose to articulate some such diplomatic resolution. The core suggestion is that (I), (D), and (OIC) are not only each true but actually not in tension with each other in the first place. Instead 
of attempting to dispel the puzzle, notice, this solution proposes to evade it instead: to solve it by properly understanding, and by thereby accepting without contradiction, all of its constitutive claims. I will refer to this as the evasive strategy against the puzzle. My discussion examines this evasive strategy in light of recent developments in debates about normativity and the semantics of ought-claims. In the end, however, what is revealed is that such evasion is not a fully diplomatic strategy-it is not without its own surprising consequences. As I argue in the second part of the chapter, the evasive strategy forces us to rethink our understanding of the place of normative reasons in epistemology. More exactly, it seems to come at the cost of one central way of thinking about our reasons for having doxastic attitudes, one where such reasons are goodstanding exemplars of normative reasons in general. The evasive strategy, that is, threatens to lead us very quickly to what I will call a deflationary picture of epistemic normativity: it rescues normative talk, but sacrifices normative substance. I conclude by explaining why I think this is more consequential than some have made it out to be, and by suggesting that these consequences are welcome nonetheless.

\section{Evaluations and Prescriptions}

Talk of "normativity" is often obscure. Sometimes such talk is about certain speech acts; sometimes it is about certain judgments expressed or presumed by certain speech acts; sometimes it is about certain concepts deployed in certain judgments; sometimes it is about certain properties captured by certain concepts. Even worse, it is often unclear what philosophers are indicating when they claim that a speech act, a judgment, a concept, or a property is normative in the first place. I want to avoid this kind of obscurity, so I begin by discussing what I mean by talk of normativity in this chapter.

However we capture it in our theories, talk of normativity, at bottom, is talk of two familiar kinds of experiences. We experience what I will call evaluativenormativity when we evaluate a state of affairs by some standard that we endorse or take for granted. When I say sincerely of a guest that she is "polite," I am evaluating her behavior with respect to some standard of etiquette that I endorse or take for granted (that I have actively or passively accepted). When I say sincerely of an actress that she does not "deserve" to win the award, I am evaluating her acting with respect to some inchoate artistic standard that I endorse or take for granted as well. In one case, the evaluation is positive; in the other, the evaluation is negative. In both cases, the evaluation is quite familiar.

Ernest Sosa $(2007,70)$ has in mind precisely these experiences of evaluativenormativity when he says the following:

We humans are zestfully judgmental across the gamut of our experience: in art, literature, science, politics, sports, food, wine, and even coffee; and so on, across many other domains. We love to evaluate even when no practical interest is in play. We judge performances, whether artistic or 
athletic; grade products of craft or ingenuity; evaluate attitudes, emotions, institutions, and much more.

So when we say that some speech act, judgment, concept, or property is normative, sometimes we simply mean to indicate, however vaguely, its special place within these familiar experiences of evaluative-normativity.

A bit differently, we experience what I will call prescriptive-normativity whenever it seems to us that some action or attitude is all-things-considered required of someone or, in short, is simply to be done. ${ }^{5}$ When I say sincerely to a friend that he ought to be faithful to his partner, for example, I don't take myself as merely saying that cheating scores poorly with respect to a standard that I happen to actively accept or passively endorse. I would certainly deny this description if offered to me as an account of what I mean. I do, of course, take myself to be saying that as well, but some such claim seems too parochial to capture all of what I am trying to convey. Instead, what is characteristic of our experiences of prescriptive-normativity-and what distinguishes them from our experiences of mere evaluative-normativity-is a perception of certain actions as being "demanded" of us (cf. Street 2012, 44), a perception of "being called on" to behave in a certain way (cf. Thomson 2008, 207), and a sense that some facts simply "settle what to do" (cf. McPherson 2018, 244) in my situation. It is this alleged feature of morality, for example, the fact that we experience its claims as prescriptive-normative, that Kant $(1788,86)$ eulogized ("Duty! Thou sublime and mighty name that dost embrace nothing charming or insinuating but requirest submission") and that Mackie $(1977,38)$ took as "utterly different from anything else in the universe" and as ultimately reflecting some of our mistaken beliefs about a purely natural world. ${ }^{6}$

Stephen Grimm (2009, 253-4) is alluding to these experiences of prescriptivenormativity when he says the following:

When we judge a belief to be unjustified or irrational, we seem to be doing more than just evaluating (in this case, in a negative way) the skill or virtuosity of the believer's performance ... To judge someone's belief to be unjustified or irrational is thus to judge that the person's attitude towards the content of the belief should be reconsidered, in some apparently binding sense of "should."

So when we say that some speech act, or judgment, or concept, or property is normative, sometimes we mean to indicate something more than merely its special place within our familiar experiences of evaluative-normativity; sometimes we mean to indicate, however vaguely, its special place within our equally familiar experiences of prescriptive-normativity instead. ${ }^{7}$

At bottom, then, talk of normativity (colloquial or academic) is at times talk of our experiences of evaluative-normativity and at times talk of our experiences of prescriptive-normativity. Whether we are advising, criticizing, or deliberating, we sometimes engage in these practices by indicating or noticing our active or passive acceptance of some standard of evaluation, and 
sometimes we go beyond and indicate or notice something a bit more binding. A theory of normativity, of course, aims at explaining what makes it appropriate, if anything, for some speech act, or judgment, or concept, or property to play a role in these familiar experiences and practices, and it proceeds by examining what these items and contexts, and the world in general, would have to be like for any of this to make good sense. But simply distinguishing between these two kinds of normativity will suffice for now. ${ }^{8}$

\section{The English “Ought”}

Passages such as the above by Grimm, however, may seem to suggest that the English "ought" is only appropriate in the context of prescriptive-normativity. The passage may suggest, that is, that "ought" always serves to express that something is required or to be done. But this is not the case and is in fact the source of some confusion.

Declarative sentences employing the English "ought"-ought-claims—can be ambiguous in familiar and uncontroversial ways. An utterance of "it ought to rain tomorrow" sometimes expresses a claim about what would be best to happen (as in "it ought to rain tomorrow, if we are to survive this drought"), and it sometimes expresses a claim about what is likely to occur (as in "it ought to rain tomorrow, if the readings of the Doppler radar are correct"). According to a widely accepted view, nonetheless, this familiar feature of ought-claims does not reflect underlying semantic differences.

According to this orthodox view, ought-claims always express that some proposition $\mathrm{p}$ is true in all the best contextually salient possible worlds, given a contextually salient standard of evaluation. ${ }^{9}$ On Angelika Kratzer's (1977; 1981) widely used terminology, the contextually salient worlds form a modal base (a set of possible worlds consistent with the information in the conversational background), and the contextually salient standard of evaluation consists of an ordering source (a feature of the conversational background that produces a partial ranking of the worlds in the modal base). Let W stand for the set of contextually salient possible worlds, and let $S$ stand for the contextually salient standard of evaluation. We can then say that, according to the orthodox variety of the Uniformity View, the semantic structure of (simple) ought-claims is always " $\mathrm{O}(\mathrm{p})^{\mathrm{W}, \mathrm{s} \text { " }}$ and it always means something like " $\mathrm{p}$ is true in all the worlds ranked highest in W, given S." 10

Beside the elegance and plausibility that comes from its simplicity, one of the main advantages of this view is that it allows us to understand the compositional structure of ought-claims, despite its many variations, and therefore explain language acquisition and communication (cf. Chrisman 2012c, 313). Another key advantage, more relevant to our present purposes, is that this view can easily explain the common ambiguities by noticing that different contexts can make salient different kinds of standards of evaluation (epistemic, deontic, prudential, etc.). The same set of contextually salient possible worlds, that is, can be ranked differently, at different times, thereby expressing different meanings. 
No doubt there is a use of "ought" closely connected to our experiences of prescriptive-normativity. "Ought," in what we can call prescriptive-normative ought-claims, expresses that there is an authoritative relation of normative requirement or obligation holding between a certain agent $S$ and a certain action $\Phi$. This is likely what we mean when we tell a tempted friend that he ought to be faithful to his partner. Prescriptive-normative ought-claims, in other words, function by ranking salient possible worlds according to some authoritative standard of evaluation - a standard that is guided by values that "call for certain responses and make us criticisable if we're not invested or committed to serving" them (cf. Côté-Bouchard and Littlejohn, forthcoming, 6-7). But there are uses of the English "ought" closely connected to our experiences of evaluativenormativity as well. "Ought," in what we can call evaluative-normative oughtclaims, merely expresses the ranking of a state of affairs with respect to a non-authoritative standard that is being accepted or taken for granted. This is likely what we mean when we tell a visiting friend that she ought to take the second exit on the left: we do not thereby express a normative requirement, we rather express what ranks best according to the familiar standards of efficient traveling - standards that we reasonably presume to be shared and salient in this context. The English "ought" is thus appropriate in contexts of prescriptivenormativity as well as in contexts of evaluative-normativity, depending on what it is used, at that time, to express: a relation of normative requirement between agents and actions, or merely a ranking-relation between standards and states of affairs. ${ }^{11}$ Expressing the latter-it is worth emphasizing the key point-is not always the same as expressing the former.

This feature of the English "ought" is quite important. Since evaluativenormative ought-claims and prescriptive-normative ought-claims express different kinds of relations, they can be expected to have different truth conditions. In particular, it is plausible that only evaluative-normative ought-claims can be true when the grammatical subject of the sentence is not capable of bringing about the relevant state of affairs (cf. Chrisman 2008, 56-7). Consider the claims:

(A) The clock ought to strike on the quarter hour.

(B) Wealthy Americans ought to donate to Oxfam.

Since clocks have no agency, and since striking on the quarter hour is not an action which clocks can choose to perform or not, (A) would be false or incoherent if it claimed that there is a relation of normative requirement holding between a certain agent (clocks) and a certain action (striking on the quarter hour). Yet (B) seems coherent and even true when taken in that way. Wealthy Americans are agents, after all, and we typically think of them as perfectly capable of choosing between alternative actions. This "agency condition" to the truth of some but not all ought-claims, we can now say, depends on the kind of standard that is being employed by the ought-claim. The surface-grammar similarity between (A) and (B), in other words, does not reflect a normative similarity. While (A) is simply an evaluative-normative claim, (B) is also a prescriptive-normative claim; while (A) is simply an evaluation of a certain 
state of affairs, (B) is also a claim about a certain relation of normative requirement that holds between certain agents and a certain action. As a consequence, claims like (A) can be true in kinds of situations where claims like (B) cannot. ${ }^{12}$

The English "ought" is thus an instructive example of the importance of being clear about our talk of normativity. I have suggested that, at bottom, such talk is about our familiar experiences of what I have called evaluative-normativity and prescriptive-normativity. What the English "ought" illustrates, however, is that what makes a speech act, a judgment, a concept, or a property appropriate in the context of one of these experiences may well differ from what makes it appropriate in the context of the other. Depending on which standard of evaluation is employed, different kinds of claims, with different truth conditions, are expressed.

\section{The Evasive Strategy}

For our present purposes, we can turn the doxastic puzzle into an argument against $(\mathrm{D})$ :

(1) If $\Phi$-ing at $t$ is not within S's effective control at $t$, then it is false, at $t$, that "S ought to $\Phi$ at t."

(2) For all S, p, and t, having doxastic attitude D toward p at t is not within S's effective control at $t$.

C So claims of the form "S ought to have doxastic attitude D toward $\mathrm{p}$ at $\mathrm{t}$ " are never true at $\mathrm{t}$.

This argument seems to show that a commitment to (OIC) and (I) forces a rejection of $(\mathrm{D})$. But this appraisal is premature. We have already noted the surface-grammar ambiguity between evaluative-normative ought-claims and prescriptive-normative ought-claims. Now we must clarify which of these two kinds of ought-claims are being deployed in each of the premises. In general, very many debates in normative philosophy would be clearer if this fact were foregrounded and more energy were consequently focused on determining which kind of normativity is at stake.

The first stage of the evasive strategy is precisely the suggestion that true claims of the form "S ought to have doxastic attitude D toward $\mathrm{p}$ at $\mathrm{t}$ " are always evaluative-normative ought-claims and never prescriptive-normative oughtclaims. When we say truly that $S$ ought to have doxastic attitude D toward $\mathrm{p}$, that is, we are always expressing something of a kind with what we express by saying that the clock ought to strike on the quarter hour; we are always merely claiming that S's having doxastic attitude D toward $\mathrm{p}$ at $\mathrm{t}$ is well-ranked by a certain epistemic standard that we accept or take for granted, and we are never claiming that there is a relation of normative requirement holding between $S$ and the having of $\mathrm{D}$ at $\mathrm{t}$. As Côté-Bouchard and Littlejohn (forthcoming) put it:

Unlike moral facts, epistemic facts are only thinly normative. Unlike moral norms, and just like etiquette, fashion, and the law, epistemic norms are such that there is not necessarily a robust reason to conform to them. 
In precisely this sense, Kornblith $(2001,238)$ takes true doxastic oughtclaims as expressions of our epistemic ideals, Chrisman (2008, 364; 2012b, $603)$ takes them as rules of criticism or state-norms; and Feldman (2000, 676; $2008,351)$ takes them as role oughts. Though different in their details, these are all accounts of why doxastic ought-claims are not prescriptive-normative but evaluative-normative instead.

For clarity, let "ought $\mathrm{E}_{\mathrm{E}}$ " stand for the evaluative-normative sense of the

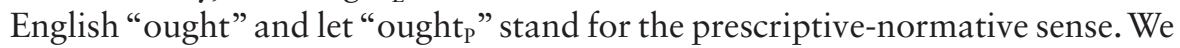
can now say that, according to the evasive strategy, the proper understanding of $(\mathrm{D})$ is the first of these and not the second:

Evaluative-Normative Doxastic Deontology $\left(D_{\mathrm{E}}\right)$ : Some claims of the form "S ought $\mathrm{E}_{\mathrm{E}}$ to have doxastic attitude $\mathrm{D}$ toward $\mathrm{p}$ at $\mathrm{t}$ " are true.

Prescriptive-Normative Doxastic Deontology $\left(D_{\mathrm{p}}\right)$ : Some claims of the form "S ought to have doxastic attitude D toward $\mathrm{p}$ at $\mathrm{t}$ " are true.

If this interpretation is correct, and if we accept the suggestion in the previous section, then the truth of claims of the form " $S$ ought to have doxastic attitude $D$ toward $p$ at $t$ " does not require that $S$ be capable of bringing about the state of affairs of having D. $D_{E}$ can be true, that is, even if $S$ lacks effective control over having $\mathrm{D}$ at $\mathrm{t}$.

The second stage of the evasive strategy, then, is the suggestion that (OIC) cannot be true if its consequent refers to evaluative-normative ought-claims. Having effective control, after all, is simply not required for their truth. According to the evasive strategy, that is, the proper understanding of $(\mathrm{OIC})$ is the first of these and not the second:

$\left(\mathrm{OIC}_{\mathrm{P}}\right)$ : If $\Phi$-ing at $\mathrm{t}$ is not within S's effective control at $\mathrm{t}$, then it is false, at $t$, that "S ought $t_{\mathrm{p}}$ to $\Phi$ at t."

$\left(\mathrm{OIC}_{\mathrm{E}}\right)$ : If $\Phi$-ing at $\mathrm{t}$ is not within S's effective control at $\mathrm{t}$, then it is false, at $\mathrm{t}$, that "S ought $\mathrm{E}$ to $\Phi$ at t."

According to Southwood $(2016,10)$, in fact, the ambiguity behind careless statements of $(\mathrm{OIC})$ explains our ambivalence towards its truth:

Whether or not "ought" implies "feasible" depends on which core practice-serving ought is at issue. There is some salient core practiceserving ought for which it is true that "ought" implies "feasible." There is some other salient core practice-serving ought for which it is false that "ought" implies "feasible." The interpretation of those normative claims that seems false on account of demanding the infeasible-and for which it seems objectionably unworldly to insist otherwise-involves the former. The interpretation of the claims that seems true in spite of demanding the infeasible-and for which it seems unduly lenient to insist otherwiseinvolves the latter. Our ambivalence, far from involving any mistake, is entirely appropriate. 


\section{Luis Oliveira}

Properly understood, therefore, (OIC) is the claim that a certain relation of normative requirement holds between an agent and an action only if that action is within that agent's effective control. ${ }^{13}$ Properly understood, (OIC) places no constraints on the truth of any positive or negative mere evaluation. This is what Feldman (2008, 347-348) has called modest deontologism.

The third and final stage of the evasive strategy simply replaces the original premises of the relevant argument with their appropriate disambiguations:

$\left(1^{*}\right)$ If $\Phi$-ing at $t$ is not within S's effective control at $t$, then it is false, at t, that "S ought to $\Phi$ at t."

(2) For all S, p, and t, having doxastic attitude D toward p at t is not within S's effective control at t.

C* So claims of the form "S ought $\mathrm{p}_{\mathrm{p}}$ to have doxastic attitude D toward $\mathrm{p}$ at $\mathrm{t}$ " are never true at $\mathrm{t}$.

$\left(C^{*}\right)$, however, is not the denial of $\left(\mathrm{D}_{\mathrm{E}}\right)$. While $(\mathrm{I})$ and $\left(\mathrm{OIC}_{\mathrm{P}}\right)$ show that no prescriptive-normative ought-claims are true about an individual and her doxastic attitudes, they nonetheless spell no trouble for $\left(D_{E}\right)$. Whatever we say about S's agency, sometimes it is true that $S$ believing that $\mathrm{p}$, for example, is well ranked according to the typical epistemic standards that we actively or passively accept or take for granted.

The evasive strategy thus amounts to accepting the conjunction of the following claims:

\section{The Evasive Strategy: $(\mathrm{I}) \wedge\left(\mathrm{OIC}_{\mathrm{P}}\right) \wedge\left(\mathrm{D}_{\mathrm{E}}\right) \wedge \sim\left(\mathrm{OIC}_{\mathrm{E}}\right) \wedge \sim\left(\mathrm{D}_{\mathrm{P}}\right)$}

This is why evasion, to me, seems to be the least controversial and the least costly of the available maneuvers against the doxastic puzzle: it does not require a rejection of (I), it does not require a wholesale rejection of (OIC), and it does not require abandoning normative talk about what we ought to believe.

\section{Evasion and Normative Reasons}

Despite appearing to be a more diplomatic resolution to the puzzle than its alternatives, and despite its full or partial widespread favor, the evasive strategy is not without its own substantive implications. On one widely accepted picture of the relation between normative reasons and normative requirements, the evasive strategy sacrifices the very existence of normative reasons for being in a doxastic state. I will outline the four-step argument for this claim in this section.

The first step is accepting the familiar picture of normative reasons as the building blocks of relations of normative requirement: it is precisely because $S$ has undefeated normative reasons in favor of $\Phi$-ing that an authoritative relation of normative requirement holds between $S$ and $\Phi$-ing. While our reasons are considerations of various strengths in favor of various and sometimes conflicting actions at a certain time, the balance of these considerations 
determines what we are required to do. Using standard terminology, the idea here is that the prescriptive-normative English "ought"- "ought $t_{\mathrm{p}}$ ", the "ought" that expresses a relation of normative requirement between an agent and an action-indicates what we have all-things-considered reasons, or decisive reasons, to do. Consider Parfit (2011, 33):

When we have decisive reasons, or most reason, to act in some way, this act is what we should or ought to do in what we can call the decisivereason-implying senses. Even if we never use the phrases "decisive reason" or "most reason", most of us often use "should" and "ought" in these reason-implying senses.

Parfit's view of the connection between normative reasons and what I have been calling prescriptive-normativity is echoed by McPherson $(2011,233)$ : "almost all of us take reasons to be normative in a way that contrasts with other formally normative systems such as the rules of chess." While the rules of chess ground various evaluations that we at times might take quite seriously, they do not, by themselves, provide us with the kind of normative reason that can ground an authoritative requirement.

We can call the view behind these claims normative rationalism:

Normative Rationalism (NR): There is a normative requirement for $S$ to $\Phi$ if and only if (and because) there is most normative reason for $S$ to $\Phi .{ }^{14}$

Accepting (NR), notice, does not require taking a stand on the controversial question of whether considerations other than evidence can count as a reason to have doxastic attitude D. It also does not require taking a stand on whether these reasons are reasons to promote some value or to respect some norm. (NR) is simply an account of the source of normative requirements, of the kind of normativity that we experience as binding. As such, (NR) is initially compatible with whatever views one has about what counts as reasons for doxastic attitudes, as well as whatever views one has about the sources of these reasons. It is important not to confuse one's reasons for rejecting one of these other views with a reason to reject (NR). All that said, I think (NR) is true and will take it on board in what follows. Those who are unsure or positively resistant can restate my argument in conditional form.

The second step is noticing an implication of $(\mathrm{NR})$ : if there is no relation of normative requirement holding between $S$ and $\Phi$-ing, then either (a) there are no normative reasons for $S$ to $\Phi$, or (b) these reasons are defeated by reasons in favor of doing something else that is incompatible with $\Phi$-ing, or (c) there are normative reasons for $\mathrm{S}$ to $\Phi$, reasons that are undefeated by reasons for doing something else that is incompatible with $\Phi$-ing, but reasons that nonetheless are not strong enough to ground a relation of normative requirement between $S$ and $\Phi$-ing. At nearly all times, there are available actions such that it is not the case that $S$ ought $_{\mathrm{p}}$ to perform them at that time. Sometimes this is the case because $S$ has no reason whatsoever to perform them. Perhaps right now, for 
example, I have absolutely no reason to raise my index finger straight up into the air; consequently, it is not the case that I ought to raise my finger in that way: raising my finger, right now, is not something that I am required to do. But sometimes it is not the case that $S$ ought $_{\mathrm{p}}$ to perform a certain action despite in fact having reasons for performing it. Perhaps right now, for example, I have a reason to have a cup of coffee (because I have a non-conflicted desire for it), but have even stronger reasons not to have it (because I've already had too many in a short amount of time). So while I have a reason to have a cup of coffee, it is not the case that I ought $\mathrm{p}_{\mathrm{p}}$ to have a cup of coffee: having a cup of coffee is not something that I am required to do. Finally, sometimes it is not the case that $S$ ought $_{\mathrm{p}}$ to perform a certain action despite in fact having undefeated reasons for performing it. Perhaps I have reasons to go help my neighbor set up his garage sale, reasons that are not defeated by my reasons for doing anything else right now, but reasons that are nonetheless too weak to ground a requirement to go across the street. It's just not true that I ought $t_{\mathrm{p}}$ to go help him with his chairs. The point here, however, is that one of these three explanations is true whenever we have the absence of a relation of normative requirement between $S$ and $\Phi$-ing.

The third step is noticing an implication of the conjunction of (NR) and the evasive strategy's denial that claims of the form "S ought $t_{\mathrm{p}}$ to have doxastic attitude D toward p at t" are ever true. Given the implication of (NR) just mentioned as my second step, this denial means accepting that it is always true that either:

$\left(\mathrm{a}_{1}\right)$ There are no normative reasons for $\mathrm{S}$ to have doxastic attitude D toward $\mathrm{p}$ at $\mathrm{t}$.

$\left(b_{1}\right)$ S's reasons for having doxastic attitude $\mathrm{D}$ toward $\mathrm{p}$ at $\mathrm{t}$ are defeated by S's reasons in favor of doing something else that is incompatible with having doxastic attitude $\mathrm{D}$ toward $\mathrm{p}$ at $\mathrm{t}$.

$\left(c_{1}\right)$ S's undefeated reasons for having doxastic attitude D toward $\mathrm{p}$ at $t$ are not strong enough to ground a requirement to believe that $p$.

Since reasons are the building blocks of relations of normative requirement, denying that a certain relation of normative requirement holds between $S$ and $\Phi$ means denying that there are decisive reasons for $S$ to $\Phi$. Denying that there is ever a relation of normative requirement holding between $S$ and $\Phi$, therefore, means denying that there are ever decisive reasons for $S$ to $\Phi$ (because of (a) or (b) or (c) considerations). But this calls out for explanation.

The fourth and final step, then, is realizing that consideration (a) is always the best explanation for why there is no normative requirement for $S$ to have doxastic attitude $\mathrm{D}$ toward $\mathrm{p}$ at $\mathrm{t}$. It would certainly be odd if every case where $\mathrm{S}$ has a normative reason for having doxastic attitude $\mathrm{D}$ toward $\mathrm{p}$ were also a case where that reason is defeated by S's reasons for doing something else that is incompatible having $\mathrm{D}$ toward $\mathrm{p}$. The only thing that seems incompatible with believing that $\mathrm{p}$, for example, is yet another doxastic attitude: not believing that $\mathrm{p}$ or suspending judgment about $\mathrm{p}$. So the only way to have reasons for 
having some doxastic attitude $\mathrm{D}$ that are defeated by decisive reasons that are incompatible with having $\mathrm{D}$ is to have decisive reasons for another doxastic attitude and, consequently, a normative requirement to have it. Similarly, it would certainly be odd if every case where $S$ has an undefeated normative reason for having doxastic attitude $\mathrm{D}$ toward $\mathrm{p}$ were also a case where those reasons are not strong enough to be decisive. If there are no decisive reasons for believing that $\mathrm{p}$, once again, and no decisive reasons for believing that not$\mathrm{p}$, then ipso facto there are decisive reasons for suspending judgment about $\mathrm{p} .{ }^{15}$ So there are doxastic normative requirements for having some doxastic attitude D toward $\mathrm{p}$ in that case as well, no matter what. So the best explanation for the inexistence of any normative requirement for having doxastic attitude D toward $\mathrm{p}$, and perhaps even the only explanation, is that no one ever has normative reasons for having doxastic attitude $\mathrm{D}$ toward $\mathrm{p}$ at all. There are simply no such things.

We can state my argument in this section more precisely in the following way:

\section{The No Reasons Argument}

(1) If the evasive strategy is correct, then claims of the form " $S$ ought $t_{\mathrm{P}}$ to have doxastic attitude $\mathrm{D}$ toward $\mathrm{p}$ at $\mathrm{t}$ " are always false.

(2) If claims of the form " $S$ ought $\mathrm{p}$ to have doxastic attitude $\mathrm{D}$ toward $\mathrm{p}$ at $t$ " are always false, then there are never decisive normative reasons for having doxastic attitude D toward $\mathrm{p}$.

(3) If there are never decisive normative reasons for having doxastic attitude $\mathrm{D}$ toward $\mathrm{p}$, then there are no normative reasons for having doxastic attitude $\mathrm{D}$ toward $\mathrm{p}$.

C So if the evasive strategy is correct, then there are no normative reasons for having doxastic attitude $\mathrm{D}$ toward $\mathrm{p}$.

Premise 1 follows from the fact that the evasive strategy accepts both (I) and $\left(\mathrm{OIC}_{\mathrm{P}}\right)$. This is an important element of the evasive strategy, since it thereby avoids some of the costs of alternative strategies against the doxastic puzzle. Premise 2 follows from the familiar picture of normative reasons as the building blocks of requirement-relations: (NR). Premise (3) follows from the traditional three-way exclusive division of doxastic attitudes and the structural connections between any possible reasons for or against them.

It is here that we see the most important implication of the evasive strategy: while it succeeds at escaping the doxastic puzzle by taking doxastic oughts as evaluative-normative ought-claims that do not require agency, it sacrifices the existence of normative reasons for having doxastic attitudes. While it retains one kind of normativity for belief, it abandons the kind of normativity that we experience as binding. As I will put it, it thereby deflates epistemic normativity by removing any of its prescriptive bite. Evading the doxastic puzzle by deflating epistemic normativity, as we now can see, is not as fully diplomatic as it looked on first inspection. ${ }^{16}$ 


\section{Conclusion}

I have argued that the evasive strategy, despite the widespread appeal of its constitutive parts, comes at the cost of normative reasons for having doxastic attitudes. The significance of this consequence cannot be overstated. Since talk of reasons is ubiquitous in epistemology, the evasive strategy forces sympathizers to find something ameliorative to say about such talk. Perhaps, for example, talk of "epistemic reasons" is talk of a merely domain-relative kind of reason (cf. Sosa 2007, chapter 4) and, as such, not talk of full-blown, authoritative, normative reasons after all. Perhaps, for another example, talk of "having evidence for p" is not the same as (and it doesn't imply) talk of "having a reason to believe that p" (cf. Leite 2007), such that we can retain talk of evidence while abandoning talk of reasons. Both maneuvers, I should say, seem good to me. ${ }^{17}$ Yet it is important to note one central way in which they fail to be fully ameliorative, relative to the full implications of the evasive strategy.

Consider my fellow deflationary epistemologists Côté-Bouchard and Littlejohn (forthcoming). They argue that "our epistemic speech can correctly pick out epistemic facts even if there are no robustly normative facts and reasons" (p. 5), and that "epistemic norms ... are thinly normative, not robustly so" (p. 7). This is very much in the spirit of the evasive strategy and the deflated epistemic normativity I have outlined above. However, they go on to argue that nothing of importance is really lost by deflating epistemic normativity in this way. This is because we can still do and say everything that normativity and normative talk is supposed to allow: we can still ground epistemic evaluations, these evaluations can still be important, we can still talk in terms of epistemic permissions, epistemic standards can still be inescapable, and we can still talk in terms of epistemic reasons. What more could we want from epistemic normativity? And yet while this is very much in the spirit of my view, there is a deeper loss to deflating epistemic normativity in the ways I have suggested.

Deflating epistemic normativity in the wake of evasion, as I will put it, rules out the possibility of normative upgrade. And normative upgrade, in turn, is the key ameliorative feature that makes deflation palatable to most others. We see this, for example, when Côté-Bouchard and Littlejohn compare epistemic normativity to the normativity of etiquette: "the connection between belief and epistemic standards seems more akin to the connection between arrangements of cutlery and the standards of etiquette than the connection between actions and moral standards" (p. 9). The suggestion, of course, is that, like the reasons of etiquette, epistemic reasons, despite being themselves only thinly normative, can also be upgraded: "We think that the force of the criticism that we level against a thinker for failing to believe what she ought to believe comes from non-epistemic reasons-reasons to form beliefs that meet epistemic standards" (p. 9). Just like you can have a true binding requirement to follow the thinly normative rules of etiquette on some extraordinary occasion (whenever authoritative normative reasons enjoin you to so do it) the suggestion is that you can likewise have a true binding requirement to follow the thinly epistemic 
norms as well. Consider another pair of deflationary epistemologists, Maguire and Woods (forthcoming, 6), on this very same point:

We often have practical reasons to have correct beliefs. And here, epistemic reasons play a key role. The interaction of epistemic reasons explains which belief is correct in a given situation. This is analogous to other activities. Chess-based reasons-that this move will win material, or that that move will cost you a tempo, are not authoritative either. They don't explain what you just plain ought (henceforth: ought) to do. Practical reasons do that. But we sometimes have practical reasons to make correct chess moveswhere by this we mean: make the strategically best move within the rules of the game. The interaction of chess-based reasons explains which move is correct. This structure preserves a key normative role for epistemic reasons for beliefs, and a key normative role for practical reasons for beliefs. Each plays a distinctive role in the explanation of what we ought to believe.

With the possibility of normative upgrade, that is, indeed very little is lost by deflating epistemic normativity. But this is precisely where the deflationary epistemology produced by the evasive strategy reveals its cost. As the No Reasons Argument makes clear, the evasive strategy does not merely dampen the authority of a certain source of normative reasons for having doxastic attitudes, but rather it eliminates the very existence of normative reasons for having doxastic attitudes in the first place. It does this, more exactly, by relying on the "agency condition" for the truth of certain ought-claims. On the resulting picture, then, epistemic normativity is not at all like the normativity of chess and etiquette, both of which can be upgraded when other kinds of reason are at play, but rather like the normativity of clocks (as suggested by Chrisman) or digestion (as suggested by Alston). The evasive strategy, as we can now see, deflates epistemic normativity all the way down to its lowest or thinnest level, and it is incompatible with the kind of ameliorative normative upgrade that other deflationary epistemologists take for granted.

With that in mind, I should say that I myself am attracted to a reconstructive reply to the consequences of evasion: I take it as an invitation to excise the notion of an epistemic reason from its center place in epistemology. Kornblith (2015), for example, argues that talk of "reasons" is a relic from epistemological theorizing that is overly focused on the phenomenology of deliberation, anyway, and is lacking attention to the psychology of belief fixation. I think something along those lines is promising. Externalist theories such as process reliabilism, for example, can provide us with the tools to understand the central epistemic notions (knowledge and justification) without any reference to epistemic reasons, and we have just seen that we can recover talk of "ought to believe" without them just as much. Of course, there is much more to be said about this. Nonetheless, I think there is good reason to see what would happen to an epistemology that truly put talk of "epistemic reasons," and corresponding talk of "epistemic obligations," to the side. ${ }^{18}$ 


\section{Notes}

1 Alston is extremely careful in his discussion of a variety of agential notions: basic voluntary control, non-basic immediate voluntary control, long-range voluntary control, and indirect voluntary influence. Nonetheless, since my concern here is not with the voluntarism vs. involuntarism debate, I will simply use the term effective control as a cover term for whatever key aspect of one's agency is most plausibly a requirement on obligation and most plausibly controversial in the context of belief.

2 I will take an epistemic obligation to be a specific kind of doxastic obligation, one originating from exclusively epistemic sources (the value of truth or knowledge, for example, or the nature of belief, or the nature of the practice of forming beliefs, and so on). Plausibly, one can have non-epistemic doxastic obligations too, originating perhaps from moral or prudential sources. (One can accept this, of course, without endorsing any particular claim about the interaction between these sources and obligations-see Maguire and Woods (forthcoming) for discussion.) At any rate, since my chapter discusses a challenge to the existence of doxastic obligations in general, it ipso facto discusses a challenge for the existence of epistemic obligations in particular.

3 I am following Friedman (2013) in taking suspension of judgment as a distinctive doxastic attitude

4 For representative arguments, see Ryan (2003), Steup (2008), and Weatherson (2008) for denials of (I); Sosa (2007), Hazlett (2013), and Papineau (2014) for denials of (D); and Chuard and Southwood (2009), Graham (2011), and McHugh (2012) for denials of (OIC).

5 An all-things-considered requirement is the final word about what to do. This is potentially different from a requirement being categorical, or inescapable, or objective. As Foot $(1972,311)$ has famously argued, many requirements that do not seem to have the "practical oomph" (cf. Joyce 2006) that I am trying to capture can nonetheless be categorical, inescapable, and objective. Setting aside the important task of capturing these experiences descriptively in theory, I here assume the reader has enough of a working sense of what I am talking about when I allude to them.

6 The source of the normative authority that we seem to commonly experience, and its very existence in fact beyond just thought and language, is obviously a matter of debate. I don't mean to take a stand on that matter. My only intention, at this point, is to describe and distinguish the common experience that lies behind that debate.

7 Nolfi $(2014,98)$ and others claim that prescriptions are generally connected to the giving of advice, guidance, or direction. But what I am here calling prescriptivenormativity is more narrowly characterized as the experience or expression of an all-things-considered requirement. Nolfi's way of talking about prescriptions is in fact orthogonal to the distinction between evaluative-normativity and prescriptivenormativity that I am suggesting since we can certainly give advice, guidance, or direction without implying that the prescribed behavior is required in this way (e.g. "You shouldn't steal this car; you should steal that car over there instead!"). The same remarks apply to hypological notions about praise and blame: nothing here is presumed about whether they properly belong to our experiences of evaluativenormativity or prescriptive-normativity instead. Finally, Joshua DiPaolo (2019) distinguishes between norms of perfection and norms of compensation, where the former tell us how agents ought to behave if they're to be perfect and the latter tell us how imperfect agents ought to behave in order to compensate for their imperfections; my distinction is orthogonal to his as well. 
8 My labels for this distinction follow Southwood (2016, 17-19), though I do not here endorse his full analysis. See Wodak $(2019,1-5)$ as well for a helpful discussion of this distinction under a different label: substantively normative standards versus merely formally normative standards. Other labels for the same distinction include reason-involving normativity and rule-involving normativity (Parfit 2011, 144-145), robust and formal normativity (McPherson 2011, 232-233), and thin and robust normative standards (Côté-Bouchard and Littlejohn, forthcoming). Whatever labels we choose, it is important to recognize, following Chrisman (2008), that evaluative ought-claims sometimes contextually imply prescriptive ought-claims, specially depending on what is taken as shared background in the conversation.

9 For some proponents, see Phillips (1998), Wedgwood (2007), Chrisman (2012a, 2012c), and Finlay and Snedegar (2014).

10 I am simplifying things a bit since the variations within this view are irrelevant for my arguments in this chapter.

11 Southwood (2016) distinguishes between four different “oughts." My distinction is broader and encompasses his.

12 See Southwood $(2016,23-28)$ for the claim that "prescriptive oughts" (in his sense) do not always require effective control. His argument, however, depends both on a particularly narrow sense of "control," as well as on a classification of prescriptive oughts as something belonging to the category I am calling evaluative-normativity.

13 Thus Côté-Bouchard and LittleJohn (forthcoming, 8): “Animals are not subject to moral standards. Your dog's actions cannot be morally right or wrong. More generally, since animals lack the rational capacities needed for agency and attributions of responsibility, they are exempt from robustly normative standards. They cannot have robust reasons that apply to them and the "oughts" that require such reasons do not apply to them."

14 This is one way of expressing the view made famous by W. D. Ross (1930) and further developed by Nagel (1970), Scanlon (1998), Raz (2002), and, as quoted, Parfit (2011). Notice that (NR) could be stated as a weaker, satisficing principle by substituting "most normative reason" for "sufficient normative reason." My argument in this section goes through on either formulation. For some resistance to the import of this meta-normative view to the epistemic domain, see Sylvan and Sosa (2018).

15 This may seem to be in tension with permissivism: the view that "some bodies of evidence permit more than one rational doxastic attitude toward a particular proposition" (Jackson and Turnbull forthcoming). But this is not the case. Permissivism, strictly speaking, is a view about "evidence," and not a view about "normative reasons." Any sense of tension here depends on additional substantive commitments. I am grateful to Justin Coates for bringing this to my attention.

16 Here is another potential cost of the evasive strategy: perhaps $S$ is responsible for believing that $\mathrm{p}$ only if there are normative reasons for $\mathrm{S}$ to believe that $\mathrm{p}$. There is nothing implausible about this claim. As Skorupski $(2010,295)$ puts it: "there can be no reason to blame someone who had no reason not to do what he did." But if (NR) and this claim are both true, then the evasive strategy sacrifices not only the existence of normative reasons for belief, but also the existence of epistemic responsibility. I won't pursue that line of argument here, but see Perrine (forthcoming) for a recent discussion of the doxastic puzzle and matters of responsibility.

17 I have argued elsewhere against versions of evidentialism stated in terms of prescriptive ought-claims (Oliveira 2017, 2018a), and against internalist notions of justification stated in agential terms (Oliveira 2015, 2018b). 
18 For comments and discussions, I am grateful to Hilary Kornblith, Chris Meacham, Louise Antony, Peter Graham, Justin Coates, Timothy Perrine, Josh DiPaolo, Ed Ferrier, Dennis Kavlakoglu, Daniel McGloin, Lucas Santos, Heidi Garbe, and the editors of this volume.

\section{References}

Alston, William. 1988. "The Deontological Conception of Epistemic Justification.” Philosophical Perspectives 2: 257-299.

Chrisman, Matthew. 2008. “Ought to Believe.” Journal of Philosophy 105 (7): 346-370.

Chrisman, Matthew. 2012a. "Ought and Control." Australasian Journal of Philosophy 90 (3): 433-451.

Chrisman, Matthew. 2012b. "The Normative Evaluation of Belief and the Aspectual Classification of Belief and Knowledge Attributions." Journal of Philosophy 109 (10): 588-612.

Chrisman, Matthew. 2012c. "On the Meaning of 'Ought'.” In Russ Shafer Landau, ed., Oxford Studies in Metaethics. Oxford: Oxford University Press, vol. 7: 304-333.

Chuard, Philippe, and Southwood, Nicholas. 2009. "Epistemic Norms without Voluntary Control.” Nô̂s 43 (4): 599-632.

Côté-Bouchard, Charles, and Littlejohn, Clayton. Forthcoming. "Knowledge, Reasons, and Errors about Error Theory." in Christos Kyriacou and Robin McKenna (eds), Metaepistemology: Realism and Anti-Realism. Basingstoke: Palgrave Macmillan.

DiPaolo, Joshua. 2019. "Second Best Epistemology: Fallibility and Normativity." Philosophical Studies 176 (8): 2043-2066.

Feldman, Richard. 2000. "The Ethics of Belief." Philosophy and Phenomenological Research 60 (3): 667-695.

Feldman, Richard. 2008. "Modest Deontologism in Epistemology." Synthese 161: 339-355.

Finlay, Stephen and Snedegar, Justin. 2014. "One Ought Too Many.” Philosophy and Phenomenological Research 86 (1): 102-124.

Foot, Philippa. 1972. "Morality as a System of Hypothetical Imperatives.” Philosophical Review 81 (3): 305-316.

Friedman, Jane. 2013. “Suspended Judgment.” Philosophical Studies 162 (2): 165-181.

Graham, Peter A. 2011. “Ought and Ability.” Philosophical Review 120 (3): 337-382.

Grimm, Stephen. 2009. "Epistemic Normativity.” In A. Haddock, A. Miller and D. Pritchard (eds), Epistemic Value. . Oxford: Oxford University Press, 243-264.

Hazlett, Allan. 2013. A Luxury of the Understanding: On the Value of True Belief. Oxford: Oxford University Press.

Hieronymi, Pamela. 2008. "Responsibility for Believing." Synthese 161 (3): 357-373.

Jackson, Elizabeth, and Turnbull, Margaret Greta. Forthcoming. "Permissivism, Underdetermination, and Evidence." In Clayton Littlejohn and Maria LasonenAarnio (eds), Routledge Handbook for the Philosophy of Evidence. Abingdon, Oxon: Routledge, 1-13.

Joyce, Richard. 2006. The Evolution of Morality. Cambridge, MA: MIT Press.

Kant, Immanuel. 1788/1956. Critique of Practical Reason, tr. Lewis White Beck. Chicago, IL: University of Chicago Press.

Kornblith, Hilary. 2001. "Epistemic Obligation and the Possibility of Internalism.” In A. Fairweather and L. Zagzebski (eds), Virtue Epistemology: Essays on Epistemic Virtue and Responsibility. Oxford: Oxford University Press, 243-264.

Kornblith, Hilary. 2015. “The Role of Reasons in Epistemology.” Episteme 12: 225-239. 
Kratzer, Angelica .(977. "What Must and Can Must and Can Mean.” Linguistics and Philosophy 1: 337-355.

Kratzer, Angelica. 1981. "The Notional Category of Modality." in H. Eikmeyer and H. Rieser (eds), Semantics from Different Points of View. Berlin: Springer, 117-147.

Leite, Adam. 2007. "Epistemic Instrumentalism and Reasons for Belief: A Reply to Tom Kelly's 'Epistemic Rationality as Instrumental Rationality: A Critique'.” Philosophy and Phenomenological Research 75 (2): 456-464.

Mackie, J. L. 1977. Ethics: Inventing Right and Wrong. Harmondsworth: Penguin.

Maguire, Barry, and Woods, Jack. Forthcoming. "The Game of Belief." Philosophical Review.

McHugh, Conor. 2012. "Epistemic Deontology and Voluntariness." Erkenntnis 77 (1): 65-94.

McPherson, Tristram. 2011. “Against Quietist Normative Realism.” Philosophical Studies 154 (2): 223-240.

McPherson, Tristram. 2018. "Authoritatively Normative Concepts.” In Russ ShaferLandau (ed.), Oxford Studies in Metaethics. Oxford: Oxford University Press, vol. 13, 253-278.

Nagel, Thomas. 1970. The Possibility of Altruism. Princeton, NJ: Princeton University Press.

Nolfi, Kate. 2014. "Why is Epistemic Evaluation Prescriptive?” Inquiry 57 (1): 97-121.

Oliveira, Luis R. G. 2015. "Non-Agential Permissibility in Epistemology.” Australasian Journal of Philosophy 93 (2): 389-394.

Oliveira, Luis R. G. 2017. "Deontological Evidentialism, Wide-Scope, and Privileged Values." Philosophical Studies 174 (2): 485-506.

Oliveira, Luis R. G. 2018a. "Deontological Evidentialism and Ought Implies Can." Philosophical Studies 175 (10): 2567-2582.

Oliveira, Luis R. G. 2018b. "Ampliative Transmission and Deontological Internalism.” Pacific Philosophical Quarterly 99 (2): 174-185.

Papineau, David. 2014. "There Are No Norms of Belief." in T. Chan (ed.), The Aim of Belief. Oxford: Oxford University Press, 64-80.

Parfit, Derek. 2011. On What Matters. Oxford: Oxford University Press.

Perrine, Timothy. Forthcoming. "Strong Internalism, Doxastic Involuntarism, and the Costs of Compatibilism." Synthese.

Phillips, David. 1998. "The Middle Ground in Moral Semantics." American Philosophical Quarterly 35 (2): 141-155.

Raz, Joseph. 2002. Engaging Reason. Oxford: Oxford University Press.

Ross, W. D. 1930/2002. The Right and the Good. Oxford: Clarendon Press.

Ryan, Sharon. 2003. "Doxastic Compatibilism and the Ethics of Belief." Philosophical Studies 114 (1-2): 47-79.

Scanlon, T. M. 1998. What We Owe Each Other. Cambridge, MA: Harvard University Press.

Skorupski, John. 2010. The Domain of Reasons. Oxford: Oxford University Press.

Sosa, Ernest. 2007. A Virtue Epistemology: Apt Belief and Reflective Knowledge, Vvol. 1. Oxford: Oxford University Press.

Southwood, Nicholas. 2016. "Does 'Ought' Imply 'Feasible'?” Philosophy and Public Affairs 44 (1): 7-45.

Steup, Mathias. 2008. “Doxastic Freedom.” Synthese 161 (3): 375-392.

Street, Sharon. 2012. "Coming to Terms with Contingency: Humean Constructivism about Practical Reason.” In J. Lenman and Y. Shemmer (eds), Constructivism in Practical Philosophy. Oxford: Oxford University Press, 40-59. 


\section{Luis Oliveira}

Sylvan, Kurt, and Sosa, Ernest. 2018. “The Place of Reasons in Epistemology.” In Daniel Starr (ed.), The Oxford Handbook of Reasons and Normativity. Oxford: Oxford University Press, 555-575.

Thomson, Judith J. 2008. Normativity. La Salle, IL: Open Court.

Weatherson, Brian. 2008. "Deontology and Descartes' Demon.” Journal of Philosophy 105 (9): 540-569.

Wedgwood, Ralph. 2007. The Nature of Normativity. Oxford: Oxford University Press.

Wodak, Daniel. 2019. "Mere Formalities: Normative Fictions and Normative Authority." Canadian Journal of Philosophy 49: 828-850. 


\title{
4 Epistemic Tension and Epistemic Duty A Rossian Account
}

\author{
Mark T. Nelson
}

Given the many parallels between ethics and epistemology, we might suppose that we have duties in epistemology, just as we have in ethics: that there are things we should and should not believe, just as there are things we should and should not do. I have argued elsewhere that, while we may have negative epistemic duties, we have no positive ones; there are things that we ought not to believe, but there is nothing that we ought to believe, on purely epistemic grounds. ${ }^{1}$

I explained this in terms of what I called a "permissive" approach to normative epistemic theory. ${ }^{2}$ The core idea of the permissive theory is that our believings are constrained and licensed by our epistemic circumstances. These circumstances (including the experiential and propositional evidence available to us) set limits to what we are epistemically permitted to believe, while other, non-epistemic considerations (such as needs, interests, or goals) determine, within those limits, what we should believe. ${ }^{3}$

On this permissivist picture, the licensing features of our epistemic circumstances seem not to give rise to any epistemic duties at all, positive or negative. The constraining features of our epistemic circumstances, on the other hand, do seem to give rise to duties. At least, that's what I used to think. Now I am not so sure.

\section{What Should I Not Believe?}

For example, I claimed: "I should believe nothing that is clearly incompatible with any beliefs that are on balance licensed for me." ${ }^{4}$ What exactly does this entail, for me, now? That depends on my epistemic circumstances. As I write this, it is early on a Saturday morning. I have not yet had my breakfast, but I am having a cup of tea. I am seated at a table in my kitchen at home. Through the window, I can see, past the magnolia tree, Christie's house across the street. Outside, the mockingbirds are making a racket. Inside, the house is quiet. I have given the dog her breakfast, so she is no longer whining. My daughter is still asleep. My wife is visiting her sister in Seattle.

So, what should I not believe, given all that? Intuitively, at least, given that I see a teacup on the table in front of me, I ought not believe that there is no 
teacup on the table. Likewise, given that I know that Pauline is in Seattle, and that I know that If Pauline is in Seattle, she is not in Santa Barbara, I ought not believe Pauline is in Santa Barbara. These seem like negative epistemic duties; they don't tell me what to believe, just what to avoid believing. I could satisfy these duties by forming no beliefs at all, by cultivating ataraxia or rendering myself unconscious.

Of course, I may also have epistemological duties of a general sort. These may concern epistemological policies such as, "You ought to proportion your beliefs to the evidence." 5 Or they may concern epistemological virtues and vices, such as "You ought to work to overcome your tendency to jump to conclusions." Again, however, some of these policies are best construed as merely negative and could be satisfied by not forming any beliefs at all. But what of the policy that, "If you discover that your beliefs are logically inconsistent, you ought to give up at least one of them"? This does seem to be a positive obligation in that (once you discover that you have inconsistent beliefs) it cannot be satisfied merely by rendering oneself unconscious. Moreover, satisfying it seems to have direct implications for the contents of one's belief-set. Given that I know Pauline is in Seattle, if I catch myself believing somehow that Pauline is in Santa Barbara (e.g., when I absent-mindedly accept a dinner invitation for the both of us), then I should drop that particular belief.

Of course, given the terms of this example, it is obvious what I should do. Since I know that $P$ and If $P$ then $\sim Q$, I ought to drop my belief that $Q$, and normally this is easy to do: that latter belief (if it even deserves to be called a belief) is so lightly held that all I need to do in order to drop it is to remind myself that $P$. (I need not consciously work through any syllogism.) But what if I do not know that $P$ and If $P$ then $\sim Q$, but merely believe them? If, in that case, I find myself believing $Q$, then what should I do? Is it so obvious that I have a duty to give up $Q$ ? Of course, if I am strongly justified in believing that $P$ and If $P$ then $\sim Q$, but only weakly justified in believing $Q$, then probably I do have a duty to give up Q. But what if I am justified in believing all three of them? Do I still have a duty to drop at least one of them? ${ }^{6}$ If so, which ones and how quickly?

Let me approach this question indirectly by introducing the idea of "epistemic tension": the feeling of being pulled between two opposed but equally plausible ideas. This feeling will be familiar to most of us, but it may reveal something less familiar about the nature of epistemic justification. That is what I shall argue-but first an example from a different branch of philosophy.

\section{Example: Walzer on Naked Soldiers}

In his modern classic Just and Unjust Wars, Michael Walzer argues that war is "a rule-governed activity, a world of permissions and prohibitions-a moral world, therefore, in the midst of hell." ${ }^{7}$ According to these rules, the aggressing side is always wrong, but ordinary soldiers on both sides enjoy a limited sort of moral equality. Walzer puts it this way: "They can try to kill me, and I can try to kill them. But it is wrong to cut the throats of their wounded or to shoot them down when they are trying to surrender." "According to Walzer, these rules "are 
most fully understood ... as efforts to recognize and respect the rights of independent and associated men and women. The morality I shall expound is in its philosophical form a doctrine of human rights ..." ${ }^{9} \mathrm{He}$ develops and refines his position over the first eight chapters, defending it from both Clausewitzian and utilitarian criticisms. But then, in a particularly moving passage, Walzer presents five historical accounts in which various real-life soldiers were in a position to kill enemy soldiers but declined to do so. In one case, it was because that particular enemy was running in a comically awkward way. In another case, it was because the enemy was having a bath. In still other cases, it was because the enemy was holding up his pants or smoking a cigarette or enjoying a spring sunrise. These, says Walzer, are occasions when we "recognize a fellow creature, who is not threatening me, whose activities have the savor of peace and camaraderie, whose person is as valuable as my own"-a creature who has a right to life. ${ }^{10}$

In taking a class of undergrads through this passage recently, I pointed out to them that, almost in the next breath, Walzer returns to the position he has painstakingly developed over the previous eight chapters: "It is not against the rules of war as we currently understand them to kill soldiers who look funny, who are taking a bath, holding up their pants, reveling in the sun, smoking a cigarette." ${ }^{11}$ I pointed out the tension between these two claims ("It is not wrong for solders to kill soldiers" and "Humans have a right to life so it is wrong to kill them") and how Walzer seemed to be pressing a strong case for both. A bit coyly, I asked whether Walzer knew what he was doing here, or whether he had lost track of his own argument. One of my students snorted, "Oh, Walzer knows exactly what he's doing! He wants us to feel the tension!"

\section{Epistemic Tension and How to Deal with it}

I think my student was right, and this raises an interesting question: why would a philosopher want us, his or her audience, to feel such an epistemic tension? Doesn't this fly in the face of our standard approach to such things, which is to relieve the tension, as quickly as possible, in one of two ways? When we feel epistemic tension, it is because we are aware that two propositions under consideration, $P$ and $Q$, are logically incompatible ${ }^{12}$ but also "epistemically equipollent," i.e., strongly but equally ${ }^{13}$ justified for us at that time. ${ }^{14}$ Relieving the tension thus requires either denying that $P$ and $Q$ are truly logically incompatible or denying that they are equally strongly justified for us. We might even suppose, given the standard approach, that at least one of these is a duty.

And yet some philosophers (such as Walzer) do not always try to relieve the tension, or are in no hurry to do so. Indeed, some try to prevent the tension from being relieved too quickly, or even work to heighten it. Why would anyone do this? Here are some possible reasons:

1. Dialethism: some philosophers might be in no hurry to relieve the tension because they deny a presupposition of the standard approach, namely, that contradiction is a sign that anything has gone wrong. These philosophers accept dialethism, the claim that there are true contradictions. ${ }^{15}$ 
2. Perversity: a few philosophers, I suppose, might work to preserve (or even create) epistemic tension, not because they are dialethists, but because they are perverse and find amusement in causing philosophical mischief in the same way that some high schoolers find amusement in putting Ex-Lax in the brownies at the Chess Club bake sale.

3. Romantic Misologism: other philosophers might work to preserve or create epistemic tension because they endorse a sort of romantic misologism according to which Reason (human or Western or scientific or secular or ...) is overweening and presumptuous and needs to be humbled. Showing how Reason leads to contradictions (and thence to epistemic tension) is one way of doing this. Such accounts typically invoke Hamlet's pronouncement that "There are more things in heaven and earth than are dreamt of in your philosophy" or the stoner myth that, "From an engineering standpoint, bumblebees shouldn't be able to fly. But here's the thing, man: THEY DO.”

4. Kantian Critical Philosophy: misologism's more reputable cousin is the Kantian idea that philosophical reason, when applied in certain ways, to certain topics, will inevitably lead to contradictions in the form of antinomies and paralogisms. The point of dwelling on such contradictions and the epistemic tensions they generate is to demonstrate that such reasoning is indeed misguided.

But even if we are not dialethists, not perverse, not misologists and not Kantians-Walzer is none of these-we might still hold that epistemic tension is not always to be relieved as quickly as possible, or may even be preserved. We might do this for aesthetic reasons: e.g., if in my philosophical argumentation, I prolong the epistemic tension (or even heighten it), that may make my solution to the problem all the more dazzling when I finally reveal it. Or I might do this for rhetorical reasons: rejecting the easy resolution of epistemic tension can be a way of establishing my bona fides as a scrupulous thinker who appreciates how difficult the issues are, and can be trusted not to cut corners or settle for pat answers. This may make my solution to the problem all the more trustworthy when I finally arrive at it. Even so, these approaches to tension treat it as merely temporary: the tension is relieved when eventually I reveal my dazzling or trustworthy solution. But could it make sense for someone who had a relatively traditional view of philosophical reason to recognize long-term epistemic tensions and even tolerate them, for reasons other than showmanship or trust-building? ${ }^{16}$ I believe that it could, because, in addition to the aesthetic or rhetorical reasons we may have for embracing epistemic tension, there may also be normative epistemic reasons for embracing it: there will be facts to which we cannot do cognitive justice unless we feel the epistemic tension.

I conjecture that feeling the epistemic tension between $P$ and $Q$ may sometimes be fitting, given certain facts about the epistemic justification of both $P$ and $Q$ : namely, when I have strong epistemic reason to believe $P$ and $I$ have strong epistemic reason to believe $Q$, even though $P$ and $Q$ are incompatible. 
Before examining this more closely, however, let us consider what would have to be the case for the idea even to make sense.

\section{Assumptions}

1. Doxastic justification is a property of beliefs (i.e., a property of token beliefs or "believings"), in relation to particular believers and their particular circumstances.

2. This property is the sort of thing that comes in amounts or degrees, or at least admits of "more" and "less".

3. This degree of justification depends on, or varies with, the evidence (or other epistemic reasons) we have for believing propositions.

4. The degree of justification that my belief possesses is the sort of thing we can be aware of.

5. Incompatible beliefs may possess high but roughly equal degrees of this property.

\section{Implications}

Most of these assumptions are not especially controversial, though some may balk at (5), the claim that incompatible beliefs can be equally strongly justified. They may doubt this if, say, they hold a conception of justification such that it is impossible to be doxastically justified in believing incompatible propositions. They may hold that degrees of justification for incompatible propositions stand in an inverse relation to one another: to the extent that $P$ is positively justified, to that same extent, $Q$ is unjustified. On some such accounts, any justification for $P$ automatically destroys or neutralizes one's justification for $Q$, or vice versa. Hume, e.g., suggests something like this in his famous discussion of testimony concerning miracles:

Suppose, for instance, that the fact, which the testimony endeavours to establish, partakes of the extraordinary and the marvelous; in that case, the evidence, resulting from the testimony, admits of a diminution, greater or less, in proportion as the fact is more or less unusual. The reason why we place any credit in witnesses and historians, is not derived from any connection, which we perceive a priori, between testimony and reality, but because we are accustomed to find a conformity between them. But when the fact attested is such a one as has seldom fallen under our observation, here is a contest of two opposite experiences; of which the one destroys the other, as far as its force goes, and the superior can only operate on the mind by the force, which remains. The very same principle of experience, which gives us a certain degree of assurance in the testimony of witnesses, gives us also, in this case, another degree of assurance against the fact, which they endeavour to establish; from which contradiction there necessarily arises a counterpoise, and mutual destruction of belief and authority. ${ }^{17}$ 
An implication of my claims about epistemic tension is that the abovementioned conceptions of justification must be wrong. A corollary is that, whatever epistemic justification is, it cannot be the same as logical probability, precisely because the logical probabilities of contradictory propositions $d o$ stand in an inverse relation with each other. ${ }^{18}$ This is because, as Bryan Skyrms notes, "all theories of probability treat probability as some kind of proportion." 19 This is why probability is the sort of thing of which there can be only a limited amount: this is why, when one belief becomes more probable, incompatible beliefs become less probable; this is why the scale of measurement of probability is " $0-1$." Epistemic justification, however, is not best understood as a proportion; it is not the sort of thing of which there is only a limited amount; it is not best measured on " $0-1$ " scale. Instead, it is best measured on a " $0-\infty$ " scale, meaning that the degrees of justification of $P$ and $Q$ are to some extent independent of each other, and may (in principle) both increase as long as the evidence for, or reasons to believe, both of them continue to accumulate. ${ }^{20}$

Fortunately (as I have argued elsewhere), there is no compelling reason to identify justification with probability, or even to model it on probability. ${ }^{21}$ I propose instead to model the theory of epistemic justification on W. D. Ross's theory of moral rightness. This proposal is not arbitrary, as both theories are about normative reasons; I am proposing to model reasons for belief on reasons for action. ${ }^{22}$

\section{Rossian Obligation}

In chapter 2 of The Right and the Good, Ross presents a theory of right action that is commonsensical, pluralist, defeasibilist, intuitionist, and deontological. ${ }^{23}$ The following passage shows some of these distinctive features and the general flavor of the work:

When a plain man fulfils a promise because he thinks he ought to do so, it seems clear that he does so with no thought of its total consequences, still less with any opinion that these are likely to be the best possible. He thinks in fact much more of the past than of the future. What makes him think it right to act in a certain way is the fact that he has promised to do so-that and, usually, nothing more. That his act will produce the best possible consequences is not his reason for calling it right. ${ }^{24}$

For present purposes, its most salient features are its pluralism, defeasibilism, and intuitionism. It is pluralist in that, according to Ross, we are subject to a plurality of basic types of duty (i.e., sources of "obligatoriness"). Ross lists seven different types (duties of fidelity, reparation, gratitude, justice, beneficence, non-maleficence, and self-improvement), without insisting that this list is complete or unrevisable. He does insist, though, that when we are subject to some duty, it is always in virtue of certain feature(s) of our circumstances which he says "cannot seriously be held to be without moral significance." 25 For example, I am subject to the duty of beneficence when I am able to benefit 
someone, and I am subject to a duty of fidelity when I have made a promise. Furthermore, the pluralism is irreducible in that keeping promises, e.g., may tend to benefit persons, but (as he notes above), that is not the only reason fidelity is a duty. The problem with utilitarianism, by contrast, is that it is monistic, collapsing all our duties into the single duty of maximizing utility. A monistic theory might be tidier, but according to Ross, "Loyalty to the facts is worth more than a symmetrical architectonic or a hastily reached simplicity." 26

Ross's theory is defeasibilist in that it allows that duties may conflict, and therefore regards all duties as prima facie or pro tanto duties. Each duty may override or be overridden by another, but unless it is overridden, we ought to fulfill it. In cases where one prima facie duty defeats another, it emerges as my actual duty, the thing I actually ought to do. Even so, when beneficence, e.g., defeats fidelity, we do not say that I have a duty to break promises. Instead, we say that I have a strong moral reason to do X (keep an appointment with my wife) and a stronger moral reason to do Y (play host to some old friends who have arrived from out of town unexpectedly), even though doing Y makes doing X impossible.

Famously, Ross's account of obligation is also intuitionist, and in two ways: first, in its account of our knowledge of the general principles of prima facie duty, and second, in its account of our knowledge of actual duty in concrete circumstances. Regarding the former, Ross holds that the general principles of prima facie duty are self-evident:

That an act, qua fulfilling a promise, or qua effecting a just distribution of good, or qua returning services rendered ... is prima facie right, is selfevident; not in the sense that it is evident from the beginning of our lives, or as soon as we attend to the proposition for the first time, but in the sense that when we have reached sufficient mental maturity and have given sufficient attention to the proposition it is evident without any need of proof, or of evidence beyond itself. It is evident just as a mathematical axiom, or the validity of a form of inference, is evident. ${ }^{27}$

Regarding our actual duty in concrete circumstances, Ross holds that we come to know it via a different sort of intuition. How do I decide, in the absence of a monistic, consequentialist decision-procedure, which of these competing prima facie duties is my duty proper? Ross' answer is that:

When I am in a situation, as perhaps I always am, in which more than one of these prima facie duties is incumbent on me, what I have to do is to study the situation as fully as I can until I form the considered opinion (it is never more) that in the circumstances one of them is more incumbent than any other; then I am bound to think that to do this prima facie duty is my duty sans phrase in the situation. ${ }^{28}$

The process of reasoning that leads to this opinion will, according to Ross, be holistic, non-algorithmic, and less than certain, and these characteristics are 
connected. Ross states that "Our judgements about our actual duty in concrete situations have none of the certainty that attaches to our recognition of the general principles of duty" and (later) that there is "much truth in the description of the right act as a fortunate act. If we cannot be certain that it is right, it is our good fortune if the act we do is right." ${ }^{29}$ This is because such judgments are themselves neither self-evident nor logical conclusions from self-evident premises. Instead, says Ross:

In this respect the judgement as to the rightness of a particular act is just like the judgement as to the beauty of a particular natural object or work of art. A poem is, for instance, in respect of certain qualities beautiful and in respect of certain others not beautiful; and our judgement as to the degree of beauty it possesses on the whole is never reached by logical reasoning from the apprehension of its particular beauties or particular defects. Both in this and in the moral case we have more or less probable opinions which are not logically justified conclusions from the general principles that are recognized as self-evident. ${ }^{30}$

Finally, a consequence of his combination of pluralism and defeasibilism is that, when one obligation is defeated by another, the moral reason for the first obligation does not always simply evaporate. The moral wrongness of promise-breaking persists, e.g., even when we are morally justified in breaking a promise. We recognize the existence of this moral "residue," says Ross, by feelings of regret and by our belief that we owe an apology to the person to whom we broke the promise.

\section{Rossian Justification}

What does a Rossian theory of justification look like, one that parallels Ross's theory of obligation at all the main points? ${ }^{31}$ It, too, will be pluralist, intuitionist, and defeasibilist. On such a theory, there exists a plurality of sources of justification: "doxastic practices" such as perception, introspection, memory, testimony, deductive inference, and inductive inference. My beliefs acquire such justification in virtue of particular features of my epistemic circumstances, e.g., that they are the product of perceptual, introspective, memorial, or testimonial doxastic practices, given certain experiential or cognitive inputs. ${ }^{32}$ For example, my belief that a certain article contains a quotation from Flaubert may have some justification just because I remember reading it there, and my belief that the article does not contain that quotation may gain some justification when I look but do not find it there. About the justificationconferring status of individual doxastic practices, two points are especially important: first, none of our doxastic practices can be shown to be reliable (or justification-producing) in any non-circular fashion. Any argument that they are justified will have to be based on beliefs, but those beliefs themselves will have to be justified. If those beliefs are produced by some other doxastic practice, then the argument merely shifts to the justification-conferring ability 
of that other practice. But if the argument is based even in part on beliefs produced by the doxastic practice in question, it is presupposing precisely what it is meant to show. This might seem obvious, but it has not stopped philosophers from giving deductive arguments for the reliability of deduction, inductive arguments for the reliability of induction, track-record arguments for the reliability of memory, and empirical arguments for the reliability of sense perception..$^{33}$ Our only alternative, if we are to avoid wholesale skepticism, is to adopt an "innocent till proven guilty" approach to our doxastic practices and their products. ${ }^{34}$ Second, it is doubtful that, say, memory in general could be empirically validated as a source of justification, but even if it could, that would not be the only reason that it is a source or transmitter of justification, and the same holds true of all the other doxastic practices which are sources of justification. To privilege one doxastic practice as the only basic source of justification and to require that all other doxastic practices justify themselves in terms of the privileged practice is, ultimately, an unwarranted sort of monism. ${ }^{35}$

As we have already observed, these diverse sources of justification may pull in different directions, so we may have justified incompatible beliefs. Justification is, of course, always prima facie justification, and the degree of justification enjoyed by a belief simply in virtue of being from an appropriate source (e.g., perceptual, memorial, inferential) is not necessarily enough to "epistemize" that belief. Moreover, one prima facie justified belief may be defeated by another, but until it is defeated, we have reason to believe it. In some cases of defeat, one of our justified beliefs entirely neutralizes the prima facie justification of another belief (as when we learn that the person whose testimony we believed was lying). In other cases, both types of justification persist, but one outweighs the other. In still others, both types of justification persist and neither neutralizes nor outweighs the other. In judging which belief (if any) is most justified overall, we must study the situation as carefully as we can, weigh up the competing considerations, and form the considered opinion that in the circumstances one belief is more justified than others for us. In the absence of a monistic account of the sources and sorts of justification, this judgment, too, will be holistic, non-algorithmic, and less than certain.

Interestingly, on such a model, there is room for an epistemic residue when one prima facie justified belief is defeated by another but still retains some epistemic "force." Bernard Williams once denied this possibility, but many of us will be familiar with such residues in the form of perplexity. ${ }^{36}$ After searching fruitlessly through that article for the passage I remember, I think to myself, "I clearly recall reading that line from Flaubert in this article; I can even picture where it is on the page. But now I can't find it anywhere. How can this be?!" More relevantly to present purposes, we may also be familiar with it in the form of epistemic tension: "I have strong reason to think that it is wrong for anyone to kill anyone, but I also have strong reason to think that it is not wrong for soldiers to kill soldiers! How can this be?"

We should not push the analogy between Rossian moral obligation and epistemic justification too far: e.g., we need not see it as implying that we 
have positive epistemic duties. Still, striking similarities exist between these approaches, and illuminate those features of justification that make epistemic tension possible. For example, in Ross's theory of obligation, rightness is not understood, as in act consequentialism, as "comparative ethical weight", i.e., of an action's being "weightier" than any other action open to the agent. It is understood most basically in terms of prima facie rightness, which is, as it were, the "intrinsic ethical weight" that an action has simply in virtue of being an act of its type. In the same way, prima facie justification appears to be a matter of intrinsic, rather than comparative, epistemic weight-or pull. Also, on Ross's view, the moral weight of any particular duty may increase indefinitely-in the same way that the epistemic weight of a belief, indeed, even of two conflicting beliefs, may increase indefinitely as evidence accumulates. The existence of such similarities, and our ability to extend them plausibly, is no proof that Ross's theory of obligation is the correct model for justification, yet its aptness and plausibility may attract us and loosen the hold of monistic alternatives.

\section{Taking Stock}

So far, I have identified the phenomenon of epistemic tension, its necessary conditions, and its distinctive phenomenology. And I have sketched what justification would have to be like-and what it couldn't be like-for it to be possible, and I have tried to at least to suggest reasons for doubting that we have a duty to relieve such tensions as quickly as possible. I shall now try to make good on my proposal that epistemic tension reveals something about the nature of epistemic justification.

Recall: I have proposed that, in feeling epistemic tension, I am aware that two propositions, $P$ and $Q$, are strongly justified for me, and that the strength of my justification for $P$ and the strength of my justification for $Q$ are roughly equal. Since justification is the sort of property that comes in degrees or amounts (as per Assumption (2)), I must have some sense of how much justification $P$ and $Q$ have for me, at least in comparison with each other.

But we have no objective, external technique for measuring this degree of justification. ${ }^{37}$ It would be nice if we did, and no less a philosopher than Leibniz fantasized about it: "If we had a balance of reasons where the arguments presented in favour of and against the case were weighed precisely and the verdict could be pronounced in favour of the most inclined scale ... [we would have] a more valuable art than that miraculous science of producing gold." 38 Unfortunately, however, there are no units of measurement (like yards or pounds) for justification, and there is no device for measuring justification in terms of these units (like a yardstick or scales). So I must have some other way of gaining this information. I propose that our experience of epistemic tension reveals something about how we get this information, in that the tension reveals a phenomenologically salient property of justified propositions that I shall christen their "helketic" character-or "helketicity". 39 "Helketic" is from the Greek, helkein, meaning "pull," and is meant to name the fact that, 
when we are aware of evidence for a proposition, we experience it as "to-bebelieved"; and we commonly feel its "to-be-believed-ness" as an attraction or a pull, analogous in some ways to a physical pull. But maybe that is not quite accurate: if the analogy with a physical pull were perfect, then to say that we feel it as a pull would imply that we were somehow resisting believing it. But normally we so readily believe that for which we have strong evidence (e.g., perceptual or memorial or testimonial) that we offer little or no resistance to believing it at all: we simply, immediately and "automatically" believe, as if we were being pulled through a frictionless fluid. We feel it as a pull only when we also feel some sort of resistance-e.g., a disinclination to believe the proposition in question, or a pull in the opposite direction, i.e., a pull to believe some incompatible proposition. It is in these sorts of cases that we feel what I am calling epistemic tension. In any case, just as the physical pulls of opposing physical forces can be stronger or weaker and we can feel them as stronger or weaker, relative to each other, so, too, we can feel the epistemic pull of justified beliefs as stronger or weaker relative to each other. It is this feeling that may enable us to know that we are strongly justified in believing $P$ and strongly justified in believing $Q$, and that the degree of justification is roughly the same in both cases.

\section{Excursion: A Familiar Deficiency in Quantitative Act Utilitarianism}

Here again we observe a parallel with Ross's account of rightness. As already noted, Ross holds that our duties may occasionally conflict, such that I simultaneously have a prima facie duty of fidelity and a prima facie duty of beneficence but cannot satisfy both. In such cases, I need to decide which one is more my duty (or which would be a greater violation of duty if left undone). This suggests that prima facie rightness also comes in varying degrees or strengths, and we need to decide, in the event of a conflict, which action is more right or more obligatory. And here again we have no objective, "external" way to measure rightness. Of course, if act utilitarianism were true, there might be such a way, but Ross rejects utilitarianism, so that way is not open to him. He rejects it mainly for yielding incorrect normative conclusions:

Suppose ... that the fulfilment of a promise to A would produce 1,000 units of good for him, but that by doing some other act I could produce 1,001 units of good for B, to whom I have made no promise, the other consequences of the two acts being of equal value; should we really think it self-evident that it was our duty to do the second act and not the first? I think not. ${ }^{40}$

More importantly for our purposes, however, Ross also could have rejected quantitative act utilitarianism for failing to provide a realistic way of measuring the utility (hence rightness) of actions. And this is for the most elementary and familiar of reasons: there are no units of measurement for prima facie rightness, and there is no device for measuring justification in terms of these 
units. ${ }^{41}$ The "utile" is a heuristic fiction on a par with the physicist's "point mass," and the Utiliti-ometer ${ }^{\circledR}$ is science fiction.

Don't get me wrong: I am not claiming that utilitarianism in general is false. Even if act or direct versions of utilitarianism were all false, rule or indirect versions might still be true. Moreover, act utilitarianism can be viewed as a decision-making procedure or as an account of the right-making characteristics of an action, so its failure qua decision-making procedure would not entail its failure qua account of the right-making characteristics of an action..$^{42} \mathrm{I}$ am claiming merely that act utilitarianism does fail qua decision-making procedure. No one, in the whole history of the human race, has ever accurately and precisely calculated in quantitative terms the utility of the main courses of action open to them, and made a meaningful, real-life decision on that basis. Of course, this sort of failure is not unique to act utilitarians. Pluralistic act deontologists like Ross also are unable to measure objectively and quantitatively the strength of prima facie duties, so as to determine that, say my benefitting A would possess 71 units of rightness, while breaking my promise to B would possess only 23. And Ross knows this full well; it is why he concludes that "what I have to do is to study the situation as fully as I can until I form the considered opinion (it is never more) that in the circumstances one of them is more incumbent than any other."

Ross does not explicitly tell us what is involved in "studying the situation," but, as noted above, it involves looking for all the morally relevant features of one's circumstances, reflecting on them and bringing these reflections together in a holistic, non-algorithmic conclusion that some action is "more to-be-done" than any other. This "to-be-done-ness," though objective, is not cognized by way of any quantitative calculation, but by some other way. Traditionally, the Rossian has characterized this other way as "intuition," but we could just as easily characterize it as the sensing of greater or lesser degrees of "moral helketicity," whether this is described in terms of "pull" (or "pressure" or "weight"). ${ }^{43}$

I bring this up to illustrate my general point that, given the many parallels between ethics and epistemology, and given the attractiveness of Ross's theory of rightness, it is not surprising that we can construct an attractive account of epistemic justification parallel to it. Moreover, it is not surprising to find that the parallels extend even to how we form judgments about the comparative degrees of moral rightness and epistemic justification. In this parallel account of epistemic justification, we find that, here again, we are able to make these judgments, even in the absence of an objective, mechanical means of calculation, because of the helketicity of (say) evidentially justified beliefs. This helketicity is revealed in the experience of epistemic tension, because each justified belief pulls us, and because incompatible justified beliefs pull in different directions. And incompatible beliefs can be justified because there are multiple irreducibly basic sources of justified beliefs, and the justified beliefs produced by these sources do not always simply neutralize each other or cancel each other out. Sometimes they do, but sometimes they do not. If they do not, and if they 
are truly incompatible, then sometimes the epistemically appropriate response may be to live with the tension and not to relieve it as soon as possible. ${ }^{44}$

\section{Notes}

1 See Nelson 2010. The next paragraph draws on that article.

2 I have since learned that Roger White, e.g., uses the term "permissivism" for a somewhat different position. See White 2005.

3 For some incisive criticisms of my earlier position, see Stapleford 2013.

4 Nelson 2010, 87.

5 See Stapleford 2013.

6 Let us set aside the question of whether dropping beliefs is something we can do directly, at will. Even if beliefs are largely not directly voluntary-which need not be accepted without qualification - they may nevertheless be subject to normative evaluation generally, as, e.g., rational or irrational, silly or wise, credulous or cautious.

7 Walzer 2015, 36.

8 Ibid.

9 Ibid., p. xxiv (my emphases).

10 Ibid., p. 142 (my emphasis).

11 Ibid.

12 Two or more. For simplicity's sake, I will confine my discussion to pairs of incompatible propositions. Propositions $P$ and $Q$ are incompatible when and only when $P$ implies $\sim Q$.

13 They need be only roughly equally justified. No call for specious exactitude!

14 I have in mind here doxastic justification and not mere propositional justification: "Epistemologists commonly distinguish between doxastic and propositional justification. Very roughly, one has propositional justification when one has justification for belief in a proposition-i.e., when one possesses good reasons, evidence, or justification to believe a proposition. One has doxastic justification when one not only has justification to believe a proposition but also believes the proposition and believes it at least partly on the basis of good reasons, evidence, or justification one has." From Hasan and Fumerton 2016.

15 For basic information on dialethism, see Priest and Berto 2017.

16 There may also be moral or prudential reasons for tolerating epistemic tension, but I shall ignore these for the time being.

17 See Hume 1955, 120-121, my emphasis.

18 My discussion here is based on partially based on Nelson 2002.

19 Skyrms 1992, 374-378, at p. 374 (my emphases).

20 My point here in recommending a " $0-\infty$ " scale is not to suggest that some beliefs may be infinitely justified, but simply that justification is not a zero-sum game and that the degree of justification for some beliefs may increase indefinitely; for any degree of justification that they currently enjoy, they may in principle garner more.

21 Nelson 2002, 270-271.

22 Dancy also explores this analogy in "Intuitionism in Metaepistemology", op. cit. See also Nelson 2001.

23 Actually, it is best described as "mixed", since it contains both forward-looking and backward-looking elements.

24 Ross 1930, 17.

25 Ibid., p. 21. 
26 Ibid., p. 23.

27 Ibid., p. 29.

28 Ibid., p. 19.

29 Ibid., pp. 30, 31.

30 Ibid., p. 31. Using the same analogy with poetry, Robert Audi elucidates the holistic and non-algorithmic nature of such judgments by characterizing them as "conclusions of reflection," which he distinguishes from "conclusions of inference." See Audi 2004, 45.

31 The general outline of this theory is inspired by Alston 1993b.

32 If talk of "products" here sounds too externalist and not evidentialist enough, then this may be changed to "My beliefs acquire such justification in virtue of being grounded in the relevant sort of perceptual, introspective, memorial, testimonial state, etc.” My instincts are evidentialist, but I would like my Rossian theory of justification to be neutral as between evidentialism and non-evidentialism as far as possible.

33 A clear example of the latter is Locke's argument for the reliability of the senses based on "concurrent reasons." In Essay, Bk. V, ch. XI, Locke asserts, e.g., "It is plain those perceptions are produced in us by exterior causes affecting our senses: because those that want the organs of any sense, never can have the ideas belonging to that sense produced in their minds." See Locke 1961, vol. 2, $229 \mathrm{ff}$.

34 Why not opt for skepticism then? We are free to do so, but even that begs just as many important questions. See Chisholm 1982 and 1977, ch. 7.

35 Elsewhere, Alston calls this "epistemic imperialism.” See Alston 1993a, $199 \mathrm{ff}$.

36 Williams 1965.

37 "Objective" here means "not wholly dependent on the experience of some subject"; "external" means (roughly) "outside of myself."

38 G.W. Leibniz, quoted in Dascal 2005, at p. 27.

39 Thanks to Sophie Grace Chappell, Nicholas Denyer, Ralph Wedgwood, and Michael Morris for advice on this linguistic point.

40 Ross 1930, 34.

41 Not to mention the many other challenges to quantitative act utilitarianism as a way of judging between actions. See Nelson 1991; and Lenman 2000.

42 See Bales 1971.

43 This sounds like the "action-guidingness" of moral judgments beloved of motivational internalists. I do not think that my view is committed to motivational internalism, but I take it to be a strength of my account that it makes room for this phenomenon to which internalists call our attention.

44 Acknowledgements: the writing of this essay was supported by the Provost's Office and the Martin Institute of Westmont College. Earlier drafts were presented at the Westmont Philosophy Colloquium and at the "Epistemic Duty" Workshop at St. Thomas University in 2019. I thank the other participants in those events, especially Miriam Schleifer McCormick, Sharon Ryan, Scott Stapleford, Matthias Steup, Jim Taylor, and David VanderLaan, for their helpful comments and criticism.

\section{References}

Alston, W. P. 1993a. Perceiving God: The Epistemology of Religious Experience. Ithaca, NY: Cornell University Press,.

Alston, W. P. 1993b. The Reliability of Sense Perception. Ithaca, NY: Cornell University Press. 
Audi, R. 1993. "Ethical Reflectionism.” The Monist 76 (3): 295-315.

Audi, R. 2004. The Good in the Right: A Theory of Intuition and Intrinsic Value. Princeton: Princeton University Press.

Bales, R. E. 1971. "Act-Utilitarianism: Account of Right-Making Characteristics or Decision-Making Procedure?” American Philosophical Quarterl, 8 (3) July: 257-265.

Chisholm, R. 1977. The Theory of Knowledge, 2nd edition. Englewood Cliffs, NJ: Prentice-Hall.

Chisholm, R. 1982. “The Problem of the Criterion.” In The Foundations of Knowing. Minneapolis, MN: University of Minnesota Press, 61-75.

Dancy, J. 1982.. "Intuitionism in Meta-Epistemology.” Philosophical Studies, 42 (3): 395-408.

Dancy, J., and Sosa, E. (eds). 1992. A Companion to Epistemology. Oxford: Blackwell.

Dascal, M. 2005. "The Balance of Reason." In D. Vanderveken (ed.), Logic, Thought and Action: Logic, Epistemology, and the Unity of Science, vol. 2. Dordrecht: Springer, 27-47.

Hasan, A., and Fumerton, R. 2016. "Foundationalist Theories of Epistemic Justification.” In Edward N. Zalta (ed.), The Stanford Encyclopedia of Philosophy (Winter Edition), $<$ https://plato.stanford.edu/archives/win2016/entries/justep-foundational/>.

Hughes, N. 2017. “Dilemmic Epistemology”, Synthese, https://doi.org/10.1007/s11229017-1639, November 28.

Hume, D. 1955. An Inquiry Concerning Human Understanding (1748), ed., with an introduction by C. W. Hendel. Indianapolis, IN: Bobbs-Merrill.

Lenman, J. 2000. "Consequentialism and Cluelessness", Philosophy and Public Affairs 29 (4) Autumn: 342-370.

Locke, J. 1961. An Essay Concerning Human Understanding, ed. J. W. Yolton. London: Dent, vol. 2.

Nelson, M. 1991. “Utilitarian Eschatology.” American Philosophical Quarterly 28 (4) Oct.: $339-347$.

Nelson, M. 2001. “On the Lack of 'True Philosophic Spirit' in Aquinas.” Philosophy 76 (276), 283-296.

Nelson, M. 2002. "What Justification Could Not Be." International Journal of Philosophical Studies 10 (3): 265-281.

Nelson, M. 2010. “We Have No Positive Epistemic Duties.” Mind 119 (473): 83-102.

Priest, G., and Berto, F. 2017. "Dialetheism.” In Edward N. Zalta (ed.), The Stanford Encyclopedia of Philosophy (Spring 2017 Edition), <https://plato.stanford.edu/ archives/spr2017/entries/dialetheism/>.

Ross, W. D. 1930. The Right and the Good. Oxford: Oxford University Press.

Skyrms, B. 1992. "Probability, Theories of." In J. Dancy and E. Sosa (eds), A Companion to Epistemology. Oxford: Blackwell,) 374-378.

Stapleford, S. 2013. "Epistemic Duties and the Justificational Fecundity of Evidence." Synthese 190 (18): 4065-4075.

Vanderveken, D. (ed.). 2005. Logic, Thought and Action: Logic, Epistemology, and the Unity of Science, vol. 2. Dordrecht: Springer, 27-47.

Walzer, M. 2015. Just and Unjust Wars: A Moral Argument with Historical Illustrations, 5 th edition. New York: Basic Books.

White, R. 2005. "Epistemic Permissivism.” Philosophical Perspectives 19 (1): 445-459.

Williams, B. 1965. "Ethical Consistency." Proceedings of the Aristotelian Society, supplementary vol. 39: 103-124. 


\title{
5 Intellectual Responsibility and the Scope of the Will
}

\author{
Robert Audi
}

We can be criticized for our beliefs as well as our actions, and beliefs as well as deeds can be rational or irrational, justified or unjustified, reasonable or unreasonable. Deeds and beliefs that are irrational, unjustified, or unreasonable ought not to be done, or held. A major question these points raise is what kind of responsibility we bear for our actions and beliefs or, prospectively, to prevent them. It would seem that we have many intellectual responsibilities as well as many behavioral obligations-roughly, responsibilities for doing certain deeds. It is natural to think that what we are obligated to do we can intend to do and that what we can intend to do is behavioral, consisting in action. Are intellectual responsibilities, then, a species of behavioral obligations? It is not altogether clear what this question means or what conception of agency it presupposes. This chapter will clarify this and other questions and, in that light, identify some major intellectual responsibilities and, so far as possible, indicate how they may be fulfilled.

\section{The Range of Intellectual Responsibilities}

Talk of intellectual-“epistemic"-responsibilities is perhaps best clarified in comparison with moral responsibilities. Temporally, responsibilities can be retrospective, contemporaneous, or prospective, e.g. for having done something, for continuing to do something, or to do something in the future. Moral responsibility presupposes, in the retrospective case, some kind of causal responsibility for the occurrence of the action or belief and, in the other cases, some kind of causal power to realize the relevant act-type. My concern is responsibility of a normative kind. Moreover, I will speak mainly of intellectual responsibility rather than epistemic responsibility because my concern is with belief, especially in relation to justification, not just with knowledge, and 'epistemic' is often used regarding both knowledge and justification.

Illustrations will help. One might be intellectually responsible retrospectively for having believed implausible testimony or, contemporaneously, for attending to changing evidence as a trial unfolds, or, prospectively, for seeking new evidence before reaching a verdict. Attending to and seeking evidence are actions. But can we behavioralize responsibility for having believed implausible testimony and, correspondingly, the obligation to resist believing 
it, as, fundamentally, responsibilities to do rather than to believe? Similarly, does saying 'You ought not to believe that' imply that believing is a kind of voluntary doing?

Here distinguishing the directly from the indirectly voluntary becomes crucial. I regard 'directly voluntary' as applicable to both act-types and act-tokens:

\section{Direct Voluntariness}

An act-type, $A$, is (1) directly voluntary for an agent, $S$, at time $t$, if and only if, at $t, S$ can $A$ at will, i.e. basically in the sense that $S$ can $A$ other than by instantiating any different act-type; and (2) $A$-ing is, at $t$, directly voluntarily performed (tokened and thereby instantiated) by $S$ if and only if, at $t, S A$-s at will. ${ }^{1}$

It is essential to distinguish what we do at will from what we do on selfcommand, as where we say to ourselves something like 'Believe this honestsounding witness!' Saying, even if not vocalized, is action, and one might treat belief-formation that results from such self-addressed imperatives as indirectly voluntary. Another needed formulation (for which again I presuppose the transitivity of the by-relation) is this:

\section{Indirect Voluntariness}

An act-type, $A$, is indirectly voluntary for $S$ at $t$ if and only if, at $t,(1) A$ ing is not directly voluntary for $S$ at $t$, but (2) $S$ can $A$ at $t$; and (3) $A$-ing is indirectly voluntarily performed by $S$ at $t$ if and only if, at $t, S A$-s by doing something else.

Consider typing. We normally type by moving our fingers at will; no selfcommand directed at moving them or other generative action is needed. If it is needed, then at least some mental act such as a volition to start typing would be directly voluntary, as compared with, say raising my injured right arm by using my left hand. This shows that an act-type may be basic for $S$ at $t$ but, later, non-basically instantiated.

The case shows something else of importance: a difference between direct positive control and direct negative control. Suppose I decide to raise my right arm using my left hand. If a surgeon, seeing me begin, says 'Don't move it!' I can at will stop moving my left hand. As to mental action, I can also muse to myself that $p$ seems implausible and thereby (sometimes) bring about withholding belief regarding $p$. This direct negative power can be exercised whether or not withholding is action or a non-actional mental event.

\section{Are Beliefs Acts of Intellect?}

I have presupposed that beliefs are not actions. But isn't it natural to think that just as there are acts of will, there are acts of intellect, perhaps with cognitive self-commands and belief-formations being the paradigms? This picture 
may have seemed plausible to Plato in, e.g., The Republic where he speaks in agential terms of parts of the soul. Perhaps we can speak loosely of the Platonic (or Socratic) model to designate the view that intellect and will each represent a kind of subpersonal agency with their direct outputs being volitional actions in the behavioral case and, in the intellectual case, cognitive "doings": belief-formations. We can even call belief-formation itself doing, as in answering "What did he do that so upset the other jurors?" with "He believed that trumped-up testimony".

This reasoning has at least two defects. First, “do" applies to natural events such as volcanic eruptions (what a volcano does) and involuntary movements, as with an unconscious accident victim. To "What is he doing?" the nurse may answer, "Shivering." Such shivering, unlike act-types, has no tokens that are intentional. Secondly, although belief-formation entails a belief's forming, that does not entail an action of forming a belief. Clouds form too. Is there any action of forming a belief, as opposed to causing a belief to form, which is obviously possible by such indirect means as manipulating one's brain using a machine?

Metaphysically, believing and acting are in different ontological categories. This is evidenced by actions' being occurrences and, unlike beliefs, entailing change. Even if we may assume that an activity, such as contemplating the universe, could be eternal divine action, it is occurring at any time and, unlike merely seeing, entails some change. ${ }^{3}$ If, as is plausible, actions are doings that have a description under which they are intentional, this is another reason to consider beliefs different. I doubt that someone can be intelligibly said to believe intentionally unless this is a misleading way to describe something at least very similar to (a) intentionally abstaining from withholding, (b) causing oneself to believe or, perhaps (c) accepting (say, for the sake of argument), as where one forms an intention to act on the proposition in question. Broadly and more positively, beliefs are dispositional properties, actions occurrent properties.

If believing and acting are categorially different, how should we interpret Sosa's point about "live statues one sees at tourist sites": "Some acts are performances, of course, but so are some sustained states" ?" The term "state" has multiple uses. Is the "sustained" state dispositional in the way belief as a kind of "state of mind" is, or is it eventful in the way a state of excitement is? If the former, then the performance would seem to be merely putting oneself into a state that, like a temporary frozen posture a machine might induce in someone, requires no maintenance, which is an activity of, e.g., monitoring minute changes and preventing (visible) movements. If the latter, then we have action - the activity of attending, making muscle movements, and so forth. There is performance in Sosa's intriguing case; but, on analysis, it is apparently either that of putting oneself into a static (frozen) physical condition or, more likely, maintaining a statuesque-looking condition. That is a kind of monitorial activity. Like attending, it may have gaps in the relevant attentional events; but it is not the kind of dispositional property that, like believing, can exist between formation and dissolution without the occurrence of any relevant change. 


\section{Responsibility as Presupposing a Kind of Alternative Possibility}

It is both natural and reasonable to consider intellectual responsibility for $A$-ing to presuppose some kind of control such that one had, has, or will have, an appropriate kind of alternative to $A$-ing. Does this mean that "could have done otherwise" in some sense applies to the kinds of basic actions crucial for indirect control of one's actions and of such events as belief-formation? In a sense, it does, but I do not believe the relevant notion is the one involved in cases of finks. Again, I find the analogy to moral responsibility helpful. On my view, 'could have done otherwise' in the relevant sense is non-conditional. ${ }^{5} \mathrm{It}$ implies subjunctives, but it is not equivalent to a conjunction of subjunctives.

Granted, in ethical matters, we can speak of what we "had to do," referring to a kind of moral compulsion. Here we presuppose not determinism but overriding obligation. Similarly, there is doxastic compulsion: we must believe what plainly conclusive evidence clearly shows us. In another sense, if brain manipulation wrought by a neurosurgeon induces a belief that $p$ in us, we presumably also must believe $p$. Responsibility is possible in the first two cases and likely not possible in the last one (it might be possible if the manipulation is not irresistible). One reason I raise this issue is that I take intellectual responsibility to trace to basic action that we can, in a relevant sense, perform and that foreseeably affects (or may affect) what we believe or tend to believe. This point is neutral with respect to determinism. I am here presupposing compatibilism, but most of what I say can be adapted to the most plausible incompatibilist views.

For both compatibilists and incompatibilists, intellectual responsibility may be taken to presuppose some degree of positive or negative indirect control of belief-its formation, continuation, or elimination. The degree of control we have, and whether control is compatible with determinism, are different matters. Even without theories that might settle this issue, there can be much agreement on specific appraisals of particular beliefs or persons. The rest of this chapter is devoted to such normative questions as types of intellectual responsibility, how we determine it, and how what we learn on these matters bears on how to deal with disagreement.

\section{The Scope of the Will}

Much said so far presupposed that the contents of intentions are act-types, which may be considered abstract elements expressed by infinitive clauses such as 'to seek more evidence'. I here include activity-types: they may be as simple as walking over to Susan to shake hands or as complex as reciting a memorized passage. Here, as with intending to do something as simple as walk, one need not have intentions (say) to move one's right foot, then one's left ... Yet by virtue of the way such movements are contained in one's conception of the intended activity, each may be considered intentional. Suppose that, walking toward you to shake hands, I see wet leaves in my path. I may stop short. Until I saw them I intended (though not focally) to step forward. 
There is an exception to the infinitival expressibility of intentions. We can intend that our client get a fair hearing-call this a subjunctive intention, a kind that seldom if ever reduces to intending to $A$, to $B, \ldots$ to $\mathrm{N}$, where these are the sorts of things one would form intentions to do in a normal effort to realize the subjunctive intention. ${ }^{6}$ The kinds of intentions important for intellectual responsibility may also take this form. I can intend that every piece of significant evidence get my attention even without having a precise idea what individual acts this will require. How to determine just what these acts are is an empirical matter, but some of them would go with one's sense of relevant kinds of acts, such as opening a file regarding a student.

Once we countenance subjunctive intentions, we can see that even if obligations and, in particular, intellectual responsibilities, presuppose intendability, and that in turn presupposes that the objects of intention are actional, the scope of intellectual responsibility may still be very wide. In every case, however, what is willable is intendable and what is intendable is directed toward the future or the present conceived as extending beyond the felt time of "willing," by which I mean self-commanding (one kind of "voliting"), occurrently intending to do here and now, deciding, and the like. This view goes with the idea of a world-to-mind direction of fit: practical attitudes properly function to get the world to match their content. By contrast, beliefs have a mind-to-world direction of fit: they properly function to represent how the world (including the abstract realm) is. Assuming we presuppose that we cannot affect the past, this idea goes with the future-oriented content of intention.

\section{Dimensions of Doxastic Self-Control}

We now have a framework for exploring intellectual responsibilities. We can set aside direct voluntarism, countenance indirect forms of doxastic voluntarism, and take our questions to rest on how what we are intellectually responsible for can trace to acts under our direct voluntary control. These acts and capacities will be the grounds from which the wide scope of the will is built. There are empirical questions here, and I will presuppose no more answers to them than necessary. I want to leave open many questions for the psychology of cognitive self-regulation. But psychological inquiry needs a conceptual framework, and that is one place where philosophical action theory and epistemology are important for psychology.

My aim here is to clarify an aspect of intellectual responsibility that is too rarely explored: the normative aspects of our relation to grounds for belief. This is of course important for fulfilling responsibilities regarding belief itself. Consider six cases. In each, $S$ already believes $p$, and the question is what $S$ can do at will in relation to grounds for $p$. I refer both to (1) normative grounds, whether propositional or (as is common with perceptual experience) non-propositional, and whether potential-hence not a psychological basis of belief-or actual, and (2) to psychological grounds, whether normative (as in the case of a justified belief that expresses evidence for $p$ ) or non-normative, as with an unjustified assumption that is a causal basis of a belief that $p$ but 
provides no evidence for $p$. Normative grounds may be practical, say promising to A, or evidential, as with memorial grounds to believe a claim. The analogy between the two is illuminating and will be considered, but the latter is our main concern here. ${ }^{7}$

Suppose I am correct in denying that we have direct control of whether we form a certain belief. Do we have direct control of why we believe some proposition $(p)$ that we do or may come to believe? ${ }^{8}$ This is important not only for understanding the scope of the will but also because the case is quite analogous to that of our control of our action. As should now be evident, although I argue for ontic difference between action and belief, I find extensive and important similarities in aspects of our responsibility for them, both normative and causal.

First, imagine that I seek good premises for $p$ in order to convince someone that $p$, which I myself believe. I might have in consciousness evidence for believing $p$, say $q$. Can I at will believe on that evidence? I may have some other ground and may even think it better supports $p$, but, where my interlocutor has plausibly denied $p$, I may seek other evidence. Call the view that we can at will achieve this (causal) grounding the direct harnessability thesis. Applied to $S$ 's believing $p$ at $t$ and a ground for believing $p$, it entails that $S$ can, at will, bring about $S$ 's believing $p$ on that ground. I am unaware of anyone's seriously defending it; but that it is sometimes presupposed is suggested by the not uncommon locution 'I base my belief on ...' (say, someone's testimony). This gives the false impression that we can harness at will. Compare the often reasonable 'My belief is not based on ...' where this is a report of a psychological condition and not of a quasi-action. Here one makes a descriptive claim, with no pretension of reporting an action.

Second, suppose we consider the testimony of someone we respect yet think unreliable on the subject $p$ concerns. The person says that $p$, but we have independent and good, if limited, probabilistic evidence for $p$. May we at will bring it about that we believe $p$ only on the evidence and not on the basis of the mistrusted testimony? Call the view that we can have this partly negative control the direct selective harnessability thesis. This thesis is suggested by teachers' saying to their students such things as 'You're welcome to disagree with me, but please don't base your opinions on weak evidence like the reasons just given'. The students are supposed to consider their grounds and, assuming they retain their beliefs, cease basing them on weak evidence. This may not require relinquishing premises; it may call for simply unharnessing premises or other presumptive grounds.

Third, suppose we have no evidence for $p$ but a merely psychological ground that, if we believe on it, is only a psychological basis of belief, e.g. testimony from someone we know is highly biased. People can sometimes be quite tempted by bad grounds, such as the kind that lead to committing the gambler's fallacy. May we, at will, block our inclination to believe on a tempting bad ground? Call this direct veto power over a ground. It might function differently depending on whether we already believe $p$ : if it eliminates or prevents acceptance of the ground and also the belief that $p$, it is double-barrelled. 
The fourth case emerges when we reflect further on negative doxastic control. Suppose we see that we could have veto power and, as in the third case, thereby prevent a potential ground from becoming an actual one-one on which we believe. Still, if we do believe $p$ on some other ground, $g$, we do not have the power to cease, at will, to have $g$ as an actual ground of our belief that p. Call this "detachment" power, which one might want to exercise on recognizing a failure to veto a misleading ground, the power to unharness at will: to eliminate the causal influence of a ground on our belief. Unharnessing $g$ might eliminate the belief if we hold that belief on no other ground, but it need not, and it might instead free us from believing $p$ on an unsound basis.

My fifth case concerns the possibility of enhancing or reducing the psychological support that a ground gives to a belief based, whether wholly or in part, on that ground (the latter case occurs where the ground is only part of what sustains the belief, which is also partly sustained either by another ground or by a causal factor, such as wishful thinking, which is not a ground). Call this power sustenance control of a ground. Where it is positive, one can enhance the sustaining support of a ground; where it is negative, one can reduce that support. The question here is control of degrees of psychological support for a belief, which will be explored briefly in relation to my sixth case. As with harnessability, sustenance control has direct and indirect forms. One might think sustenance control is implied by harnessability or unharnessability, but our psychological make-up could be such that we might be able, say, to harness a ground to a belief we hold, or to unharness it, without being able to affect what degree of psychological support it adds or subtracts. Some grounds could be like one-speed engines: harnessing them at all engages their full power.

A sixth case, closely related to the fifth, concerns intensity control. Here the relevant variable is the degree of confidence with which the belief that $p$ is held. This variable differs from psychological strength, understood as resistance to cessation of belief (though both may be considered indicative of or even equivalent to "degree of belief," a term used quite variously ${ }^{9}$ ). A belief held with only moderate confidence might be highly resistant to decay or forgetfulness or elimination by counterargument; a belief held with the certitude of a dogmatic convert might be readily abandoned by exposure to a new argument that is even more plausible or more convincing. With intensity as with strength, one might expect harnessing an additional ground to produce an increase. But it need not. Confidence might be like a one-speed fan: it can only be on or off. This possibility does not imply that the relevant belief must be maximally confident (a notion that, to be sure, needs analysis). Some people might simply reach a point of doxastic fixity at which, barring new considerations that evoke additional thinking, they simply store new evidence alongside the foundation(s) of their belief. It may add potential resistance to ceasing to believe $p$ yet leave the level of confidence, conceived as psychological assuredness, as it is. ${ }^{10}$

All six of the theses that have emerged-the two harnessability ones, the veto thesis, the unharnessability thesis, and the sustenance and intensity control theses-are important. We are told by many philosophers not only that we ought to believe, for instance, obvious truths or ought not to believe (are 
responsible for avoiding believing) what some people say, but also that we ought to believe for good reasons. This sounds like an imperative applying directly to actions, but it is not: believing is not action, and expressions of the form of 'believing $p$ for reason $r$ ' do not simply designate believing. They indicate both what is believed and why.

There are, then, at least six positions that should be explored regarding voluntary control of doxastic grounds: harnessability, both selective and nonselective, veto power over grounds, unharnessability, and sustenance and intensity control, both positive and negative. ${ }^{11}$ Throughout we must distinguish direct from indirect control; and, as with control of belief itself, indirect control over doxastic grounding seems more nearly within our reach than direct control, if that is possible at all. The two dimensions of control-one concerning belief itself and the other grounds for belief-are logically independent, though surely psychologically connected. The same holds for the positive and negative direct theses: it could be, for instance, that we can unharness directly but cannot harness directly. ${ }^{12}$

For (causal) grounding of belief, as for that of action, our possessing negative direct control seems more likely than our having positive direct control; and indirect control seems possible. But we know less about how to achieve it for belief than for action. With action, if we abstain from acting, we can in effect veto a grounding relation. Some element in our ken may (normatively or psychologically) ground a desire to $A$ but, if we do not $A$, it of course cannot (causally) ground our $A$-ing. Abstaining from believing may be less readily achieved, if it is ever achieved, voluntarily. If I see a car rushing at me, I cannot but believe it to be approaching me. Still, can't I at will "refuse to believe" some accusation against a friend? Using this locution is a natural way to manifest withholding belief (including disbelief); but it is not at all clear that withholding is action as opposed to an event that characteristically occurs when the relevant proposition is a candidate for belief, e.g. is asserted in a discussion; considered in a certain way, say in relation to evidence; and, in the light of that consideration, becomes an object of an attitude akin to doubt. Indirect control of withholding, as opposed to withholding "at will," is a different matter: there are many things we can cause ourselves to withhold, to cease to believe, or to believe, and how much indirect positive or negative control we have in any of these cases is highly variable.

Suppose we leave open whether there is any action of withholding, as opposed, e.g., to making a judgment-hence mentally judging (which is mental action) - that the evidence for $p$ is inadequate, and thereby causing oneself to enter a state of withholding, in way just sketched. I am inclined to take 'withholding' to designate either mental actions that produce this state or the state itself. I doubt that there is a basic act-type properly called withholding if indeed withholding is distinct from certain actions that produce the state in question.

Even 'judging' has uses in which the mental event in question is a nonactional response to a proposition rather than an act of (assentingly) ascribing some property to it, such as being implausible or being contrary to some other 
proposition (commonly one $S$ believes). If we extend the notion of veto power described in relation to grounds and apply it to believing itself, we can see that on one conception of withholding, it manifests a kind of veto power over would-be belief-formation-call this doxastic veto power. My suggestion is that, in some situations, we have indirect doxastic veto power, for instance by way of judging evidence to be insufficient, but not direct doxastic veto power. To be sure, there is such a thing as a sense of non-commitment, possibly provided by a sense of non-assent to a proposition in some way presented as true. The sense of non-commitment may be attended by unwillingness to reconsider the proposition, perhaps manifested in refusing to reconsider. These and related points can help to explain why one may take withholding to be action, but they do not imply that it is.

To understand withholding in wider terms, we should consider whether, when broadly attitudinal, it is (as is often said or presupposed) a propositional attitude. If it is, we should ask what content withholding belief of $p$ has. Not $p$ itself, necessarily - at least if what is withheld is belief rather than a proposition. If 'I withhold $p$ ' is a counterpart of 'I believe $p$ ', the reasons for rejecting direct doxastic voluntarism similarly apply to it. Must the content of withholding (if it is a propositional attitude) be to the effect that $p$ is doubtful? This is too narrow. Must the content be that of some epistemic judgment, say that the evidence regarding $p$ is evenly divided? If so, would that not be a mental event that yields the attitudinal state of withholding, rather than withholding itself? Such judgments might be elements in indirect doxastic veto power. In any case, may one not enter a state of withholding in ways too complex to be describable as a response to judgment or reflection? Withholding need not have any one kind of history and, if it has propositional content at all rather than just a proposition—or envisaged believing of it—as the object it concerns, it has no one type of propositional content. ${ }^{13}$

We can clarify harnessing and, at least indirectly, withholding, through more examples. Suppose that, on the ground that God forbids it, I believe lying is wrong. I might still want to offer secular friends an argument they will accept. I might think that lies cause suffering and want to argue from this premise but also want it not merely to rationalize my belief. I want to present it as a basis of my conviction, not just as evidence to move listeners. ${ }^{14}$ Granted, if I find the premise plausible I will tend, as a rational person, to have my belief at least partly rest on it. But suppose I find the non-theological consideration minor compared with the divine command. Can I nevertheless will that the premise become a psychological basis of my conviction? I know what it is to wish this to be so but I do not see how to will it, if that is like willing to raise my hand, as opposed to willing to utter the imperatival words, 'Believe that premise!' in a stern inner voice. I doubt that any clear path to direct voluntary harnessing can be found. Conceptually, harnessing, like believing itself, seems the wrong kind of thing to be an object of willing.

The case for an indirect behavioral path to belief-formation seems better, though the matter is empirical and can be only tentatively judged here. I can concentrate on the secular premise. This could enhance my sense of its importance, 
but that need not harness the ground to the belief I want it to support. Even when the fittings for harnessing are present, putting them close to the horse need not suffice for fastening. I can also tell myself that my premise lends some probability to my conclusion and that conviction should be proportioned to degree of support. This may help, but does not guarantee success. Clearly individuals differ in the ease with which, even indirectly, they can harness evidential considerations.

The case for unharnessing is similar. There is apparently no direct volitional path to it. There are, however, many kinds of thinking that may indirectly sever the psychological connection in question. Rational persons by their very nature tend to respond in a self-corrective or even negative way to finding one or more defects in reasoning that has taken them from some apparent ground(s) to belief that $p$, e.g. to cease believing $p$ on a basis that they come to think does not genuinely support $p$. Where a ground they think defective is the only one their belief is based on, this may well be a case of withholding. Indeed, rational persons tend to cease believing $p$ at all if they come to think they have no ground for it; but, if they quickly find some other ground for $p$ that becomes harnessed in its support, withholding may not occur.

\section{Intellectual Virtue and Doxastic Self-Control}

At this point it should be clear that, concerning grounds of belief that are accessible to us or, especially, also in our consciousness, we may sometimes have a good measure of indirect negative control. As to positive control, there seems to be little if any that is direct, but apparently there is much that is indirect. Moreover, the relevant behavior is not of a kind that only the highly educated can achieve (though education may tend to help). Intellectual virtue is partly constituted by cognitive traits manifested in the relevant behavior; intellectual responsibility is partly a matter of living up to the standards internalized in those traits, and "epistemic agency" should be governed by those standards. Here are five major cases that indicate what these standards require.

\section{Evidential Concern}

It is uncontroversial that we should in many instances seek evidence and counterevidence for propositions of certain kinds, say concerning issues on which we must vote. This is not something that, for every belief, we need to do, or even can do. But some beliefs are signally important. Some are also credibly challenged; and at least for important beliefs, we should take credible challenges seriously. Some categories of people, moreover-e.g. philosophers-tend to have a greater obligation than is usual to seek evidence and counterevidence.

\section{Reflective Equilibrium}

Second, we should seek a kind of reflective equilibrium, both in our overall view of the world and in important aspects of that view, such as its ethical side. 
This requires comparing generalizations with cases to which they are responsible and comparing intuitions about cases with generalizations about the kind of case in question. Here we should try to eliminate inconsistencies, to minimize internal tensions, and to maximize coherence. With points of these sorts in mind, we should also periodically review our outlook on important matters, such as moral issues.

\section{Grounds Sensitivity}

Third, identifying and focusing on grounds with the aim of clearly assessing them is intellectually salutary. Focusing on grounds may automatically result in adjustments that enable intellectual virtue to manifest itself. By reflection, we may see that a ground is unclear or less supportive of $p$ than we presupposed. It is useful in any case to identify our actual grounds for believing, especially when defending our views. We can then explain ourselves better and are less likely to overlook some evidential basis of our belief or to rationalize by seeking reasons that, being sought to fill an evidential gap, may be too slight to bear the weight they should sustain. Rationalizing is a liability because it tends to lead to adducing considerations on which our belief is not based or which we do not even accept. A liability of the first failure is misleading others or even ourselves, of the second insincerity to people who ask for evidence.

\section{Interpersonal Comparison}

Fourth, interpersonal comparison is often desirable, with grounds as with beliefs themselves. Someone else may have evidence we lack or may be less biased about the force of evidence we share. And suppose we agree that $p$. Our agreement is likely to be more stable, and our communication better, if we agree on at least some of the grounds for $p$ and, if possible, on how strong they are.

\section{Justificational Proportionality}

Fifth, confidence or belief strength or both may be disproportional to the normative strength of our grounds. One may believe $p$ with unjustified confidence or with undue diffidence. Since we can sometimes determine such epistemic facts about ourselves, we may be justly criticized if we do nothing to rectify such disproportions. A parallel point holds for the case in which a ground is in some way underestimated and merits not reduced influence, but an enhanced role, in supporting beliefs.

In many cases of the kinds we have been considering, the intellectually virtuous may form beliefs about the epistemic status of their grounds or of their beliefs or of the relation between the former and the latter. Much intellectual virtue does not, however, require forming higher-order beliefs. But the selfscrutiny that goes with identifying and appraising grounds for one's beliefs tends to produce higher-order beliefs. A good measure of intellectual virtue 
seems possible without higher-order beliefs, but they are natural for most selfcritical persons. Some people are blessed with an ability to assess grounds and propositions and to respond appropriately without forming beliefs about their own beliefs; but such responses may be uncommon, and in a world in which our beliefs are often challenged we often cannot help forming beliefs about them or about our grounds for holding them.

\section{Intellectual Virtue as a Basis for Responding to Rational Disagreement}

It will be no surprise that I consider the intellectual standards sketched here pertinent to justified responses to rational disagreement: roughly disagreement in which (rational) persons each rationally hold positions clearly incompatible with the other's and realize that they do. These do not have to be "peer disagreements," which represent an idealized case at best rarely realized. In broad terms, how, in a world of widespread disagreements among educated people, is one to find a mean between Sidgwickian skepticism, which would occur upon realizing how challenging our disagreements are, and dogmatic self-trust, which would prevent even serious doubts about one's view? ${ }^{15}$

One response is indicated by the possibility (already noted) of forming higher-order beliefs. One might, e.g., continue believing $p$ while adopting a second-order conviction that believing $p$ might be mistaken and resolving to seek further evidence. Here are two main cases, depending on whether the higher-order question concerns whether one knows that $p$ or whether one has justification for believing it. In the first case, one might say to a disputant: "I see your reasons for thinking him guilty; but, though I realize I don't have conclusive evidence for it, I still believe he's innocent." Given a realization that one disbelieves someone else's rational belief that $p$, it is plausible to hold that one is not justified in believing one knows that not-p (though one may). One might, however, reasonably consider one's belief more rational than the disputant's, even if one does not think it is (unqualifiedly) justified. In the second case, where justification for $p$ is in question, it would seem reasonable at least to doubt that one is justified in believing one is justified in believing $p$.

A quite different response to discovering rational disagreement, and one that often bespeaks humility, is reduced confidence that $p$ - something one can achieve given indirect doxastic self-control of a kind many have. Even if (as I maintain) we cannot in general control our degree of confidence at will, we are capable of-we are indeed intellectually responsible for-acquiring and maintaining a critical intellectual disposition that naturally yields our gaining or losing conviction in accordance with our sense of how good our grounds for $p$ are. The degree of intellectual responsibility we bear in such disputational cases-though this might be plausibly considered a kind of moral responsibility as well-rises with the importance of actions that we may take or affect in the light of our surviving belief(s) pertaining to them

The points that have emerged suggest a number of normative standards concerning an intellectually responsible approach to rational disagreement. 


\section{Dialectical Moderation}

Other things equal, one should avoid flatly asserting that $p$ in contexts of rational disagreement. Other things are not equal when, e.g., one must exhibit confidence to energize discouraged friends in matters in which one has excellent evidence. This cautionary principle is especially plausible if knowledge is the "norm of assertion," in a sense implying that there is (typically) a normative impropriety in asserting that $p$ without knowing $p$-and commonly, one may think one does not know when aware of rational disagreement on $p$. The principle does not, however, depend on that view. ${ }^{16}$

\section{Intellectual Humility}

A plausible principle in the same range is suggested by the point stressed by Hume among others. Noting that "there are all imaginable degrees of assurance, from the highest certainty to the lowest level of moral assurance," Hume continues: "A wise man, therefore, proportions his belief to the evidence." ${ }^{17}$ Hume does not here distinguish confidence from belief strength and sounds more voluntaristic than his point requires. But he is right if read with indirect voluntary control in mind. Rational disagreements bear on how we should view our evidence, and the wise characteristically seek proportionality of conviction to degree of evidential justification. One guiding principle might be: Other things equal, even if one is justified in believing $p$ and knows that another person who has virtually the same evidence rationally disbelieves $p$, one is unjustified in having high confidence that $p$ and should be open to reconsidering whether $p$. Moreover, the better one's justification for believing that the person rationally disbelieves $p$, the weaker one's justification for high confidence that $p$ and the more reason one has to reconsider $p$. High confidence does not imply a tendency to ascribe any particular probability to $p$, but high confidence does preclude substantial doubt that $p$, and some instances of it manifest psychological certainty. The behavioral implications of this humility principle prominently include a prima facie obligation to act with appropriate caution: roughly, to see to it that we have sufficient ground for acts we intend or are seriously considering that are justified only if $p$ is true.

\section{Tolerance}

A general ethical principle supported by the considerations brought out so far is this: If it is not reasonable to consider a disputant epistemically inferior relative to $p$, or less justified than oneself regarding it, then it is not reasonable, and is (prima facie) morally wrong, to coerce that person either to believe $p$ or to perform an action that would be justified only if $p$ is true. This principle partly captures the intellectual responsibility not to act "cognitively" toward otherssay by psychological or neural manipulation-on the basis of an inadequately 
justified belief. Here 'inadequacy' of justification is consistent with a fairly high degree of it, such as grounds implying $p$ 's being more likely than not- $p$. The level required for adequacy, ethically speaking, is in part a matter of how important the issue is and what further evidence is accessible, but the principle is useful even if there is no way to be absolutely precise about this aspect of its rationale.

Something should also be said about the rationale for some of the standards I have proposed. Assuming evidential determinacy - that a given body of evidence supports $p$ to a determinate degree ${ }^{18}$ - the level of conviction regarding $p$ should, for rational persons, tend to be the same in one's own case as for equally rational persons having the same relevant evidence for $p$ that they have considered equally conscientiously. Rational persons who make this assumption tend to be disturbed upon discovering, in certain important matters, the kind of rational disagreement I have described. Here the proposed principle of toleration is a helpful guide in moving toward resolving such disagreements-or at least toward rapprochement.

We have limited and mainly indirect control over what we believe, and indeed over whether it is on adequate grounds that we believe what we do, as opposed to believing it on a justificationally inadequate basis. But our control in these cases is sufficiently extensive, and sufficiently improvable, to provide a basis for an account of intellectual responsibility. That control also enables us to make good sense of an ethics of belief constituted by standards for evidential conduct applied in the light of a sound moral psychology.

I have distinguished between acting at will and acting on the basis of selfcommand and, partly on that ground, rejected the idea that we ever have direct positive voluntary control of belief-formation. But I have argued for our having a significant degree of indirect control of many aspects of our belief system and for its tracing to direct control of certain kinds of basic actions that have cognitive import. The chapter distinguishes many kinds of doxastic self-control and distinguishes control of belief-formation from the related phenomenon of control of belief-grounding. With respect to the latter-involving harnessing or unharnessing of grounds for belief-I have argued that our direct voluntary control is highly limited and mainly negative.

With this analytical and psychological framework in view, I have described five kinds of standards governing fulfillment of intellectual responsibilities. These standards demand seeking evidence, attempting to achieve reflective equilibrium in our belief systems, focusing in a certain way on normative grounds for our beliefs, making interpersonal comparisons in grounds and cognitions, and rectifying certain disproportions in our own cognitive systems. These standards indicate some important kinds of responses an intellectually responsible person will make to rational disagreement. There is far more to say about intellectual responsibility and the kinds of virtues we should cultivate, but if the conceptual and normative points I have made are sound, the essay provides a basis for a plausible detailed theory of the nature and dimensions of intellectual responsibility. ${ }^{19}$ 


\section{Robert Audi}

\section{Notes}

1 This is a rough formulation; e.g. it leaves open how 'can' is to be interpreted, and it does not pin down which token is in question when two occur simultaneously, as where I raise my right arm at will and my left by pushing a button in my right hand that raises my left by activating a pulley. Both token raising an arm.

2 This is the kind of case discussed by Blake Roeber (2019). He argues that in "equipollent cases," those in which one believes one has as good reason to believe as to withhold, one can believe at will (something he does not claim is possible in other cases). For general discussion of voluntarism, see Matthias Steup (2001) and Nikolaj Nottelmann (2013).

3 This is not to deny that an activity can occur during an interval containing periods during which no change occurs; but an agent's having, at $t, A$-ed entails a relevant change, at or before t, that at least partly constitutes $S$ 's $A$-ing.

4 Sosa (2007), 23.

5 For defense of the view see ch. 10 of my (1993), which also takes account of "Frankfurt cases."

6 Subjunctive intentions have not to my knowledge been much discussed by philosophers but are considered in detail in my (2016).

7 A detailed theory of psychological grounds and of normative grounds, practical and epistemic, is provided in my (2001).

8 I have discussed this question in (2008), and the remainder of this chapter owes much to that paper.

9 For helpful discussion of credences and pertinent references to recent discussions see Jackson (2019).

10 One might wonder why what Bayesians call degree of belief is not discussed, where this is conceived as the probability the believer attributes, or would, under certain conditions, attribute, to $p$. I distinguish this degree from belief strength, but much of what I say also bears on voluntary control of the former. Still, even persons who have the concept of probability need not attribute a probability to every proposition they believe, whereas every belief does have some degree of strength. The universal applicability of the latter variable by contrast with the former in part explains why I do not discuss the former.

11 It is worth emphasizing that I find at least six needing exploration. Even using only the categories I introduce, one could identify further theses. We might also use other terminology that might facilitate discussion, as does Nottelmann (2013).

12 Here as elsewhere, practical and theoretical reason are significantly analogous. Our questions on beliefs also apply to actions, and (for reasons given in my 2001) the answers should be parallel. In the Groundwork Kant considered actions not done "from duty" without moral worth and held that when motives of inclination and duty support $A$-ing, we cannot know whether we $A$ from duty. He does not raise the question whether, at will, we can veto or unharness a motive, and it is reasonable to take him to be committed at least to unharnessability).

13 Withholding is discussed informatively in works by R. M. Chisholm and by Earl Conee and Richard Feldman (2019).

14 This kind of case, as well as the even more controversial case of abortion, is discussed at length in the context of political philosophy in my (2000), esp. ch. 4, which construes civic virtue as entailing a prima facie obligation not only to have, but also to be motivated by (thus have as harnessed grounds), adequate secular reasons for laws or public policies that restrict liberty. 
15 Henry Sidgwick, in The Methods of Ethics, proposed a quite skeptical response to rational disagreements, and Roger Crisp has defended him. See Crisp's paper and my reply in Timmons et al. (2007).

16 For an influential statement of the view see, e.g. Williamson (2000).

17 David Hume, An Enquiry Concerning Human Understanding, Sec. 10, Part I (p. 73 in the edition ed. Eric Steinberg [Indianapolis: Hackett: 1977]).

18 This is an idealized notion. Degrees of support are not in general precisely measurable. But there is this much determinacy: if you and I are epistemic peers having the exactly same relevant evidence for $p$, then whatever the degree to which it supports $p$ for me is the same as the degree to which it supports $p$ for you. To be sure, if phenomenal states are evidence-and "the evidence of the senses" should be considered phenomenal-then we will not have exactly the same evidence even if we have evidence of exactly the same kind.

19 This chapter benefitted from discussion at the Epistemic Duty Workshop held at St. Thomas University, New Brunswick, in 2019 and from comments by Scott Stapleford, Matthias Steup, and, especially, Kevin McCain.

\section{References}

Audi, Robert. 1993. Action, Intention, and Reason. Ithaca, NY: Cornell University Press. Audi, Robert. 2008. "The Ethics of Belief: Doxastic Self-Control and Intellectual Virtue." Synthese 161: 403-418.

Audi, Robert. 2016. Means, Ends, and Persons. New York: Oxford University Press.

Conee, Earl, and Feldman, Richard. 2019. "Between Belief and Disbelief." In Kevin McCain (ed.), Believing in Accordance with the Evidence. Cham: Springer, 71-89.

Jackson, Elizabeth. 2019. "Belief and Credence: Why the Attitude-type Matters." Philosophical Studies 176: 2477-2496.

Nottelmann, Nikolaj (ed.). 2013. New Essays on Belief: Structure, Constitution, and Content. New York: Palgrave-Macmillan.

Roeber, Blake. 2019. “Evidence, Judgment, and Belief at Will.” Mind 128: 837-859.

Sosa, Ernest. 2007. A Virtue Epistemology. New York: Oxford University Press.

Steup, Matthias (ed.). 2001. Knowledge, Truth, and Duty. New York: Oxford University Press.

Timmons, Mark, Mele, Alfred R., and Greco, John (eds). 2007. Reason and the Good: Critical Essays on the Ethics and Epistemology of Robert Audi. New York: Oxford University Press.

Williamson, Timothy. 2000. Knowledge and its Limits. Oxford: Oxford University Press. 


\title{
6 We are Like American Robins
}

\author{
Ema Sullivan-Bissett
}

Many have argued that there are specifically epistemic duties that we have relating to what we believe. Here I construct and consider arguments for this philosophical dogma. First I argue that epistemic duties cannot be generated by appeal to belief's standard of correctness, normativism about belief, or our rational nature. Next I sketch my biological account of belief. According to the picture I advance, there are only standards derived from biological norms, which do not generate obligations to follow the pronouncements of these standards. If we ought to do anything epistemically, this is only in the sense that an American robin ought to build a nest-that is, to do so is to function properly. There are then, no distinctly epistemic duties. From here I turn to an alternative kind of argument for the dogma of duties, those which claim that the existence of epistemic duties is supported by inference to the best explanation. I argue that my biological picture can accommodate the explananda these arguments appeal to without letting epistemic duties in, and so, perhaps, on grounds of parsimony, should be preferred. I conclude that we are yet to be given a reason, either from reflecting on the nature of belief or our epistemic practice, for thinking that there are irreducible distinctly epistemic duties.

\section{Preliminaries}

There are, very broadly speaking, two questions to be asked concerning epistemic duties. First, do we have any? And second, what are they? A natural thought is that we ought not speculate on the second question until we have good reason to endorse a positive answer to the first. ${ }^{1}$ Given this, I will not be interested in the contents of our epistemic duties here, and that is because I think we do not have any.

Debate concerning the first question has been rather one-sided. That is, although a good many folk have argued against distinctly epistemic duties, there has been very little independent argument for the claim that we have these duties. To give a flavour of the literature, some have argued that we have no epistemic duties because that would require doxastic voluntarism, and doxastic voluntarism is false (Alston 1988, cf. Chisholm 1991; Feldman 1988; Heil 1984; Heller 2000; Olson 2015; Russell 2001; Ryan 2003, 2015; Stapleford 2012; Steup 2000). Others have argued that any plausible positive epistemic 
duty would be too demanding (Nelson 2010, cf. Stapleford 2012). Still others have argued that we have duties relating to what we believe but such duties can be understood not as distinctly epistemic duties, but as moral or prudential ones (Ryan 2015; Wrenn 2007, cf. Stapleford 2015b), and others still that we only have all things considered duties (Booth 2012, cf. Stapleford 2015a). ${ }^{2}$ Responses to these arguments proceed not by making a positive case for epistemic duties, but by undermining the case against them. Once done, this is taken to have cleared the way for a discussion of what our epistemic duties are.

We thus find ourselves with arguments against the existence of duties relating to the epistemic, or arguments against the existence of duties which are distinctly epistemic, but with comparatively little making the case for the existence of epistemic duties, beyond responding to the arguments against. This is surprising. There are all sorts of activities which we do not take to have duties attached to them, at least not beyond hypothetical ones relating those activities to our moral or prudential aims. So why is it taken that we have epistemic duties, in a way that we do not, for example, have duties with respect to traveling, cooking, or exercising, which are not reducible to some other duties related to those activities? Why is it taken to be "a familiar fact" (Lackey forthcoming) or "almost a platitude among educated people" (Levy 2006: 55) that we have epistemic duties?

I will try to uncover some motivation for the often-assumed claim that we have sui generis epistemic duties relating to what we believe. It seems to me that the assumption that we have such duties has the status of dogma, and so I will consider two routes to making good on this dogma, namely, via reflection on (1) the nature of belief and (2) features of our epistemic practice. I argue that neither route gets us to the existence of epistemic duties.

\section{What Kinds of Duties?}

To be clear, I have no argument with folk who make epistemic duties hypothetical (e.g. Maffie 1990). This would not set such duties apart from many others which are derivable from our interests. If folk want to say that I have a duty to form true beliefs about some subject area insofar as I have the aim of learning about some topic, I have no disagreement with them providing this case is no different from my having a duty to use fresh ingredients insofar as I have the aim of producing tasty food, or a duty to improve my Rubik's cube completion time insofar as I have the aim of impressing my friends.

Some folk might distinguish duties regarding belief from those regarding cooking or Rubik's cube completion by saying that there is some moral duty attached to belief, and so duties concerning forming beliefs are moral ones (Ryan 2015; Wrenn 2007). I have no argument with those people either. My aim here is not to argue that there are no duties of any kind beyond the hypothetical, but only to engage with arguments for there being irreducible epistemic duties, and showing that those arguments do not work.

The target of the chapter then is the claim that we have epistemic duties which are not reducible to, or dependent on, some other species of duty. The 
putative duties I am interested in are those which "arise from a purely impartial and disinterested perspective" (Feldman 1988, 236). Once here, much ink has been spilled on exactly what our epistemic duties are. But how did we get to the point where a discussion over the content of these duties was the business of the day? Why should we think there are any such duties at all?

My overall line is fourfold. First, that appeal to the standard of belief does not generate duties. Second, that normativism about belief is ill-motivated and so, even granting that epistemic duties fall out of this position, we still do not have good reason to posit epistemic duties. Third, that appeal to our rational nature or occupying the role of believer is not duty-generating. And fourth, that those arguments for the existence of epistemic duties which appeal to them as the best explanation for some features of our epistemic practice can be undermined by an alternative biological explanation which does not involve duties.

\section{Standards}

As above, there are all sorts of activities for which any duties attached to them are not sui generis activity-specific kinds of duties, but rather are ones derived from our other aims. Duties relating to what we believe, however, according to many philosophers, have a different kind of status. They are much more like, as well as being irreducible to, moral duties, insofar as they are not duties which get their oomph from their contingent relationship to our other aims.

Here is one thing the duties proponent might say. Although it is not obvious that beliefs come with duties, it is fairly uncontroversial that beliefs are subject to some standard. So although many of our cognitive states are truth-evaluable (imagining, supposing), truth and falsehood are "a dimension of assessment of beliefs as opposed to many other psychological states or dispositions" (Williams 1972, 136). The standard of belief is that a belief is correct if and only if it is true. Perhaps duties of the kind we are looking for arise from this standard. If beliefs are correct if and only if they are true, perhaps there is thus an irreducible epistemic duty to form beliefs which meet the standard (or at least, to engage in epistemic practices which make it more likely that one's beliefs will meet the standard).

This will not do. Standards simpliciter do not generate duties, since correctness is perfectly well understood non-normatively:

Judging that $\varphi$-ing is correct is compatible with judging that one ought not to $\varphi$. Judging that $\varphi$-ing is incorrect is compatible with judging that one ought to $\varphi$. When it is a fact that $\varphi$-ing meets a certain standard, there is always a further question whether the standard ought to be met. In some cases, the standard ought to be met, in others, not.

(Bykvist and Hattiangadi 2013, 103)

The point is straightforward: standards alone do not generate obligations. To do that they require an additional element, namely, there being something normative about that standard. So granting that the standard of correctness for 
belief is that a belief is correct if and only if it is true does not yet get us to duties regarding our beliefs. Now of course, belief's standard of correctness is one that many folk endorse, and so it can be difficult to see the difference between a standard being in place and there being something duty-generating about that standard. But consider an example for which the difference is clear: judging that "driving as a woman in Saudi Arabia contravenes conventional standards is not to think a woman in Saudi Arabia ought not to drive" (Bykvist and Hattiangadi 2013, 104). It can be correct to $\varphi$ without generating any corresponding duties to $\varphi$. It can be correct to believe that $p$ (truly), without that generating any corresponding duty to believe that $p$. So we cannot move from belief having a standard of correctness to belief having duties associated with it.

\section{Normativism}

I have argued that there being a standard in place does not generate nonhypothetical obligations to meet that standard. For that, the standard needs to be shown to be a normative one, and if that is shown, it may not be quite so much of a jump to the claim that we have epistemic duties derivable from that standard. One way of making good on this idea is to endorse normativism about belief, which, in the broadest terms, is to take belief to be constitutively normative.

There are broadly two routes to normativism about belief, motivated by (1) perceived explanatory credentials or (2) antecedent plausibility. If one is attracted to normativism by its perceived explanatory credentials, one might reason that if a view with such explanatory riches generates epistemic duties (or even relies on them for those riches), then we have good reason for positing such duties and we can get on with figuring out what precisely our duties are. However, normativism is not explanatorily powerful after all.

Some normativists are motivated to their position by its ability to explain why we cannot believe at will, but this explanation faces serious problems (Noordhof 2001). Others are motivated by its being able to explain transparency in doxastic deliberation, but again, this is highly dubious (SteglichPetersen 2006; Sullivan-Bissett 2018; Sullivan-Bissett and Noordhof 2020). If the plausibility of epistemic duties hinges on the explanatory credentials of normativism, there is no such plausibility after all. $^{3}$

The second route to normativism is that belief as constitutively normative is itself antecedently plausible. For folk who find it so, the interest is in properly describing the normativity attached to belief, and indeed, considering what obligations we have regarding our beliefs. This is the route to normativism which I suspect is taken by proponents of epistemic duties. Antecedent plausibility attached to the idea of belief as normative and duty-generating would go some way to explaining the dogmatic status of epistemic duties we often find in the literature. The idea of epistemic duties attached to our belief formation is, from this point of view, simply in no need of defense. In the present discussion however, that route to normativism is not going to give us the justification we seek for positing duties which are distinctly epistemic. Even granting that 


\section{Ema Sullivan-Bissett}

such duties would follow from belief being normative, without good reason to endorse normativism, so too are we without good reason to posit epistemic duties.

Other folk might appeal not to a normative pressure coming from the nature of belief, but to the kinds of things belief allows us to do. To this I say: feel free to generate norms of this kind, but these are not the sui generis, hailingfrom-a-disinterested-perspective norms philosophers have been talking about. Generating prudential or moral obligations is perfectly consistent with my alternative picture, but it is also consistent with the views of many folk often understood as opponents of epistemic duties.

\section{Our Rational Nature}

Another option for the epistemic duties proponent is to appeal to our rational nature. Indeed, it might even be said that the domain of the epistemic "is categorically prescriptive and intrinsically motivational relative to the requirements imposed upon all cognizers qua rational, intellectual beings" (Maffie 1990, 335, my emphasis). ${ }^{4}$ One might take it to be plausible that a being capable of reasoning correctly ought to reason correctly (Stapleford 2015b, 86), and perhaps this amounts to a conceptual truth (Stapleford 2012, 164). However, we have not yet been given any reason to find this more plausible than the claim that if you are a being capable of singing the national anthem correctly while standing on one leg, then you ought to sing the national anthem correctly while standing on one leg. I do not suppose that will convince anyone that there are duties attached to this activity.

In light of this, we might usefully turn to the idea of role oughts, which are simply ought statements which result from occupying a role (Feldman 2004). From here we could build an argument by reflection on the fact that we occupy the role of believers, and in so doing, certain role oughts apply to us. Ought statements of this kind specify the correct ways to perform a role, setting the standards for evaluation (Stapleford 2015b, 87). A spin class instructor ought to shout clearly and be aware of injuries, a board game designer ought to think carefully about game mechanics. These oughts arise out of occupying the role of spin instructor or board game designer. Richard Feldman thinks that the role we occupy as believers equally generates oughts. There are correct ways to perform the role of believer, and these set the standards for evaluation. Now of course, this does not yet get us to duties; as Scott Stapleford notes, role oughts do not translate to duties (consider Stapleford's example of a carriage horse: she ought to not stray from the road, but she does not incur a duty to not stray from the road) (Stapleford 2015b, 87).

Stapleford suggests that we can add two further conditions which need to be met before role oughts can generate duties. The first is that a subject needs to understand that there are correct and incorrect ways to perform her role (see also discussion in Stapleford 2012, 163). Second, she must be able to fail to comply with the ought as a matter of choice (Stapleford 2015b, 87). Believing meets these two further conditions: as a believer I understand that there are 
correct and incorrect ways to form beliefs (although filling those in is a matter of great dispute). And I can fail to comply with the oughts of believing well as a result of ignorance, negligence, or other epistemic vices.

Now, Stapleford does not take this to amount to a full argument. Nevertheless, he does say that these two further conditions at the very least are two of "the core necessary conditions of obligation" (2015b, 87), and so their being met by belief is suggestive of belief being subject to duties. However, although noting the modesty in this argument, it is nevertheless not persuasive. Let us go back to our subject singing the national anthem whilst standing on one leg: call her Theresa. Let us say, that in pursuit of doing this, Theresa occupies the role of national anthem singer standing on one leg. That does not yet generate duties. Let us return to Stapleford's further conditions which rule out duties for carriage horses. Can Theresa understand that there are correct and incorrect ways to perform the role? Sure. Can she, as a matter of choice, fail to perform the role? Sure. Have we been given any reason to think that there are duties relating to national anthem singing whilst standing on one leg? I do not think that we have. And if we have, to parallel the case more precisely, have we been given any reason to think there are sui generis irreducible duties relating to this activity? I cannot see why one would think so.

In a discussion elsewhere Stapleford notes that there is a sense of ought that we might mean when we say that "an American robin ought to build a nest, ought to eat berries and insects," and so on (Stapleford 2012,163). This is the sense which picks out whether something is functioning properly. But these oughts do not amount to duties. Stapleford draws the difference between American robins and humans like this: we, but not the robins, are capable of understanding our roles. But as we have seen, there is no reason to suppose that understanding one's role is duty-generating. My view, embodied in the title of the chapter and in slogan form, is that we are like American robins. The claim that we ought to believe truly is only true in the sense that we are functioning properly when we believe truly. ${ }^{5}$ It may well be that "the capacity for reason is present in any case where we ascribe a duty" (Stapleford 2012, 163), but we have been given no reason to take this capacity to be suggestive of duty.

\section{Biologizing the Epistemic}

Space constraints prevent a full detailing of my biological account of belief (see my 2017b and 2018). Instead, I give the contours of my view to undercut the inference to the best explanation arguments for epistemic duties presented later.

I take what is necessary to belief to be its having some motivational role, and make use of the following specification of that role found in (but not endorsed by) Lucy O'Brien's work to do the job: all that is necessary to something being a belief is that it "by itself, and relative to a fixed background of desires, disposes the subject to behave in ways that would promote the satisfaction of his desires if its content were true" $(2005,56)$. I take this to be a necessary condition on belief, such that all beliefs across all worlds meet it. I add to this an account of actual world beliefs, i.e., the beliefs of humans. 
These attitudes will meet the motivational condition, but they will have some additional features in virtue of the particular circumstances in which they are formed. Importantly, the biological functions I attribute to our mechanisms of belief formation are not essential to belief, but are the consequence of the nature of belief in the actual world.

\subsection{Proper Function One: The Production of True Beliefs}

I attribute to our mechanisms of belief formation two biological functions, adopting a historical account of function defended elsewhere (Sullivan-Bissett 2017c). The first function of these mechanisms is the production of true beliefs. Such mechanisms have proliferated because-given the essential nature of belief (its motivational role)—creatures with true beliefs enjoyed biological advantages which increased inclusive fitness: they were more likely to survive because their actions were successful.

I said earlier that belief having a standard of correctness is utterly uncontroversial (although I argued that this is not enough to generate epistemic duties) $(\$ 2)$. An account of belief then had better honor this feature. I accommodate belief's standard of correctness by noting that our belief-producing mechanisms have as (one of) their proper function(s) the production of true beliefs, and this provides the only sense in which, in at least some contexts, true beliefs are correct and false beliefs are incorrect. The correctness here is analogous to the correctness of a chameleon's skin pattern determined by whether it performs its function of matching the environment. The contents of beliefs can vary with respect to their meeting the correctness conditions laid down by biology. In at least some cases, when a belief is true, the mechanisms which have produced it have performed their function; when a belief is false the mechanisms have failed to perform their function (or stronger, have malfunctioned). It is in this sense only that beliefs have a standard of correctness.

Notice that this understanding of belief's standard of correctness does not generate duties to form beliefs in particular ways. It does not follow from our belief-producing mechanisms having the function of producing true beliefs that they ought to do so. Nor does it follow that we, as believers, ought to facilitate the meeting of this standard independently of our other aims. However, I grant that there are features of our epistemic practice that suggest we do have obligations of this kind (it is from this that one might argue for epistemic duties as part of an inference to the best explanation argument, $\$ 6$ ).

\subsection{Proper Function Two: The Production of Useful Beliefs}

It is clear, I think, that true belief production is not the only thing at which our mechanisms for belief-production are aimed. There are lots of cases of false belief which seem to have been produced by mechanisms doing what they are supposed to do that is, producing adaptive beliefs, which are usually false. If there are cases in which our mechanisms for belief-production are functioning 
properly when they produce such beliefs, we have good reason to specify some second function proper to these mechanisms.

What kinds of beliefs might be produced without being directed at truth? Consider those produced via biases which we might usefully distinguish as hot and cold (Funkhouser 2019: 14). Hot biases are those driven by emotions and desires (e.g. self-deceptive beliefs about my own abilities); cold biases are those which are non-motivational, and emerge from heuristics. Cold biases such as the availability bias may well be present because they tend to get things right in most contexts, and so can be subsumed under the mechanisms which have the function of producing true beliefs. Hotly biased beliefs, however, are a good candidate for inclusion in the set of beliefs produced because they are useful, not because they approximate to truth, but rather in spite of the fact that they do not. We all hold many beliefs which are the result of non-truth-directed biases, and this suggests that if we are to give a complete account of belief by appeal to biological function, we ought to recognize a function proper to our mechanisms of belief-production which can accommodate such beliefs.

My suggestion is that the second function is that of producing beliefs useful in self-organization, and I will use the term organizing beliefs to pick out those beliefs which facilitate self-organization, that is, which maintain self-esteem, avoid psychological damage, and so on. ${ }^{6}$ Such beliefs are useful insofar as they assist the effective functioning of the believer but not in virtue of being true.

With my account of belief now outlined, ${ }^{7}$ I turn to arguments for epistemic duties from inference to the best explanation. I will argue that my account can accommodate the features of our epistemic practice appealed to in these arguments without positing epistemic duties.

\section{Inference to the Best Explanation}

We have seen that the standard of correctness for belief does not generate epistemic duties to fulfill it, nor is normativism or appeal to our rational nature well placed to generate those duties. An alternative route to epistemic duties may be as part of an inference to the best explanation argument. If the presence of some phenomenon is best explained by there being epistemic duties, we may have been given a good reason to think that there are such duties after all.

In this section I consider features of our epistemic practice which might be thought best explained by appeal to epistemic duties. One such proponent of this kind of argument, Stapleford, suggests that we would need to posit epistemic duties if the evidence favored positing them, and/or if doing so significantly increased the explanatory power of our conceptual scheme (and the evidence is not otherwise against them) (2015b, 78). The flipside of these two considerations is that we can only reasonably exclude epistemic duties from our ontology if they are not favored by the balance of evidence, and they do not significantly increase the explanatory power of our conceptual scheme. My claim is that my biological account of belief accommodates the evidence which might be put into service in an inference to epistemic duties as the best 


\section{Ema Sullivan-Bissett}

explanation. This undercuts the claim that duties are favored by the balance of evidence. In addition, positing duties does not increase the explanatory power of our conceptual scheme given the explanatory reach of my alternative biological model.

My goal is not to show that there are no epistemic duties, but rather to show that we have been given no good reason to think that there are. I agree with Stapleford that, even if the evidence for epistemic duties were indifferent (which he claims it is not), it would nevertheless be rash to deny that epistemic duties exist, since the absence of evidence for a phenomenon is not always a good guide to the absence of that phenomenon $(2015 \mathrm{~b}, 83)$. That is fine by me. I just want to show that epistemic duties cannot be derived from the standard of belief, from belief as normative, from our rational nature, or from an inference to the best explanation argument going via any of the sources of evidence I discuss in the next sub-sections. Whilst one epistemic duties proponent concludes that "there is no reason to doubt that we have epistemic duties and some reason to think that we do" (Stapleford 2015b, 88), I will seek to show that there is no reason to think that we do have epistemic duties, and perhaps, via considerations of parsimony, some reason to think that we do not $(\mathbb{S 7})$.

My overall approach will be to appeal to the first function of our beliefproducing mechanisms (production of true beliefs) to accommodate the first phenomenon (transparency, $\$ 6.1$ ). Thereafter I will appeal to the second function of belief, namely the function of producing organizing beliefs (those beliefs which are useful but not as an approximation to truth). It will be by appeal to this second function that we can explain the features of our epistemic practice which might be explainable by appeal to epistemic duties $(\$ 6.2-\$ 6.4)$. As I said earlier, the function of producing true beliefs can explain belief's standard of correctness. The only sense in which beliefs are correct when true is that their proper function is truth. So, there are not sui generis epistemic duties relating to what we believe, but our taking there to be in our evaluative practice is adaptive. These doxastic strategies that we engage in, and criticize folk for not engaging in, do not generate any obligations regarding how we ought to believe. That our mechanisms for belief-production have the biological function of producing true beliefs does not get us to the claim that they ought to, nor that we at the agent level ought to facilitate that. Of course, we do feel that we have epistemic duties (as we will see), but my view is that our epistemic practice is not in fact tracking any duties we have. Rather, the biological function of many of our beliefs is to be true (a function derived from the mechanisms which produce them), and the dimensions of our practice discussed below facilitate the meeting of belief's biologically grounded standard of correctness. My overall strategy then is to give a biological errortheoretic explanation of why we believe that we have epistemic duties. ${ }^{8}$

\subsection{Transparency}

One way of arguing for epistemic duties is to reflect on how we form beliefs in a deliberative context, specifically, the kinds of things to which we consciously 
respond in forming and maintaining beliefs. Consider the phenomenon of transparency which structures our doxastic deliberation: "when asking oneself whether to believe that $p$ " one must "immediately recognize that this question is settled by, and only by, answering the question whether $p$ is true" (Shah 2003, 447). Proponents of transparency argue that one cannot deliberatively form beliefs for non-epistemic reasons. ${ }^{9}$ This is not to say that one cannot believe for non-epistemic reasons (or causes), but is rather only to say that one cannot do so deliberatively. That our deliberation is structured by transparency has been put to work in an argument for evidentialism (Shah 2006), which, if true, might be suggestive of epistemic duties concerning our belief regulation. However, Shah himself notes that evidentialism "does not follow directly from the mere psychological truth that we cannot believe for non-evidential reasons," but only from "the normative conceptual truth about belief which explains why we cannot do so" (Shah 2006, 481). As I noted earlier (\$3), normativism cannot in fact explain transparency (Steglich-Petersen 2006; Sullivan-Bissett 2018; SullivanBissett and Noordhof 2020), and so evidentialism following from the explanatory success of normativism does not get us to evidentialism after all. In addition, my account of belief outlined above can explain transparency in a way which has it coming out as a mere psychological truth (Sullivan-Bissett 2018), and, from this, evidentialism and the epistemic duties it might suggest does not follow.

\subsection{Negative Epistemic Appraisal}

Consider negative epistemic appraisal as it occurs in our evaluative practice with respect to irrational or unjustified belief. In this context we use phrases such as "you're jumping to unwarranted conclusions" (Stapleford 2015b, 84). What guides our appraisal might also be informative, specifically, we think it is appropriate to criticize people for believing for the wrong reasons. If someone has masses of practical reasons to believe something, we nevertheless criticize them for doing so (Marušić 2011, 35). We take it that beliefs ought to be connected to evidence.

We expect that alerting folk to their epistemic errors will motivate doxastic change. In addition, we blame people for irrational or improperly reflective beliefs. We cannot say of this that what we are up to here is holding the believer to some moral, ${ }^{10}$ legal, or prudential standard which she fails to meet, since there are cases where these appraisals come from a purely epistemic perspective (that is, they occur when no moral, legal, or prudential standard has been violated). Negative epistemic appraisal is ubiquitous, and is precisely the kind of thing we would expect to see if there were epistemic duties (Stapleford 2015b, 84-85).

I do not deny that this is indeed a feature of our epistemic practice. I only deny that it tracks truths relating to certain beliefs being irrational or unjustified, or believers having reneged on some obligation. So why do we engage in negative epistemic appraisal? And why do we take our criticisms to be tracking some distinctly epistemic obligation? Part of the answer is that if we judge that epistemic considerations amount to epistemic duties, as demanding of us, 


\section{Ema Sullivan-Bissett}

as binding our practice, we will be more likely to arrive at true beliefs about our environment (lest we fail to comply with our duties). ${ }^{11}$ Negative epistemic appraisal is the mechanism via which we socially encourage one another to believe in line with belief's biologically grounded standard of correctness. ${ }^{12}$

\subsection{Excuse-Making}

We engage in making excuses for our non-ideal epistemic behavior, which can be thought of as the "flipside of negative epistemic appraisal" (Stapleford 2015b, 85). We say things like, "I shouldn't let my emotions guide my beliefs," which might suggest that we take careful reflection on our doxastic practice to be an obligation, for if we did not so take it, excuse-making in this context would not make sense. Again, we find such practice even in cases where the relevant obligation does not plausibly stem from moral, legal, or prudential considerations. Those who want to deny the existence of epistemic duties need to explain this feature of our epistemic practice (Stapleford 2015, 86).

I agree that we respond to negative epistemic appraisal by making excuses, saying that we should not have believed as we did for example, suggesting that we take ourselves to have not complied with our obligations in this domain. That we engage in this kind of talk can also be explained by our feeling that there are duties which bind our epistemic practice, without those feelings being a reliable guide to the obligations we in fact have. Our feeling that there are such duties is, rather, just one mechanism via which we believe in line with belief's biologically grounded standard of correctness. In order to make our mechanisms of belief-production more likely to perform their proper function of producing true beliefs, our biological history has ensured we have thoughts about correct and incorrect belief formation, where we take such evaluations to involve sui generis normativity. ${ }^{13}$ We hold our beliefs up to epistemic standards; we feel we ought to have sufficient or good evidence for our beliefs. We make excuses because we believe that we have believed badly, we believe that we have not met our epistemic obligations. But that is not to say that we have, in fact, reneged on an obligation.

\subsection{Authority of Logic}

A fourth kind of evidence for epistemic duties comes from what might be called the "Authority of Logic" (Stapleford 2015b, 85). Particular patterns of reasoning are truth-preserving, either perfectly by deduction, or imperfectly by, for example, induction or abduction. Patterns of reasoning which are truthpreserving lead us from truths to truths more often than they lead us from truths to falsehoods. Stapleford identifies such patterns as "logical" in the broadest sense of that term $(2015 b, 85-6)$. Next, formalized statements of these truth-preserving patterns of reasoning are principles of logic. All good so far. Stapleford's next claim is that the connection of the principles of logic with truth "makes them normative" (2015b, 86). That claim is elaborated upon by noting that the principles distinguish good thinking from bad thinking, 
and correct inferences from incorrect inferences. He then notes that "there is a sharp propensity to regard the rules of logic as authoritative in epistemic contexts and logical support translates into evidential support in matters of belief," from which it seems that the normativity of logic implies the truth of statements containing epistemic oughts $(2015 b, 86)$. Overall the claim is that:

[T] he perceived authority of logic in epistemic contexts is another reason to suppose that some epistemic ought statements are true and it seems obvious that their truth imposes certain constraints on what we believe independently of any moral, legal or prudential considerations.

(Stapleford 2015b, 86)

I see two things going on here: (1) the claim that logic is normative, and (2) the claim that we regard the rules of logic as authoritative and as ones which generate epistemic oughts. Let me take them in turn. The first claim looks closer to the kind of thing I said at the start of the chapter regarding standards. I do not deny that logic generates certain standards (of say, believing, arguing, inferring). But one cannot move from a standard to normativity; we learned this earlier. Standards alone do not generate oughts, and they do not come with normativity for free. Just because principles of logic are connected up with truth (insofar as they are truth-preserving) they are not thus normative. So logic generating a standard does not yet get us anywhere towards epistemic oughts or duties. ${ }^{14}$

Turning to the second claim, that we regard the rules of logic as authoritative and as generating oughts. Let us grant that this is roughly the attitude we have towards the rules of logic. It does not follow that the best explanation of this involves appeal to epistemic duties. Rather, if we recognized that the only sense in which true belief is correct belief is the biological sense, we might be less inclined to form beliefs in accordance with what we identify as our epistemic duties, that is, doxastic strategies which facilitate the meeting of belief's biologically grounded standard of correctness. Similarly to Joyce's parallel account of moral judgment, these "feelings of 'inescapable requirement' will, in certain circumstances, serve reproductive fitness more effectively" (2001, 140) than our having true beliefs regarding the absence of duties relating to the epistemic.

\section{Parsimony}

For the sake of argument, let us grant that considerations of parsimony are at best tie-breaking ones (Stapleford 2015b, 80). Nevertheless, given that my biological account of belief can explain key features of our epistemic practice, it thus gets itself into a tie with the epistemic duties explanation. At this point I am entitled to appeal to parsimony considerations to prop up the biological explanation as preferable, since it does not posit epistemic duties.

Stapleford approximates a preemption of my explanation of the evidence when he concedes that it is possible that these features of our evaluative practice 
just show that we are confused. However, he responds by saying that "I think it's more likely that we regard ourselves as epistemically obligated to do certain things because we are epistemically obligated to do certain things" and that although the evidence presented is not decisive, "the pervasiveness of this practice puts some additional weight behind the idea that we are bound by duties of a purely epistemic description" $(2015 \mathrm{~b}, 85)$. However, now that we have an explanation of these features of our practice-one which can accommodate its pervasiveness which does not require such an expansion of our ontologyperhaps we can appeal to parsimony as a tie-breaking consideration.

I do not want to hang too much on considerations of parsimony, particularly since it is not uncontroversial that categorical duties are non-parsimonious. If it is part of the concept of duties that there is some extra metaphysical commitment, then my biological picture may be more parsimonious insofar as it does not make such a commitment. ${ }^{15}$

\section{Conclusions}

In this chapter I have been interested in whether we have epistemic duties relating to what we believe. I started by noting that assenting to this has the status of philosophical dogma. I argued against four routes to this claim: (1) that belief has truth as its standard of correctness which is duty-generating, (2) that belief is constitutively normative, and thus duty-generating, (3) that epistemic duties fall out of our rational nature or our occupying the role of believer, and (4) the existence of epistemic duties is part of the best explanation of some features of our epistemic practice. I argued against all of these routes. To the first I noted that standards alone do not generate oughts, that there needs to be something in addition to the standard to do so. To the second I suggested that normativism is plagued with problems, and that the two routes to normativism (perceived explanatory credentials versus antecedent plausibility) are bad places to begin a program of epistemic duty generation. To the third I argued that the role oughts which fall out of occupying the role of believer have not been shown to be categorical ones. Finally, in response to arguments from inference to the best explanation I offered an alternative account of the nature of belief which could explain dimensions of our epistemic practice thought to prop up duties talk. On this view, we are like American robins: we ought to behave in particular epistemic ways in the same way that an American robin ought to build a nest.

Given the range of nearby claims I was not interested in taking on, it might be wondered what philosophical significance the work here has. Recall, I have no argument with those who have it that we have epistemic duties (insofar as we have moral or prudential duties relating to what we believe), or that we have such duties insofar as we have some other aims. Nor do I have any argument with those who take extant objections to epistemic duties not to work (i.e. arguments from voluntarism, arguments from ought implies can, and so on). However, what I have shown is that the groundwork is unstable. Discussions over the content of epistemic duties, or whether arguments against them are successful, ought not 
be had until there is good reason to think any such duties exist in the first place. I have argued that so far, we have been given no such reason.

\section{Acknowledgments}

I am grateful to audiences at the Work in Progress seminar at the University of Birmingham and the Epistemic Duties workshop at St. Thomas University. Thanks also to Paul Noordhof, Michael Rush, Scott Stapleford, and Scott Sturgeon for comments on an earlier version of this chapter.

\section{Notes}

1 The irony of appealing to a natural thought which embeds a description of an epistemic duty is not lost on me. It might be argued that we cannot figure out if we have any epistemic duties until we know what epistemic duties, as a category of things, are. That seems quite right to me. I only mean to point out that we should work out whether we have duties relating to belief before seeking to identify the precise contents of those duties.

2 See Steglich-Petersen (2011) for a similar account of epistemic reasons, specifically the idea that one ought to believe that $p$ is entailed by epistemic reasons to believe that $p$ only in the context of an all things considered reason to form a belief about $p$.

3 Note that for reasons of space I have not properly made good on this claim. I reassure the reader that the claim is defended at length in my work referred to above.

4 Following this characterization of the epistemic James Maffie moves to give a naturalistic account of it which does not honor such a characterization. Relevant to this discussion is Maffie's view that epistemic requirements can be identified with descriptive facts and are prescriptive only hypothetically $(1990,338)$. As noted earlier $(\mathbb{S} 1)$ I have no argument with folk who understand epistemic duties in this way.

5 (Putting aside cases of accidental true belief which need not be brought about by a properly functioning system.) For the view that the function of our mechanisms of belief production is knowledge (not mere true belief) see Bird (2019). An additional difference between my view and Bird's is that correct functioning does not always result in true belief, since on my view in some contexts our mechanisms of belief production function properly when they produce false beliefs (see Sullivan-Bissett $2017 \mathrm{~b}, 103, \mathbb{\$} 4.4$ ). Although Bird recognizes these other functions of "some beliefforming mechanisms," he stops short of allowing the production of false beliefs in some contexts to be correct (Bird 2019, 183, fn. 18).

6 It might be wondered whether a simpler picture would just have it that all beliefs are produced by mechanisms aiming at producing adaptive beliefs. I do not object to putting things in such terms. However, in doing so we would nevertheless still need to specify two sets of historically normal conditions for the operation of these mechanisms: conditions in which beliefs are adaptive by being true, and conditions in which they are adaptive by being organizing. Talk of different functions maps these different sets of historically normal conditions, moving to talk of producing adaptive beliefs would still require distinguishing these contexts.

7 For a fuller fleshing out of this picture, including responses to objections, see SullivanBissett (2017b). 


\section{Ema Sullivan-Bissett}

8 An obvious parallel to my project is evolutionary metaethical accounts of our moral judgments and behavior. Just as normative ethics is a biological adaptation (see Ruse 1995, 1999; Joyce 2000, 2001), so too is our epistemic practice (see Street 2009).

9 Recently some philosophers have denied that exclusivity to considerations of truth characterizes our deliberative belief formation (see McHugh 2012, 2013, cf. Archer 2017 and Sullivan-Bissett 2017a, and McCormick 2015, cf. Sullivan-Bissett 2017d).

10 For a similar argument but against a background of epistemic obligations as moral obligations, see Ryan (2015).

11 A similar idea comes from Sharon Street when she says that judging that considerations of truth represent normative reasons for belief will be adaptive in this way $(2009,234)$. In the debate on the evolution of our moral judgments, Joyce argues that we think of morality as binding since hypothetical requirements will not always get the job done $(2001,134)$. Maffie suggests that the reason epistemic discourse seems categorically normative is because "epistemic facts are of such central and enduring concern to us that over time we have come to assume that everyone is interested in and motivated by them" $(1990,347)$. This suggestion is consistent with my view, and I can offer an explanation of why we care so much about what we take to be epistemic facts: doing so is biologically useful.

12 In his argument for practical considerations properly influencing belief formation, Jack Meiland suggests that our resistance to non-evidential factors influencing belief may be to do with the importance of true beliefs for survival $(1990,17)$.

13 The mistake we make in our epistemic discourse may not be as serious as taking there to be sui generis normativity involved, but may instead simply fail to reflect the biological basis of what we take to be epistemic normativity. For discussion see $\$ 5.1$ in Sullivan-Bissett (2017b).

14 So far I have talked of oughts and duties interchangeably, that is, I have taken it that if one ought to believe that $p$ one has a duty to believe that $p$. Some folk want to distinguish these claims. In Stapleford's case, ought statements themselves do not imply duties to believe any particular propositions, but combined with other assumptions suggest that we have an imperfect duty to reflect on our evidence (see Stapleford 2012). Those sympathetic to duties not following from oughts should take the argument from this section to be against deriving oughts from the authority of logic.

15 One worry is that my view comes with baggage of its own, in particular, a not uncontroversial conception of biological function. However, function-talk in this context merely describes the history of the development of our mechanisms for belief-production. My claim is only that appeal to our evolutionary history can explain features of our epistemic practice. Non-historical function theorists who separate evolution-talk from function-talk can still accept such a story. They will just not talk in terms of function. Thanks to Henry Taylor for encouraging me to make this clear.

\section{References}

Archer, Sophie. 2017. "Defending Exclusivity." Philosophy and Phenomenological Research 94 (2): 326-341.

Alston, William P. 1988. "The Deontological Conception of Epistemic Justification.” Philosophical Perspectives 2: 257-299.

Bird, Alexander. 2019. "The Aim of Belief and the Aim of Science." Theoria 34 (2): 171-193. 
Booth, Anthony. 2012. “All Things Considered Duties to Believe.” Synthese 187: 509-517.

Bykvist, Krister, and Hattiangadi, Anandi. 2013. "Belief, Truth, and Blindspots" In Timothy Chan (ed.), The Aim of Belief. Oxford: Oxford University Press, 100-122.

Chisholm, Roderick. 1991. "Firth and the Ethics of Belief." Philosophy and Phenomenological Research 51 (1): 119-128.

Feldman, Richard. 1988. "Epistemic Obligations." Philosophical Perspectives 2: 235-256.

Feldman, Richard. 2004. "The Ethics of Belief." Philosophy and Phenomenological Research 60 (3): 667-695.

Heil, John. 1984. “Doxastic Incontinence.” Mind 93 (369): 56-70.

Heller, Mark. 2000. "Hobartian Voluntarism: Grounding a Deontological Conception of Epistemic Justification.” Pacific Philosophical Quarterly 81: 130-141.

Joyce, Richard. 2000. "Darwinian Ethics and Error." Biology and Philosophy 15: 713-732.

Joyce, Richard. 2001. The Myth of Morality. Cambridge: Cambridge University Press.

Lackey, Jennifer. Forthcoming. "The Duty to Object.” Philosophy and Phenomenological Research. doi: 10.1111/phpr.12563

Levy, Neil. 2006. “Open-Mindedness and the Duty to Gather Evidence." Public Affairs Quarterly 20 (1): 55-66.

Maffie, James. 1990. Naturalism and the Normativity of Epistemology.” Philosophical Studies 59 (3): 333-349.

Marušić, Berislav. 2011. “The Ethics of Belief.” Philosophy Compass 6 (1): 33-43.

McCormick, Miriam Schleifer. 2015. Believing Against the Evidence: Agency and the Ethics of Belief, Abingdon, Oxon: Routledge.

McHugh, Conor. 2012. “Beliefs and Aims.” Philosophical Studies 160 (245): 425-439.

McHugh, Conor. 2013. "The Illusion of Exclusivity." European Journal of Philosophy 23: 1117-1136.

Meiland, Jack. 1980. "What Ought We to Believe? Or the Ethics of Belief Revisited." American Philosophical Quarterly 17 (1): 15-24.

Nelson, Mark. 2010. "We Have No Positive Epistemic Duties.” Mind 119: 83-102.

Noordhof, Paul. 2001. "Believe What You Want." Proceedings of the Aristotelian Society ns 101: 247-265.

O’Brien, Lucy. 2005. "Imagination and the Motivational Role of Belief." Analysis 65 (1): 55-62.

Olson, Dustin. 2015. “A Case for Epistemic Agency.” Logos \& Episteme 6 (4): 449-474.

Ruse, Michael. 1995. "Evolution and Ethics: The Sociobiological Approach." In his Evolutionary Naturalism: Selected Essays. Abingdon, Oxon: Routledge, 223-256.

Ruse, Michael. 1999. "Evolutionary Ethics in the Twentieth Century: Julian Sorell Huxley and George Gaylord Simpson.” In Jane Maienschein and Michael Ruse (eds), Biology and the Foundations of Ethics. Cambridge: Cambridge University Press, 198-224.

Russell, Bruce. 2001. "Epistemic and Moral Duty.” In Matthias Steup (ed.), Knowledge, Truth, and Duty: Essays on Epistemic Justification, Responsibility, and Virtue. Oxford: Oxford University Press, 34-47.

Ryan, Sharon. 2003. "Doxastic Compatibilism and the Ethics of Belief." Philosophical Studies 144: 47-79.

Ryan, Sharon. 2015. “In Defense of Moral Evidentialism.” Logos \& Episteme 6 (4): 405-427. 


\section{Ema Sullivan-Bissett}

Shah, Nishi. 2003. "How Truth Governs Belief." Philosophical Review 112 (4): 447-482.

Shah, Nishi. 2006. “A New Argument for Evidentialism.” Philosophical Quarterly 56 (225): 481-498.

Stapleford, Scott. 2012. "Epistemic Duties and Failure to Understand One's Evidence." Principia 16 (1): 147-177.

Stapleford, Scott. 2015a. "Epistemic Versus All Things Considered Requirements." Synthese 192: 1861-1881.

Stapleford, Scott. 2015b. "Why There May Be Epistemic Duties." Dialogue 54: 63-89.

Steglich-Petersen, Asbjørn. 2006. "No Norm Needed: On the Aim of Belief." Philosophical Quarterly 56 (225): 499-516.

Steglich-Petersen, Asbjørn. 2011. "How to Be a Teleologist about Epistemic Reasons.” In Asbjørn Steglich-Petersen and Andrew Reisner (eds), Reasons for Belief. Cambridge: Cambridge University Press, 13-33.

Steup, Matthias. 2000. "Doxastic Voluntarism and Epistemic Deontology." Act Analytica 15 (24): 25-56.

Street, Sharon. 2009. "Evolution and the Normativity of Epistemic Reasons." Canadian Journal of Philosophy 39: 213-248.

Sullivan-Bissett, Ema. 2017a. "Aims and Exclusivity.” European Journal of Philosophy 25 (3): 721-731.

Sullivan-Bissett, Ema. 2017b. "Biological Function and Epistemic Normativity." Philosophical Explorations 20 (1): 94-110.

Sullivan-Bissett, Ema. 2017c. "Malfunction Defended.” Synthese 194 (7): 2501-2522.

Sullivan-Bissett, Ema. 2017d. "Transparency Defended." Syndicate Philosophy. Symposium on Miriam McCormick's Believing Against the Evidence: Agency and the Ethics of Belief.

Sullivan-Bissett, Ema. 2018. "Explaining Doxastic Transparency: Aim, Norm, or Function?" Synthese 195 (8): 3453-3476.

Sullivan-Bissett, Ema, and Noordhof, Paul. 2020. "The Transparent Failure of Norms to Keep up Standards of Belief.” Philosophical Studies 177 : 1213-1227.

Williams, Bernard. 1972. "Deciding to Believe." In his Problems of the Self. Cambridge: Cambridge University Press, 136-151.

Wrenn, Chase. 2007. “Why There Are No Epistemic Duties.” Dialogue 46 (1): 115-136. 


\section{Part II}

\section{Epistemic Duties of Individuals}


$\because$ Taylor \& Francis Taylor \& Francis Group

http://taylorandfrancis.com 


\title{
7 Bound by the Evidence
}

\author{
Scott Stapleford and Kevin McCain
}

\section{Introduction}

Some days even we disagree about the evidence. But united we stand on justification. In particular, we think that epistemic justification is a matter of belief aligning with evidence-and nothing else. So we're evidentialists. There are shades of difference between evidentialists and plenty of family feuds. We won't go into that. ${ }^{1}$ The big picture is all we need, since we're looking at epistemic duties and they take us beyond epistemic justification. Evidentialists who think that evidence imposes obligations will surely agree with Richard Feldman (2000) that if one takes any doxastic attitude towards a proposition it ought to be the one that fits the evidence. ${ }^{2}$ Accepting this is consistent with holding a wide variety of evidentialist views concerning the nature and scope of our epistemic obligations. ${ }^{3}$

At one extreme are reductionists, who limit epistemic obligatoriness to the having of doxastic attitudes that fit the evidence. Trent Dougherty is a prime example: " $[T]$ here is no epistemic notion of responsibility other than the 'responsibility' one has to believe in accordance with one's actual evidence at a time" (Dougherty 2014, 148). That our epistemic obligations are fully satisfied by the mere having of fitting attitudes is a clear implication of Dougherty's view: "My position is that the content of the 'epistemic ought' is exhausted by considerations pertaining to evidential fit" (Dougherty 2014, 153). For evidentialists like Dougherty, the only genuine epistemic duty we have is the duty to believe in accordance with our evidence. Nothing is said about our having to $d o$ anything to get ourselves into that optimal position.

At the other extreme are expansionists, who extend the list of things that are epistemically required beyond the mere having of evidential fit. Jason Baehr, for example, thinks we have epistemic obligations regarding "carefulness and thoroughness in inquiry, inquisitiveness, attentiveness, fair-mindedness, openmindedness, intellectual honesty and intellectual integrity" (Baehr 2011, 98). ${ }^{4}$ Expansionism has sometimes been turned against evidentialism. One such argument looks like this: It can be the case that $p$ fits $S$ 's evidence, that $S$ believes $p$ because of her evidence, and yet $S$ 's belief that $p$ is unjustified because she failed to conduct proper inquiry concerning $p$ (see Baehr 2011, DeRose 2000, and 


\section{Scott Stapleford and Kevin McCain}

Miracchi forthcoming). This is no good for evidentialists since it violates the supervenience thesis they treat as axiomatic:

ES The epistemic justification of anyone's doxastic attitude toward any proposition at any time strongly supervenes on the evidence that person has at that time.

(Conee and Feldman 2004: 101)

Our view is pretty simple: We don't like extremists. More precisely, we think they're wrong. While we think there is more required on epistemic grounds than the obtaining of evidential fit, we deny that "carefulness and thoroughness in inquiry, inquisitiveness, attentiveness, fair-mindedness, open-mindedness, intellectual honesty and intellectual integrity" are epistemically obligatory. We applaud the cultivation of such virtues or practices, and can see how they might help a person achieve her epistemic aims, become a better epistemic agent and that sort of thing. We just don't think she's under any obligation to do this—at least none that it makes sense to call 'epistemic'.

In this chapter we propose a golden mean between the two extremes. It comes down to three complementary theses: (1) There is no epistemic duty to believe every proposition that fits one's evidence (NAP-Not All Propositions); (2) There is an imperfect epistemic duty to tailor one's beliefs to the evidence through reflection (DTR-Duty to Reflect); (3) There is no epistemic duty to gather more evidence with respect to any of one's beliefs (NDI-No Duty to Inquire). What results is our own brand of evidentialism that departs in some ways from the classics, while still committing to ES and other paradigm evidentialist principles.

\section{Not All Propositions}

Defending Feldman is our nine-to-five, and we've already said we're with him on the following conditional: If one adopts any doxastic attitude towards $p$, one (epistemically) ought to adopt the attitude that fits one's evidence. ${ }^{5}$ If? Why not simply say that we epistemically ought to believe the propositions that fit our evidence, disbelieve those whose negations fit our evidence, and withhold on those that fit our evidence no better or worse than their negations do? Why the more restrictive NAP, in other words?

The problem with the categorical statement-one epistemically ought to adopt the attitude that fits one's evidence-is that it asks too much of any human agent. Consider the evidence we gain from perception. Perceptual experience is so evidentially rich that an infinite (or nearly infinite) number of propositions are supported by any bit of perceptual data. ${ }^{6}$ We simply cannot believe all of them. Similarly, any true claim that we are justified (or unjustified) in believing entails every necessary truth. As a result, every one of our justified (or unjustified) true beliefs entails an infinite number of propositions. Within the infinite set of propositions entailed by each of our true beliefs is an infinite number of propositions that are so complex that no human could ever grasp 
them. Clearly no human can believe a proposition without comprehending it, and no one can actually believe an infinite number of propositions. Hence, if we are epistemically obligated to believe every proposition supported by our evidence (because we are epistemically obligated to adopt the appropriate doxastic attitude towards every proposition), we've got no hope of meeting our epistemic obligations-ever.

To put it differently, if NAP is false-if we do have an epistemic obligation to believe every proposition that fits our evidence-then we're doomed to fail in our epistemic obligations no matter how much care we take, or how much evidence we gather, because we're utterly incapable of adopting the appropriate attitudes towards all the relevant propositions. But guaranteed failure seems inconsistent with obligation. It can't be that we're epistemically required to do what no human could ever possibly do. So NAP is true.

It's tempting to beat up straw men. Our argument for NAP turns on accepting that ought implies can for epistemic duties, and the ought-impliescan principle isn't obviously true. So our argument isn't very good.

Well, it might not be very good, but it's not because of that. There are at least two importantly different readings of 'ought implies can' in the context of epistemic duties. One way to gloss it is this:

O/C1: $S$ ought to believe (disbelieve or withhold) that $p$ on the basis of $e$ at $t$ only if at $t, S$ can believe (disbelieve or withhold) that $p$ on the basis of $e$.

But that's not the same as this:

O/C2: $S$ ought to believe (disbelieve or withhold) that $p$ on the basis of $e$ at $t$ only if at $t$, it is nomologically possible for a human being to believe (disbelieve or withhold) that $p$ on the basis of $e$.

There's good reason to draw this distinction, for on some readings of 'can', accepting $\mathrm{O} / \mathrm{C} 1$ commits you to doxastic voluntarism; accepting $\mathrm{O} / \mathrm{C} 2$ does not, however you spin the 'can'.

Moreover, Feldman (2000; 2008) argues convincingly that the oughtimplies-can principle is false, if we allow that role oughts exist. Taking on a role comes with certain obligations whether the person stepping into the role is able to fulfill them or not. For example, if you're a science journalist, then you ought to write well, even if it happens that you can't. And if you have children, you should teach them to be good and provide them with food, even if bad character or a prison sentence prevents you from doing either. Considerations like these-deriving from Feldman-tell against O/C1 but not against $\mathrm{O} / \mathrm{C} 2$.

Take the case of parenting: O/C1 implies that the parent, $S$, ought to feed her child at $t$ only if she can feed her child at $t$. But that's not true. You ought to provide for your children-and this includes feeding them when they're hungry—even if you wound up in jail and have no income. You're still a parent 


\section{Scott Stapleford and Kevin McCain}

and you still have obligations. Why think that? Because the corresponding implication of $\mathrm{O} / \mathrm{C} 2$ is arguably true. It is nomologically possible for a parent to provide for her children. If it weren't possible for any human to look after her children, then it doesn't seem that $S$ could be obligated to look after hers.

So we don't need $\mathrm{O} / \mathrm{C} 1$ to get NAP. It follows from $\mathrm{O} / \mathrm{C} 2$ and the justificational fecundity of evidence. After all, it isn't nomologically possible for any human to adopt the fitting attitude towards every proposition that her evidence makes probable, improbable or as probable as not. Hence, there's no duty to always have the fitting attitude-NAP.

\section{Duty to Reflect}

We mentioned role oughts in passing—obligations a person has just in virtue of occupying a certain role. Here we want to emphasize the role of epistemic agent: This role is unavoidable. We can't help but be epistemic agents and we're going to form beliefs no matter what. It's part of normal human functioning. Given our role as epistemic agents-which we understand and can't renounce- there are things we ought to do. Those things concern belief, and they can be done well or done poorly. You should believe well is what we're suggesting. It's not an outrageous claim. ${ }^{7}$

The big question is what this means. Truth is the constitutive aim of belief, according to some (Shah 2003; Wedgwood 2002). If they're right-and we think they are-then believing well involves aiming at true belief. ${ }^{8}$ Our role as epistemic agents thus imposes on us an obligation to aim at truth. Sadly, there's no direct path to truth. You get there by way of evidence-specifically, the evidence you have-if you get there at all. That's why we say that believing well involves aiming at true belief rather than believing truly. (You can believe truly without believing well.) Hence, in order to satisfy the obligation of believing well, we must believe according to the evidence. Any evidentialist who recognizes epistemic obligations should therefore accept that our obligation to believe well grounds our obligation to believe those propositions (and only those) that fit our evidence. ${ }^{9}$ As perfect fit is unattainable, we must settle for approximation.

From the obligation to believe according to the evidence-and the reasonable goal of approximation-we infer an epistemic duty to reflect (DTR). The inference hinges on the fact that we are unlikely to form beliefs that fit our evidence often enough without reflection. If we are to believe according to our evidence reasonably often, then we must (reasonably often) reflect upon our evidence and what it supports. Since our role as epistemic agents carries with it an obligation to believe according to the evidence, and since we can't accomplish this reliably without reflection, it is incumbent upon us to reflect upon our evidence and what it supports reasonably often. We can't tell you what 'reasonably often' amounts to-at least not with any precision. But it's clear that there's a threshold below which an agent is not sufficiently reflective to fulfill her epistemic obligation, and a threshold above which she is. The duty is therefore imperfect. ${ }^{10}$ 


\section{No Duty to Inquire}

Critics have argued that evidentialism is unsatisfactory since it pays no attention to evidence one should have had but doesn't have (see, for example, Baehr 2011; DeRose 2000; Miracchi forthcoming). The worry is that failure to inquire when our epistemic circumstances make inquiry obligatory can adversely affect the justificatory status of certain beliefs, and that evidentialism is insensitive to any such influence. Cases like the following make the point:

George represents the epitome of intellectual laziness, apathy, and obliviousness ... George [believes] that exposure to secondhand smoke poses no significant health risk. Given his extremely narrow and practical focus, George is oblivious to all of the well-publicized research indicating the hazards of secondhand smoke. In fact, George has some evidence in support of his belief. He recalls having learned from a reliable source some years ago that a considerable amount of research had been conducted concerning the effects of exposure to secondhand smoke and that this research had failed to establish any correlation between such exposure and any serious health problems. And, as far as George knows, the research on this topic has not changed. (Nor, we may suppose, does he have any reason to think that it might have changed).

(Baehr 2011, 70)

The evidentialist gums this up, according to Baehr. George's belief that secondhand smoke is safe fits the evidence he has. So it's justified on the evidentialist picture. But that seems overly generous, since George is a lousy inquirer. What went wrong? He failed to be epistemically virtuous: He should have got more evidence.

We're not happy with this assessment. George's complacency is admittedly obnoxious, and there's nothing good about willful blindness. But his belief is totally justified. ${ }^{11}$ After all, it's supported by his evidence, and it would surely be irrational for him to disbelieve or suspend on the relevant proposition when his evidence makes it more probable than not. ${ }^{12}$ What should George think about the effects of secondhand smoke, given the evidence he has? He should think that the fumes are harmless. We admit that he's a fool and that he should have got more evidence. But the should is not epistemic. Actively seeking information may be a moral or practical requirement, but believing well is a matter of alignment. Epistemic justification is about what you should do now with the evidence you have. It's not about long-term benefits. George would gain by improving his evidence-gathering practices. Of course we agree with that. But right now, with no evidence that his evidence is crappy, George's belief is perfect.

Let's bring home the alignment view of epistemic justification with two additional examples. Here's one from Richard Feldman (2003, 47):

A professor and his wife are going to the movies to see Star Wars, Episode 68. The professor has in his hand today's newspaper, which contains 
the listing of movies at the theater and their times. He remembers that yesterday's paper said that Star Wars, Episode 68 was showing at 8:00. Knowing that movies usually show at the same time each day, he believes that it is showing today at 8:00 as well. He does not look in today's paper. When they get to the theater, they discover that the movie started at 7:30. When they complain at the box office about the change, they are told that the correct time was in the newspaper today.

The guy's wife was a little bit miffed—one feels her irritation—but his belief was epistemically justified. It would have been sensible for him to open the paper: New evidence was readily available. Not having taken that step, however, his mistaken belief was appropriate.

Another example to consider is this:

Jon hates to find out the results of a football game before he has had a chance to watch the game in its entirety. He missed yesterday's game, so Jon tries very hard to avoid learning the score. He refuses to consult any of the typical sources for this information. He will not read newspapers, watch the news, or even listen to the radio. In fact, he goes so far as to avoid talking to people he knows are likely to have watched the game. While running out of a room with his ears plugged to avoid hearing the latest sports report Jon runs into a newspaper rack and sees on the front page of a newspaper he knows to be extremely reliable that the Bears won the game yesterday.

(McCain 2014, 151)

This is worse than not getting the evidence: It's a case of trying to avoid it. But still, before colliding with the information outside, Jon was justified in suspending judgment. He had no evidence about the score either way, so forming a belief was out of the question. Given that suspension accorded with his evidence, there was no epistemic reason for him to get more. There's no epistemic duty to inquire (NDI).

Note that we've been relying on examples. We find them quite compelling, but some will be unconvinced. It would be nice to give a reason-beyond intuitive examples-for thinking that gathering evidence is not an epistemic requirement. We'll produce one in response to an objection.

\section{Objection 1: Aim of Belief Supports Duty to Inquire}

Middle-of-the-road evidentialism has hardly been topping the charts, so we expect to meet resistance. We pay no mind to anyone denying the basic evidentialist premise that a justified belief is a belief supported by evidence. That's a fight for another day. ${ }^{13}$ But there are a couple of 'friendly' objections we can easily put to rest. The first is that the aim of belief-which imposes a duty to reflect-also imposes a duty to inquire. The considerations making $D T R$ plausible, it might be said, count equally against NDI. 
Let's review the argument for DTR. It arises, we said, from our occupying the role of epistemic agent-a role that grounds an obligation. We unavoidably form beliefs and there's a way to do that well. As agents who understand the role, we should aspire to good performance. Believing well means aiming at truth, since truth is the constitutive aim of belief. Evidence is the index of truth, so evidence needs to be comprehended. Since reflection aids comprehension, we are obligated to reflect on the evidence. How much reflection? How much weighing of evidence? This is a matter of degree, so the duty to reflect is imperfect.

Now here's where you might want to hit us: We denied any duty to inquireNDI is the third of our conservative theses-but the line of reasoning just sketched makes inquiry as obligatory as reflection. At least that's how it seems. If our guide to truth is evidence, and we're obligated to aim at truth, then we're obligated to gather evidence. Of course the duty of inquiry has a limit-we can't forage for evidence indefinitely. Still, getting a sufficient amount of evidence in appropriately virtuous ways sounds like a reasonable requirement. Aren't we being inconsistent, then—or at least a little arbitrary—in asserting a duty of reflection while denying a duty of inquiry?

There's nothing arbitrary about it and the view is perfectly consistent. Aiming at truth is essential to being a belief, but aiming at propagation is not. A belief is just not the sort of thing that needs to proliferate-or round up company-in order to be properly constituted. You can be a belief, in other words, without increasing the ranks. But you can't be a belief without setting your sights on truth. We think this point is significant.

Another way to say the same thing (or a way to say something similar) is this: Rationality is not proportional to number of beliefs or amount of evidence. Having evidence is epistemically valuable—and promotes rationalityonly if one responds to it appropriately. Consider two individuals, $S 1$ and $S 2$. The total evidence of $S 1$ is $e$, and she believes what $e$ supports. $S 2$ has $e$ and does some digging - she acquires more evidence in a virtuous manner. Her evidence is $e+n$. But her beliefs diverge from her evidence. $S 1$ is clearly better off. How many items does she have on the shelf? That's not the question. It's what you do with evidence that matters, not how much you have. There may be moral or practical reasons to look around and gather more. Who cares? There's no epistemic duty to be moral or practical. And we weren't talking about anything else.

\section{Objection 2: Duty to Reflect is a Duty to Inquire}

Another worry is that DTR just is a duty to inquire. There may be something in that. Don't we say that a person learns or discovers that her evidence supports $p$ after she's spent some time thinking about it? That is a common way of speaking, and it's plausible that such a discovery would give $S$ evidence. She's learning something new, after all. ${ }^{14}$ And that could make a difference to justification. Suppose $S$ has $e$ and $e$ entails $p$, but $S$ is oblivious to the entailment. Despite the fact that $e$ entails $p$, you might want to say that $e$ does not support 
believing that $p$ for $S$, given her lack of comprehension. ${ }^{15}$ The following thought conveys this: If $S$ were to find herself believing $p$ out of nowhere, it seems that her belief would not be justified. If she were to reflect on $e$ and grasp the relation of entailment, by contrast, it's arguable that her evidence has changed: It now includes $<e$ entails $p>.{ }^{16}$ And while belief that $p$ does not fit $e$, on this view, it does fit $e+<e$ entails $p>\cdot{ }^{17}$ Assuming this is correct, there are situations in which reflection can change justification. Prior to reflection, $S$ was not justified in believing that $p$; after reflection she was.

Reflecting on evidence can lead to discoveries-we're not denying that. But is this a matter of discovering what our evidence supports or acquiring a new kind of evidence? Here we have different intuitions. Is the duty to reflect a duty to inquire? It depends on who you ask. But our principles are consistent regardless. Let's think about the duty to reflect, and whether reflection produces evidence. We'll claim that DTR and NDI are compatible, if you follow either one of us.

From a certain point of view, $e$ supports $p$ for $S$ just as strongly as $e+<e$ entails $p>$ does. That's because appreciation of evidence doesn't change evidence: It's kind of out there in the world on its own. ${ }^{18}$ If this quasi-Platonic position is correct, then although $S$ 's reflection may teach her what her evidence supports, it makes no difference to evidential relations: $e$ supports $p$ whether $S$ can see that it does or not. This is the pitiless outlook of Stapleford. McCain is more forgiving: The attitude towards $p$ that is justified for $S$ may differ after reflection. The assumption here is that in order for $p$ to be supported by $e$ one must be disposed to have an awareness of the connection between $e$ and $p$ when $e$ and $p$ are considered. ${ }^{19}$ On this way of slicing it, $S$ 's justification for $p$ may be altered by reflection, if, prior to reflection, she wasn't disposed to recognize the connection between $e$ and $p$ (perhaps reflection instilled new dispositions that were not in place before). So new evidence, possibly relevant to justification, could sometimes be gained through reflection: $S$ could become justified in believing that $p$ on the basis of $e$ where she wasn't justified before. The evidential relations in some sense depend on our apprehension of them. The duty to reflect (DTR) could thus be seen as a duty to inquire- to acquire new evidence through reflection. ${ }^{20}$

What are the implications of this for the consistency of our theses? We don't see any conflict. DTR and NDI can both be held, whether you accept the 'no change' view of Stapleford or the 'reflection can make a difference' view of McCain. Either way reflecting is relevantly different from inquiry in the everyday sense, which is the sense picked out by DTR and the sense that critics of evidentialism have in mind when they say that we have a duty to inquire (or to inquire virtuously). The critics are generally not saying that we have a duty to generate evidence through reflection. They're saying we have a duty to gather evidence-in the sense of going out and getting some. And that's precisely what we deny. Consider our positions in turn.

Stapleford can take a snooze, since he opposes the idea that reflection generates new evidence. On his old-fashioned way of thinking, reflection informs us what our evidence supports-the pile of evidence remaining the same. It's McCain who's got to shuffle. In fulfilling the duty to reflect, $S$ can 
affect what her evidence supports, since reflection can generate evidence. To square this with NDI, we need to draw a distinction. There are two basic methods of inquiry: One gathers evidence from reflection and one gathers evidence from the world. When we say there's no duty to inquire (NDI), we mean no duty to inquire in the world. But we do have a duty to reflect (DTR). Aside from helping McCain, this is an independently plausible distinction. There's such a thing as investigating the world and consulting outside sources of information. It's something very different to flop on the couch and think. The latter is epistemically obligatory $(D T R)$; the former (we're claiming) is not $(N D I)$.

\section{Conclusion}

We've tried to strike a balance between reductionism and expansionism. The reductionist's mistake is to think that nothing needs to be done: Evidential fit is good, but you don't have to aim for it. The expansionist's mistake is to require too much: You've got to beat the bushes for evidence. On the conservative view we're proposing here, there is an imperfect duty to reflect-on our evidence and what it supports. But there's no duty to engage in inquiry, at least no 'inquiry' beyond reflection. So we're bound by the evidence to reflect, but only on the evidence we have.

\section{Notes}

1 For an 'explanationist' approach to evidentialism that one of us favours and the other finds plausible, see McCain $(2014,2016)$.

2 Note that when we speak of belief 'aligning' with or 'fitting' the evidence, we mean the evidence that one possesses-however that is understood. Not all evidentialists agree that we have epistemic obligations. Earl Conee has mentioned in conversation that he's skeptical about the existence of epistemic obligations, and he's a benchmark evidentialist.

3 We're not suggesting that every position discussed below is an evidentialist position. But they're all positions an evidentialist could adopt.

4 See Axtell (2011) as well.

5 One of us (Stapleford 2012) has argued that we never have an epistemic duty to believe any particular proposition, but that we epistemically ought to believe every proposition supported by our evidence on the basis of that evidence. The claims are consistent if we draw a distinction between epistemic duties and epistemic oughts, where the latter are somewhat deflated.

6 For a careful defence of this claim, see Nelson (2010). For criticism, see Stapleford (2013).

7 You should withhold well too, but we'll mostly talk about belief in order to avoid complications. For criticism of the reasoning sketched in this section, see SullivanBissett (this volume).

8 Don't take 'aim' literally. Thanks to Ema Sullivan-Bissett for flagging this.

9 As explained in the previous section, we have no obligation to believe every proposition that fits our evidence. The idea is rather that for any proposition about which we are going to have a doxastic attitude, it ought to be the one that fits the evidence. 


\section{Scott Stapleford and Kevin McCain}

This is a view that tempts both of us, though note again that Stapleford wants to amp it up in one respect and tone it down in another: We ought to believe every proposition that our evidence supports-in a wimpy sense of 'ought'-but we have no duty to believe any particular proposition, where duty is connected with blame. See Stapleford 2012, 2013, 2014, 2015a, 2015 b.

10 For more on this, see Stapleford 2013 and 2015b.

11 Totally justified if we're assuming that the strength of his belief matches the strength of his evidence exactly.

12 For further discussion of this case, and a different sort of response, see Matheson (this volume).

13 See Conee and Feldman 2004, McCain 2014, and Smithies 2019 for arguments supporting the basic evidentialist premise we favour. Also see Williamson 2000, who, while mistaken about the nature of evidence, correctly endorses evidentialism when it comes to justification. As he $(2000,207)$ concisely puts it, "evidence is what justifies belief."

14 It's worth noting that even on a knowledge-first approach (as in Williamson 2000), $S$ could gain new evidence through reflection, since 'learn' and 'discover' are factive. Hence, in a situation where $S$ discovers or learns that $p$, she would thereby come to know that $p$. And, according to Williamson, that would mean that $p$ is now part of $S$ 's evidence as a result of her reflection.

15 Alternatively, you might want to say that $e$ supports believing that $p$ on the basis of $e$, whether or not $S$ can do it. (See Smithies 2019 and Stapleford 2014 for this angle.)

16 We put this in terms of $S$ having a particular proposition as evidence for the sake of simplicity. We're not taking a stand on the ontology of evidence. In fact, we both think that evidence is best understood in terms of mental states. It's thus more accurate to describe the new evidence $S$ gains-if it is new evidence-as her belief that $<e$ entails $p>$ or her awareness of the entailment relation (or some other mental state of $S)$. See McCain $(2014,2018)$.

17 This is not to say that $S$ must have a higher-order mental state expressing that $<\mathrm{e}$ entails $p>$ in order to be justified in believing $p$ on the basis of $e$. Such a requirement would fall prey to the sort of regress that Caroll 1895 discusses. Rather, the idea is that in order to be justified in believing $p$ on the basis of $e S$ has to appreciate, in some sense, that $e$ supports $p$. Reflection might lead to $S$ appreciating the support that $e$ provides for $p$, and this appreciation-whether it is a belief, an inferential seeming of the sort Huemer (2016) claims is required for inferential justification, direct acquaintance with a probability relation as Fumerton (1995) suggests, or a disposition to have a seeming as McCain (2014) claims-is plausibly evidence that $S$ has.

18 A little more precisely, it's the evidential relations that await discovery. Evidence is always mental; evidential relations are abstract and ideal.

19 For the full account, see McCain (2014, 2015, 2016, 2017).

20 Looking for something in between? See Smithies (2019). Smithies threads the needle by claiming (as Stapleford does) that in this sort of case $S$ has propositional justification for $p$ because she has $e$ regardless of her appreciation or lack thereof concerning the fact that $e$ supports $p$; nevertheless, he claims (as McCain does) that if $S$ were to believe that $p$ without this appreciation she would lack doxastic justification. Smithies relies on the idea that in a situation where $S$ lacks appreciation of what her evidence supports she can't base her belief on that evidence, despite having propositional justification. This builds more into the basing relation than the causal 
theory of basing that we prefer (see McCain 2012 and 2014). However, the view is not insane, and it accommodates the intuitions we're building on here.

\section{References}

Axtell, Guy. 2011. “Recovering Responsibility.” Logos \& Episteme 3: 429-454.

Baehr, Jason. 2011. The Inquiring Mind: On Intellectual Virtues and Virtue Epistemology. Oxford: Oxford University Press.

Caroll, Lewis. 1895. "What the Tortoise Said to Achilles.” Mind 104: 691-693.

Conee, Earl, and Richard Feldman. 2004. Evidentialism. New York: Oxford University Press.

DeRose, Keith. 2000. "Ought We to Follow Our Evidence?" Philosophy and Phenomenological Research 60: 697-706.

Dougherty, Trent. 2014. “The 'Ethics of Belief' is Ethics (Period): Reassigning Responsibilism.” In J. Matheson and R. Vitz (eds), The Ethics of Belief. New York: Oxford University Press, 146-166.

Feldman, Richard. 2000. "The Ethics of Belief." Philosophy and Phenomenological Research 60: 667-695.

Feldman, Richard. 2003. Epistemology. Upper Saddle River, NJ: Prentice Hall.

Feldman, Richard. 2008. "Modest Deontologism in Epistemology." Synthese 161: 339-355.

Fumerton, Richard. 1995. Metaepistemology and Skepticism. Lanham, MD: Rowman \& Littlefield.

Huemer, Michael. 2016. "Inferential Appearances.” In B. Coppenger and M. Bergmann (eds), Intellectual Assurance: Essays on Traditional Epistemic Internalism, New York: Oxford University Press, 144-160.

McCain, Kevin. 2012. "The Interventionist Account of Causation and the Basing Relation.” Philosophical Studies 159: 357-382.

McCain, Kevin. 2014. Evidentialism and Epistemic Justification. New York: Routledge.

McCain, Kevin. 2015. "Explanationism: Defended on All Sides.” Logos \& Episteme 6: 333-349.

McCain, Kevin. 2016. The Nature of Scientific Knowledge: An Explanatory Approach. Cham: Springer.

McCain, Kevin. 2017. “Undaunted Explanationism.” Logos \& Episteme 8: 117-127.

McCain, Kevin. 2018. “Explanationist Evidentialism: A Defense.” In K. McCain (ed.), Believing in Accordance with the Evidence: New Essays on Evidentialism. Cham: Springer, 375-391.

Miracchi, Lisa. Forthcoming. "When Evidence Isn’t Enough: Suspension, Evidentialism, and Knowledge-First Virtue Epistemology.” Episteme.

Nelson, Mark. 2010. "We Have No Positive Epistemic Duties.” Mind 119: 83-102.

Shah, Nishi. 2003. "How Truth Governs Belief." Philosophical Review 112: 447-482.

Smithies, Declan. 2019. The Epistemic Role of Consciousness. New York: Oxford University Press.

Stapleford, Scott. 2012. "Epistemic Duties and Failure to Understand One's Evidence." Principia 16: 147-177.

Stapleford, Scott. 2013. "Imperfect Epistemic Duties and the Justificational Fecundity of Evidence." Synthese 190: 4065-4075.

Stapleford, Scott. 2014. "Completing Epistemic Oughts." Philosophical Forum 45: 133-148. 


\section{Scott Stapleford and Kevin McCain}

Stapleford, Scott. 2015a. "Why There May Be Epistemic Duties.” Dialogue 54: 63-89. Stapleford, Scott. 2015b. "Epistemic Versus All Things Considered Requirements." Synthese 192: 1861-1881.

Wedgwood, Ralph. 2002. "The Aim of Belief." Philosophical Perspectives 36: 267-297.

Williamson, Timothy. 2000. Knowledge and its Limits. New York: Oxford University Press. 


\title{
8 Epistemic Duty and Implicit Bias
}

\author{
Lindsay Rettler and Bradley Rettler
}

\section{Introduction}

Here's a riddle: A father and son are on their way to the zoo when they get into a car crash. They are rushed to the hospital and taken to separate operating rooms. A surgeon rushes into the boy's room, but upon looking at him, says, "I can't operate on this boy; he's my son!" How is this possible?!

Here's another: A mother and son are on their way to the zoo when they get into a car crash. They are rushed to the hospital and taken to separate operating rooms. A surgeon rushes into the boy's room, but upon looking at him, says, "I can't operate on this boy; he's my son!" How is this possible?!

The answer to both riddles is that the surgeon is the boy's other parent. The first of these is very common. We have never heard the second, despite the fact that it differs from the first in only one word - 'mother' instead of 'father'. Why is this? Presumably it's that people who tell riddles think that, in the second riddle, we would come up with the idea that the surgeon is the boy's father. Apparently it's much more difficult to think of a mother being a surgeon. But when asked, "Can a mother be a surgeon?", far more people would say "yes" than correctly answer the first riddle.

People's difficulty answering the riddle illustrates implicit bias. People explicitly say that mothers can be surgeons, and yet when all that it takes to answer a riddle is to consider the possibility that a mother is a surgeon, people have trouble doing so. This may be an example of gender bias-people don't think of women being surgeons. Or it may that people have no intellectual problems with women becoming surgeons as long as those women don't have children. Of course, there are many kinds of implicit biases: race, gender, ethnicity, accent, ideology, size, age, and so on. ${ }^{1}$

Implicit biases are incredibly common. In fact, according to the Kirwan Institute for the Study of Race and Ethnicity, "Everyone possesses [implicit biases], even people with avowed commitments to impartiality such as judges."

In this chapter, we argue that people have an epistemic duty to eradicate at least some of the implicit biases we have. ${ }^{3}$ We begin, in $\$ 2$, by giving a few examples of implicit bias and noting a few important features. In $\$ 3$, we clarify the notion of epistemic duty with which we're concerned. In $\mathbb{\$}$, we offer the 
main argument: implicit biases prevent us from fulfilling our other epistemic duties, we ought to eradicate mental states that prevent us from fulfilling our other epistemic duties, so we ought to eradicate implicit biases. We conclude in $\$ 5$ by responding to what we take to be the strongest objection: we only have duties to do things that are under our control, and our implicit biases aren't under our control, so we can't have duties to eradicate them. In our view, we have indirect reflective control over our implicit biases.

\section{Implicit Bias}

Let's start with two examples of implicit bias.

\section{Ted}

At the age of 22, Will applied for a job working as a bank teller after finishing his bachelor's degree in Business Administration. He was eventually called in for an interview with the VP, Ted, which went very well, and Will was offered the job. He eagerly accepted. His career goal was to work his way up to a branch management position. He learned quickly, was proactive in taking on more responsibilities and attending training seminars, always came in on time and never missed work, and was overall an excellent employee. Every time a promotion came available, Will applied for the job. But promotions were slow in coming. Will was often passed over for jobs in favor of people who seemed less qualified. When asked why, Ted couldn't point to any particular feature of Will's resume or interview that threw up red flags, but Ted mentioned in passing that Will just didn't quite fit the profile of the role for which he was applying. But Ted was appalled at the suggestion that it had anything to do with the fact that Will is black. ${ }^{4}$

\section{Gina}

Gina is a recently tenured philosophy professor at a state school. Much of the teaching that she does is for a required Introduction to Ethics course. Rather than lecture, Gina likes to run the course as a kind of guided discussion, regularly throwing out provocative questions for the students to answer out loud. She has become frustrated that the women in the class tend to answer these questions with "feelings" language. She often reminds the women after they speak that, in philosophy, reasons trump emotions. Once a year, her teaching is evaluated by a peer and the department head. This year, in his evaluation, her peer writes that she mildly chastised a woman for starting a response with "I feel that ..." but didn't do so for a man who started his answer in the same way just a few minutes before. This surprised Gina, and so in the next few classes she specifically paid attention to how everyone started their responses. She realized that, contrary to her impression, the men in the class used feelings language just as much as the women. ${ }^{5}$ 
Ted doesn't explicitly believe that black people shouldn't be branch managers. Gina doesn't explicitly believe that women are more likely than men to use emotive language when discussing philosophical arguments. And yet both believe and act in ways that betray biases towards certain groups. These are implicit biases. There are a number of ways to carve out the difference between implicit and explicit biases. Perhaps implicit biases are the result of automatic processing, whereas explicit biases are the result of controlled processing. Perhaps implicit biases are unconscious, whereas explicit biases are conscious. We won't take a stand on the correct analysis of implicit biases, or whether there is a unified analysis. ${ }^{6}$ But we do conceive of an implicit bias as a mental state or process, rather than an output, such as a biased decision or action. ${ }^{7}$ And one important question that we'll return to later in $\$ 4$ is whether implicit biases are propositional attitudes or not.

If implicit biases are propositional attitudes, then the correct locution is "S's implicit bias that $p . "$ " And the propositions involved can be true or false, so implicit biases can be described as being true or false. It still would remain a question whether implicit biases are sui generis propositional attitudes or whether they can be subsumed under another propositional attitude, like belief.

But implicit biases as propositional attitudes is the minority view. The predominant view in both psychology and philosophy is that implicit biases are something like associations, presumably between concepts. ${ }^{9}$ For example, according to Jules Holroyd (2012, 275), "An individual harbors an implicit bias against some stigmatized group $(G)$, when she has automatic cognitive or affective associations between (her concept of) $G$ and some negative property $(\mathrm{P})$ or stereotypic trait $(\mathrm{T}) \ldots$..." On this view, the correct locution is " $S$ 's implicit association between Fs and Gs". So, the propositional view has it that the implicit racial bias against Will is of the form, "S's implicit bias that black people aren't professional," whereas the associative view puts it, "S's implicit association between black people and unprofessionalism." Associations between concepts or predicates aren't truth-apt, so on this view implicit biases can't be true or false. In fact, it's difficult to see how associations like this can be evaluated.

What's important for our purposes is whether we have an epistemic duty to eradicate implicit bias, and relatedly, whether we have the right kind of control over implicit bias. The argument we offer is compatible with multiple conceptions of implicit bias, but partly depends on whether implicit biases are propositional. We now turn our attention to epistemic duties.

\section{Epistemic Duties}

There are three important clarifications of the duty we're arguing for. First, the duty is epistemic, as opposed to moral, or social, or pragmatic, etc. ${ }^{10}$ Second, the duty is robust, as opposed to weak or attenuated in some sense. And third, the duty pertains to eradicating certain kinds of implicit bias, as opposed to not having such biases in the first place.

We likely have many duties regarding implicit bias. For example, perhaps we have a moral duty to not act on an implicit bias if doing so would harm 
another person. Maybe we have a social duty to call other people out on their implicit biases when we notice them. Perhaps we have a professional duty to proactively figure out if we have implicit biases, the having of which would compromise our ability to do our jobs well. These are not the duties we are interested in in this chapter. The duty we're interested in here is epistemic in nature. Epistemic duties are duties that we have with respect to the epistemic realm-belief, evidence, knowledge, etc. But that's not enough to adequately distinguish them, because we might have other kinds of duties with respect to the epistemic realm, like moral duties. We might be morally obligated to, say, have certain beliefs or acquire certain evidence.

While we don't have a definitive way to carve out what makes a duty epistemic, consider some paradigm examples of general epistemic duties that have been put forward. First, Chisholm (1989) suggests that we have a duty to believe that $p$ if and only if $p$ is true. ${ }^{11}$ That is, we ought to believe that $p$ if and only if $p$ is true. Chisholm thinks that it's plausible that this follows from our nature as intellectual beings. It is part of being a believer that we have this duty. But he also thinks that it is merely a prima facie duty, and often (and perhaps easily) overridden by other duties. One might have an epistemic duty to $\phi$ but a moral duty not to $\phi$, and all things considered one ought not to $\phi$. Another suggestion is that we have the following epistemic duty: for every proposition of which I am not certain, I ought to look for more evidence regarding its truth. ${ }^{12}$ Perhaps we have an epistemic duty to maximize true beliefs and minimize false ones. ${ }^{13}$ Perhaps we have an epistemic duty to maximize justified beliefs. Perhaps we have an epistemic duty to maximize knowledge. Perhaps we have an epistemic duty to proportion our beliefs to our evidence. ${ }^{14}$ Perhaps we have a duty to cultivate certain epistemic dispositions, like the disposition to believe a proposition when we know our evidence supports it, or as Sharon Ryan argues in this volume, the disposition to be open-minded. Perhaps there are many epistemic goals and many epistemic duties. ${ }^{15}$ Perhaps we even have epistemic duties to act in certain ways-maybe we have an epistemic duty to gather evidence.

All these are examples of paradigm epistemic duties, as opposed to duties that are moral or social or pragmatic, etc. ${ }^{16}$ One way to think about what unites these examples is that they are duties we have qua believers or knowers, etc. ${ }^{17}$ But one could be forgiven for thinking this is circular, and so not an illuminating analysis of what makes a duty epistemic. Hopefully we have said enough to distinguish epistemic duties from other duties. Whatever our epistemic duties are, implicit biases get in the way of fulfilling those duties. So, our duty to eradicate them is connected with our other epistemic duties. (This argument is the topic of the next section.)

Our second clarification is that the epistemic duty to eradicate implicit bias is what we'll call a robust obligation. Robust obligations are such that their violation makes one blameworthy. If we fail to eradicate implicit bias, then we can be legitimately blamed for this failure, as long as there are no exonerating or excusing conditions in place. The idea is that we are responsible for eradicating implicit biases. 
This contrasts with a view according to which violation of the epistemic duty makes the agent in question worthy of, at most, criticism or negative evaluation. On this sort of view our epistemic duty to eradicate implicit bias is what we might call a weak obligation. ${ }^{18}$ In other words, it's merely a standard for evaluation. Accordingly, if we fail to eradicate implicit bias, then we can be criticized or judged to have failed the standard, but not blamed.

Moral duties are paradigm examples of robust obligations: if you violate the duty not to wantonly harm an innocent person, then you can be legitimately blamed for this failure. While there are many different accounts of the nature of moral blame, it's fairly agreed upon that moral blame has "a characteristic depth, force, or sting" that goes beyond merely evaluative grading against a moral standard. ${ }^{19}$ This force can be explained in many ways, but we cast our lot with those who hold that to morally blame someone is to place a normative demand on her. ${ }^{20}$ Moral blame involves a demand for justification on the basis of moral standards we expect reasonable people to accept. ${ }^{21}$ The demand is that the agent acknowledge her moral failure given the moral reasons she had. As it is with moral blame, so also with epistemic blame, i.e. blame for violating epistemic duties: blaming someone for violating a robust epistemic duty involves demanding that the agent acknowledge her epistemic failure given the epistemic reasons she had. ${ }^{22}$

In this chapter, we do not offer arguments for the existence of robust epistemic duties. We assume that there are such duties, i.e. that at least some of what philosophers call "epistemic duties" are not merely standards of epistemic evaluation. Accordingly, the epistemic duty to eradicate implicit bias is not merely a standard of epistemic evaluation. It's a robust duty, such that failure to fulfill it merits blame.

It's important to note that we're not claiming that all epistemic duties are robust. Whether an epistemic duty is robust-i.e. whether an agent is blameworthy for failing to fulfill it-depends on whether the agent has the right kind of control. Weak duties, i.e. merely evaluative standards, do not require that an agent has control. Suppose Maya shows up for an open college basketball tryout and stands in the group wanting to play center. The coach looks everyone over, and her 5'4" height is noticeable. He says, "If you want to play center, you should be taller." He has evaluated her as falling short of the height norm for NCAA centers. This is a legitimate judgment, despite the fact that it is something over which she has no control. However, if Maya were to deserve blame for failing the NCAA height standard-i.e. if the standard was a robust duty-then she would have to have control over her height. Similarly, in order for agents to be subject to the epistemic duty to eradicate implicit bias, they must have control over whether they eradicate such bias.

Our third clarification relates to the specific epistemic duty we defend: that of eradicating implicit bias. The duty in question is to eradicate implicit biases we already have. It does not address the question of whether we should have acquired them in the first place. It may well be the case (although we suspect it is not) that we have a duty, epistemic or otherwise, to not acquire implicit 
biases. But that's not what we're concerned with in this chapter. ${ }^{23}$ We now turn our attention to the argument.

\section{An Epistemic Duty to Eradicate Implicit Bias}

Our argument proceeds by first noting that implicit biases have a negative epistemic impact. For example, in TED, Ted has formed the belief that Will is unqualified for the job for which he is applying. Ted's implicit bias has caused him to form this false and unjustified belief about Will (and likely other black people). In GINA, Gina forms the belief that her women students are using "feelings language" more than her men students, which is false and unjustified.

Several philosophers have discussed what are sometimes referred to as the "epistemic costs" of implicit bias. Jennifer Saul (2013b) details quite a few. For example, "shooter bias" can negatively influence our perception (245-246). Implicit biases lead to inaccurate judgments about the best job candidate, which papers deserve to be published, and who is a credible witness $(246,248)$. And in philosophy they can lead to inaccurate philosophical beliefs, given that they influence which arguments we accept and reject (247). Implicit bias influences which testimony we accept and reject, as well, which Saul points out can thus influence our evidence base for various beliefs (247-249). Uwe Peters (2019) discusses the epistemic costs of what he calls "ideological bias"-associations between various ideologies and positive or negative properties-and argues that in combination with other relevant factors, ideological bias threatens "reliable belief formation and comprehensive knowledge acquisition" in the field of philosophy (395).

This suggests that implicit biases prevent us from fulfilling our other epistemic duties-things like believing what's true, believing what you're justified in believing, not believing what you're not justified in believing. They cause us to have false beliefs and unjustified attitudes, they block knowledge and understanding, they cause our credences to not match our evidence. And we ought to eradicate mental states that prevent us from fulfilling our other epistemic duties. So, since implicit biases prevent us from fulfilling our other epistemic duties, we ought to eradicate implicit biases.

Consider a parallel argument that establishes a moral duty to eradicate implicit biases. Implicit biases have a negative causal impact on our morality. We have moral duties regarding others' well-being, our relationships with people, and to cultivate virtues like justice, patience, empathy, kindness, and compassion. But having implicit biases causes agents to violate these moral duties. For example, Ted consistently passes Will over for jobs for which Will is better qualified than the people who get the jobs; that's unjust. Gina might well grade women in her class more harshly than she grades men, since she implicitly associates women with emotive language and men with rational language. The general argument is that (i) we ought to fulfill our moral duties, (ii) having implicit biases prevents us from fulfilling our moral duties, so (iii) we ought not to harbor implicit biases. The conclusion, that is, is that we (morally) ought to eradicate our implicit biases. 
The moral and epistemic arguments have the same structure. Both rely on the connection between implicit biases and other things-moral or epistemic duties. ${ }^{24}$ It is in virtue of this connection that we have a duty to eradicate our implicit biases. This way of arguing for the epistemic duty to eradicate implicit bias is, one might think, instrumental or relational or extrinsic: it's bad to have implicit biases because they cause other bad things. This certainly seems like a reasonable line of argument.

But there's another potential line of argument; it might also be true that implicit biases are epistemically bad in and of themselves, i.e. intrinsically. ${ }^{25}$ This may depend on whether implicit biases are propositional. If they are-e.g. if they turn out to be beliefs-then they can be evaluated as true or false, justified or unjustified. In that case, implicit biases are epistemically bad when they are false or unjustified, in addition to being epistemically bad when they cause other false attitudes.

If, on the other hand, implicit biases are non-propositional, then they can't be evaluated with respect to truth or justification. However, we might still evaluate them as epistemically bad pairings. In "On Being Good at Seeming Smart", Eric Schwitzgebel notes that some associations with the concept of intelligence seem "good," for example, poise, confidence, giving a moderate amount of detail but not too much, providing some frame and jargon, etc., but others are not: "whiteness, maleness, a certain physical bearing, a certain intellect." ${ }^{26}$ Other pairings that seem epistemically bad (even if not false), include associating black people with violence, women with timidity, children with insignificance, people of certain regions or religions with lack of intelligence. We can call these pairings "epistemically inapt.” Perhaps, as Daniel Kelly and Erica Roedder suggest, we can also evaluate implicit biases with respect to rationality depending on whether the association between concepts "accurately reflects a correlation or statistical regularity that holds among those referents of the concepts" $(2008,529)$.

So, at the very least we have a duty to eradicate implicit biases because of their negative epistemic impact. But perhaps we have an additional motivation for the duty, if implicit biases themselves are either false, irrational, or in some other way inapt. This parallels what we might say about why we ought not to have a false belief (if one thinks we have such a duty): because it's inaccurate-it fails to represent the world correctly—but also because it causes other epistemically bad attitudes.

But it seems that not all implicit biases have extrinsic negative epistemic impact as a matter of necessity. As Jennifer Saul (2013a) notes, "one might unconsciously associate groups with different flavors of ice cream without this having any negative effects" $(40$, n. 4$)$. Or the impact of the implicit bias might be what we could call "epistemically neutral." For example, implicit biases can sometimes cause agents to confabulate explanations of our decisions and actions, which might well be considered a negative epistemic impact. However, Ema Sullivan-Bissett (2014) argues such confabulatory explanations might sometimes be epistemically innocent. In these sorts of cases, the implicit bias does not have a negative, but rather, a neutral epistemic impact. Additionally, 


\section{Lindsay Rettler and Bradley Rettler}

an implicit bias might have positive epistemic impact. Consider an example from Uwe Peters: "the implicit ... negative evaluation and exclusion of some political view-points (e.g., extreme right-wing positions) and their advocates is arguably epistemically ... beneficial for philosophy" $(2019,395)$. Accordingly, we do not claim that agents have an epistemic duty to eradicate implicit biases that are apt and have no negative epistemic impact.

Some implicit biases are epistemically worse than others-namely those with greater negative epistemic impact. Therefore, the duty to eradicate these biases is stronger-i.e. more important-than the duty to eradicate other less epistemically problematic biases. Which biases are worse than others is relative to the agent in question, and depends on her other beliefs, what she attends to, her professional sphere, her personal sphere, etc. For example, as professional philosophers it is epistemically worse for us to hold a bias against women in philosophy than it is for a person working the front desk at a hotel, because we hold many more beliefs that are likely to interact with the bias against women in philosophy (e.g. an association pairing women with being less capable of rational argument). So an implicit bias against women in philosophy will lead to more epistemic error in a philosopher than in a person working the front desk at a hotel. Thus the professional philosopher has a stronger epistemic duty to eradicate implicit bias against women in philosophy, than the front desk clerk. ${ }^{27}$

We'll conclude this section by noting that it might be the case that people have an epistemic duty to eradicate at least some implicit biases that actually have no negative epistemic impact. Here's why. Most of us have the sense that we shouldn't be able to avoid fulfilling duties purely as a matter of luck. For example, we have a duty not to drive while drunk. If someone is driving drunk and is lucky enough to not encounter another person on their whole trip, we do not say that they aren't blameworthy for their actions. They still violated a duty; they just got lucky. If there had been a person, they may well have killed them. And in plenty of nearby possible worlds, they do just that.

Similarly, we shouldn't be able to avoid epistemic duties purely as a matter of luck. If someone has an implicit bias against black people but never meets a black person and so doesn't form false and unjustified beliefs about that person, we do not say that they aren't blameworthy for having that bias. They still violated an epistemic duty. If they were to meet a black person, they'd form false and unjustified beliefs about that person. And in plenty of nearby worlds, they do just that. So maybe an implicit bias having an actual negative epistemic impact isn't necessary for us to have a duty to eradicate it.

\section{Control over Implicit Bias}

We've argued that we have an epistemic duty to eradicate at least some implicit biases. But consider the following objection: if it turns out that we don't have control over them, then we can't be subject to a duty to eradicate them-even if it's true that having implicit biases has negative epistemic impact. A major part of defending the epistemic duty to eradicate implicit bias is to respond to 
this objection-to show that we have the right kind of control over implicit biases, such that we can fulfill this duty. Here's a formalization of what we'll call the Control Challenge:

\section{Control Challenge}

1. If agents have an epistemic duty to eradicate implicit bias, then they have control over whether they eradicate implicit bias.

2. It is not the case that agents have control over whether they eradicate implicit bias.

3. Therefore, agents do not have an epistemic duty to eradicate implicit bias.

We grant (1); we think that having a duty to do something requires that the agent have some kind of control over that thing. As we explained in $\mathbb{S} 4$, the kind of duty we're concerned with is such that failure to fulfill it can engender legitimate blame. The sort of control that satisfies the control condition for robust duty thus has at least two features: (a) it enables the agent to fulfill or not fulfill the duty, and (b) it enables the agent to respond to blame were she to fail the duty. ${ }^{28}$

That leaves us with the task of rejecting (2). (2) seems initially plausible because implicit biases seem like the kind of thing we don't have control over. As mentioned in $\$ 2$, if implicit biases are the result of automatic processing, then they occur regardless of whether the agent is attending to them. Moreover, on some understandings of implicit bias, people are not even aware that they have them. And if they're not aware that they have them, how could they control them? So Jennifer Saul (2013a) argues, "we should abandon the view that all biases against stigmatised groups are blameworthy ... [because a] person should not be blamed for an implicit bias that they are completely unaware of, which results solely from the fact that they live in a sexist culture" $(55$, emphasis in original). Lack of awareness suggests (though does not entail) a lack of control, which in turn rules out legitimate blame.

Given our lack of awareness of implicit biases, it seems that introspection doesn't help us correct for them. ${ }^{29}$ For example, reflecting on whether you have an implicit bias that associates women with emotionalism or a bias that associates black men with unprofessionalism will not necessarily reveal to you whether you have that bias. Additionally, it seems that implicit biases are not directly responsive to reflection..$^{30}$ Even if you come to realize that you have an implicit bias associating women with emotionalism and you explicitly believe that women are not emotional, your implicit bias does not automatically come into alignment with your explicit belief just by reflecting on the matter. ${ }^{31}$ This resistance to reflection makes implicit biases particularly insidious. Another reason why implicit biases seem out of our control is that they seem to reoccur despite intentional efforts to eradicate them. ${ }^{32}$

We grant all of these points. But we think that what these considerations show is that implicit biases are not under our direct control. Specifically, we 


\section{Lindsay Rettler and Bradley Rettler}

cannot form an intention regarding our implicit biases and then directly or immediately carry out that intention. ${ }^{33}$ However, these considerations do not show that implicit biases are not under our indirect control. And we don't think that direct control is necessary for being subject to the duty to eradicate implicit bias.

We have many moral obligations regarding things over which we lack direct control: the duty to keep our promises, to be a good friend, to take care of the environment, to refrain from wantonly harming others, and so forth. None of these duties can be fulfilled directly. ${ }^{34}$ Instead they are fulfilled indirectly by carrying out intentions to do other things. For example, for Duncan to carry out the intention to be a good friend, he must carry out intentions to spend time with his friends, to listen to them, to help them when they're in need, to say kind things to them. So, it seems that with respect to moral duties, while direct control is sufficient to satisfy the control condition for being subject to a duty, it is not necessary. Instead agents can be subject to a duty even if they only have indirect control over fulfilling it.

Now consider epistemic duties. If we are subject to robust duties regarding our beliefs-i.e. if failure to comply with various doxastic duties makes agents blameworthy-then we must have control over our beliefs. But as William Alston has famously argued, we lack direct control over our beliefs-we cannot believe that $p$ as the direct result of an intention to believe that $p \cdot{ }^{35}$ However, like moral duties, there is no reason to think that direct control is required for doxastic duties, so long as we have the right kind of indirect control over our beliefs.

Some have argued that we have a different kind of direct control over our beliefs that we might call reason-based, rather than intention-based. Instead of carrying out intentions regarding our beliefs, we control our beliefs by believing directly in response to various reasons and evidence. ${ }^{36}$ It might seem that we can appeal to this "reason-responsiveness" as a form of direct control that satisfies the control condition for epistemic duties regarding belief. However, reason-responsiveness is not the right sort of control to appeal to in order to help explain why we are blameworthy for failing to comply with epistemic duties, because the kind of control that grounds blame must be reflective. And reason-responsiveness is not reflective. ${ }^{37}$ (More on this below.)

In any case, appeal to reason-responsiveness seems even less plausible with respect to implicit biases, given that they are not responsive to reasons in the way that explicit beliefs are. ${ }^{38}$ As noted above, our implicit biases do not necessarily reflect our rational judgments, and in fact often conflict with them. If Gina were to consider her reasons for believing that women are more likely to use feelings language than men, and conclude on the strength of the evidence that this claim is false, such a conclusion would not necessarily overturn her implicit association of women with emotionalism.

However, though we lack direct intention-based control over our beliefs, and though reason-responsiveness does not satisfy the control condition for legitimate blame, one of us has argued elsewhere that we do have a form of indirect control over our beliefs that does satisfy the control condition: indirect 
reflective control. An agent has indirect reflective control over whether she believes that $p$ if and only if she can actively engage in critical reflection that causally influences whether or not she holds the belief that $p .{ }^{39}$ The reflection involved is critical because it is second-order reasoning involving conceptualization of reasons as such, and conceptualization of support relations between propositions and between our attitudes toward those propositions. This contrasts with what is sometimes called "merely first-order reasoning." And the reflection involved is active in that an agent forms and executes intentions to do the mental actions that compose reflection. Engaging in reflection makes a causal difference to whether we have various beliefs, thus giving us indirect influence-based control over those beliefs. For example, we can ask ourselves various questions and try to answer them: "what are my reasons for believing $p$ ?", "are these good reasons?", "is there any relevant evidence I haven't considered?”, and so forth. We can direct our attention to various reasons, try to remember relevant data, reconstruct arguments, etc. All of these mental actions are part of reflection, and doing them causally influences what we believe (Rettler 2018b, 2217). This kind of control is both necessary and sufficient to satisfy the control condition for legitimate blame. It enables an agent to respond to the demand inherent in blame, which is a demand to acknowledge one's failure. Without the capacity to actively engage in reflection that causally influences one's beliefs, an agent would not be able to understand or respond to blame (Rettler 2018b, 2216).

We think that this kind of control is something we also have over many of our implicit biases-indeed, over all the implicit biases we can be blamed for failing to eradicate. However, the relationship between reflection and implicit bias is not as tightly linked as the relationship between reflection and belief; our control over implicit bias is even more indirect than our control over belief. With respect to believing that $p$, reflecting on the evidence for $p$ influences whether we believe that $p$. But as we have seen, this is not necessarily the case with implicit bias: reflecting on whether women are more emotional than men will not necessarily overturn Gina's implicit bias associating women with emotionalism.

However, some empirical research indicates that reflection on arguments suitably related to the group that one is implicitly biased against can have an impact on whether one harbors the bias. Briñol et al. (2009) conducted a series of experiments designed to test the impact of argument evaluation on implicit biases (what they call "automatic evaluations"), and they found that reflection on strong arguments does indeed make a difference to implicit biases. ${ }^{40}$ In one particular experiment, differing participants were offered either strong or weak arguments in favor of integrating more African-American professors into a university. Additionally, some were given additional prompts to encourage more thoughtful reflection on the arguments. When tested for implicit bias against black people, those given stronger arguments measured as having less implicit bias than those given weaker arguments. Moreover, the difference between the strong and weak argument groups was even greater between the groups prompted to think more carefully about arguments. These findings 


\section{Lindsay Rettler and Bradley Rettler}

provide reason to think that reflection on strong arguments that cast the group one is biased against in a positive light make a difference to whether we have the biases. Thus, while Gina might not be able to eradicate her implicit bias by reflecting on reasons to not have it, it would help eradicate it if she were to reflect on (for example) strong arguments in favor of trying hard to recruit more women as philosophy majors.

Additionally, there seems to be evidence that implicit biases are causally related to various explicit beliefs and values. Insofar as reflection can causally influence these beliefs and values, reflection can causally influence whether we harbor implicit biases. Jules Holroyd argues that the manifestation of implicit bias is influenced by our explicit beliefs and values (2012, 288). For example, according to Holroyd's interpretation of Devine et al. (2002, 288), "Individuals who are highly committed to responding without prejudice, for its own sake (and not rather or also for reasons of social pressure or norms), manifest significantly less negative race bias across a range of texts for implicit biases." ${ }^{41}$ Though this research is concerned with control over whether we manifest our implicit biases, as opposed to control over whether we have implicit biases, the same idea applies to both having and manifesting bias. There are certain beliefs and values, the having of which influences whether we continue to have an implicit bias. Voluntarily engaging in reflection makes a difference to our beliefs about values, as well as to our values themselves. And insofar as engaging in reflection has this indirect influence on beliefs and values that are causally related to implicit bias, it has an indirect influence on implicit bias.

Consider an example of this influence. Jennifer Saul (2013a, 53) argues that "The view that traits are fixed makes one more prone to stereotype endorsement and to implicit bias. If intellectual ability is viewed as a more complicated set of abilities and skills, both of these problematic phenomena are reduced." ${ }^{42}$ Voluntarily engaging in reflection on the proposition that traits are fixed causally influences whether one believes this proposition, which in turn causally influences whether one has various implicit biases.

The above considerations involve reflection-on arguments, on the content of various beliefs, and on values. This reflection makes a difference to whether we harbor implicit bias. But empirical research also shows that there are various other actions we can take that make a difference to whether we harbor implicit bias-various techniques that have been proven to help individuals rid themselves of their implicit biases.

One such technique is interacting with other social groups; the more people spend time with members of groups other than their own, the less biased they appear to be..$^{43}$ Additionally, long-term exposure to individuals that counter stereotypes can help remove implicit bias. ${ }^{44}$ Another is "approach training." People are asked to push a button when they see a stereotype depicted on a television screen. After spending some time doing this, they measure as having less implicit bias than beforehand. ${ }^{45}$ Another technique is showing pictures of admired people in a group that the subject is biased against and disliked people in a group that the subject is biased towards. ${ }^{46}$ Yet another technique is to have 
light-skinned people interact in virtual reality as dark-skinned virtual bodies. ${ }^{47}$ Finally, diversity education lowers implicit bias. ${ }^{48}$

When discussing implicit bias against women in philosophy, Jennifer Saul identifies the existence of stereotypes as part of the cause of implicit biases, and she argues that anything done to break down those stereotypes helps "alleviate the problem" (2013a, 50). There are many ways to break down stereotypes. For example, Ted could hire Will, praise Will's work to others, make sure the photos in the bank and on its website feature black bankers, and things like that.

Empirical research shows that doing these sorts of things influences whether one harbors implicit bias. We might conclude as Holroyd (2012) does, that we have what she calls "long-range" control over many of our implicit biases (286-288). ${ }^{49}$ We have this long-range control over whether we eradicate implicit bias insofar as we can over time carry out intentions to do various things which then results in eradication of implicit bias.

But notice that long-range control is a form of intention-based control: an agent controls whether she does $X$ by carrying out an intention to $Y$, which then over time results in her doing $X$. For example: an agent controls whether she harbors implicit bias $B$, by carrying out an intention to engage in approach training which over time results in eradicating $B$. But, we argue, long-range control by itself is not sufficient to satisfy the control condition for robust duties. If one is subject to a robust duty, then one can be legitimately blamed for failing the duty. But such blame is only legitimate if one has the kind of control that enables one to both satisfy the duty and to understand and respond to blame in case one fails the duty. To be able to respond to blame, agents must be able to acknowledge their failure, which requires the capacity for reflection. Suppose Gina fails to eradicate her implicit bias against women. She can't be blamed for failing to do so on account of the fact that she could have engaged in approach training, unless she can also recognize as a reason to engage in approach training that it will help eradicate her implicit bias. Without the ability to grasp this connection between approach training and eradicating implicit bias, Gina can't be held responsible for failing to eradicate her implicit bias via approach training. And to make this connection, Gina must have the capacity for reflection. In other words, she must be capable of engaging in reflection on whether to do approach training as a method to eradicate her implicit bias. Note that she doesn't have to in fact engage in such reflection; she just has to be capable of doing so. If she is not, then she can't be blamed for her implicit bias given her failure to engage in approach training. And the same is true for any actions or activities that make a difference to whether she harbors implicit bias.

Note also that Gina doesn't need to be aware of approach training as a method for eradicating her implicit bias. To be held responsible for failing her duty to eradicate her bias, it's enough that she could become aware of the various methods that would enable her to satisfy her duty. There are a number of things that it's plausible that agents must be able to be aware of in order to be subject to the epistemic duty to eradicate implicit bias: for example, that one has an implicit bias or that it's likely or possible that one does, that one has 


\section{Lindsay Rettler and Bradley Rettler}

an epistemic duty to eradicate implicit bias, that implicit biases have negative epistemic impact, that there are various methods one can implement to help eradicate one's implicit bias, and so forth. To be able to become aware of these things, there must be evidence available to the agent, and she must be able to recognize and evaluate it. To the extent that an agent cannot become aware of these things-whether because the evidence out there is very difficult to acquire or because the agent has a hard time recognizing or evaluating it-the agent is not as blameworthy for failing to eradicate her implicit bias..$^{50}$

To summarize: there are two ways in which we have indirect reflective control over whether we harbor implicit biases. One is that we can actively engage in reflection on particular arguments, as well as various beliefs and values that we hold, and this reflection causally influences whether we harbor various implicit biases. The other is that we can actively engage in reflection on various techniques that help eradicate implicit biases, and this reflection makes a difference to whether we engage in these activities, which in turn makes a difference to whether we harbor various implicit biases. Again, it's not that agents have to actually reflect in these ways in order to be said to have indirect reflective control; but rather it's that agents are capable of such active reflection.

The control that we have over implicit bias is even more indirect than our control over our beliefs. The more indirect (or mediated) our control, the less blameworthy we are for our failures; we don't hold an individual as responsible for her implicit biases as we do her explicit ones. For example, the explicit belief that black men are more likely to commit crimes than white men, is something which we have indirect reflective control over and thus can be blamed for, given that our evidence does not support it. Voluntarily engaging in reflection on the evidence for this claim makes a difference to whether we believe it. But since reflection on the evidence for the claim doesn't necessarily make a difference to whether we harbor an implicit bias associating black men with crime, our reflective control over the bias is more indirect. It's mediated by reflecting on things not directly related to the content of the bias, such as other beliefs and values, and techniques for eradicating implicit bias. Given this mediation, it will often be the case that it's hard for agents to exercise control in these ways, and to the extent that they don't have indirect reflective control, they are not blameworthy for failing to eradicate their implicit biases. ${ }^{51} \mathrm{We}$ think this fits with our intuitions about blame for implicit bias: we are not as blameworthy for implicit bias as we are for explicit bias, because our control over implicit bias is more indirect than our control over explicit bias.

Ultimately, the question of whether we in fact have indirect reflective control over our implicit biases is an empirical one. But as we have noted, there is empirical data suggesting that, with respect to many of our implicit biases, we have what amounts to indirect reflective control over whether we harbor them.

\section{Conclusion}

Implicit bias is widespread. We have argued that we have an epistemic duty to eradicate implicit biases with negative epistemic impact. This is because 
implicit bias prevents us from fulfilling other epistemic duties, and it is perhaps also intrinsically bad. But we only have this duty, it seems, if we have the right kind of control over implicit biases. That control, we argued, is indirect reflective control. If it turns out that we have this kind of control over our implicit biases-and we've offered empirical evidence that we do-then we have a robust epistemic duty to eradicate them, and we are thus blameworthy if we fail to do so. ${ }^{52}$

\section{Notes}

1 One popular test to measure implicit bias is the Implicit Association Test: https:// implicit.harvard.edu/implicit/. Some concerns with the test can be found in Azar (2008).

2 See Kirwan Institute for Race and Ethnicity (2015). For more on the pervasiveness of implicit bias, see Jost et al. (2009).

3 This may or may not entail that people also have a duty to identify the implicit biases they have. We don't take a stand on that. People may think that they might have an implicit bias, and thereby take steps to eradicate it; or they might simply do things that help eradicate the bias without being aware that they have it.

4 This is a fictional story but very similar things happen all the time. See Bertrand and Mullainathan (2004).

5 This too is a fictional story. Schwitzgebel $(2010,532)$ offers a similar example of a racially biased American philosophy professor. See also Holroyd et al. (2017, 2).

6 The interested reader should see Holroyd and Sweetman (2016).

7 For more on this distinction, see Holroyd and Sweetman (2016, 81-82).

8 See De Houwer (2014). Some advocate for the view that implicit biases are beliefs of some kind, or are based on beliefs, and thus have propositional structure: Frankish (2016, 26-29); Mandelbaum (2016); Hughes et al. (2011), and Mitchell et al. (2009). Schwitzgebel (2013 argues that implicit biases are "in-between" beliefs. For criticism, see Levy (2015), who argues that implicit biases are "patchy endorsements," and see Madva (2016).

9 See, e.g., Fazio (2007), Gawronski and Bodenhausen (2011), Gendler (2008b, 577, 2008a, 641-642), Ashburn-Nardo (2001), Holroyd (2012), Rydell and McConnell (2006), Saul (2013b, 244).

10 For an argument that epistemic duties aren't just a special case of moral duties, see Haack (2001).

11 This occurs on p. 14. Roderick Firth $(1978,224)$ also discusses a duty to believe propositions if and only if they are true, but he does not ultimately endorse it.

12 See, e.g., Hall and Johnson (1998) and Corlett (2003, 68).

13 Truth seems to be a popular epistemic goal. See David (2001) and Hess (2010). For an argument against the view, see Kvanvig (2005).

14 See Stapleford (2012).

15 See DePaul (2001) and Kvanvig (2005).

16 Of course, for some duties, there is likely some overlap between the epistemic dimension of the duty and other dimensions. For example, Jennifer Lackey (n.d.) argues that the source of our duty to object to things that people say has both an epistemic dimension and a moral one.

17 See, e.g., Feldman (1988, 236): "The peculiarly epistemic judgment concerns not practical merits but rather the propriety of a disinterested believer in [the] situation.” 
18 Stapleford (2012) distinguishes "oughts" from "duties" and carves out what he calls a "deflationary sense of 'ought" " (pp. 150, and 172, n. 8). What we're referring to as a "weak duty" or "weak obligation" is what Stapleford refers to as a "deflationary ought."

19 See Hieronymi (2004, 116-117). See also Scanlon (1998, 269), Smith (2008, 369), and 2013, 29), Wallace (1994, 80-81), and Wolf (1990, 40-41, 64).

20 See Hieronymi (2004, 117); McKenna (1998); Strawson (1974, 6-7, 14-16), and Wallace $(1994,2007,2010$, and 2011).

21 See Smith $(2008,369)$.

22 See Rettler (2018b, 2208-2210) for more detailed discussion of the normative demand inherent in epistemic blame.

23 The reason we're not concerned with it is that we don't think we have the right kind of control over whether we acquire implicit biases. So, we don't want to defend this duty.

24 The argument could also be filled out in terms of moral and epistemic values. We could say that we ought to pursue things of moral/epistemic value, implicit biases prevent us from realizing things of moral/epistemic value, therefore we ought to eradicate our implicit biases. We encourage the reader to use whichever formulation is most persuasive.

25 See Kelly and Roedder (2008) for reasons why (in particular, racial) implicit bias is intrinsically morally bad.

26 See Schwitzgebel (2010) and a discussion in Saul (2013a, 53-54).

27 Note that this is not a question of a professional obligation. Which professional duties a person has are relative to a person's profession, and agents can have professional duties to believe certain things. For example, a surgeon has a professional duty to believe correctly about the best surgical procedures and devices. Similarly, philosophers have a professional duty not to discriminate against women in philosophy, which is a duty which professional chefs do not have. But we're not talking about professional duties here; we're talking about biases that are worse for a philosopher to have given their greater potential for negative epistemic impact.

28 There may well be attenuated forms of blame that do not require control, such as blaming the weather for ruining one's picnic, but again, that's not the kind of blame involved in violating the epistemic duty to eradicate implicit bias.

29 "Neither introspection nor honest self-report are reliable guides to the presence of such mental states, and one may harbor implicit biases that are diametrically opposed to one's explicitly stated and consciously avowed attitudes" (Kelly and Roedder 2008, 532). See also Holroyd (2012, 275). See Ballantyne $(2015,150)$ for helpful discussion of the relation between bias and introspection.

30 See Holroyd $(2012,275)$.

31 See Gregg et al. (2006), and Levy $(2016,20)$ for discussion.

32 See Huebner (2009), Follenfant and Ric (2010), Macrae et al. (1994), and Holroyd $(2012,283)$ for more discussion of this "rebound effect."

33 As Neil Levy (2016) puts it, we lack control that is "exercised in the service of an explicit intention (to make it the case that such and such)" (pp. 8-9, emphasis in the original).

34 For additional examples of things for which we hold agents responsible but over which we lack direct control, see Holroyd (2012, 284-285), Rettler (2018b, 22122213), and Smith (2005). Not all of their examples are examples of duties, but rather responsibility more generally. For example, Holroyd points out that we hold individuals responsible for cultivating various virtues though we only have 
indirect control over such cultivation. It's unclear whether we have a duty to cultivate virtue. But regardless, the same considerations regarding control apply: we are held responsible for failing to cultivate virtues even though we only have indirect control over doing so; we have a duty to cultivate virtues even though we only have indirect control over doing so.

35 Alston (1988,263-277), and see Rettler (2018b, 2212) for discussion of the argument.

36 For various versions of this kind of view, see Ryan (2003) and Steup (2008, 2011, 2012 ), both of whom refer to their views as "doxastic compatibilism." See also Hieronymi (2006 and 2008, 362-3); Shah (2002, 443); Smith (2000, 40-46, and 2005, 236-271); and Weatherson (2008, 546).

37 Or at least, that's what one of us has argued and the other believes on the strength of that argument. See Rettler (2018b, 2213-2217).

38 Even those who hold the view that implicit biases are beliefs do not advocate that they are as responsive to reasons as explicit beliefs. They are at best, minimally responsive. See Mandelbaum (2016, 645); and Kelly and Roedder (2008, 528529); and Holroyd (2012, 295).

39 See Rettler (2018b, 2217, and 2018a, 103).

40 See pp. 291-297. See also Mandelbaum (2016, 640-641) for discussion.

41 See also Levy $(2016,20)$ for discussion.

42 Saul even explicitly encourages philosophers to reflect on this point "because it seems to me that philosophers are very prone to claims about 'who's smart' and 'who's stupid" " (p. 53). Such encouragement supports the view that reflection is something we can actively engage in, and that such reflection can make a difference to whether agents harbor implicit bias against women and against women in philosophy.

43 See, e.g., Amir (1969), Cook (1985), Brewer and Miller (1988).

44 See Dasgupta (2013), and Levy $(2016,6)$ for discussion.

45 See, e.g., Kawakami et al. (2007), Phills et al. (2011a, 2011b), and Madva (2017).

46 As in Dasgupta (2001).

47 See Peck et al. (2013).

48 See Rudman et al. (2001).

49 Though Holroyd thinks the evidence more strongly supports the idea that we have long-range control over manifestation of implicit biases, rather the having of such biases. See also, Alston $(1988,274-277)$ for a discussion of what he calls "indirect long-range voluntary control" over our beliefs.

50 Alternatively, one might hold that if an agent is incapable of the requisite awareness, she is to that extent not subject to the duty.

51 There are two ways to understand the impact of an agent's lack of control over $X$ on the agent's duty with respect to $X$ : lack of control might entail that the agent is therefore not subject to a robust duty regarding $X$, or it might entail that, though she is subject to the duty, she is not blameworthy for failing to fulfill it.

52 Thanks to Andrew M Bailey, Franz-Peter Griesmaier, and Kevin McCain for helpful comments and discussion.

\section{References}

Alston, William P. 1988. “The Deontological Conception of Justification.” Philosophical Perspectives 2: 257-299.

Amir, Yehuda. 1969. "Contact Hypothesis in Ethnic Relations.” Psychological Bulletin 71: 319-342. 
Ashburn-Nardo, Leslie, Monteith, Margo, and Voils, Corrine. 2001. "Implicit Associations as the Seeds of Intergroup Bias: How Easily Do They Take Root?" Journal of Personality and Social Psychology 81: 789-799.

Azar, Beth. 2008. "IAT: Fad or Fabulous?" Monitor on Psychology 39: www.apa.org/ monitor/2008/07-08/psychometric.

Ballantyne, Nathan. 2015. "Debunking Biased Thinkers (Including Ourselves).” Journal of the American Philosophical Association 1: 141-162.

Bertrand, Marianne, and Mullainathan, Sendhil. 2004. "Are Emily and Greg More Employable than Lakisha and Jamal? A Field Experiment on Labor Market Discrimination.” American Economic Review 94: 991-1013.

Brewer, Marilynn B., and Miller, Norman. 1988. "Contact and Cooperation: When Do They Work?" In P. A. Katz and D. A. Taylor (eds), Perspectives in Social Psychology. Eliminating Racism: Profiles in Controversy. New York: Plenum Press, 315-326.

Briñol, Pablo, Petty, Richard E., and McCaslin, Michael J. 2009. "Changing Attitudes on Implicit Versus Explicit Measures: What is the Difference?" In Richard E. Petty, Russell H. Fazio and Pablo Brinol (eds), Attitudes: Insights from the New Implicit Measures. Hove, East Sussex: Psychology Press, 285-326.

Chisholm, Roderick. 1989. Theory of Knowledge. Englewood Cliffs, NJ: Prentice-Hall, 3rd edition.

Cook, Stuart W. 1985. "Experimenting on Social Issues: The Case of School Desegregation." American Psychologist 40: 452-460.

Corlett, J. Angelo. 2003. Race, Racism, and Reparations. Ithaca, NY: Cornell University Press.

Dasgupta, Nilanjana. 2013. "Implicit Attitudes and Beliefs Adapt to Situations: A Decade of Research on the Malleability of Implicit Prejudice, Stereotypes, and the Self-Concept." Advances in Experimental Social Psychology 47: 233-279.

Dasgupta, Nilanjana, and Greenwald, Anthony G. 2001. "On the Malleability of Automatic Attitudes: Combating Automatic Prejudice with Images of Admired and Disliked Individuals." Journal of Personality and Social Psychology 81: 800-814.

David, Marian. 2001. "Truth as the Epistemic Goal.” In Knowledge, Truth, and Duty. New York: Oxford University Press, 151-169.

De Houwer, Jan. 2014. “A Propositional Model of Implicit Evaluation.” Social and Personality Psychology Compass 8: 342-353.

DePaul, Michael. 2001. "Value Monism in Epistemology." In Matthias Steup (ed.), Knowledge, Truth, and Duty: Essays on Epistemic Justification, Responsibility, and Virtue. Oxford: Oxford University Press, 170-186.

Devine, Patricia G., Plant, E. Ashby, Amodio, David M., Harmon-Jones, Eddie, and Vance, Stephanie L. 2002. "The Regulation of Explicit and Implicit Race Bias: The Role of Motivations to Respond without Prejudice." Journal of Personality and Social Psychology 82: 835-848.

Fazio, Russell H. 2007. "Attitudes as Object-Evaluation Associations of Varying Strength.” Social Cognition 25: 603-637.

Feldman, Richard. 1988. "Epistemic Obligations.” Philosophical Perspectives 2: 235-256.

Firth, Roderick. 1978. "Are Epistemic Concepts Reducible to Ethical Concepts?" In Alvin Goldman and Jaegwon Kim (eds), Values and Morals: Essays in Honor of William Frankena, Charles Stevenson, and Richard Brandt. Dordrecht: Kluwer, 215-229. 
Follenfant, Alice, and Ric, Francois. 2010. "Behavioral Rebound Following Stereotype Suppression.” European Journal of Social Psychology 40: 774-782.

Frankish, Keith. 2016. "Playing Double: Implicit Bias, Dual Levels, and Self-Control." In Michael Brownstein and Jennifer Saul (eds), Implicit Bias and Philosophy, vol. 1. Metaphysics and Epistemology. Oxford: Oxford University Press, 23-46.

Gawronski, Bertram, and Bodenhausen, Galen V. 2011. "The Associative-Propositional Evaluation Model: Theory, Evidence, and Open Questions." Advances in Experimental Social Psychology 44: 59-127.

Gendler, Tamar Szabó. 2008a. "Alief and Belief." Journal of Philosophy 105: 634-663.

Gendler, Tamar Szabó. 2008b. "Alief in Action (and Reaction)." Mind and Language 23: 552-585.

Gregg, Aiden P., Seibt, Beate, and Banaji, Mahzarin R. 2006. "Easier Done than Undone: Asymmetry in the Malleability of Implicit Preferences." Journal of Personality and Social Psychology 90: 1-20.

Haack, Susan. 2001. “'The Ethics of Belief' Reconsidered.” In Matthias Steup (ed.), Knowledge, Truth, and Duty: Essays on Epistemic Justification, Responsibility, and Virtue. Oxford: Oxford University Press, 21-33.

Hall, Richard J., and Johnson, Charles R. 1998. "The Epistemic Duty to Seek More Evidence.” American Philosophical Quarterly 35: 129-139.

Hess, Markus Patrick. 2010. Is Truth the Primary Epistemic Goal? Berlin: Ontos.

Hieronymi, Pamela. 2004. "The Force and Fairness of Blame." Philosophical Perspectives 18: 115-148.

Hieronymi, Pamela. 2006. “Controlling Attitudes.” Pacific Philosophical Quarterly 87: 45-76.

Hieronymi, Pamela. 2008. "Responsibility for Believing.” Synthese 161: 357-373.

Holroyd, Jules. 2012. "Responsibility for Implicit Bias." Journal of Social Philosophy 43: 274-306.

Holroyd, Jules, and Sweetman, Joseph. 2016. "The Heterogeneity of Implicit Bias." In Michael Brownstein and Jennifer Saul (eds), Implicit Bias and Philosophy, vol. 1. Metaphysics and Epistemology. New York: Oxford University Press, 80-103.

Holroyd, Jules, Scaife, Robin, and Stafford, Tom. 2017. "What is Implicit Bias?" Philosophy Compass 12 (online resource).

Huebner, Bryce. 2009. “Trouble with Stereotypes for Spinozan Minds.” Philosophy of the Social Sciences 39: 63-92.

Hughes, Sean, Barnes-Holmes, Dermot, and Houwer, Jan De. 2011. “The Dominance of Associative Theorizing in Implicit Attitude Research: Propositional and Behavioral Alternatives." The Psychological Record 61: 465-496.

Jost, John T., Rudman, Laurie A., Blair, Irene V., Carney, Dana R., Dasgupta, Nilanjana, Glaser, Jack, and Hardin, Curtis D. 2009. "The Existence of Implicit Bias is Beyond Reasonable Doubt: A Refutation of Ideological and Methodological Objections and Executive Summary of Ten Studies that No Manager Should Ignore." Research in Organizational Behavior 29: 39-69.

Kawakami, Kerry, Phills, Curtis E., Steele, Jennifer R., and Dovidio, John F. 2007. “(Close) Distance Makes the Heart Grow Fonder: Improving Implicit Racial Attitudes and Interracial Interactions through Approach Behaviors." Journal of Personality and Social Psychology 92: 957-971.

Kelly, Daniel, and Roedder, Erica. 2008. "Racial Cognition and the Ethics of Implicit Bias.” Philosophy Compass 3: 522-540. 
Kirwan Institute for Race and Ethnicity. 2015. http://kirwaninstitute.osu.edu/research/ understanding-implicit-bias/.

Kvanvig, Jonathan L. 2005. "Truth and the Epistemic Goal." In Matthias Steup and Ernest Sosa (eds), Contemporary Debates in Epistemology. Malden, MA: Blackwell, 285-95.

Lackey, Jennifer. Forthcoming. “The Duty to Object.” Philosophy and Phenomenological Research.

Levy, Neil. 2015. "Neither Fish Nor Fowl: Implicit Attitudes as Patchy Endorsements.” Nô̂s 49: 800-823.

Levy, Neil. 2016. "Implicit Bias and Moral Responsibility: Probing the Data." Philosophy and Phenomenological Research 93: 3-26.

Macrae, C. Neil, Bodenhausen, Galen V., Milne, Alan B., and Jetten, Jolanda. 1994. "Out of Mind But Back in Sight: Stereotypes on the Rebound." Journal of Personality and Social Psychology 67: 808-817.

Madva, Alex. 2016. "Why Implicit Attitudes Are (Probably) Not Beliefs." Synthese 193: 2659-2684.

Madva, Alex. 2017. "Biased Against Debiasing: On the Role of (Institutionally Sponsored) Self-Transformation in the Struggle Against Prejudice." Ergo 4: 145-179.

Mandelbaum, Eric. 2016. "Attitude, Inference, Association: On the Propositional Structure of Implicit Bias.” Nô̂s 50: 629-658.

McKenna, Michael. 1998. "The Limits of Evil and the Role of Moral Address: A Defense of Strawsonian Compatibilism.” Journal of Ethics 2: 123-142.

Mitchell, Chris J., Houwer, Jan De, and Lovibond, Peter F. 2009. “The Propositional Nature of Human Associative Learning." Behavioral and Brain Sciences 32: 183-198.

Peck, Tabitha C., Seinfeld, Sofia, Aglioti, Salvatore M., and Slater, Mel. 2013. "Putting Yourself in the Skin of a Black Avatar Reduces Implicit Racial Bias." Consciousness and Cognition 22: 779-787.

Peters, Uwe. 2019. "Implicit Bias, Ideological Bias, and Epistemic Risks in Philosophy." Mind and Language 34: 393-419.

Phills, Curtis E., Kawakami, Kerry, Tabi, Emmanuel, Nadolny, Daniel, and Inzlicht, Michael. 2011a. "Mind the Gap: Increasing Associations between the Self and Blacks with Approach Behaviors." Journal of Personality and Social Psychology 100: 197-210.

Phills, Curtis E., Santelli, Alexander G., Kawakami, Kerry, Struthers, C. Ward, and Higgins, E. Tory. 2011b. "Reducing Implicit Prejudice: Matching Approach/ Avoidance Strategies to Contextual Valence and Regulatory Focus." Journal of Experimental Social Psychology 47: 968-973.

Rettler, Lindsay. 2018a. "Faith, Belief, and Control." American Philosophical Quarterly 55: 95-109.

Rettler, Lindsay. 2018b. "In Defense of Doxastic Blame." Synthese 195: 2205-2226.

Rudman, Laurie A., Ashmore, Richard D., and Gary, Melvin L. 2001. "'Unlearning' Automatic Biases: The Malleability of Implicit Prejudice and Stereotypes.” Journal of Personality and Social Psychology 81: 856-868.

Ryan, Sharon. 2003. "Doxastic Compatibilism and the Ethics of Belief." Philosophical Studies 114: 47-79.

Rydell, Robert J., and McConnell, Allen R. 2006. "Understanding Implicit and Explicit Attitude Change: A Systems of Reasoning Analysis.” Journal of Personality and Social Psychology 91: 995-1008.

Saul, Jennifer. 2013a. "Implicit Bias, Stereotype Threat, and Women in Philosophy." In Fiona Jenkins and Katrina Hutchison (eds), Women in Philosophy: What Needs to Change? Oxford: Oxford University Press, 39-60. 
Saul, Jennifer. 2013b. "Scepticism and Implicit Bias.” Disputatio 5: 243-263.

Scanlon, T. M. 1998. What We Owe to Each Other. Cambridge, MA: Harvard University Press.

Schwitzgebel, Eric. 2010. “On Being Good at Seeming Smart.” http://schwitzsplinters. blogspot.com/2010/03/on-being-good-at-seeming-smart.html.

Schwitzgebel, Eric. 2013. "A Dispositional Approach to Attitudes: Thinking Outside of the Belief Box.” In Nikolaj Nottelmann (ed.), New Essays on Belief. New York: Palgrave-Macmillan, 75-99.

Shah, Nishi. 2002. "Clearing Space for Doxastic Voluntarism.” The Monist 85: 436-445. Smith, Angela M. 2000. "Identification and Responsibility." In Ton Van Den Beld (ed.), Moral Responsibility and Ontology. Dordrecht: Kluwer Academic Publishers, 233-246.

Smith, Angela M. 2005. "Responsibility for Attitudes: Activity and Passivity in Mental Life." Ethics 115: 236-271.

Smith, Angela M. 2008. “Control, Responsibility, and Moral Assessment.” Philosophical Studies 138: 367-392.

Smith, Angela M. 2013. "Moral Blame and Moral Protest.” In D.Justin Coates and Neal A. Tognazzini (eds), Blame: Its Nature and Norms. Oxford: Oxford University Press, 27-48.

Stapleford, Scott. 2012. "Epistemic Duties and Failure to Understand One's Evidence." Principia 16: 147-177.

Steup, Matthias. 2008. “Doxastic Freedom.” Synthese 161: 375-392.

Steup, Matthias. 2011. "Belief, Voluntariness, and Intentionality." dialectica 65: 537-559.

Steup, Matthias. 2012. "Belief, Control, and Intentionality." Synthese 188: 145-163.

Strawson, P. F. 1974. Freedom and Resentment and Other Essays. London: Methuen.

Sullivan-Bissett, Ema. 2014. "Implicit Bias, Confabulation, and Epistemic Innocence." Consciousness and Cognition, 33: 548-560.

Wallace, R. Jay. 1994. Responsibility and the Moral Sentiments . Cambridge, MA: Harvard University Press.

Wallace, R. Jay. 2007. "Reasons, Relations, and Commands: Reflections on Darwall.” Ethics 118: 24-36.

Wallace, R. Jay. 2010. "Hypocrisy, Moral Address, and the Equal Standing of Persons." Philosophy and Public Affairs 38: 307-341.

Wallace, R. Jay. 2011. "Dispassionate Oppobrium: On Blame and the Reactive Sentiments." In R.J. Wallace, R. Kamar and S. Freeman (eds), Reasons and Recognition: Essays on the Philosophy of T. M. Scanlon. Oxford: Oxford University Press, 348-372.

Weatherson, Brian. 2008. “Deontology and Descartes' Demon.” Journal of Philosophy 105: 540-569.

Wolf, Susan. 1990. Freedom Within Reason. Oxford: Oxford University Press. 


\title{
9 Robust Justification
}

\author{
Jonathan Matheson
}

According to evidentialism, a subject is justified in believing a proposition at a time, just in case their evidence on balance supports that proposition at that time. Evidentialist justification is thus a property of fit-fitting the subject's evidence. However, evidentialism does not evaluate the subject's evidence beyond this relation of fit. For instance, evidentialism ignores whether the subject was responsible or negligent in their inquiry. A number of objections have been raised to evidentialism involving cases of irresponsible inquiry and the relevance of unpossessed evidence. In this chapter, I argue that, while these objections miss their mark, they do help motivate a distinct, and richer, concept of epistemic justification. This different concept of justification, what I call "robust justification," supplements the evidentialist account of epistemic justification with an assessment of the subject's evidence with respect to their inquiry. According to this proposal, to be robustly justified in believing a proposition at a time, the subject's evidence must support that proposition at that time and that evidence must be the result of the subject's responsible inquiry. While robust justification is not necessary for knowledge, I argue that it is an independently valuable epistemic state.

\section{Evidentialism}

Evidentialism is a theory of epistemic justification. Evidentialists endorse the following principle (Conee and Feldman 2004a, 101):

\section{ES}

The epistemic justification of anyone's doxastic attitude toward any proposition at any time strongly supervenes on the evidence that person has at that time.

So understood, evidentialism is a supervenience thesis. ${ }^{1}$ No two subjects who are alike evidentially differ in terms of their epistemic justification. Evidentially alike subjects are also justificationally alike subjects. For the evidentialist, epistemic justification is entirely a matter of one's evidence and what that evidence 
supports. In particular, justification is a matter of fitting the evidence. Thus, evidentialists also endorse the following (Conee and Feldman 2004b, 83):

\section{EJ}

Doxastic attitude $D$ toward proposition $p$ is epistemically justified for $S$ at $t$ if and only if having $D$ toward $p$ fits the evidence $S$ has at $t$.

What EJ makes clear is that epistemic justification is a property of fit-fit between one's evidence (at a time) and a doxastic attitude toward a proposition. For the evidentialist, epistemic justification just is this property of evidential fittingness.

Evidentialism is really a family of views, and so evidentialists can disagree as to what counts as evidence (e.g. experiences, propositions), what the relevant doxastic attitudes are (e.g. all-out beliefs or more fine-grained credences), as well as what precisely it takes for a doxastic attitude to fit a body of evidence. $^{2}$ These familial differences needn't concern us here, however, since for our purposes it is sufficient to note that, for the evidentialist, epistemic justification is simply a matter of fit. It is from this feature of evidentialism that a problem arises.

\section{Evidentialism and Irresponsibility}

Before examining our focal problem, it is worth briefly looking at some objections to evidentialism that are distinct from our concern, but are nevertheless in the neighborhood. What these objections have in common is that they all involve evidence that the subject does not possess but in some sense should possess. ${ }^{3}$ Consider the following case.

\section{Emma's Email}

While responding to some emails, I receive an email from my former colleague Emma with the subject line, "Devastating Objection to your Current Research Project." I know that Emma has been recently working on a similar research project and that she is a good and fair-minded evaluator of the evidence. However, I like my current view (which resulted from my current research project), and I rather like being justified in believing it (let's suppose I am at least up until the point of receiving the email). ${ }^{4}$ So, in a maneuver to maintain the status quo, I simply delete the email without reading it (and perhaps even block all future emails from Emma). ${ }^{5}$

According to this objection, evidentialism wrongly gives the verdict that, despite my irresponsible behavior I remain justified in believing my view. If epistemic justification is simply a matter of evidential fit, and I work diligently to avoid evidence that would change which doxastic attitude my current total 
body of evidence fits, it seems as though I can remain justified in believing my view in the above scenario. However, that would be the wrong result and would license a kind of ostrich epistemology. ${ }^{6}$ Ostrich epistemology occurs when you get some favorable evidence, and proceed to bury your head in the sand, avoiding any conflicting information, in order to remain justified in maintaining the target belief. Such an agent, and such beliefs, are hardly deserving of positive epistemic assessment.

However, evidentialism is not without a response here. While I delete Emma's email and never get to hear what her actual objection to my view is, it does not follow that I fail to receive any evidence against my view. In simply seeing the email subject line, and knowing it is coming from Emma (a person of high intellectual character), I get higher-order evidence that there is powerful evidence against my view. Higher-order evidence is evidence about what evidence there is, its quality or quantity. In learning that Emma believes that she has strong evidence against my view, I come to have higher-order evidence that there is strong evidence against my view. I know Emma to be a reliable judge of such matters, and that the way that she sees things is that the balance of evidence is against my view. Once this higher-order evidence is added to my total body of evidence (by way of seeing the email's subject line), my new total body of evidence no longer supports believing my view. ${ }^{7}$ This is in line with Feldman's famous slogan, "evidence of evidence is evidence." ${ }^{\prime}$ So, evidentialism does not allow my epistemic irresponsibility here to protect the epistemic status of my view for me, or at least it need not.

A parallel response applies to the "ostrich epistemology" concern more generally. If I am "burying my head" to avoid getting evidence against my view, evidence that I know is out there, even if not possessed by me, it does not follow that this unpossessed evidence has no bearing on what I am justified in believing. Even if I don't have the particular items of first-order evidence, my evidence of their existence is already part of my evidence and this higher-order evidence will have effects on what I am justified in believing even absent my access to the first-order evidence itself. The effect of this unpossessed evidence is indirect, but there is nevertheless an effect. So, evidentialism is not committed to the view that agents can manipulate their evidence in ways to remain justified in believing their most cherished beliefs. If an agent is intentionally avoiding evidence, then they have higher-order evidence that such evidence is out there to be avoided. ${ }^{9}$ Even in the absence of the relevant first-order evidence, the subject's awareness of the existence of such evidence is higher-order evidence that they do possess, and thus it will have an effect on what they are justified in believing. So, the evidentialist has a response to cases where an agent intentionally manipulates their evidence in an effort to be justified in their beliefs.

Another potential problem for evidentialism concerns cases where the subject unintentionally has an impoverished body of evidence. Such cases might seem just as problematic as cases where the subject intentionally manipulates their evidence, and the same evidentialist response is not available here. If the subject is unaware that their evidence is seriously impoverished, they will lack 
the relevant higher-order evidence to rescue the desired verdict. An objection to evidentialism along these lines comes from Jason Baehr $(2009,547) .{ }^{10}$

\section{Oblivious George}

George epitomizes the vices of intellectual laziness, apathy, and obliviousness. He lacks any natural curiosity and is almost entirely tuned out to the news of the day. He goes about his daily routine focusing only on the most immediate and practical of concerns: feeding himself, getting to work on time, doing his job in a minimally satisfactory way, paying the bills, etc. Unsurprisingly, George has many beliefs he should not and fails to believe many things he should. In the former category is George's belief that exposure to secondhand smoke poses no significant health risks. Given his extremely narrow and practical focus, George is oblivious to all of the well-publicized research indicating the hazards of secondhand smoke. In fact, George actually has positive evidence in support of his belief. He recalls having learned from a reliable source some years ago that a considerable amount of research had been conducted concerning the effects of exposure to secondhand smoke and that this research had failed to establish any correlation between such exposure and any serious health problems. And as far as George knows, the research on this topic has not changed. Nor, we may suppose, does he have any reason to think that it might have changed.

In this case, George's total body of evidence supports the proposition that secondhand smoke poses no significant health risks, even though there is a very real sense in which George should know better. George's total body of evidence is drastically deficient on the matter, but importantly George has no idea that this is the case. In fact, his evidence even supports the proposition that his evidence on the matter is entirely adequate. So, unlike our earlier case, George lacks any higher-order evidence that can take the place of his missing firstorder evidence. Since George is oblivious to the existence of powerful evidence against his belief, he has no evidence of its existence. In fact, George arguably even has evidence against its existence. For instance, he might have evidence that, if the data had changed, then he would have heard about it. If George's total evidence supports the view that research on the topic has not changed, then he even has higher-order evidence that his evidence on the matter remains representative of the evidence that there is on this issue. Such evidence would be misleading, but misleading evidence is still evidence.

Baehr takes the case of George to raise a counterexample to evidentialism, since while George's total body of evidence supports believing that secondhand smoke poses no significant health risks, George is not epistemically justified in believing this due to his epistemic irresponsibility in inquiry. Along these same lines, Cloos (2015) argues that George is culpably ignorant due to his epistemically blameworthy inquiry, and that this ignorance prevents him from 
being epistemically justified in his belief. Since George would have acquired defeating evidence had he been a responsible inquirer, Cloos too declares his target belief unjustified.

While it is clear that something has gone wrong here, and that George has been epistemically irresponsible, the case of George is not a counterexample to evidentialism. To see this, let's first consider the alternative epistemic assessments to make of George and his doxastic attitudes. If belief is not the attitude that George is justified in adopting toward the proposition that secondhand smoke poses no significant health risks, what is? Should he disbelieve this claim? ${ }^{11}$ Is disbelief the doxastic attitude he is epistemically justified in adopting toward this claim? While we are all familiar with evidence that strongly supports that this claim is false, George is entirely ignorant of this information. All George can do is work with the evidence that he has, and the evidence that he has strongly supports believing the proposition. Should he be suspending judgment? Is suspension of judgment the epistemically justified attitude for George to adopt toward this claim? This can't be correct either, since all the information George has on the matter supports believing this proposition. From George's perspective, suspension of judgment cannot seem, or be, rational.

So, if we take belief, disbelief, and suspension of judgment to be George's doxastic options here, belief is the one for George to go with. While there may be plenty to criticize George for, believing in accordance with his evidence and having a justified belief are not among them. George's epistemic situation is not too dissimilar to those who predated Copernicus and believed that the Earth was the center of the solar system. While they were mistaken, and there was plenty of evidence to the contrary that was "out there" in some sense, this evidence to the contrary was entirely outside of their ken. Given that they had no idea that such evidence existed, it would be a mistake to think that such evidence should factor in to what they were justified in believing. The same holds for George. Given that he is entirely unaware of the powerful evidence that secondhand smoke is harmful to your health, he remains justified in believing that it isn't.

Further, there is a problem with the epistemic assessment of George given by both Baehr and Cloos. Baehr and Cloos each maintain that it is George's epistemic irresponsibility that prevents him from having an epistemically justified belief. However, if epistemic irresponsibility is sufficient to undermine epistemic justification, then it would be impossible for there to be epistemically lazy or irresponsible knowers (since epistemic justification is a necessary condition for knowledge). But there are epistemically lazy or irresponsible knowers. Consider the following case.

\section{Sally's Spoiler}

Sally is a big Bears fan. She has been travelling and missed the last game. She has worked hard to avoid any information about the game by disabling her phone and avoiding TV and radio, so that she can watch the game when she gets home. Unfortunately for Sally, she has a mean 
friend-Suzy. Suzy is a Packers fan and so wants to make Sally's life miserable. Aware of Sally's plan, Suzy foils her plans and blurts out the final score despite Sally's best efforts to avoid her testimony. ${ }^{12}$

Sally has been an irresponsible inquirer regarding the final score in the Bears game. In fact, Sally has even been an actively bad inquirer. Sally has devoted significant effort to avoid any evidence on the matter. Nevertheless, Sally now knows the final score on the basis of Suzy's testimony. ${ }^{13}$ So, Sally knows the outcome despite doing all she can to avoid having a true belief on the matter! Since epistemic justification is a necessary condition for knowledge, this case shows that epistemic justification does not require responsible inquiry on the part of the subject. Given that epistemic justification does not require responsible inquiry, the analysis of Oblivious George given by both Baehr and Cloos cannot be correct. If George is not justified in his belief, it would need to be for some alternative reason.

\section{A Problem}

While the above irresponsibility objections to evidentialism fail, there is a problem that nevertheless lurks in the neighborhood. To see the problem that arises for evidentialism, let us begin by considering an analogy. The analogy that I want us to consider regards the evaluation of arguments, and deductive arguments in particular. There are two general ways in which an argument can go wrong: (i) its conclusion can fail to follow its premises, and (ii) it can have bad premises. One way for an argument to avoid the first problem is for it to be valid.

\section{V}

An argument is valid just in case its form is such that it cannot have all true premises and a false conclusion.

Valid arguments have conclusions that follow their premises (and follow them in a rather strong way). In this way, validity is entirely a property of fit. Valid arguments have conclusions that fit their premises. ${ }^{14}$

However, as we are well aware, an argument being valid is not all that much of an achievement. Plenty of horrific arguments are valid. To give but one example, consider the following:

1. If the moon is made of green cheese, then triangles don't have corners.

2. The moon is made of green cheese.

3. So, triangles don't have corners.

While no one would be convinced to believe (3) on the basis of the above argument, it is a perfectly valid argument. The problem is not that the conclusion does not fit the premises. Indeed, given the truth of those premises, the conclusion must be true. 


\section{Jonathan Matheson}

The problem with the above argument, of course, is that it has ridiculous premises (one of which is false). The argument fails to avoid our second type of problem that arguments can encounter. To pick out this problem we appeal to the concept of a sound argument.

\section{S}

An argument is sound just in case it is valid, and it has all true premises.

Sound arguments avoid both ways that an argument can go wrong. The problem with the argument given above is that, while it is valid, it is not sound. For an argument to be sound it takes more than a relation of fit between the premises and the conclusion; the premises themselves (a relata of the fit relation) require some positive evaluation. What is being fit must itself have some positive status. To be sound, it matters what kind of premises the conclusion of the argument is fitting.

The analogy to evidentialism should be quite clear. Evidentialist justification is solely a matter of fit-fit between one's evidence and a doxastic attitude toward a proposition. In this way, evidentialist justification is like validity, which is also simply a matter of fit. While validity and evidentialist justification each offer some positive evaluation of the intended target, each leaves something more to be desired. Like a conclusion can fit bad premises, a doxastic attitude (toward a proposition) could fit a bad, or impoverished, body of evidence. A richer, and more robust, epistemic evaluation would go beyond the mere relation of fit to also include an evaluation of the individual's body of evidence as well - an evaluation of what is that the doxastic attitude is fitting.

To further motivate this point, consider the following example:

\section{The Tale of Two Students}

Pat and Kat are two economists. They have each been tasked with the project of determining whether the newly proposed tax plan will in fact be revenue neutral. The tax bill is quite complicated and its effects on the economy are no simple matter. However, both Pat and Kat are skilled economists well qualified to determine the matter. Kat has been dutifully researching the matter for a month. Pat has been enjoying the World Cup. One night at a bar where Pat had been watching the match, Kat comes in after another long day of research and sits down in the booth next to Pat. Pat overhears Kat telling her friend that she has concluded that the new plan will add to the deficit. Pat, knowing of Kat's credentials, also comes to believe that the plan will add to the deficit.

Against this backdrop, let me stipulate a few other things. Let's suppose that Kat has correctly responded to her evidence on the matter. So, let's suppose that her belief is epistemically justified by evidentialist standards. In addition, let's suppose that Pat has also correctly responded to her evidence on the matterthat she too is epistemically justified in her belief on the matter. While Pat and 
Kat have very different bodies of evidence on the matter, each can support believing the proposition that the tax plan will add to the deficit. Further, we can even suppose that each body of evidence supports believing the relevant proposition to the same degree - that these distinct bodies of evidence offer the same level of support to the proposition that the tax plan will add to the deficit. While Kat's body of evidence on the matter is much more extensive, we can suppose that it has some pieces of evidence that point in each direction, some defeaters, some defeater-defeaters, and so forth. On the other hand, Pat's body of evidence on the matter is pretty sparse. She may have some initial intuitions about various things, but on this matter her evidence is principally Kat's testimony (at least coupled with what she knows about Kat). That said, we can suppose that the evidential scales in each case both support believing the target proposition, and both support the attitude of belief to the same degree.

Given all of this, evidentialism has it that Kat and Pat are equally justified in their respective beliefs that the tax plan will add to the deficit. End of the evidentialist assessment. While there may be a sense in which Kat and Pat are epistemically on a par, such an epistemic verdict appears to be importantly incomplete. While both of our subjects have responded correctly to their respective bodies of evidence, the evidentialist's evaluation ignores quality and quantity of the total body of evidence that each subject is responding to as well as the lengths to which each subject went to acquire their evidence. Put more bluntly, the evidentialist assessment fails to assess how good or bad a subject's body of evidence is. ${ }^{15}$

A second example may help.

\section{Ways of Withholding}

Will and Wilma both suspend judgment about the proposition that God exists, and both are justified in adopting this doxastic attitude toward this proposition. However, this is where the similarities between the two end. Will suspends judgment because he has never thought about the matter. He has no evidence at all about whether God exists and so his total evidence does not support believing or disbelieving that God exists. The only doxastic attitude that it would be justified for him to adopt toward this proposition is suspension of judgment. Wilma, on the other hand, has thought extensively about the matter. She has studied the strongest arguments and considerations both for and against God's existence. Overwhelmed by the extensive state of disagreement she suspends judgment.

Here too we can suppose that each subject has responded correctly to their evidence; that each state of withholding is supported by the respective bodies of evidence (and equally so). The evidentialist assessment has it that Will and Wilma are equally justified in their suspending judgment about whether God exists. End of assessment. Here too, such an assessment seems woefully incomplete. Even if both Will and Wilma have done equally well with respect to responding to the evidence they have, if the epistemic assessments end there, 
we are left without an assessment of how well each has done with respect to acquiring the evidence they have to work with.

What these cases show is that evidentialism is inadequate in giving some epistemic assessments. This is not to say that evidentialism is false, just that it is incomplete-other important epistemic assessments remain unaccounted for by evidentialism. We should have a way to distinguish the epistemic state of Pat from that of Kat, and the epistemic state of Will from that of Wilma. Evidentialism does not give us the tools to make these assessments.

The above is not an objection to evidentialism since it does not dispute the verdicts given by evidentialism. These cases do not point to examples where believing $p$ fits the subject's evidence, yet they are not epistemically justified in believing $p$. Nor are they cases where a subject is epistemically justified in believing $p$ without belief toward $p$ fitting their evidence. The problem here is merely that the verdicts of evidentialism are incomplete-that we shouldn't stop our epistemic assessment ${ }^{16}$ with the evidentialist verdicts. There are important epistemic assessments that evidentialism does not have the resources to make.

\section{The Solution: Robust Justification}

To solve this problem we need to supplement the evidential fit property, which is the focus of evidentialism, with an evaluation of the body of evidence the subject possesses. Let's call this richer conception of epistemic justification "robust justification".

\section{$\mathrm{RJ}$}

Doxastic attitude $D$ toward proposition $p$ is robustly justified for $S$ at $t$ if and only if (i) having $D$ toward $p$ fits the evidence $S$ has at $t$ (it meets $\mathrm{EJ}$ ) and (ii) S's evidence is

Returning to our analogy with arguments, the goodness of a sound argument requires supplementing the fit property of validity with a positive evaluation of the premises-they must be true. So, what kind of assessment of the subject's evidence will deliver the desired verdicts? How should we fill in the blank in our account? What makes a subject's body of evidence good, or right, or otherwise appropriate?

One might be tempted to lean even more heavily on the analogy with argument evaluation and claim that, just as the premises of a sound argument must be true, the subject's evidence must be true for them to be robustly justified in what they believe. While there are interesting debates about the factivity of evidence, such a proposal does not help here. We can suppose that all evidence is propositional and that to be robustly justified a subject's evidence must all be true, but this will not help us distinguish Pat and Kat (or Will and Wilma). To see this, we can suppose that both Pat and Kat only have true propositions as their evidence. Nevertheless, there appears to be an important epistemic 
difference between the two. The truth of their evidence does not get at the relevant difference.

A natural way to fill in the blank is to appeal to responsible inquiry. Responsible inquiry seems to be what differentiates Pat from Kat, and Will from Wilma. This would also provide a place for responsible inquiry in epistemic justification like others have sought to do in their attacks on evidentialism. This leads us to the following:

\section{RJ'}

Doxastic attitude $D$ toward proposition $p$ is robustly justified for $S$ at $t$ if and only if (i) having $D$ toward $p$ fits the evidence $S$ has at $t$ (it meets EJ) and (ii) $S$ has been responsible in gathering evidence relevant to $p \cdot{ }^{17}$

This understanding of robust justification gets our cases correct. It provides an explanation of what differentiates the epistemic status of Kat's belief from that of Pat's, and Wilma's withholding from Will's. Kat and Wilma have been responsible inquirers, while Pat and Will have not. ${ }^{18}$ While all four have correctly responded to the evidence they possess, only Kat and Wilma have bodies of evidence that are the result of responsible inquiry. This understanding of robust justification also harnesses the intuitions that motivated the irresponsibility objections to evidentialism considered above. While those objections failed to show that evidentialism gives an incorrect account of epistemic justification (the kind of justification requisite for knowledge), the motivating force behind them can be used to help motivate a different conception of justification that captures this responsibilist element, although in a different way. ${ }^{19}$

Before moving on, it is worth noting two important differences between robust justification and soundness-the players in our analogy. First, while soundness supplemented a (normative) fit property (validity) with a metaphysical property (truth), robust justification supplements a (normative) fit property (EJ) with a further normative property (responsible inquiry). ${ }^{20}$ So, robust justification is doubly normative. Second, while soundness is an allor-nothing property, robust justification comes in degrees. Both conditions (i) and (ii) of robust justification can be met to varying degrees. A body of evidence can support a doxastic attitude to differing degrees, and a responsibly gathered bodies of evidence can differ in the degrees of responsibility exercised in their attainment. Since both elements of robust justification come in degrees, it is best to think of robust justification as a degreed notion. Neither of these notable disanalogies, however, diminishes the usefulness of the analogy. ${ }^{21}$

\section{The Value of Robust Justification}

Having made the case for robust justification and a responsibilist understanding of it, it is worth pausing to consider the value of robust justification. Why care about robust justification? 


\section{Jonathan Matheson}

As we have seen, robust justification is not a necessary condition for knowledge. The case of Sally's Spoiler shows that even irresponsible inquiry can result in knowledge. A subject can come to know $p$ despite their best efforts to avoid having a true belief about $p$. So, the value of robust justification cannot come by way of its connection to knowledge.

The value of robust justification can best be seen by looking at those who seem to have conflated it with the kind of epistemic justification that is a necessary condition of knowledge, like in the above objections that reside in the neighborhood. For instance, in giving his necessary and sufficient conditions for knowledge, A. J. Ayer proposed the following:

$S$ know $p$ just in case:

i) $\mathrm{p}$ is true,

ii) $\mathrm{S}$ is sure of $\mathrm{p}$,

iii) $S$ has the right to be sure that $\mathrm{p}^{22}$

The concept of having "the right to be sure" or having "the right to believe" is captured nicely by the concept of robust justification. If they are believing in line with their evidence and they have been responsible in their inquiry and collection of evidence, then they have the right to that resulting belief. They have the best possible doxastic response to the evidence it can reasonably be expected for them to have. This is an epistemically valuable state to be in, even though Ayer was incorrect in believing that it was a requirement for knowledge.

W. K. Clifford, though guilty of confusing evidentialist justification and robust justification, does nicely highlight the value and importance of robust justification. Along the same lines as Ayer, Clifford says of the negligent shipowner in his famous example, "he had no right to believe on such evidence as was before him." ${ }^{23}$ The idea here seems to be that even if the shipowner is correctly responding to the evidence that he has, this is insufficient since he should have had more (and better) evidence on the matter. More forcefully, when evaluating the individual who has no time for detailed inquiry, Clifford claims that such an individual also has no time for belief! Here too the focus is on robust justification for a belief-a belief being supported by your total evidence when that total evidence is the result of responsible inquiry. It is such justification that puts you in a stronger epistemic standing toward your belief than mere evidential support, and this standing does not hinge upon your belief being true (unlike knowledge).

Miracchi (2019), puts the point this way,

There may be a positive normative property possessed by people who believe in accordance with their evidence no matter how that evidence was arrived at, but such a property does not deserve a primary place in our epistemological theorizing. This is because we in fact do have substantial control over what evidence we have, what reasoning capabilities we have, whether we jump to conclusions, and so on. This control is often 
diachronic, and so does not entail any kind of problematic voluntarism about belief. Because we do, over time, have control over the quality of our bodies of evidence, such quality can properly figure into how we hold people accountable for their epistemic attitudes.

While she too draws the wrong conclusion from such an insight (rejecting the evidentialist notion of epistemic justification), she does show why robust justification is valuable.

Finally, returning to our analogy with arguments can also help solidify the value of robust justification. Sound arguments are much more valuable than merely valid arguments. Sound arguments not only have conclusions that fit their premises, but what they fit is in fact true. Fitting with the truth is much more valuable than mere fit. Similarly, robust justification is more valuable than mere evidential fit. Robustly justified beliefs do not merely fit the subject's evidence, but the evidence that they fit is the result of responsible inquiry. Fitting bodies of evidence that are the result of responsible inquiry is much more valuable than simply fitting some body of evidence or other. In extending the epistemic evaluation beyond evidential fit, robust justification provides a more valuable epistemic assessment, even if it is not a necessary condition for knowledge.

\section{Conclusion}

In this chapter we have seen the need for an epistemic evaluation beyond the notion of epistemic justification supplied by evidentialism. While we have seen reason to resist several extant objections to evidentialism that all center or irresponsible inquiry, we have also seen that a richer conception of epistemic justification-robust justification-supplements the property of evidential fit (provided by evidentialist justification) with the property of one's evidence being the result of responsible inquiry. Appealing to robust justification allows us to make important epistemic distinctions that evidentialist justification does not, and we have also seen that robust justification is epistemically valuable in ways that are independent of knowledge. ${ }^{24}$

\section{Notes}

1 However, see Beddor (2015) for an argument that understanding evidentialism as a thesis about grounding may be more apt.

2 For one such account, see McCain (2014).

3 Further discussions of unpossessed evidence and its significance can be found in Ballantyne (2015), Benton (2016), DeRose (2000), Goldberg (2016, 2017), Kornblith (1983), and Lackey (2008).

4 Somewhat ironically, this supposition is quite significant, at least if one of my research projects is correct. See Matheson (2015).

5 A similar kind of case, one where the subject intentionally ignores evidence, is given by Kornblith $(1983,36)$. Kornblith describes a case of an ego-driven young physicist who "pays no attention" to a senior colleague's criticisms of his view (not even 


\section{Jonathan Matheson}

hearing what the colleague says), and so fails to appreciate the degree of support his own theory enjoys (relative to evidence already in possession by the scientific community). Here, according to Kornblith, the intuitive verdict is that he is "culpably ignorant” $(1983,36)$.

6 I first heard the term 'ostrich epistemology' from Alvin Goldman when he was raising a similar challenge to evidentialism.

7 See Matheson (2009).

8 See Feldman (2007) and (2014).

9 Acknowledging such an impact of higher-order evidence does not entail taking a particular stand in the epistemology of disagreement (conciliationist vs. steadfast views). Parties in both camps can agree that the beliefs of others are some higherorder evidence. What will matter for which view of disagreement one opts for is how they think those pieces of higher-order evidence interact with your own firstorder evidence, considerations of self-trust, and so forth.

10 A similar objection is put forward in Miracchi (forthcoming).

11 Here the 'ought' language is picking out propositional justification. There are parallel debates concerning evidentialism and doxastic justification as well. See DeRose (2000) for a statement of the issue and Stapleford (2014) for a helpful response.

12 Such a case appears in McCain $(2014,141)$ as Football Jon.

13 Despite her bad moral character, Suzy is a very reliable testifier, and Sally knows this.

14 One might worry that the talk of 'fit' is stretched here. While the conclusions of valid arguments follow from their premises, it might be strained to think of them as fitting their premises. While I don't share this concern, we needn't be troubled by it here. What is important to the analogy is that validity is entirely a formal/structural property involving a relation.

15 Does this imply that testimonial evidence is epistemically inferior to first-hand evidence? I don't think so. Non-testimonial evidence does not entail responsibly gathered evidence, and testimonial evidence does not entail irresponsibly (or even less responsibly) gathered evidence. For instance, we can get at our same difference even while restricting the relevant evidence to testimonial evidence alone. Consider two detectives. One interviews all the eye-witnesses and forensic experts. The other just hears the conclusion of the first. While both may have beliefs justified to their evidence (and to the same degree), and bodies of evidence comprised entirely of testimonial evidence, there remains an important epistemic distinction between the two detectives.

16 It is worth noting that not everyone will consider this additional assessment epistemic. Stapleford $(2012,2015)$ agrees that justification is a matter of evidential fit, but he also claims that a certain degree of reflection on the evidence one possesses is required-on purely epistemic grounds. Dougherty (2014) argues that such assessments are solely within the domain of ethics.

17 Compare with Cloos' (2015) account of responsibilist evidentialism. The key difference here is that Cloos is after an account of the justification required for knowledge, and as we have seen above, robust justification is a different matter.

18 One might resist the claim that Pat has been an irresponsible inquirer. After all, Pat has gathered testimony from someone known to be a reliable source. Similarly, it might be thought that Will is no inquirer at all, and so not an irresponsible inquirer. These details needn't get in the way of our point, however, since it is clear that Pat and Kat (and Will and Wilma) differ with respect to their responsibility in inquiry. Kat has been much more responsible than Pat (and Wilma has been much more responsible than Will). This is a difference that our epistemic concepts should capture. Thanks to Kevin McCain for pressing this worry. 
19 While appealing to responsible inquiry distinguishes our cases, it is not the only candidate capable of doing so. Another candidate appeals to the quantity and quality of the subject's evidence-the resilience of the subject's justification-regardless of whether it was the result of responsible inquiry. While responsible inquiry is often coupled with more and better evidence, it needn't be. So, to evaluate our candidates we need to consider cases where the two come apart-cases where one has a vast body of evidence without responsible inquiry or cases where despite responsible inquiry one's evidence is quite sparse. Suppose that Tom is looking into the aftereffects of near-death experiences. Tom looks into the issue diligently for years, but the evidence is sparse and what's there is not very strong. Nevertheless, the evidence Tom collects supports that survivors of a near-death experience have increased compassion for others. Tom's evidence is the result of responsible inquiry, but Tom's evidence is not resilient. New information could easily shift what his evidence supports. Tom is robustly justified in his belief-he's done well in inquiry and he's following the evidence he has. This gives us reason to prefer the responsibilist account of robust justification. For a discussion of the relevance of resilience, see McCain and Poston (2014).

20 Thanks to Scott Stapleford for pointing this out.

21 Since each condition for robust justification comes in degrees, interesting questions emerge regarding how the degrees to which each condition are met combine to give a degree to which one is robustly justified. Such details, like the details regarding responsible inquiry, are left to fuller treatments of robust justification. This project simply aims to get the concept on the map.

22 Ayer (2000).

23 Clifford $(1999,70)$.

24 I am very grateful for feedback from Kevin McCain and Scott Stapleford, as well as audiences at the Southeastern Epistemology Conference and the Alabama Philosophical Society.

\section{References}

Axtell, Guy. 2011. “Recovering Responsibility.” Logos \& Episteme 3: 429-454.

Ayer, A. J. 2000. "Knowing as Having the Right to be Sure." In Sven Bernecker and Fred I. Dretske (eds), Knowledge: Readings in Contemporary Epistemology. Oxford: Oxford University Press, 7-12.

Baehr, Jason. 2009. “Evidentialism, Vice, and Virtue.” Philosophy and Phenomenological Research 78: 549.

Ballantyne, Nathan. 2015. "The Significance of Unpossessed Evidence." Philosophical Quarterly 63: 315-335.

Beddor, Bob. 2015. "Evidentialism, Circularity, and Grounding." Philosophical Studies 172: 1847-1868.

Benton, Matthew. 2016. “Knowledge and Evidence You Should Have Had.” Episteme 13 (4): 471-479.

Clifford, W. K. 1999. The Ethics of Belief and Other Essays. Amherst, NY: Prometheus Books.

Cloos, Christopher Michael. 2015. "Responsibilist Evidentialism.” Philosophical Studies 172: 2999-3016.

Conee, Earl, and Feldman, Richard. 2004a. "Making Sense of Skepticism.” In E. Conee and R. Feldman (eds), Evidentialism. New York: Oxford University Press, 277-306. 
Conee, Earl, and Feldman, Richard. 2004b. “Evidentialism.” In E. Conee and R. Feldman (eds), Evidentialism: Essays in Epistemology. New York: Oxford University Press, 83-107.

DeRose, Keith. 2000. "Ought We to Follow Our Evidence?" Philosophy and Phenomenological Research 60: 697-706.

Dougherty, Trent. 2014. “The 'Ethics of Belief' is Ethics (Period): Reassigning Responsibilism.” In J. Matheson and R. Vitz (eds), The Ethics of Belief: Individual and Social. Oxford: Oxford University Press, 146-166.

Feldman, Richard. 1988. “Epistemic Obligations.” In Matthias Steup (ed.), Knowledge, Truth, and Duty: Essays on Epistemic Justification, Responsibility, and Virtue. Oxford: Oxford University Press, 77-92.

Feldman, Richard. 2004. "The Ethics of Belief." In E. Conee and R. Feldman (eds), Evidentialism. Oxford: Oxford University Press, 166-196.

Feldman, Richard. 2007. "Reasonable Religious Disagreements.” In L. Anthony (ed.), Philosophers without Gods: Meditations on Atheism and the Secular. Oxford: Oxford University Press, 194-214.

Feldman, Richard. 2014. "Evidence of Evidence is Evidence." In J. Matheson and R. Vitz (eds), The Ethics of Belief: Individual and Social. Oxford: Oxford University Press, 284-300.

Goldberg, Sanford. 2016. “On the Epistemic Significance of Evidence You Should Have Had.” Episteme 13 (4): 449-470.

Goldberg, Sanford. 2017. "Should Have Known.” Synthese 194 (8): 2863-2894.

Kornblith, Hilary. 1983. "Justified Belief and Epistemically Responsible Action." Philosophical Review 92 (1): 33-48.

Lackey, Jennifer. 2008. Learning from Words. Oxford: Oxford University Press.

Matheson, Jonathan. 2009. "Conciliatory Views of Disagreement and Higher-Order Evidence.” Episteme 6 (3): 269-279.

Matheson, Jonathan. 2015. The Epistemic Significance of Disagreement. London: Palgrave.

McCain, Kevin. 2014. Evidentialism and Epistemic Justification. New York: Routledge.

McCain, Kevin, and Poston, Ted. 2014. "Why Explanatoriness Is Evidentially Relevant.” Thought 3: 145-153.

Miracchi, Lisa. 2019. "When Evidence Isn’t Enough: Suspension, Evidentialism, and Knowledge-First Virtue Epistemology.” Episteme 16(4): 413-437.

Stapleford, Scott. 2012. "Epistemic Duties and Failure to Understand One's Evidence." Principia: An International Journal of Epistemology 16 (1): 147-177.

Stapleford, Scott. 2014. “Completing Epistemic Oughts.” Philosophical Quarterly 45 (2): 133-148.

Stapleford, Scott 2015. "Epistemic Versus All Things Considered Requirements." Synthese: An International Journal for Epistemology, Methodology and Philosophy of Science 192 (6): 1861-1881.

Zagzebski, Linda. 1996. Virtues of the Mind. Cambridge: Cambridge University Press. 


\title{
10 Ought to Believe vs. Ought to Reflect
}

\author{
Anthony Robert Booth
}

\section{Introduction}

Several philosophers think that we do not have duties or obligations to believe but that we can nevertheless be held to blame for having certain beliefs because our duties relevant to our doxastic attitudes are exclusively duties to critical reflection (broadly construed such as to include evidence gathering). One important line of argument (due to Alston 1989) for this claim begins with the following thought: we at most have influence (and not control) over our doxastic attitudes. We can influence, say, what are our beliefs regarding the War of the Roses, by typing <the Wars of the Roses> into Google. Before doing so, for instance, I mistakenly believed that Richard III was not a Yorkist, but after my Google search, I believe differently. Thus, while we might not have control over our beliefs, we might be nevertheless blameworthy for our beliefs because of the control we have over our actions. I might not be able to just decide what to believe about Richard III's allegiances, but I can nevertheless be blameworthy for believing false things about them given my ability to gather evidence and to critically reflect on such matters. For Alston, it is important that this has the corollary that we do not strictly speaking have doxastic obligations-that is, obligations to believe that $p$, disbelieve that $p$, or withhold judgement on whether $p$. For him, we can only have obligations with respect to things we can control (that is the point of "ought implies can"), and our ability to critically reflect on our beliefs, or to gather evidence, does not give us control, but at most doxastic influence. When I type $<$ The Wars of the Roses $>$ into Google, I do not antecedently know what the result of my search will be, and so consequently do not know what my ensuing doxastic attitude will be. So, claims Alston, my ability to perform things like a Google search merely gives me the power to influence my doxastic attitudes-it does not give me the power to control them. This does not mean that we are never blameworthy with respect to our doxastic attitudes, since blame supervenes on obligation in at least two ways: we can be blameworthy for breaking an obligation, but we can also be blameworthy when a state of affairs obtains that would not have obtained had we not violated an obligation. I am blameworthy for car accidents I cause while drunk-driving and out of control, for example, since I violated the obligation not to get behind the wheel while drunk. If I have a duty to stay informed 


\section{Anthony Robert Booth}

about the Wars of the Roses (say I am a History teacher, teaching a module on the subject) and I break that requirement, I am blameworthy for believing that Richard III was not a Yorkist King.

In this chapter I want to defend the idea that we have only duties to critical reflection (where this includes evidence gathering and training oneself to be a better thinker, perhaps less prone to implicit bias and the like), and do not have duties to believe. ${ }^{1}$ But I think that Alston's argument, as roughly stated above, is problematic. In section 2, I levy several objections to Alston's argument: that the distinction between doxastic control and influence is not a sharp as Alston needs (2.1) and that his claim about the supervenience relation between blameworthiness and obligation rules in the existence of "derivative" obligations. I then thus propose a new argument to the same conclusion. Roughly stated, the argument goes: (supposing, for reductio, that there are duties to believe) if $S$ has a duty to believe that $p$, then $S$ also has a duty to reflect on whether $p$. But the existence of duties to reflect on whether $p$ always undercuts duties to believe that $p$. Thus the duties relevant to whether our doxastic attitudes are blameworthy are always duties to critical reflection. In section 3, I defend the claim that, if $S$ has a duty to believe that $p$, then $S$ also has a duty to reflect on whether $p$; in section 4 I defend the claim that the existence of duties to reflect on whether $p$ always undercuts duties to believe that $p$, and thus that the duties relevant to our doxastic attitudes are always duties to critical reflection.

\section{Indirect Doxastic Control vs. Doxastic Influence}

Alston's main argument seems to go as follows:

(1) There are doxastic obligations only if we have control (indirect or direct) over our beliefs.

(2) We do not have any kind of control over our beliefs.

(3) Therefore, we do not have doxastic obligations.

He then defends premise 2 with a further sub-argument:

(4) If we have doxastic obligations in virtue of the control we have over actions such as evidence gathering, then such actions give us indirect doxastic control

(5) Actions such as evidence gathering and critical reflection do not give us indirect doxastic control, but doxastic influence.

(6) We do not have doxastic obligations in virtue of the control we have over actions such as evidence gathering and critical reflection.

The first argument (1-3) has received extensive discussion (see Nottelmann 2007, Weatherson 2008, Chrisman 2008, Roeber 2019 among many, many others). The key premise (5) has not received comparative attention (Peels 2018 is an exception). This is a shame, since it is crucial in Alston's argument. My 
first objection to his overall case will be directed at premise 5. But there is an even further tacit argument in Alston, which has received even less attention:

\section{Background Assumption}

Blame-Obligation Supervenience Principle: blameworthiness supervenes on obligation in two ways. We can be blameworthy for violating an obligation, and we can be blameworthy for the obtaining of a state of affairs that would not have obtained had we not violated an obligation.

(7) The control we have over actions like evidence gathering makes it the case that we are sometimes blameworthy for our doxastic attitudes [Blame-Obligation Supervenience].

(3) We do not have doxastic obligations.

(8) The obligations we transgress that make our doxastic attitudes blameworthy are not doxastic obligations.

The second objection I then levy is that premises (7) and (3) are contradictory, and I argue that if we can be blameworthy for our beliefs then we must at least have "derivative" doxastic obligations.

\subsection{First Objection}

Let us now return to my first objection, vis-à-vis premise (5). Having ruled out that we have direct doxastic control, ${ }^{2}$ Alston thinks that whether we have indirect doxastic control is settled by the question: (supposing you want to believe that $p$ ) is there something you can do to bring it about that you believe that $p$ ? Analogously: you cannot by a sheer act of will bring it about that the light bulb in this room switches on, but you do have indirect (or "non-basic") control over whether it comes on, since you have direct control over whether or not you flick the working switch. But is there anything analogous we can do to bring it about that we believe that (say) it was not raining upon seeing it raining outside?

How would I do so? What button would I push? I could try asserting the contrary in a confident tone of voice. I could rehearse some sceptical arguments. I could invoke the Vedantic doctrine of maya. I could grit my teeth and command myself to withhold the proposition. But unless I am a very unusual person, none of these will have the least effect. It seems clear that nothing any normal human being can do during the uninterrupted operation of an intention to reject the proposition that it is raining will have any chance at all to succeed.

(Alston 1989, 129)

According to Alston we can nonetheless influence what we believe. Examples: Go to the library, do a Google search, critically reflect, train oneself to be a better reasoner (give your mind a "work out" by doing puzzles, etc.), take an 


\section{Anthony Robert Booth}

implicit bias training workshop. For ease of exposition, for the rest of this chapter I will refer to these kinds of activity collectively under the term "critical reflection." Our ability to embark on such ventures does not give us doxastic (indirect) control since when we embark on such ventures we do not antecedently know what our ensuing doxastic attitude will be.

These claims ignore the difference between doing $\mathrm{A}$ in order to bring about $\mathrm{E}$, and doing $\mathrm{A}$ so that some effect within a certain range will ensue. In order that the "looking for more evidence" phenomenon would show that we have immediate voluntary control over propositional attitudes in basically the way we do over the positions of doors and light switches, it would have to be the case that the search for evidence was undertaken with the intention of taking up a certain particular attitude toward a particular proposition. For only in that case would the outcome show that we have exercised voluntary control over what propositional attitude we take up. Suppose that I can't remember Al Kaline's lifetime batting average and I look it up in the baseball almanac. I read there the figure .320, and I thereby accept it. Does that demonstrate my voluntary control over my belief that Kaline's lifetime batting average was .320? Not at all. At most it shows that I have immediate voluntary control over whether I take up some propositional attitude toward some proposition ascribing a lifetime batting average to Kaline.

(Alston 1989, 131)

We could then only be blameworthy (or otherwise held to account) for our doxastic attitudes derivatively - whether we are to blame would depend on whether we have dispatched our duties to do certain things, like collect evidence. ${ }^{3}$ But it is extremely hard to give an account of what are our evidencegathering duties (given that it is obviously not our duty to be permanently gathering evidence for all propositions, nor our duty to collect evidence for any given proposition considered until there was some infallible guarantee that our belief that $p$ was true). ${ }^{4}$

The underlying operative principle is (something like) the following:

\section{IndiControl}

$S$ has (indirect) control over whether she $A$-s through $S$ 's having direct control over $S$ 's $B$-ing just in case $S$ knows that the outcome of $S$ 's $B$-ing will result in $S A$-ing.

Suppose I want to believe that Adam Curtis did not write Blackadder (I like Blackadder but I do not like Adam Curtis), but I do not know whether Adam Curtis wrote Blackadder. ${ }^{5}$ Do I have control over whether I believe that Curtis wrote Blackadder in virtue of my ability to use Google? If IndiControl is true, then I do not, since I will not know that the outcome of my Google-search will result in my believing that Adam Curtis did not write Blackadder. 
However, IndiControl looks too strong. Consider:

I want to turn on the lights.

The building's circuitry is faulty and gives me a $50 \%$ chance of success of turning on the lights by flicking the switch.

I flick the switch.

The lights go on.

I voluntarily switched on the lights.

This is paralleled in cases of direct control. Consider:

I want to raise my arm.

My neurology is damaged such that I have a 50\% chance of raising my arm by willing myself to raise my arm.

I will my arm to raise.

My arm goes up.

I voluntarily raised my arm.

So let's revise IndiControl to take this on board:

\section{IndiControl'}

$S$ has indirect control over whether she A-s through S's having direct control over $S$ 's $B$-ing just in case $S$ knows that there is at least some (nonnegligible) chance that the outcome of $S$ 's $B$-ing be $S A$-ing.

But IndiControl' is compatible with our having indirect control over several of our beliefs by critically reflecting on the evidence we have or by searching further evidence.

Consider:

I have an inkling that Adam Curtis did not write Blackadder, but I would only assign a $20 \%$ probability to it being the case.

So I currently do not believe that Adam Curtis did not write Blackadder.

I want to believe it.

So I Google it.

I come to believe that Adam Curtis did not write Blackadder as a result of Googling.

I voluntarily came to believe that Adam Curtis did not write Blackadder. I satisfy the requirement that there is least some (non-negligible) chance that the outcome of my Googling will be my believing that Adam Curtis did not write Blackadder.

\section{Objection}

This does not seem right, since my intention to believe makes no difference as to whether Adam Curtis actually wrote Blackadder. To illustrate: ${ }^{6}$ 
I want One For Arthur to win the race, and so want to believe it. Odds on One For Arthur are bad. I will find out whether One For Arthur wins the race if I switch on the TV and watch it. Suppose that One For Arthur defies the odds and wins the race. Have I voluntarily come to believe that One For Arthur won the race, via the control I have over switching on the TV? Seems not.

Put differently, the objection seems to be that I can only have indirect control over believing propositions that are true, or that will have a high subjective probability once I've done the evidence-gathering action.

\section{Reply}

First, I think it is important to disambiguate that we're here talking about control of "beliefs" qua belief states and not about "beliefs" qua the propositional contents of those beliefs (it is clearly impossible for a non-deity to change what propositions are true by doing things that do not change the world). Once we have our attention set on whether a doxastic state has been willfully brought about, it's not so clear that the intuition above uniformly rules against believing at will that One For Arthur won the race-we're not saying that I willfully made the proposition that $<$ One For Arthur wins the race $>$ true, but that I brought about the state of belief with the content $<$ One For Arthur wins the races. Second, I am here responding to Alston's claim that it is solely because we do not antecedently know what our doxastic attitude will be before critical reflection that critical reflection does not constitute control. The objection above introduces a new constraint on control: that we can come to believe something which is false/we subjectively assign a low probability to. Third, the objection relies on conflating the distinction between our ability to believe a proposition that is false and our ability to believe something that we simultaneously assign a low probability to. Google is not infallible. I could believe that Adam Curtis did not write Blackadder as a result of looking it up on Google, even if he did. So I can clearly come to believe false propositions via control I have over certain actions. Now, suppose there are lots of ways that I could find out about whether One For Arthur won the race. I could read about it in the newspaper, for instance; I could ask a bookmaker; I could ring up my uncle who was at the race and ask him; I could watch it on the TV. Suppose that One For Arthur did not win the race, and that I would have come to believe that had I done any of the things except watch it on TV. There was an unusual error and Channel 4 were showing last year's race where One For Arthur did win. Is it now so intuitively obvious that I do not come to believe that One For Arthur won the race via the indirect control I have over watching the TV? After all, my actions and beliefs here are compatible with a mutatis mutandis reading of the Principle of Alternative Possibilities, since I could have believed differently (and so we need not have to appeal to compatibilists accounts of freedom ${ }^{7}$ ). 


\subsection{Second Objection}

Recall the Blame-Obligation Supervenience Principle endorsed by Alston, which has the putative upshot that we can be blameworthy for our beliefs even though we are not subject to doxastic obligations. Parallel things can be said about certain actions over which we have no control; consider the following case discussed in Peels 2018:

imagine that I work in a hospital and that it is my task to fill the oxygen bottles that are used in the ambulance. I have an obligation to do so. Since I have control over whether or not I meet that obligation I am originally responsible for whether or not I do so. However, out of laziness I fail to do so. One day, the ambulance attendants arrive upon a scene in which someone desperately needs oxygen. Unfortunately, the bottle is now empty, so they cannot save him and he dies from a lack of oxygen. In this case, I have no control over whether or not the victim is saved, for I cannot intentionally set out to save him. I do not even know that he exists or that he is a victim. It is clear, therefore, that I have no obligation to save him. Nevertheless, it seems that I am blameworthy for his not being saved, because I had influence on that. For had I filled the oxygen bottles, as I should, he would not have died. Thus, I am not originally, but nevertheless derivatively, blameworthy for his death.

(Peels 2018, 118)

It seems clear that there is a difference in the way that the paramedic nurse is blameworthy for the fact that the patient did not get oxygen (given that the nurse could not have done otherwise) and the way in which the nurse is blameworthy for not adequately equipping the ambulance. Peels tries to capture this difference by characterizing the former as "derivative blame" and the latter as "original blame." Now, the trouble, it seems to me, is that if one accepts that this is a difference that needs to be captured, one should also accept that there can be a sub-class of obligations ("derivative" obligations) different from "original" obligations. What seems to be adjudicating in favour of ruling that there is no correlative doxastic obligation for a derivatively blameworthy belief is the principle that ought implies can (and we have no doxastic control, direct or indirect). But on a very natural reading of ought implies can, all blameworthy actions are ones where the agent could have acted otherwise. That is why we need a category of "derivative" blameworthiness to explain how assigning blameworthiness can nonetheless be compatible with ought implies can. But we could make the exact same move via parity of reasoning, mutatis mutandis, with respect to obligation, and claim that the nurse in the case above has a derivative obligation to give the patient oxygen (despite the fact that she cannot) in virtue of the fact that she has an original obligation to properly equip the ambulance. Indeed, one could claim that it is the very fact that there are such derivative obligations that explain the BlameSupervenience Principle. 
Thus, Alston either has a hard time explaining the Blame-Supervenience Principle, or else has to allow for a category of derivative doxastic obligation. As such, his case for the claim that there are no doxastic obligations, only duties to reflection, is inconclusive.

\section{3. $S$ has a Duty to Believe that $p$ Only if $S$ has a Duty to Reflect on Whether $p$}

I now want to propose an alternative argument for Alston's claim. Here is the 'master' argument.

(9) $S$ has a duty to believe that $p$ only if $S$ has a duty to reflect on whether $p$.

(10) A duty to reflect on whether $p$ always undercuts a duty to believe that $p$.

(11) There are no doxastic duties that render the holding of doxastic attitudes blameworthy, only duties to reflection.

In this section, I defend premise (9) (in the next, premise (10)). Here is my subargument for it:

(12) $S$ ought to believe that $p$ only if $S$ ought to believe that $S$ ought to believe that $p$. [Perspectival Internalism].

(13) $S$ ought to believe that $S$ ought to believe that $p$ iff $S$ ought to reflect on whether $S$ ought to believe that $p$.

(14) $S$ ought to reflect on whether $S$ ought to believe that $p$ iff $S$ ought to reflect on whether $p$. [Transparency].

(15) $S$ ought to believe that $S$ ought to believe that $p$ iff $S$ ought to reflect on whether $p$. [from 13, 14].

(16) $S$ ought to believe that $p$ only if $S$ should reflect on whether $p$.

Let me now go through premises 12, 13, 14 .

(12) $S$ ought to believe that $p$ only if $S$ ought to believe that $S$ ought to believe that $p$.

I take premise 12 to be a commitment to "perspectival" internalism, something like a commitment to the K-K thesis (see McHugh 2010 and Greco 2014 for defences of the K-K thesis, against the charge that it leads to infinite regress, for instance). "Perspectival" internalism contrasts with "access" internalism. Access internalism roughly says that a subject $S$ has some form of more privileged access to whether or not her belief is justified than has any other subject $S$ '. Perspectival internalism is the thesis that $S$ is justified in believing that $p$ only if $S$ is aware of what it is that is justifying her belief, and that it is justifying it for her (see Alston 1988). "Deontologism" in epistemology is often taken to be the thesis that $S$ is justified in believing that $p$ 
iff $S$ is blameless in believing that $p$. I've argued elsewhere (Booth 2008) that Deontologism is compatible with the failure of Access but not Perspectival Internalism. I do not think a lot hinges on that here, however, since it is uncontroversial that Deontologism entails Perspectival Internalism (though controversial whether it entail Access Internalism as per Bergmann 2006). What is prima facie controversial about 12 , assuming you think that there are such things as blameworthy/blameless beliefs, comes out by contrasting it to the following slightly different premise:

(12) $S$ ought to believe that $p$ only if $S$ believes that $S$ ought to believe that $p$.

But I think that 12 ' is expressed in 12 by something like semantic ascentthat is, if we use something like a meta-language to describe 12', 12 is in effect disambiguating that the "only if" in 12 ' is to be taken in a normative, and not merely descriptive, sense.

(13) $S$ ought to believe that $S$ ought to believe that $p$ iff $S$ ought to reflect on whether $S$ ought to believe that $p$.

I take what is on the RHS of "iff" in 13 to be analytic with what is on the LHS. The LHS of iff in 13 demands that take a second order attitude toward $p$ that (given 12) is congruent with $S$ 's first-order doxastic attitude. Put differently, it is to demand that $S$ has reflectively endorsed $S$ 's belief that $p$ (where reflective endorsement here can constitute the search for new evidence $\left.{ }^{8}\right)$. To demand reflective endorsement on $S$ 's belief that $p$ is simply to demand that $S$ reflect on whether $S$ ought to believe that $p$.

(14) $S$ ought to reflect on whether $S$ ought to believe that $p$ iff $S$ ought to reflect on whether $p$. [Transparency].

I take premise 14 to be an expression of a principle that has been called "transparency." I take transparency simply to say that the question of whether to believe that $p$ for all subjects gives way to the question of whether $p$ (see Shah 2008). I take this then to deliberately conflate the distinction some have made between transparency and "exclusivity" (McHugh 2015) and to be consistent with the idea that there can be non-epistemic reasons for belief (e.g. Leary 2017, Rinard 2017). So I think it is a relatively uncontroversial principle-or at least one that has many proponents also committed to the idea that there are doxastic obligations, and blameworthy beliefs.

\section{Obligations to Reflect on Whether $p$ Always Undercut Obligations to Believe that $p$.}

Here is my sub-argument for the other central premise of my "master" argument (premise 10): 


\section{Anthony Robert Booth}

(17) The obligation to believe can fail to be met by meeting an obligation to reflect only if the duty to believe and the duty to reflect can conflict.

(18) The duties cannot conflict.

(19) The obligation to reflect is not met by meeting the obligation to believe.

(20) The obligation to believe is always met by meeting an obligation to reflect. [From 17, 18, 19].

(21) A duty $D$ always undercuts another $D^{*}$ iff (i) meeting $D$ entails meeting $D^{*}$ and (ii) meeting $D^{*}$ does not entail meeting $D$.

(10) The duty to reflect always undercuts the obligation to believe.

Let's start by looking at premise 21 . Here I merely stipulate what I mean when I say that one duty undercuts another. The obvious comparison to draw here is between "undercutting" and "rebutting" defeaters in epistemology (see Pollock 1974). "Rebutting defeaters," roughly, give one reason not to believe a conclusion (which one seemed to have reason to believe) where undercutting defeaters give one reason to doubt that the given reasons for a conclusion really do support the conclusion. The reason I think that my stipulative definition of "undercutting" here is congruent with how the term is used vis-à-vis "undercutting defeaters" is that in my definition the duty $D$ does not compete with $D^{*}$, but rather shows how $D$ and not $D^{*}$ is really doing the normative work.

The central premise that needs defending in this sub-argument, I think, is premise 18 . To say that a duty to reflect and a duty to believe can conflict is to accept the logical possibility of such a scenario: that were you to reflect on whether $p$, you would end up believing that you ought not believe that $p$. And you ought believe that $p$. The ought involved here is a deontic ought such that you would be blameworthy (non-excused) whatever you did, reflect, or believe-you would be in an epistemic dilemma.

Now, the following two principles seem intuitive and are widely endorsed, the weakest of the two almost to the point of seeming trivial.

Epistemic Condition(strong): $S$ has a duty to believe that $p$ only if $S$ believes that $S$ has a duty to believe that $p$.

Epistemic Condition(weak): $S$ is excused for violating a duty to believe that $p$ only if $S$ reasonably fails to believe that $S$ has a duty to believe that $p .{ }^{9}$

With these principles in mind suppose (for reductio) the relevant duties can conflict, and that $S$ is in a situation such that if $S$ despatches their obligation to critically reflect $S$ would not believe that $p$ but that $S$ ought to believe that $p$. The key question to ask here I think is in such a case: could $S$ reasonably fail to believe (in accord with Epistemic Condition(weak)) that $S$ has an obligation to believe that $p$ ? Surely, it is almost analytic that the answer to this question is "yes"! $S$ would have done all she could with respect to evidence gathering and critical reflection with respect to whether $p$, and would have come to the conclusion that she should not believe $p$. No more could reasonably be asked 
of her, so surely she is reasonable in failing to believe that she should believe $p$, and thereby excused if she fails to.

\section{Contradiction}

The thought that the case is a genuine dilemma is in contradiction with the claim that $S$ would be excused. So the duties cannot conflict in a way that would make you blameworthy (not excused) for failing to meet one if you met the other, aka premise 18.

Premise 19 is obvious, so the last premise that requires defending is premise 17: The obligation to believe can fail to be met by meeting an obligation to reflect only if the duty to believe and the duty to reflect can conflict. The most obvious way to resist this premise, it seems to me, is to appeal to the idea that perhaps the obligations have different objects: our doxastic obligations have doxastic attitudes as their object, and duties to reflection have certain kinds of action as their object (mental or otherwise). As such, it is a category mistake to expect the dispatching of an obligation to critical reflection to de facto also dispatch a doxastic obligation. However, this won't do. This is because it is trivial that genuine obligations cannot be too demanding, and the duty to reflect without end is surely too demanding. Thus, our duty to reflection must always ensue with $S$ 's taking some doxastic attitude or other, even if it is suspension of judgement (see also n. 7). Thus, there will always be a determinate doxastic attitude that it is right to have as a result of dispatching a duty of critical reflection, even though from a first personal point of view, $S$ will not know what that is at the outset.

Objection: but what about simply stopping critical reflection and not taking any attitude at all, not even suspension of judgement?

Reply: if you just stop thinking about whether $p$, you have not properly dispatched your duty to critical reflection.

Objection: But doesn't this mean that the duty to reflection and the duty to believe are identical?

Reply: no, as the duty to reflection is the duty to take some doxastic attitude as a result of reflection.

\section{Conclusion and Why This Matters}

The central thing I have aimed to argue for in this chapter is that once you have met your obligation towards reflection, it is impossible for you to have not met your doxastic obligation. This ultimately means that the only relevant duties towards beliefs are our duties to reflect. This is because only by reflecting you will know both what you think you ought to believe and what you ought to believe/what you can non-culpably believe.

This matters because it enables us (deontologists) to evade Alston's epistemic poverty objection. Philosophers working on epistemic duties have up to now focused on Alston's apposite points about doxastic voluntarism, but 
have not really paid enough attention to the fact that for Alston the points about doxastic voluntarism are just a step towards arguing for the claim that epistemic deontologists to have to cash out epistemic justification in terms of blamelessness and to accept that there are no doxastic obligations. And one can be blameless and be in a poor position vis-à-vis our epistemic ends, claims Alston. And it is this that for him sounds the death knell for the deontological conception. But, surely, are we not always in a better situation with respect to our epistemic ends after we have critically reflected and collected more evidence, than where we have not done so?

\section{Notes}

1 A related, but subtly different, thesis is defended by Stapleford 2012: that while we have no duties to believe, we do have duties to proportion our beliefs to the evidence. He argues that this is John Locke's position in Book IV of An Essay Concerning Human Understanding. Unfortunately, I do not have the space to assess whether his interesting arguments for this slightly different conclusion are compatible with mine in this chapter.

2 The control we have over raising our hand is the paradigmatic case of direct control, since we (typically) do not have to do anything else than will that our arm goes up for it to go up.

3 I take the term 'derivative blamelessness' from Peels 2018.

4 Alston (wrongly!) thinks that a deontological account of epistemic justification underwritten by these duties falls prey to his 'epistemic poverty' objection. This depends on what the epistemic aim of deontological justification is: may be more to do with understanding than 'consilience' and deontological (epistemic) justification is not sui generis, in that it must be understood within a broader context of all things considered justification. I will return to this consideration in section 6 .

5 Tony Curtis in fact wrote Blackadder.

6 I owe the following case to Alex Greenberg.

7 Note, however, that, interestingly, most doxastic compatibilists have been keen to use compatibilists criteria to show that we have direct doxastic freedom, or controlthey have not typically aimed to show that we have indirect doxastic control over just doxastic influence. See for instance Steup 2008, 2012, and McHugh 2008.

8 IMPORTANT: where 'reflective on whether $p$ ' has to culminate in a doxastic attitude. So the RHS does tacitly tell us that $S$ has a belief. Thanks to Kevin McCain for raising this with me.

9 It is commonly accepted that ignorance is an excusing condition for responsibility, for discussion see (inter many alia) Van Woudenberg 2009, Smith 1983.

\section{References}

Alston, W. 1988. “An Internalist Externalism.” Synthese 74 (3): 265-283.

Alston, W. 1989. "The Deontological Conception of Epistemic Justification." In Epistemic Justification: Essays in the Theory of Knowledge. Ithaca, NY: Cornell University Press.

Bergmann, M. 2006. Justification without Awareness: A Defence of Epistemic Externalism. Oxford: Oxford University Press. 
Booth, A. R. 2008. "Deontology in Ethics and Epistemology.” Metaphilosophy 39 (5): 530-545.

Chrisman, M. 2008. “Ought to Believe.” Journal of Philosophy 105 (7): 346-370.

Greco, D. 2014. “Could KK Be OK?” Journal of Philosophy 111 (4): 169-197.

Peels, R. 2018. Responsible Belief: A Theory in Ethics and Epistemology. Oxford: Oxford University Press.

Leary, S. 2017. "In Defence of Practical Reasons for Belief." Australasian Journal of Philosophy 95 (3): 529-542.

McHugh, C. 2010. "Self-Knowledge and the KK Principle” Synthese 173 (3): 231-257.

McHugh, C. 2014. "Exercising Doxastic Freedom.” Philosophy and Phenomenological Research 88 (1): 1-37.

McHugh, C.. 2015. "The Illusion of Exclusivity.” European Journal of Philosophy 23 (4): 1117-1136.

Nottelmann, N. 2007. Blameworthy Belief: A Study in Epistemic Deontologism. Dordrecht: Springer.

Pollock, J. 1974. Knowledge and Justification. Princeton, NJ: Princeton University Press.

Rinard, S. 2017. "No Exception for Belief." Philosophy and Phenomenological Research 94 (1): 121-143.

Roeber, B. 2019. “Evidence, Judgement, and Belief at Will.” Mind 128 (511): 837-859.

Shah, N. 2008. “A New Argument for Evidentialism.” Philosophical Quarterly 56 (2): 481-498.

Smith, H. 1983. “Culpable Ignorance.” Philosophical Review 92 (4): 543-571.

Stapleford, S. 2012. "Epistemic Duties and the Failure to Understand One's Evidence." Principia: An International Journal of Epistemology 16 (1): 147-177.

Steup, M. 2008. “Doxastic Freedom” Synthese 161 (3): 375-392.

Steup, M. 2012. "Belief, Control and Intentionality.” Synthese 188 (2): 145-163.

van Woudenberg, R. 2009. "Ignorance and Force: Two Excusing Conditions for False Belief.” American Philosophical Quarterly 46 (4): 373-386.

Weatherson, B. 2008. “Deontology and Descartes' Demon.” Journal of Philosophy 105 (9): 540-569. 


\title{
11 Wisdom, Open-Mindedness, and Epistemic Duty
}

\author{
Sharon Ryan
}

\section{Introduction}

This chapter will propose an evidentialist, virtue-theoretic account of human wisdom. According to this theory of wisdom, a wise person guides their life by good evidence and develops a comprehensive understanding of the most fundamentally important and meaningful aspects of reality. On this virtue-theoretic and evidentialist account, wise people possess important intellectual virtues, and those virtues are defined within an evidentialist framework. One of the most important virtues for wisdom is open-mindedness. After providing an account of open-mindedness, I will argue that cultivating open-mindedness not only contributes to wisdom, but that we have an epistemic duty to be open-minded. I will argue that the familiar objections against epistemic deontology have no weight against the view that we have an epistemic duty to be open-minded. Finally, I will argue that open-mindedness is an attractive and promising alternative to steadfast and conciliatory positions in the peer disagreement debate.

\section{Wisdom}

A full defense and analysis of wisdom is not the purpose of this chapter. I will simply suggest and explain a promising theory of wisdom. I will then draw out some interesting implications of this theory of wisdom. My focus will be on the role that understanding and open-mindedness play in this theory of wisdom. The theory I propose is:

\section{Evidentialist Virtue Theory of Wisdom (EV)}

$S$ is wise at $t$ to the extent that (1) $S$ has a comprehensive understanding of a wide variety of fundamentally interesting and meaningful aspects of reality, (2) $S$ 's understanding is based on high-quality evidence available to diligent inquirers at $t$ and (3) $S$ has a cognitively excellent character at $t$.

This theory is evidentialist in that one's evidence is the core guiding force of all aspects of the wise person's life. It is a virtue theory because it focuses on intellectual virtues, which are spelled out in evidentialist terms. The first condition of $\mathrm{EV}$ is intended to capture both the epistemic standing of the wise 
person and the domain of wisdom. According to EV, the epistemic standing a wise person possesses is understanding, as opposed to knowledge or justified belief. The domain over which one must have understanding includes the most fundamentally interesting and meaningful aspects of reality. Spelling out what that means in specific detail is probably impossible. Possible or not, I will not be spelling out the details in this chapter. The basic idea is that wise people understand what really matters. They understand the profound difficulties, risks, and opportunities of life. They understand how to love, appreciate, and care for others. They have a basic understanding of current science and possess evidentially solid historical perspectives; they have a basic understanding of fundamental questions and potential answers to deep philosophical questions; they can imagine alternative perspectives; and they have an empathetic and evidentially grounded understanding of the human condition.

The epistemic standing noted in EV stands in contrast to some other theories of wisdom including, for example, Stephen Grimm's. Grimm's theory takes knowledge to be the epistemic standing of the wise person. The domain of what the wise person knows, on Grimm's theory, is what is good or important for living well (Grimm 2015). ${ }^{1}$

My Deep Rationality Theory of Wisdom, which I no longer accept, focused on rationality, or justified belief, as the epistemic standing of the wise person (Sharon Ryan 2012, 2017). The domain of the Deep Rationality Theory was similar to Grimm's focus on living well, but it also included justified beliefs about history, philosophy, literature, science, and the other main components of a solid liberal arts education. I argued for the epistemic standing of justified belief, rather than knowledge, for three main reasons:

(1) Confucius should qualify as wise even if he were living in the matrix, lacking knowledge about the external world, including knowledge of what really matters.

(2) Wise, pre-modern thinkers lacked knowledge of many important truths about reality, including their scientific beliefs.

(3) If we are appropriately honest and humble about the most interesting, important, meaningful and controversial claims in the domain of wisdom, we should admit that wise people often lack knowledge, even when they rationally arrive at the truth, and possess an impressive understanding in that domain. ${ }^{2}$

Paul O'Grady considers another reason to be worried about requiring knowledge for wisdom. ${ }^{3}$ To appreciate O'Grady's reservations, assume that Buddha and Jesus are paradigm examples of wise people.

On a mainstream interpretation of Christianity, Jesus holds that there is a stable entity called the self, there is a different and distinct reality called God and that well-being lies in achieving an appropriate connection between these two, which transcends the cessation of corporeal existence. So wisdom, for Jesus, involves knowledge of these truths, an assessment of 
where one is in relation to them, and following a path which leads one to achieve them. The Buddha rejects all of these. There is no self, there is no God and union of self and God is not the way to achieve well-being. On the contrary, loss of ego, realizing the unity of all things in compassion and following the noble eightfold path is the path to well-being.

(O’Grady 2018, 70)

If Jesus and Buddha genuinely disagree about how to live well, then at least one of them lacks knowledge and is therefore, on Grimm's theory, excluded as wise. More generally, if it is even possible for two or more wise people to have conflicting, but equally reasonable conceptions of the components of a good life, then knowledge is too strong a requirement for wisdom. ${ }^{4}$

\subsection{Understanding and Wisdom}

Shane Ryan's theory of wisdom uses understanding, rather than knowledge or justified belief, as the epistemic standing of the wise person (Shane Ryan 2016). The focal point of the domain of wisdom, in Shane Ryan's theory, is the same as Grimm's-how to live well..$^{5}$ Shane Ryan's critique of my earlier theory is part of what convinced me to focus on understanding as the appropriate epistemic standing for wisdom. Ryan focuses on understanding because he believes that knowledge sets the bar both too high and too low. He also believes that justified belief sets the bar too low. Ryan thinks knowledge is too demanding because he thinks having some justified, false beliefs is compatible with wisdom. ${ }^{6}$ Ryan believes knowledge and justified belief set the bar too low because one could know of a lot of important propositions (or have justified beliefs about a lot of important propositions) and lack the depth of understanding that is necessary for wisdom. For Ryan, there is something much more valuable about understanding than mere knowledge or justified belief. ${ }^{7}$

Why is understanding more valuable than justified belief or knowledge? Isn't every sentence of the form " $S$ understands that $p$ " reducible to a corresponding sentence of the form " $S$ knows that $p$ " or " $S$ is highly justified in believing that $p$ "? Duncan Pritchard and others have argued that not all claims about understanding are reducible to claims about knowledge (Pritchard 2008). According to non-reductionists, like Pritchard, knowing that $p$ is true does not guarantee understanding that $p$ is true. The intuitive idea of non-reductionism is that a person can know a lot of information but understand very little. Similarly, knowing why $p$ is true does not guarantee understanding why $p$ is true, according to this view. Pritchard borrows Berit Brogaard's "Faulty Wiring" example to support his case (Brogaard 2005). In Faulty Wiring, a father and his very young son are watching their house burn down. When the fire marshal comes over to tell them that faulty wiring caused the fire, both the father and the young child acquire testimonial knowledge that faulty wiring caused the fire. However, according to Pritchard, the father is in a much more valuable epistemic state than his young son because he, but not his son, understands that the fire was caused by faulty wiring. The son (who has no conception of 
electricity and wiring) knows, but fails to understand, that faulty wiring caused the fire. Similarly, claims Pritchard, both the father and son know why the house burned down. But it is only the father who understands why the house burned down (Pritchard 2008).

Shane Ryan insists that wise people have this deeper and more valuable grasp of how to live well than is provided by those who only know, or have justified beliefs about, how to live well. They grasp, in a much deeper way, the many explanatory connections between their beliefs.

Paulina Sliwa argued that Pritchard's example, and others like it, do not support non-reductionism. While Sliwa agrees that both the father and the son know that the fire was caused by faulty wiring, she denies that only the father understands that the fire was caused by faulty wiring. The son, according to Sliwa, also understands that the fire was caused by faulty wiring. What the son fails to understand is why faulty wiring causes fires. But he also fails to know why faulty wiring causes fires. Whatever the boy understands can be translated into a corresponding claim about what he knows. Everything he fails to understand can be traced to something he does not know. So she denies that Faulty Wiring shows that understanding that $p$ is anything more than knowing that $p$ or that understanding why $p$ is true is anything more than knowing why $p$ is true. The father's superior epistemic state is adequately explained by the fact that he knows many things that the son does not know. He knows facts about wiring, how faulty wiring can cause a fire, and so forth (Sliwa 2015). Moreover, when it comes to understanding the complex explanatory connections between one's beliefs, one could also reduce this to knowing, or having highly justified beliefs about, the complex explanatory connections between one's beliefs. Thus, if there is a good reason to prefer understanding to knowledge or justified belief as the standing of the wise agent, it is to be found elsewhere.

There is a better reason to conclude that understanding is more valuable than knowledge or justified belief, and to conclude that understanding is the correct epistemic standing for wisdom. As I noted earlier, because propositional knowledge requires truth, I believe knowledge is too strong of a requirement for wisdom. Thus, I will be more concerned with providing reasons to prefer understanding over justified belief as the appropriate epistemic standing for wisdom.

Understanding is a deeper, richer, more expansive, and more valuable epistemic state than having justified beliefs in a domain. This is simply because understanding is a cognitive achievement that is not limited to doxastic attitudes toward propositions. ${ }^{8}$ Limiting the epistemic stance to having justified beliefs or propositional knowledge would rule out many of the insights and attitudes possessed by the wise. For example, a wise person can step outside of their own experience and imagine, with great empathy, what it is like to be in another's shoes. Such imaginings, perceptions, and empathetic graspings cannot be reduced to something purely propositional or doxastic. Moreover, a wise person is normally equipped with a life of experience that puts her in a position to understand how things go for others because she might have been there herself or has learned from the experience of someone else who has 


\section{Sharon Ryan}

already been in the difficult situation. A wise person might understand how, for example, to deal with the death of a child and this will not be explained fully in terms of a set of beliefs. Understanding opens up a vast array of cognitive states not reducible to beliefs about propositions.

My 88-year-old father just moved to my current home town. My father's little sister, who is 78 years old, just came to visit. They had not seen one another for more than ten years. My father's childhood family was large and my childhood family was large, and this was the first time in my life that I had watched my dad and his sister interact in intimate, personal conversation. This was also the first time in my life that I intently observed my father in his role as a big brother. By watching and listening to my dad and my aunt with careful and loving eyes, I came to understand them in a new and delightful way. My understanding of them, of aging, of sibling love and history, increased dramatically over the course of a few hours. This experience with my father and my aunt inspired me to better understand my relationships with my four brothers. I gained some wisdom. A small portion of what I gained was in the form of new beliefs. What impacted my understanding, more than anything else, is what I felt, what I saw in their faces and smiles, and what I heard in their stories, their silences, the rhythm of their voices, and their laughter. By opening my mind and my heart, I gained a deeper and more empathetic appreciation of them-especially of my father. I can try, after the fact, to formulate this experience in words and beliefs to share with myself and others. But what I'll be trying to explain is something I understood in a profound way, prior to shaping my experience into a story.

When I understand what it would be like to be in your shoes, I don't merely have a bunch of justified beliefs about what it is like to be in your shoes. I can, to some degree, take on your perspective. When I understand how you feel, or even how I feel, I possess insight and awareness that cannot be reduced to a set of beliefs. When I really understand your shame, for example, I feel shame. There is a distinctly qualitative dimension to understanding. When a wise person who has never been homeless, feared, or hated manages to understand what it is like to be homeless, feared, or hated, this understanding cannot be reduced to a mere set of justified beliefs that she holds. A wise person understands pain, suffering, and loss "in her bones." This is a rich and deep form of understanding that cannot be completely reduced to propositional content or mere doxastic states. Therefore, the epistemic standing of wisdom is understanding, not justified belief or propositional knowledge. ${ }^{9}$

\subsection{Evidence and Wisdom}

The second condition of EV requires a wise person to base their understanding on high-quality evidence available to diligent inquirers living in their time period. This condition is subjective in that wisdom is based on the evidence that is available during a time period. But it is objective in that wisdom depends whether the person actually uses evidence that is actually good evidence at 
that time. It is an externalist theory in the sense that evidence that is available to a person but that she does not personally possess (or "have") can impact whether or not they are wise. Thus, Socrates' understanding will be judged on the evidence available to serious inquirers living at his time. He is not to be judged on all of the evidence available to diligent inquirers in 2020. Given the evidence available to serious inquirers living in his time period, Socrates had a good grasp of the human condition, philosophical quandaries, history, and other fundamentally meaningful aspects of reality. A person living in 2020 is to be evaluated in terms of the high-quality evidence available to diligent inquirers living in 2020. If a person in 2020 refuses to consider the data provided by good science in 2020, she is not a candidate for wisdom on EV. ${ }^{10}$ Confucius is wise in the matrix as long as his comprehensive understanding of the most interesting and meaningful aspects of reality is based on his use of high-quality evidence available to diligent inquirers in the matrix. Thus, on my view, a comprehensive understanding can be evidentially fabulous and not truth conducive. As was noted earlier, on this conception of understanding, the wise person's body of evidence will not be restricted to other beliefs. A wise person is patiently attentive to all forms of high-quality evidence.

\subsection{Cognitive Excellence and Wisdom}

The third condition of EV requires that a wise person have a cognitively excellent character. A person who possesses cognitive excellence has acquired a cluster of intellectual virtues that contribute to her ability to understand reality. $S$ has a cognitively excellent character to the extent that her beliefs, other rationally evaluable cognitive attitudes, and her behavior fit with, and are carefully guided by, excellent evidence. A person whose actions fail to reflect what they rationally believe demonstrates a failure of cognitive excellence. There is something that she just doesn't get. Knowing what is the right way to treat another person, and yet failing to do so is the result of a poor cognitive (and moral) character. Ignoring strong evidence and reactively and impulsively drawing conclusions and acting on them is a cognitive character flaw. Cognitive biases and all forms of epistemic injustice are, at least in part, cognitive character flaws. ${ }^{11}$ The extent of such infractions chips away at one's cognitive excellence and thereby chips away at one's qualifications for wisdom.

All of the important intellectual virtues, including open-mindedness, can be understood as ways of being cognitively excellent. Cognitive excellence is not perfection. One can have some cognitive failings over a lifetime or period of practice and still be excellent. For example, one need not be a math whiz to be cognitively excellent. One can occasionally make a poor logical inference and still possess cognitive excellence. However, some errors can be deal breakers. Imagine we were trying to understand moral excellence. A morally excellent person could give to the second-best charity or on rare occasion speak harshly to a friend who deserves none of it. But she can't intentionally drown her 
children in the bathtub. Possessing an utter contempt for science, or flat-out refusing to learn anything new, are deal breakers for cognitive excellence. ${ }^{12}$

Cognitive excellence is an achievement that is built up in a person with careful practice. In many ways, it is very similar to the sort of patient and consistent practice we find in Stoicism and in Buddhism. ${ }^{13}$ In this chapter, I will focus on the virtue of open-mindedness as one of the most significant contributors to cognitive excellence and wisdom.

\section{Open-Mindedness}

What is open-mindedness? Like most interesting concepts, there are many different and legitimate senses of open-mindedness. Not all of those senses are especially pertinent to wisdom. Before settling on the kind of open-mindedness that is required for wisdom, I will distinguish some alternative conceptions that are either not required for wisdom, or can actually undermine the pursuit of wisdom. Sometimes we use the term "open-minded" to capture a kind of flexibility in preferences. We all know a person who is a nightmare of inflexibility. When served a cup of hot tea at a friend's house, they complain that the tea is too hot and demand a new cup of tea! When they come to a dinner party, they demand to be seated in a particular chair so that they, and only they, may have the premiere view of a painting on the dining room wall. When eating in a public restaurant, they demand to have the air temperature set at a very specific degree and will not stop whining until the temperature is perfectly adjusted to their own personal liking. When ordering pesto, they demand to know the precise ratio of garlic to basil before they will order their meal. They demand to know which particular hour grapes were harvested before sampling a complimentary glass of wine! Sometimes we use the term "open-minded" to capture the refreshing alterative to the above-mentioned irritating character. The following gets at the idea:

\section{(OM1)}

$S$ is open-minded to the extent that she is flexible and easygoing with respect to her preferences and demands.

This is certainly one way to be open-minded, but it fails to capture the essence of the open-mindedness that is essential to wisdom. A wise person might be very inflexible about the most important and meaningful aspects of reality. For example, she might demand that all children, regardless of their citizenship, be treated humanely. She will not be flexible about torturing elephants. Thus, not all forms of open-mindedness are central to wisdom. Also, the kind of openmindedness we are trying to make use of is a form of cognitive excellence, so this focus on preferences and demands seems to be on the wrong track.

One might think that the virtue of open-mindedness that is pertinent to wisdom has to do with a kind of intellectual humility. Perhaps we should understand the relevant sense of open-mindedness in terms of a kind of skeptical and 
humble stance toward what one knows. The following is one way to capture this idea:

\section{(OM2)}

$S$ is open-minded to the extent that she suspends judgment on propositions about reality.

The problem with OM2 is that the more skeptical one is, the more openminded one is. But even if that is a kind of open-mindedness, that is certainly not the kind of open-mindedness we are looking for in wisdom. One can be skeptical for better or worse reasons, and one who is skeptical for terrible reasons is not thereby in a cognitively superior position than one who is rationally less skeptical. Moreover, to cling to a skeptical position in the face of strong evidence in favor of believing $p$, seems very closed-minded.

Keeping with an attempt to tie open-mindedness with intellectual humility without the problem of radical skepticism, one might consider a more reflective, thoughtful, second-order view of open-mindedness such as:

\section{(OM3)}

$S$ is open-minded to the extent that she is aware of her own fallibility as a believer, and is willing to acknowledge the possibility that anytime she believes something, it is possible that she is wrong. ${ }^{14}$

Although much better, OM3 is unfortunately consistent with a vicious closedmindedness. One could be open-minded in the sense captured in OM3 and be incredibly arrogant and closed-minded. One could believe one is fallible, but insist that everyone else on Earth is not only fallible but an idiot. And while admitting that it is always possible that they are wrong, they might always insist that they are not, in fact, wrong. Thus, such a person could refuse to consider any other alternative perspectives. They might believe that their own beliefs, though possibly wrong, are far superior to anyone else's viewpoint. A person who satisfies OM3 could fail to be humble enough and so not open themselves up to new and better evidence. A better way to formulate an intellectually humble sense of open-mindedness that avoids the pitfalls of irrational radical skepticism and a closed-minded arrogance is (from Whitcomb et al. 2017):

\section{(OM4)}

$S$ is open-minded to the extent that she is aware of her own cognitive limitations and she "owns" them.

OM4 is an extremely promising account of intellectual humility developed by Dennis Whitcomb, Heather Battaly, Jason Baehr, and Daniel Howard Snyder. By ownership, they are getting at the idea that there is a diligent response a virtuous cognitive agent has toward their fallibility and other cognitive 


\section{Sharon Ryan}

limitations. For example, if they are aware that they have limitations in their understanding of a subject, they do not boast of their brilliance on the subject matter. They do not dismiss high-quality alternative perspectives. While OM4 might be an insightful way to understand the virtue of intellectual humility, ${ }^{15}$ and avoid the pitfalls of OM2 and OM3, it is not what we need as a way of thinking about the kind of open-mindedness that is central to wisdom. ${ }^{16}$ Open-mindedness is more cognitively adventurous and outward-looking than the cautious and humble attitude in (OM4). While humility might be an important catalyst for open-mindedness, humility is not open-mindedness.

Jason Baehr (2011) offers something even better:

\section{(OM5)}

$S$ is open-minded to the extent that she is characteristically willing and (within limits) able to transcend a default cognitive standpoint in order to take up or take seriously the merits of a distinct cognitive standpoint.

But even this is not the right sense of open-mindedness. One might take seriously the merits of a distinct cognitive standpoint while nevertheless not ever adopting distinct cognitive standpoints that are available and superior to one's own. This is like the administrator who always asks for your input, takes it very seriously, sees that your idea is better than his, but always in the end does what he was initially inclined to do. Among other failures, he lacks the relevant sort of open-mindedness.

The sense of open-mindedness that is a central virtue for wisdom is both inward-looking and outward-looking. Open-mindedness is what allows us to focus our attention on the evidence, rather than our pride or our fears. Open-minded people prioritize, and have serious concern for, rationality and understanding. Open-minded people conscientiously seek out evidence in the form of alternative viewpoints and they are honest about their own evidential situation. Open-minded people self-reflect and keep their cognitive attitudes anchored in their evidence. Open-minded people develop an understanding of the views of others, even if the people they are understanding hold radically mistaken views of the world. Simply understanding someone else's way of viewing the world enhances your understanding of them. When we are openminded, we are able to be authentic and honest when looking for, appreciating and evaluating our evidence. An open-minded person who is wise is a master of being intellectually authentic and attentive. I propose the following as the right way to think about the kind of open-mindedness that is a component of the kind of cognitive excellence a wise person embodies.

\section{(OM6)}

$S$ is open-minded to the extent that (1) $S$ desires and values having an understanding of reality, (2) $S$ conscientiously seeks good evidence about reality, and (3) $S$ is attentive and fair in her interpretation and use of her evidence. 
I am not claiming that OM6 is the only legitimate sense of open-mindedness. But I am claiming that this is the most significant sense of open-mindedness that is necessary for cognitive excellence and wisdom. It captures the idea that the goal of open-mindedness is understanding reality. It requires one to seek out evidence, including taking into account alternative points of view, and it guards against being so open that one actually accepts the viewpoints of others without the scrutiny of a fair hearing.

Rebecca Wallbank posed an interesting objection to OM6 as an adequate way to understand the kind of open-mindedness that is central to wisdom. ${ }^{17}$ Wallbank maintains that following OM6 would be very unwise in very important and meaningful situations that demand interpersonal trust. Imagine, for example, that your partner is late for a dinner date. When he finally arrives, he says, "I'm very sorry I am late, but traffic was terrible and then I had trouble finding a parking spot." OM6 seems to encourage you to jump on your phone to gather more evidence, checking traffic patterns on Google Maps, and studying the downtown parking availability app. This follow-up inquiry might lead to a more evidentially rational belief about the matter, but Wallbank argues that it would not be wise and it could very well ruin the relationship. To see why it might ruin a relationship, just put yourself in the shoes of a sincere testifier and then imagine whether or not you'd want to date the skeptical inquirer who constantly doublechecks everything you tell her. Following the demands of OM6, it seems, would undermine the kind of trust one expects from one's friends. The very disposition of the relentless questioner can undermine friendship. Friendship is certainly an element of the good life that a wise person should pursue and recommend to others. Therefore, claims Wallbank, OM6 cannot be the right way to think about the kind of open-mindedness that is essential to wisdom.

I do not think this example refutes OM6, but I do think it provides a welcome opportunity to elaborate further on the sense of open-mindedness that I am advocating for. My response to Wallbank turns on how the details in her example are worked out. Specifically, it depends on whether the trust is blind or rational, and also on whether or not the partner's tardiness is important. Let's just assume, for the sake of the example, that being on time for dates is something that is very important to you because you value your time and don't want to waste it waiting. Now let's suppose that it is not yet determined within the relationship if the partner is trustworthy. If so, then I disagree with Wallbank that a wise person ought to simply trust the partner for the good of the budding friendship. While I agree that it isn't a wise idea to get on Google Maps and engage in an inquisition of the guy and ruin dinner, I think it would be unwise to just buy the testimony hook, line, and sinker. If you know that you care about timeliness, you need to acknowledge that truth, respect it, and figure out if your new partner is right for you. His testimony definitely provides some reason to think this was a regrettable mistake with a reasonable excuse. Nevertheless, you should pay attention to all of the relevant evidence. If other evidence about his trustworthiness and timeliness is available now, or down the road, pay attention and be fair and honest about that evidence. That's all OM6 demands. 


\section{Sharon Ryan}

If we work out the details of Wallbank's example supposing that there is excellent reason to trust your friend's testimony, the objection fails for other reasons. Suppose you have been friends for quite some time and you have found him to be very honest with you and very respectful of your time and feelings. In that case, listening to him and trusting him is exactly what OM6 recommends. You have high-quality evidence and you should treat it as such and enjoy your dinner. So, I agree with Wallbank that double-checking the testimony of friends whom one has good reason to trust is not wise. I also agree with her that double-checking the testimony of friends one ought to trust would not be an example of a positive cognitive character. To do otherwise would violate OM6.

This conception of open-mindedness not only helps us understand the nature of wisdom, but it also provides us with the resources to make valuable contributions to two major controversies in epistemology. One controversy is whether we have any epistemic duties or obligations. The other controversy is between conciliatory and steadfast positions in the debate about peer disagreement.

\section{Epistemic Duty}

The question of whether we have epistemic duties or obligations about the doxastic attitudes we adopt is an ongoing and complex debate in epistemology. There are those who think that we cannot have any such obligations or duties because we lack the appropriate sort of direct control over our beliefs. After all, they insist, "ought" implies "can." Beliefs, they insist, are involuntary reactions to our evidence (or what we take to be evidence). Without control, it seems to make no sense to hold people responsible for the beliefs they wind up with. On the other side of the debate, there are those who think we do have an epistemic obligation to believe exactly what our evidence supports (or to believe the truth, or to never believe falsehoods). This side understands epistemic justification within a deontological framework, where being justified in believing $p$ is believing as one ought to believe. We can, on this deontological way of viewing justification, be praised or blamed for what we believe. Those on this side of the debate typically endorse a form of doxastic voluntarism or compatibilism, arguing that our doxastic attitudes are, at least sometimes, under our control. I am a doxastic compatibilist and an evidentialist, and I think we do have an epistemic obligation to form doxastic attitudes that fit our evidence. I deny that "ought" implies "can." Despite them being repeated over and over again in the literature, I do not find any of the arguments against a doxastic compatibilist defense of such epistemic obligations convincing. But I am willing to grant those arguments for the purpose of this essay. ${ }^{18}$ That is, I am going to grant, just for the sake of the argument, the following claims: (1) Incompatibilist doxastic control is necessary for doxastic obligations or duties and (2) We lack such doxastic control. And therefore, I also grant: (3) It is false that we have any epistemic duties with respect to what we believe. (1), (2), and (3) do not, however, establish that we have no epistemic duties whatsoever. Even if (1), (2), 
and (3) are correct we can have other epistemic duties, including duties to conduct fair inquiries, the duty to gather and use high-quality evidence, the duty to do responsible research, and the duty to be open-minded epistemic agents.

I believe we have epistemic duties. I believe epistemic duties are an extremely important type of moral duty. So, I'm not arguing that epistemic duties are duties that are non-moral. What we believe, and how we conduct our epistemic practices, has an important moral impact on our own lives, the lives of other creatures, future generations, and the health of the planet. In fact, I think we cannot make sense of moral responsibility without a robust commitment to epistemic responsibilities. When I hold someone morally responsible for a hate crime, for example, I am tracing an important element of their responsibility to the epistemic practices that led them to endorse and commit their hateful actions. The extent to which we are willing to withhold moral responsibility for such crimes can be explained, in part, by our willingness to excuse responsibility for the attitudes that led to the behavior. For example, a young person who has been brainwashed by racists, will be less morally responsible for her actions due to a somewhat blameless, yet still horrendous, set of beliefs. Or a toddler who does not yet understand the potential consequences of their actions is far less morally responsible for their actions than an adult equipped with an adequate understanding of the potential consequences. ${ }^{19}$

Among our most important epistemic duties is the duty to develop an openminded character. In doing so, we develop our capacity for cognitive excellence. And cognitive excellence contributes to our capacity to be morally good and, ideally, to be wise.

None of the familiar objections against doxastic duties and deontological conceptions of justification have any weight against these other epistemic duties. I'll focus here on the duty of open-mindedness. Human beings generally do have the ability to become more open-minded. Right now, I can decide to pay more careful attention to all of my evidence and use it more fairly. Right now, I can listen to you or ignore you. Right now, I can try my best to really understand you and your life situation with empathy and without judgment. Right now, I have control over whether or not I will seek good evidence. Right now, I have control over whether or not I will try to understand reality. Right now, I have control over whether I will pay close attention to well-educated scientific researchers. I can, with practice, develop and improve many aspects of my epistemic character, including my level of open-mindedness. The familiar involuntarist considerations against duties to believe are completely irrelevant to the claim that we have an epistemic duty to cultivate, practice, develop, and master open-mindedness and other intellectual virtues.

Focusing on intellectual character also does a nice job of explaining what we care about when we find ourselves blaming (or praising) people for what they believe. Consider Clifford's shipowner. We blame him for believing his ship is seaworthy after learning that the ship needs repairs. We can explain this legitimate blame by focusing not on the fact that he formed the belief that the ship was seaworthy, but for allowing himself to push aside important evidence. $\mathrm{He}$ was closed-minded to some extremely important evidence before him and he 


\section{Sharon Ryan}

selectively focused on the evidence that favored the belief he wanted to adopt. That is what is especially bad about his epistemic practice. When a colleague fails to understand a situation because he fails to give attention or weight to the testimony of a student because of her age, race, class, or gender identity, we should see that as a form of epistemic injustice for which he is responsible. If he developed open-mindedness and gave the evidence before him its proper weight, he would improve with respect to cognitive excellence and he'd be a better person. We can blame him for his failure to be open-minded even if we cannot, for involuntarist reasons, blame him for holding particular, unjustified beliefs. Even if it is true that, once we pay attention and focus on how the world seems to us, we cannot directly and immediately control which doxastic attitude we wind up with, we are nevertheless responsible for what we do to cultivate and refine our epistemic characters. We have a strong duty to be openminded epistemic agents.

\section{Peer Disagreement}

In the past decade or so, an impressive and complex body of literature has blossomed around the question of what is the appropriate response to take when you discover that an epistemic peer disagrees with you. Some of the literature is an attempt to define what is an epistemic peer. Although there is plenty of disagreement about what is the best definition, the basic idea is that an epistemic peer is a person who is in the same cognitive and epistemic boat as you. She's someone who is roughly as informed and as intelligent as you are. Should the mere fact of the disagreement cause you to back off, or at least lower your confidence, in your conclusion? Or, should you continue to endorse your own view until you've been shown that it is you who has made a mistake. Two main camps have emerged in this literature. Steadfast approaches contend that you should stand your ground. Conciliatory approaches contend that the disagreement, all by itself, has evidential weight. That is, noticing the disagreement should at least lower the confidence of each side in the disagreement. Some conciliatory positions go further and maintain that recognition of the disagreement, all by itself, provides sufficient reason for both sides to suspend judgment.

Steadfast approaches to peer disagreement can seem arrogant and irrational, especially when we focus on simple examples along the lines of David Christensen's restaurant check case (Christensen 2007). In this example, we have the following basic story. A group of colleagues go out to dinner. They agree that they will split the bill equally after adding a $20 \%$ tip. Imagine that Sophia and Poindexter, who are equally good at mental math, volunteer to figure out what each person should pay. Sophia calculates $\$ 47.25$ per person and Poindexter calculates $\$ 42.25$ per person. Obviously, at least one of them made a mistake. Upon hearing Sophia's answer, how should Poindexter respond? How should Sophia respond? Should each one stick to their original answer until they are shown the error of their ways. Or should each one back off of their original answer? The steadfast approach says they should both 
stick to their guns. But doesn't that seem bull-headed? You know, for sure, that at least one of you is wrong. Why assume it is not you? Shouldn't you both suspend judgment, whip out your phone, recalculate together, and figure out the bill? In this sort of case, conciliatory approaches seem very humble and rational. If you have no good reason to think it is the other person, shouldn't you both back off and adjust your doxastic attitudes, at least by lowering your confidence or perhaps even suspending judgment?

However, in more complex cases where a simple recalculation with a calculator won't settle the matter, conciliatory approaches seem too deferential. If your evidence was good and you did a good job using that evidence, why should the disagreement itself move you? At the end of the day, neither of these approaches seems correct. Sometimes it seems right to lower your confidence and sometimes it does not.

Open-mindedness, as proposed in OM6, provides a solution to this debate. An open-minded person would temporarily suspend judgment in the restaurant bill case, recalculate, and come to an easy resolution. This is good, because I think conciliatory intuitions are very strong in the restaurant bill case. In more complex cases, such as ones that involve philosophical peers disagreeing about thorny problems, open-mindedness would allow one to stand one's ground while carefully and respectfully examining the other side's argument, honestly and fairly using that evidence. This is good, because in such cases, steadfast intuitions are strong. Being open-minded does not always require you to suspend judgment or lower your confidence. Nor does it always license you stand your ground. It always seems right to be open-minded to the other side's arguments when you discover that an epistemic peer disagrees with you, and that's exactly what this virtue-theoretic approach requires of you and your peer. Thus, this virtue-theoretic approach has all the benefits and none of the costs of the standard positions in this debate.

\section{Conclusion}

I have proposed a theory of wisdom that is an evidentialist, virtue theory. One of the main virtues of a wise person is open-mindedness. After proposing a way to think about open-mindedness, I have shown how open-mindedness provides us with a way of grounding epistemic duty that bypasses the worries concerning doxastic voluntarism and a deontological conception of epistemic justification. Open-mindedness also provides a more balanced response to peer disagreement that avoids both the arrogance associated with steadfast views and the overly humble responses we sometimes find in conciliatory positions. ${ }^{20}$

\section{Notes}

1 Grimm's theory also requires that one know how one stands with respect to what is good or important and also has knowledge of a strategy for obtaining what is good or important for well-being.

2 For a defense of the third reason, see Sharon Ryan (2019). 


\section{Sharon Ryan}

3 O'Grady spends his paper offering up some solutions for Grimm. Although interesting, I believe none of the proposed solutions is as convincing as O'Grady's objection.

4 I admit that my first two reasons are controversial. I don't think most people share my strong intuition that Confucius is wise if he is in the Matrix. I know many people disagree with my contention that a good grasp of science is necessary for wisdom. However, the third reason and O'Grady's worry seem to me to be very solid reasons for abandoning the requirement of knowledge in favor of something weaker. In section 2.1, I will provide reasons for requiring understanding, which I take to be in more valuable than propositional knowledge.

5 Ryan includes other requirements for wisdom such as having epistemically appropriate beliefs and being committed to acquiring a deeper understanding of how to live well and being successful at living well.

6 He makes it very clear that he also believes that not all false beliefs are compatible with wisdom.

$7 \mathrm{He}$ is in good company with Lynne Rudder Baker (2003), Catherine Elgin (2007), Jonathan Kvanvig (2003), Duncan Pritchard (2008), Dennis Whitcomb (2012), and Linda Zagzebski (2001) among others.

8 This is also a good reason to rethink the way we characterize the property of divine omniscience. It will not be sufficient to define omniscience in terms of knowing all true propositions.

9 One might point out that this kind of understanding could be captured in a nonpropositional way of knowing. For example, I can know what it is like to be in your shoes without that being fully captured in a set of beliefs. Or I can know how to do $\mathrm{x}$ without that knowledge being propositional. For reasons similar to Sliwa's one could argue for a kind of reductionism in non-propositional forms of understanding to non-propositional forms of knowledge. I think that's correct. I resist this move here because I believe knowledge is factive and understanding (and wisdom) is not factive. Thus, I'm not interested in focusing on knowledge. The contrast I am interested in is between understanding and justified belief. Justified belief is, by definition, doxastic. Furthermore, even if I am wrong about all the reasons I gave for abandoning knowledge, and reductionism is true, I think "understanding” sounds more natural than "know" when it comes to grasping what really matters.

10 Her candidacy for wisdom is threated even if she is, in some sense, blameless for failing to consider good evidence that is available to diligent inquirers. Wisdom, on this theory, holds one to a more externalist standard than typical internalist and evidentialist conceptions of justified belief.

11 Jack Kwong argues that all forms of epistemic injustices are just failures to be open-minded in his (2019). I'm not making that strong of a claim. I'm only claiming that they epistemic injustices and cognitive biases are at least failures of open-mindedness.

12 For all of us who are not omniscient.

13 See Emily McRae (2016) for an interesting, Buddhist-inspired, account of open-mindedness.

14 See Adler (2004) for a defense of this basic idea.

15 Intellectual humility may also be a form of cognitive excellence that is necessary for wisdom.

16 Whitcomb et al. were only trying to articulate a theory of intellectual humility. Thus, my criticisms of OM4 are not intended to be criticisms of their theory of intellectual humility.

17 In discussion at the Epistemic Duty workshop at St. Thomas University in Fredericton, New Brunswick, Canada on May 30, 2019. 
18 I do, however, find the arguments posed by Ema Sullivan-Bissett in "We are like American Robins" (see Chapter 6 in this volume) to be quite strong. Her arguments, however, do not undermine my view, since I think of epistemic duties to believe as a sub-category of moral duties.

19 The toddler might be completely off the hook given his ignorance. He might be causally responsible but not morally responsible at all.

20 Thanks to all of the participants at the Wisdom Workshop at Trinity College, Dublin (May 2019), especially Roger Pouivet, Paul O’Grady, Shane Ryan, and Jason Baehr for helpful comments about the theory of wisdom proposed in this chapter. Thanks to all of the participants at the Epistemic Duty Workshop at St. Thomas University, New Brunswick, Canada (May 2019): Kelley Annsley, Miriam Schleifer McCormick, Mark Nelson, Sophie Stammers, Scott Stapleford, Matthias Steup, Ema Sullivan-Bissett, Rebecca Wallbank for a helpful discussion of this chapter. Thanks most especially to Kevin McCain and Scott Stapleford for exceptionally careful, challenging, and insightful written comments and guidance. Unfortunately, a few of their best questions remain unanswered here.

\section{References}

Adler, J. 2004. "Reconciling Open-Mindedness and Belief." Theory and Research in Education 2 (2): 127-142.

Baker, L. R. 2003. “Third Person Understanding.” In A. J. Sanford and P. N. JohnsonLaird (eds), The Nature and Limits of Human Understanding. Edinburgh: T\&T Clark.

Baehr, J. 2011. The Inquiring Mind: On Intellectual Virtues and Virtue Epistemology, Oxford: Oxford University Press.

Brogaard, B. 2005. "I Know. Therefore, I Understand.” Unpublished manuscript.

Christensen, D. 2007. "Epistemology of Disagreement: The Good News.” Philosophical Review 116 (2): 187-217.

Elgin, C. 2007 “Understanding and the Facts.” Philosophical Studies 132: 33-42.

Grimm, S. 2015. “Wisdom.” Australasian Journal of Philosophy 93 (1): 1-16.

Kvanvig, J. 2003. The Value of Knowledge and the Pursuit of Understanding. New York: Cambridge University Press.

Kwong, J. 2019. "Epistemic Justice and Open-Mindedness." European Journal of Philosophy 27 (1): 243-254.

McRae, E. 2016. "Equanimity and the Moral Virtue of Open-Mindedness." American Philosophical Quarterly 53 (1): 97-108.

O’Grady, P. 2018. “Grimm Wisdom.” Annals of Philosophy 66 (1): 67-77.

Pritchard, D. 2008. "Knowing the Answer, Understanding and Epistemic Value.” Grazer Philosophical Studien 77 (1): 325-339.

Ryan, Shane. 2016. "Wisdom: Understanding and the Good Life." Acta Analytica 31 (3): 235-251.

Ryan, Sharon. 2012. "Wisdom, Knowledge, and Rationality." Acta Analytica 27 (2): 99-112.

Ryan, Sharon. 2017. "A Deeper Defense of the Deep Rationality Theory of Wisdom: A Reply to Fileva and Tresan.” Acta Analytica 32 (1): 115-123.

Ryan, Sharon. 2019. "Epistemic Humility, Defeat, and a Defense of Moderate Skepticism." in C. Braden, R. Borges and B. Fitelson (eds), Themes from Klein. Cham: Springer, 129-143.

Sliwa, P. 2015. "Understanding and Knowing." Proceedings of the Aristotelian Society 116 (2): 229-236. 


\section{Sharon Ryan}

Whitcomb, D. 2012. “Epistemic Value.” In A. Cullison (ed.), The Continuum Companion to Epistemology. London: Continuum, 270-287.

Whitcomb, D., Battaly, H., Baehr, J., and Howard-Snyder, D. 2017. "Intellectual Humility: Owning Our Limitations." Philosophy and Phenomenological Research 94 (3): 509-539.

Zagzebski, L. 2001. "Recovering Understanding.” In M. Steup (ed.), Knowledge, Truth, and Duty: Essays on Epistemic Justification, Responsibility, and Virtue. Oxford: Oxford University Press, 235-251. 


\title{
12 On What We Should Believe (and When (and Why) We Should Believe What We Know We Should Not Believe)
}

\author{
Clayton Littlejobn
}

\section{Introduction}

Here is a familiar way of thinking about epistemology. Epistemologists are interested in questions about knowledge and they're also interested in normative questions. The first set of questions concern the nature and extent of knowledge. The second concern what we should believe. Imagine this division were reflected on your syllabus. Half of your class is dedicated to each set of questions. Imagine (if you can!) that one of your students read the syllabus. She wants to know how the two parts of the course are connected. One answer, which probably wouldn't be satisfying to her, is simply that these are the questions that epistemologists try to answer. ${ }^{1}$ That's just how things are and that's why your syllabus looks like this. My answer would be different. If I were to share my own personal views with students, I would say that these two parts of epistemology are connected because knowledge plays an indispensable role in our best normative theory. ${ }^{2}$ (We shouldn't believe what we don't know! Ignorance enjoins silence!) Since I don't normally share my views with my students, I'd say that some people think these questions are connected and say that it's an interesting and open question whether they are.

In this chapter, I want to explore a new way of thinking about how they might be connected. Drawing on recent work in ethical theory, I shall offer an account of what we ought to believe on which what we ought to believe is connected to facts about what we can know. ${ }^{3}$ The idea that the two parts of epistemology are connected isn't new, but the proposal about how they're connected is. While I think that there is something right about the positive proposal offered here, my main interest in writing this chapter is not to defend this proposal about knowledge and its normative role, but to introduce a way of addressing questions about what we ought to believe that might be fruitful. Even if you don't particularly care about knowledge and don't think that it matters whether anyone knows anything, you might extract from this discussion a new way of thinking about what we ought to believe that suits your purposes if you were to strip out all the references to knowledge and substitute in something else that better reflects your values. 


\section{What is Justification?}

A theory of justification tells us what we should and should not believe. This accords with how we talk about the justification of action. Such talk is talk about what is and what is not consistent with the normative standards that determine what we ought to do. In ethics, we might follow the consequentialists in thinking that value ultimately determines what is and what is not permitted by morality's standards or we might adopt some kind of non-consequentialist view on which the values alone do not determine what is permitted or justified. Either way, we can think of justification as most closely connected to things like permission, obligation, and so on.

We have similar choices in epistemology. We might think that epistemic values ultimately determine whether a belief is justified or we might think that something else matters to justification such as conformity to norms. ${ }^{4}$ In my view, the right approach to justification is one that posits norms that don't simply enjoin us to believe in ways that promote some kind of value. There might be a sense in which it is a bad thing to believe falsehoods or a good thing to believe truths, but we have good reason to think that this isn't the starting point for a good theory of justification because the kinds of trade-offs that would matter to justification if justification were a matter of promoting some kind of good do not matter to justification. ${ }^{5}$

On the approach to justification that I prefer, a belief is justified if it violates no epistemic norms and it cannot be justified if it violates some such norm without overriding reason to do so. The potentially overriding reasons, in turn, would be provided by norms. ${ }^{6}$ In short, we can think that a belief is justified when it's not the case that we shouldn't hold it. Questions about the application conditions for these norms are substantive. We can have substantive disagreements about, say, whether the norms have internal or external application conditions (i.e., conditions that do or do not supervene upon internal conditions). We can have substantive disagreements about whether they are concerned with knowledge, truth, evidential support, coherence, etc. Questions about whether justification can be understood in terms of some connection to norms, by contrast, don't strike me as substantive. We should be able to represent every possible view about justification in terms of some connection to a norm. The real debates in epistemology are about the kinds of things that can figure in genuine epistemic norms, not whether we can state a theory of justification by specifying them.

Because I think that the fundamental norms that govern belief are knowledge norms, they figure centrally in the discussion below. ${ }^{7}$ These norms can be stated as follows:

K-: If we are not in a position to know $p$, we should not believe $p$.

$\mathrm{K}+$ : If we are in a position to know $p$, we should believe $p$.

Readers know that there is a standard objection to the claim that $\mathrm{K}$ - is a genuine epistemic norm. Even epistemologists who think that some externalist views 
are worthy of consideration are put off by the idea that a belief isn't justified if it happens to be false. When we think about brains-in-vats, for example, people often say that (a) their beliefs must be justified if ours are and (b) they should believe the false propositions that appear to them to be true (e.g., that they have hands).

These judgments about the case of systematic but undetectable error are sometimes taken to show that knowledge couldn't be the norm of belief and often taken to show that justification doesn't require knowledge. In my view, this reaction is a sign that many epistemologists are conflating justification and excuse. I don't want to argue for that point here, having argued for it extensively elsewhere. ${ }^{8}$ Instead, I want to describe a way of accommodating these kinds of intuitions without abandoning the idea that there are externalist epistemic norms that tell us we shouldn't believe what we don't know or that we shouldn't believe falsehoods. This will, in turn, give us room to define justification in terms of different connections to what we ought (in some sense to be specified) believe. ${ }^{9}$

Let me mention one more case that might seem to pose a problem for the externalist about epistemic norms, the preface case. ${ }^{10}$ Agnes has completed her first book. She heads to the library because she wants to see it on the shelves and she discovers that it's been shelved in a special section of the library reserved for books that contain precisely one false claim. She has researched each of the claims in the book very carefully, but it shouldn't come as a shock to her that her book contains an error. If anything, she should be pleased that it was only one. In such a scenario, I think that she could come to know that her book contains an error. She could also continue to know that the true claims that she put into the book were true. Under these conditions, it seems that each claim we pointed to might be one that she could continue to justifiably believe provided that she was initially justified in believing it. If, however, she ought to believe each claim in a set of claims that is inconsistent (i.e., each claim in the body of the book and the claim that the book contains an error), then isn't it wrong to say that she should only believe what she knows or that she should only believe what is true? These norms imply that we ought to have sets of beliefs that are consistent, but this seems like a difficult view to defend in light of these preface cases. ${ }^{11}$

\section{An Argument Against Externalist Epistemic Norms}

Suppose that ten miners are trapped in one of two shafts, shaft A or shaft B. ${ }^{12}$ You think it's just as likely that they'd be in one shaft as the other. It starts to rain. If you don't act the shafts will fill with water and all the miners will drown. If you do act, you have to choose between three options. You can block shaft A completely. This would ensure that there is enough air in this shaft for all ten miners to live if they're in A, but it will guarantee that the miners in $\mathrm{B}$ would all drown. You can block shaft B completely. This would guarantee that all ten miners would survive if they were in B but that all would die if they were in A. You can partially block off the openings to both shafts. Some water 
would get it, but most would be kept out. The result would be that there is enough air in both shafts for nine miners to live. In this scenario, we know that the objective consequentialist would say that you ought to save all the miners by blocking the shaft that they happen to be in, but this doesn't sit well with the intuition that we ought to partially block both shafts.

Bearing this in mind, consider this argument against objective consequentialism:

\section{The Mineshaft Argument}

P1. According to objective consequentialism, you either ought to completely block shaft A or ought to completely block shaft B.

P2. We ought to partially block both shafts.

C. Objective consequentialism is false.

Many people think that this is a decisive argument against objective consequentialism. ${ }^{13} \mathrm{My}$ interest in this argument is that it seems that we need to address similar arguments in epistemology:

\section{The Preface Argument}

P1. According to some externalists about epistemic norms, you should not believe falsehoods.

P2. If so, you should not believe an inconsistent set of propositions.

P3. If so, you should not believe each of the propositions in Agnes' book and believe that the book contains an error.

P4. You should, however, believe each of the propositions in the book and that the book contains an error.

C. These externalists are wrong about the norms of belief. ${ }^{14}$

What should we make of this second argument?

One might conclude in both cases that the arguments show us something important about norms. They might show us that the norms in question (i.e., those of the objective consequentialist, the knowledge norm, etc.) aren't genuine norms because they deliver the wrong verdicts in these cases. This response might appeal to some, but it might seem unwarranted to someone who thinks that our talk of what we 'ought' to do or 'should' believe might concern different readings of the normative language. Even if it were true (in some sense) that we ought to partially block both shafts and save only nine of the miners, it might be true (in some other sense) that we ought to save them all. And even if it were true (in some sense) that we ought to believe each of the claims in a book known to contain an error, it might still be true (in some other sense) that we ought to believe only truths.

Following Sepielli (2018), let's distinguish the debater from the divider. The debater thinks (roughly) that there is one reading of 'ought' and 'should'. They would say that it couldn't be true (in any sense) that a thinker should 
have an inconsistent set of beliefs if it's true (in some sense) that a thinker shouldn't believe falsehoods or shouldn't believe what she doesn't know. A divider thinks (roughly) that there are different ways of reading 'ought' and 'should' and that these seemingly incompatible claims about what we ought to believe or do are perfectly compatible when they're properly understood. ${ }^{15}$ Let's explore the prospects of a divider's view on which claims about what we ought or ought not believe can be interpreted in different ways to see if it gives the externalist a way of capturing intuitions that would seem to be problematic for their view.

\section{What Should ${ }_{\text {pro }}$ We Believe?}

According to the divider, questions about what we 'should' believe and claims about what we 'shouldn't' believe can be read in different ways. Even if it's true to say that we 'ought' to believe each claim in an inconsistent set of claims it might be true that we 'ought' not believe falsehoods, provided that we're talking about different senses of 'ought'. On one reading, 'ought' might be read objectively. ${ }^{16}$ On such a reading, facts that an individual might not be cognizant of might nevertheless help to determine whether the individual ought to believe something or ought not believe something. On another reading, 'ought' might be read in such a way that the truth or falsity of claims about what an individual ought to do or ought to believe would depend upon the individual's perspective on things. Let's call these the 'objective' and 'prospective' readings of 'ought' (i.e., ought $\mathrm{OBJ}_{\mathrm{OJ}}$ and ought $\mathrm{PRO}_{\mathrm{PR}}$ ).

We want an account of what we ought $\mathrm{PRO}_{\mathrm{PRO}}$ to believe. ${ }^{17}$ It makes sense to turn to ethics to look at accounts of what we ought PRO $_{\text {to }}$ do to see if it would be fruitful to model our account of ought $\mathrm{PRO}_{\mathrm{PO}}$ to believe on one of them. Here is a simple account of what we ought $\mathrm{PRO}_{\mathrm{P} O}$ to do. Whenever we face a choice between some feasible set of options, we can think of each option as being associated with various states that will result as a consequence of choosing an option. Some of these states will realize value, good or bad. The value of an option can, in turn, be understood in terms of the total value realized by these states. We can rank the options in terms of their values and say that someone ought not choose an option if there is a better one available and ought to choose an option if it is best. In cases of ties, we are free to choose amongst the best options. People often object to this account on the grounds that the ranking of options isn't sensitive in any way to the agent's information and this view is widely believed to be problematic because it gives us the wrong verdict in cases like the mineshaft case. So, we make a small modification. When we are uncertain about what will happen if an option is chosen, we think about the possible outcomes associated with each option and we rank the options by thinking about the values that attach to the possible outcomes and the probabilities that these outcomes would eventuate.

If we were to take this approach to ought $\mathrm{PRO}_{\mathrm{PR}}$ to believe, we would need to identify the relevant outcomes, assign values to them, and offer some account as to how the probabilities and values determine how our options should be 
ranked. If we adopt a veritist view, we would say that the fundamental epistemic goods have to do with accuracy and inaccuracy. ${ }^{18}$ If we adopt a gnostic view, we would say that the fundamental epistemic goods have to do with knowledge and failed 'attempts' to know. ${ }^{19}$ On the first view, we ought ${ }_{\text {PRO }}$ to believe iff it maximizes expected epistemic value as the veritist conceives of it. On the second, we ought $\mathrm{PRO}_{\mathrm{P} O}$ to believe iff this maximizes expected epistemic value as the gnostic conceives of it.

To see how this might work in practice, we can try to set things up using a belief-matrix that represents the options, states, and the values of outcomes as follows:

Veritist Belief-Matrix

\begin{tabular}{lll}
\hline & $P$ & $\sim p$ \\
\hline Believe $p$ & $\mathrm{a}$ & $\mathrm{b}$ \\
Believe $\sim p$ & $\mathrm{c}$ & $\mathrm{d}$ \\
Believe Neither & $\mathrm{e}$ & $\mathrm{f}$ \\
Believe Both & $\mathrm{g}$ & $\mathrm{h}$ \\
\hline
\end{tabular}

Gnostic Belief-Matrix

\begin{tabular}{lll}
\hline & $K p$ & $\sim K p$ \\
\hline Believe $p$ & $\mathrm{a}$ & $\mathrm{b}$ \\
Believe $\sim p$ & $\mathrm{c}$ & $\mathrm{d}$ \\
Believe Neither & $\mathrm{e}$ & $\mathrm{f}$ \\
Believe Both & $\mathrm{g}$ & $\mathrm{h}$ \\
\hline
\end{tabular}

The first matrix captures a simple veritist approach that is concerned with accuracy and inaccuracy. The second captures a gnostic approach where our concerns are with whether our beliefs would or would not constitute knowledge. ${ }^{20}$ To determine the expected epistemic value of each option (i.e., believe $p$, believe its negation, believe both, etc.), we assign cardinal numbers to each cell that represents the value of the outcome, multiply each by the probability that the relevant state obtains, and sum across the rows. If, as seems plausible, we shouldn't $t_{\mathrm{PRO}}$ believe both $p$ and $\sim p$ whatever probabilities we assign to the relevant states, the absolute value associated with $\mathrm{g}$ and $\mathrm{h}$ will be less than that of e or $\mathrm{f}^{21}$ If we want to avoid the sceptical conclusion that we shouldn't ${ }_{\mathrm{PRO}}$ believe anything, we would want the values of a and $d$ to exceed those of e and $f$.

In my view, the main problem with this approach is that it gives an account of what we ought $t_{\text {PRO }}$ to believe in terms of the values realized by the states that result from believing as opposed to the norms that determine what we ought ${ }_{\mathrm{OBJ}}$ to believe. The externalist norms that I like drop out of the picture. Of course, you might not like such norms, but that doesn't mean that you should embrace some kind of epistemic consequentialist view. I am sceptical of consequentialist 
views because I doubt that there are epistemic values that call for promotion. ${ }^{22}$ Imagine that there were such values and they determined what we ought ${ }_{\mathrm{PRO}}$ to believe. Recall Foot's (1985) point about consequentialism. The thought that it's never rational to prefer an acknowledged lesser good to a greater one makes consequentialism seem quite compelling. Consequentialist views retain this intuitive motivation if they rank options in terms of total value (i.e., the total epistemic value realized as a consequence of coming to believe). Because of this, the view is designed to allow for trade-offs. ${ }^{23}$ Indeed, one of the key selling points of a consequentialist framework is that it explains when and why trade-offs are justified. We don't like epistemic trade-offs. We don't think, for example, that the explanation as to why I shouldn't $\mathrm{PRO}_{\mathrm{PRO}}$ believe (or shouldn't $\mathrm{OBJ}_{\mathrm{OB}}$ believe) is that the opportunity costs associated with forming the relevant belief are too great. We need an approach that isn't consequentialist.

We don't have to go far to find an alternative view that doesn't assume that normative status is determined by how well an option promotes some value. Instead of looking for an epistemic axiology that tells us which states of affairs would be good or bad, better or worse, and so on, we can start with our preferred view about the identity of the epistemic norms that tell us what we ought ${ }_{\mathrm{OBJ}}$ to believe. From this, we can extract a theory of what we ought $\mathrm{PRO}_{\mathrm{PR}}$ to believe. Others have tried this, but the details are difficult to get right. Let's try a new approach. We begin by consequentializing our theory of what we ought $_{\mathrm{OBJ}}$ to believe and use some tools from decision-theory to generate our theory of what we ought $\mathrm{PRO}_{\mathrm{P}}$ to believe.

Here is a crude recipe for consequentializing a non-consequentialist epistemological theory. Each non-consequentialist epistemological theory purports to tell us which options are permitted and which ones are not. For example, suppose that we think that the knowledge norms govern belief:

K-: If we are not in a position to know $p$, we should not believe $p$.

$\mathrm{K}+$ : If we are in a position to know $p$, we should believe $p$.

When we're in a position to know neither $p$ nor $\sim p$, our theory ranks believing neither above believing $p$, believing $\sim p$, and believing both. If we're in a position to know, it ranks believing the relevant proposition ahead of the others. If, however, we think that belief is governed by truth norms, we might have this instead:

T-: If $\sim p$, we should not believe $p$.

$\mathrm{T}+$ : If $p$, we should believe $p$.

We needn't worry about conflicts between these positive and negative norms, not when we're considering a thinker's attitude concerning some particular proposition. ${ }^{24}$ We can represent the violations of the relevant norms as if they were bad outcomes. A value function that assigned numbers to 'outcomes' (i.e., situations in which we believe in conformity to or in violation of the norms) would give a faithful representation of the ordering of options associated with 
our theory. Oddie and Milne (1991) show that every non-consequentialist moral theory's deontic ordering can be faithfully represented by a value function that assigns cardinal numbers to the various norm conforming and violating acts. There is no obstacle to generalizing their result to the epistemic case.

Let's see how this would look by assigning values to our cells. We can represent the violation of a norm as a bad outcome where we might decide that we want to weight the violation of the different norms differently. We might think, for example, that it would be worse to violate T- by forming a false belief (e.g., -3 ) than it would be to violate T+ by failing to form a true belief (e.g., -1). This might have a matrix like this:

Truth-Centred Belief-Matrix

\begin{tabular}{lcr}
\hline & $P$ & $\sim p$ \\
\hline Believe $p$ & 0 & -3 \\
Believe $\sim p$ & -3 & 0 \\
Believe Neither & -1 & -1 \\
Believe Both & -3 & -3 \\
\hline
\end{tabular}

According to this truth-centred account of what we ought $t_{\mathrm{PRO}}$ to believe, we get the result that we ought ${ }_{\mathrm{PRO}}$ never believe both $p$ and believe $\sim p$ whatever evidence we happen to have. Because every proposition is either true or false there is no situation in which we ought $\mathrm{OBJ}$ to suspend, but on our view, we ought $\mathrm{PRO}_{\mathrm{PR}}$ to suspend if the expected value of believing neither is greater than that of believing $p$ or believing $\sim p$. If someone flips a fair coin and you have no more reason to believe that it landed heads than tails, you ought $\mathrm{PRO}_{\mathrm{PO}}$ to suspend because the expected value of suspension (-1) exceeds that of believing $p$ or of believing $\sim p$ $(-1.5)$. This is thus a case in which you can know that you ought (in some sense) have attitudes that you ought not (in some other sense) have. You ought PRO $_{\text {to }}$ suspend even though you're certain that you ought $\mathrm{OBJ}_{\mathrm{J}}$ to believe (i.e., ought $\mathrm{OBJ}_{\mathrm{OJJ}}$ not suspend). And we know why you ought PRO $_{\text {to }}$ have attitudes that you know

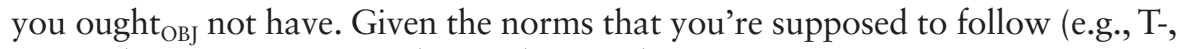
$\mathrm{T}+$ ) and your uncertainty about what it takes in your present situation to conform to them (i.e., the probability that you violate the first or violate the second if you believe one way or the other is .5), you have to rationally respond to the risks you face. That requires a sensitivity to the comparative weight of the normative considerations and the chance of failing to meet the relevant standards.

Readers might wonder how we should decide on the numbers. In the truthcentric approach, you might think of it this way. Imagine a set of books arranged in terms of length. The shortest book contains one claim. The longer books contain many more. You know that each book contains one false claim, but one that you know you won't recognize as false provided that the book contains two or more claims. You might think that it would be overly sceptical to say that someone shouldn't believe what they read in a book containing 1,000,000 claims and that someone is being insufficiently sceptical if they believe what they read in a book containing two or three claims. The weights we attach to 
the two truth norms should decide when the risk of forming a false belief is too great. The resulting view is basically the Lockean view, a view that says that we ought $\mathrm{PRO}_{\mathrm{PRO}}$ to believe when the truth of our belief is sufficiently probable. The numbers assigned to the outcomes determine the probability threshold.

Let's look at things from the perspective of a theory that takes $\mathrm{K}$ - and $\mathrm{K}+$ to be the fundamental norms that govern belief:

Knowledge-Centred Belief-Matrix

\begin{tabular}{lccc}
\hline & $K p$ & $\sim K p \& \sim K \sim p$ & $K \sim p$ \\
\hline Believe $p$ & 0 & -3 & -3 \\
Believe $\sim p$ & -3 & -3 & 0 \\
Believe Neither & -1 & 0 & -1 \\
Believe Both & -3 & -6 & -3 \\
\hline
\end{tabular}

In this matrix, we've represented the possibilities of coming to know $p$ by believing, coming to know $\sim p$ by believing, and believing where you're not in a position to know either way. One difference between this matrix and the previous one is that if you were a BIV and you were to believe correctly that you were a BIV, the veritist would say that this is good in one way even though it is irrational or what you ought ${ }_{\text {PRO }}$ not believe. On this knowledge-centred account, you ought ${ }_{\mathrm{OBJ}}$ not believe that you're a BIV even if you are (because that belief, while true, couldn't constitute knowledge) and ought ${ }_{\text {PRO }}$ not believe that you're a BIV even if you are (because the probability that you could know that you're a BIV won't be high). Unlike the previous view, this approach says that we sometimes ought ${ }_{\text {OвJ }}$ to suspend. Since we cannot know whether the number of stars is even or odd, this account says that we ought ${ }_{\mathrm{OBJ}}$ to suspend judgment while the truth-centred approach says that we ought ${ }_{\mathrm{OBJ}}$ to believe the truth about the number of stars and ought $\mathrm{OBJ}_{\mathrm{BJ}}$ not suspend..$^{25}$

The knowledge-centred view also differs from the truth-centred view in how it handles lottery propositions and Moorean absurdities. ${ }^{26}$ The probability that a ticket lost is high, so our previous view makes it hard to deny that we ought ${ }_{\mathrm{PRO}}$ to believe that a ticket we've been gifted is worthless. In turn, it makes it hard to deny that we ought ${ }_{\mathrm{PRO}}$ believe this Moorean absurdity: I don't know if this ticket lost, but it did. Since the probability of knowing such things is (i.e., that a ticket lost or the complex proposition that the ticket lost and I don't know whether it did), on some views, 0 , this account delivers the verdicts that I would want it to. As with truth-centred view just discussed, it allows for the possibility that we might know that we ought $\mathrm{OBJ}_{\mathrm{OJ}}$ not have some beliefs and still ought $\mathrm{PRO}_{\mathrm{PRO}}$ to have the beliefs in question. In preface cases, each belief might be very likely to be knowledge even if it's certain that one of the beliefs in the set is mistaken.

The knowledge-centred and truth-centred views tell us that while it might be the case that we ought ${ }_{\mathrm{OBJ}}$ not believe the false claims in the preface case, we still ought $_{\mathrm{PRO}}$ to believe each of the claims. Thus, these views can retain the idea that logic is normative for thought (i.e., that we ought ${ }_{\mathrm{OBj}}$ not hold inconsistent sets of beliefs) even if we ought ${ }_{\mathrm{PRO}}$ to believe as if probability is the guide to our doxastic 
life and that we have to tolerate inconsistency in some special cases. One advantage, to my mind, of the knowledge-centred view is that the knowledge-centred view gives a better explanation as to why we ought ${ }_{\mathrm{PRO}}$ to hold inconsistent beliefs. The truth-centred view explains this in terms of the high probability of the truth of each belief and thus doesn't distinguish the preface-type cases from the lottery-type cases. The knowledge-centred view treats them differently because the probabilities of knowing in these cases are very different. There is no chance of knowing in the lottery case and a good chance of knowing in each case where you consider a claim made in a book known to contain an error.

Once we have consequentialized the theory in this way (i.e., by replacing the deontic ordering with a value-function that preserves this ordering), we're back in business. We can say that we ought ${ }_{\mathrm{OBJ}}$ to believe in ways that the norms require and ought ${ }_{\mathrm{OBJ}}$ not believe in the ways that the norms forbid. Provided that opportunity costs don't have any direct bearing on whether we might conform to the norms that determine what we ought $\mathrm{OBJ}_{\mathrm{J}}$ to believe, we have a view that mirrors in some superficial ways the consequentialist views described above but without adopting a view that encourages us to believe that tradeoffs can require us to, say, refrain from believing what we know or to believe what we know to be false or unsupported by the evidence. ${ }^{27}$

The knowledge-centred view is like the Lockean view in that it is a kind of threshold view. It thus differs in important ways from some prominent attempts to capture more subjective aspects of normative evaluation without a knowledge-centred framework. ${ }^{28}$ It says that when the probability of a certain 'outcome' is sufficiently high, we ought ${ }_{\mathrm{PRO}}$ to believe. If it is low, we ought ${ }_{\mathrm{PRO}}$ not. ${ }^{29}$ This gives us an elegant solution to a Harman-esque puzzle about lottery cases. ${ }^{30}$ How could it be rational to form beliefs on the basis of perception and/ or testimony if it's not rational to form lottery beliefs on the basis of statistical evidence? Defenders of the knowledge-centred view will say that the difference isn't to be found in the different probabilities of truth, but in terms of the different probabilities of knowing. This difference matters because it matters whether we're responding appropriately to risks of violating the norms that determine what we ought ${ }_{\mathrm{OBJ}}$ to believe.

The knowledge-centred proposal is not unique in classifying some perceptual and testimonial beliefs as justified when it classifies lottery beliefs as unjustified. Smith (2016) proposes a view designed to deliver just this verdict. If we adopt the knowledge-centred proposal and characterize justification either in terms of what we ought ${ }_{\mathrm{OBJ}}$ to believe or what we ought $\mathrm{PRO}_{\mathrm{PRO}}$ to believe, we follow Smith in breaking from the view that justification is fundamentally about minimizing the risk of error. The knowledge-centred proposal has at least two virtues that a view like Smith's might lack. First, it gives us a natural response to a forceful challenge to explain why we should stick to rules that forbid belief in lottery cases. Consider Horowitz's observation:

a rational agent should be doing well by her own lights, in a particular way: roughly speaking, she should follow the epistemic rule that she rationally takes to be most truth-conducive. It would be irrational, the thought goes, 
to regard some epistemic rule as more truth-conducive than one's own, but not adopt it.

If our fundamental concerns (in our axiology or in our account of what we ought $_{\mathrm{OBJ}}$ to believe) concern truth and nothing but the truth, it's not clear why we should stick to rules that we know to be suboptimal. Second, there is the issue of naturalness. Someone can offer a theory of justification that fits well with our intuitions without offering one that seems to have any underlying theoretical rationale as to why, say, the evidential support relation would favour believing propositions that would be true in most normal worlds in which our evidence is true over believing propositions known to be highly probable in the kinds of situations we know ourselves to be in. ${ }^{31}$ The knowledge-centred proposal sketched here should score well on the naturalness front since it simply appropriates the natural account to give guidance about how we ought ${ }_{\mathrm{PRO}}$ to proceed in light of uncertainty.

The approach sketched here has other virtues that have been discussed elsewhere. ${ }^{32}$ One virtue is that it gives us a response to the Preface Argument because it explains why we should ${ }_{\text {PRO }}$ sometimes believe what we know we should $_{\mathrm{OBJ}}$ not believe. Even if you don't think that the knowledge-centred view gives us the right account of what we ought ${ }_{\mathrm{OBJ}}$ to believe, you know now how to give an account of what we ought ${ }_{\mathrm{PRO}}$ to believe given a theory of what we ought $_{\mathrm{OBJ}}$ to believe. If you don't believe there are any genuine externalist epistemic norms, you might think that even internalist views will need to draw the kinds of distinctions that we've drawn here. The proposed account of the connection between ought ${ }_{\mathrm{OBJ}}$ and ought $\mathrm{PRO}_{\mathrm{PR}}$ might be helpful. Suppose that you're uncertain whether some large collection of beliefs meets the standards that determine what you ought ${ }_{\mathrm{OBJ}}$ to believe. If a guru tells you correctly that there is one belief in this set that you ought ${ }_{\mathrm{OBJ}}$ not believe, what should you do? If you cannot identify which belief is the bad one, dropping lots of beliefs might raise the probability that you don't hold the belief that the guru has in mind, but the consequence might be failing to believe many things that you ought $_{\text {Ов }}$ to believe. In such a case, you might survey each belief individually and be quite confident that each of them is what you ought ${ }_{\mathrm{OBJ}}$ to believe even if you are certain that one of them must not be. The suggestion that you ought ${ }_{\mathrm{PRO}}$ to continue to maintain each of them in spite of your knowledge that one of the beliefs ought ${ }_{\mathrm{OBJ}}$ to go might seem attractive even if your account of what we ought ${ }_{\mathrm{OBJ}}$ to believe is given in purely internalist terms. While the account gives externalists a useful way of responding to objections (e.g., those having to do with error cases), it also gives internalists a way of thinking about how to deal with a kind of uncertainty that can be problematic for them as well. ${ }^{33}$

\section{Conclusion}

Let me say in conclusion that the approach being sketched here can be appropriated by anyone who believes that there are norms that determine (in 
some sense) what we ought to believe or do provided that they concede that it's at least possible for a rational agent to be uncertain to some degree about whether in a given situation the norm applies. As it happens, I think there are powerful reasons to believe that every set of norms is like this. I think that anyone who isn't a committed epistemic consequentialist should be pleased to see that we can borrow some ideas from consequentialists and work out a theory of what we ought $\mathrm{PRO}_{\mathrm{PO}}$ to believe when we're uncertain about whether our beliefs meet the standards that we take to be of fundamental normative significance. As it happens, I think that the implications of the view that combines this framework with a knowledge-centric approach to epistemic norms look very good. I have sketched one of the few views on the market that explains why we can think that perceptual beliefs differ in justificatory status from lottery beliefs without committing ourselves to implausible views about what we ought to believe in preface-type situations. I cannot think of a single alternative view in the literature that delivers verdicts about these cases that draws the distinctions in the right place. Moreover, it explains why there should be these distinctions without forcing us to say strange things about the evidential support relation. ${ }^{34}$

\section{Notes}

1 See Foley (2012).

2 This way of thinking about the connection reverses a familiar order of explanation, which is that the normative side of epistemology is connected to knowledge insofar as having justification or being justified is necessary for knowledge. An evidentialist (e.g., Conee and Feldman (2004) or McCain (2014)) would characterize this (arguably) necessary condition on knowledge in terms of evidential support. This more traditional way of thinking about the relationship explains why the normative side matters to discussions of knowledge, but doesn't give us much to say to someone skeptical of the importance of knowledge if they think that only the normative questions in epistemology matter.

3 The view that it is rational to believe, that we have justification to believe, and/ or that we ought (in some sense) believe when the probability that we're in a position to know is sufficiently high is defended by Dutant and Fitelson (n.d.), Dutant and Littlejohn (forthcoming a, b), and Littlejohn (forthcoming). I had mistakenly thought that this knowledge-centric view of proper belief was the view of Dutant (forthcoming) and proposed it as a response to Steele's (n.d.) defense of the idea that we should use statistical evidence as the basis for punishment in criminal trials. Although none of us seemed to like it all that much initially, the view seems to have grown on us. Dutant and Fitelson (n.d.) develop a version of this view in a consequentialist framework and it's intended to give an account of synchronic wide-scope rational requirements. To my knowledge, this is the first attempt at linking the view to a non-consequentialist framework.

4 See Dorst (forthcoming) and Easwaran (2016) for a discussion of how considerations of epistemic utility support a kind of Lockean view of rational belief. For defences of that view of rational belief, see also Sturgeon (2008).

5 For discussions of trade-offs and their (ir)relevance to epistemic status, see Firth (1981), Jenkins (2007), and Littlejohn (2012). For sophisticated responses to such concerns, see Ahlstrom-Vij and Dunn (2014), Singer (2018), and Talbot (2014). 
6 This view is compatible with the view that a thinker's evidence ultimately determines what a thinker should believe. We can represent the evidentialist as someone who thinks that what we ought to believe is determined by what we have sufficient evidence to believe.

7 See Williamson (2000).

8 Littlejohn (2012). For a contrasting view, see Simion et al. (2016).

9 At various points I will shift between claims about what we do know and what we are in a position to know. On the one hand, I think that if we believe but don't know there is a sense in which we shouldn't hold this belief, not unless we were to hold it in such a way that it constituted knowledge. On the other, I think that we want to focus on questions about what we are in a position to know when we are thinking about what we ought to believe because we want to be able to say that there are some things that we ought to believe or ought not believe that we don't currently have any beliefs about.

10 Makinson (1965).

11 For defences of this verdict, see Christensen (2004), Dutant and Littlejohn (forthcoming b), Easwaran and Fitelson (2015), and Worsnip (2016). For a dissenting view, see Ryan (1991, 1996).

12 This case is a modified version of the case from Parfit (1988). Regan (1980) was the first to present structurally similar cases.

13 See Zimmerman (2008), for example. He notes that objective consequentialists cannot say that we would be excused for partially blocking both shafts since we know that this is the one thing that we should not do.

14 The preface case also presents interesting challenges to some seemingly plausible claims about the normativity of logic since it is difficult to see how logic might be normative if we might find that we ought to hold inconsistent beliefs. See Steinberger (2019).

15 For a discussion of the divider's view and its virtues in dealing with cases of uncertainty and/or ignorance, see Graham (2010) and Smith (2011). The response to the Preface Argument is similar to Graham's (2010) response to the Mineshaft Argument, but it incorporates some ideas from Lazar (forthcoming) and Olsen (2018).

16 For reasons discussed below, we might instead want to talk about 'primary' and 'derivative' readings for someone who didn't believe that objective conditions matter in any sense to what we 'ought' to do or believe might find a need to draw distinctions between different readings of the relevant parts of our normative language.

17 For reasons discussed in Littlejohn (2012), I don't think this is a theory of justification in the primary or most important sense, but it might give us an important part of a theory of when we can defend the individual from criticism for failure to meet an obligation.

18 See Goldman (1999) and Joyce (1998), for example.

19 See Hyman (2015), Littlejohn (2015), and Williamson (2000) for discussion and defences.

20 We can think of ' $\mathrm{K} p$ ' and ' $\mathrm{K} p$ ' as standing for being in a position to know and not being in a position to know respectively. For reasons discussed in Dutant and Fitelson (n.d.) we might further refine this so that the options include ways of believing propositions.

21 See Dorst (forthcoming) and Steinberger (forthcoming) for discussions of the significance of and motivations for this assumption. 
22 For arguments that there aren't epistemic values that call for promotion, see Littlejohn (2018). For a defense of an opposing view, see Talbot (2014). While I think that there might be a sense in which epistemic norms are sensitive to considerations about value (and hence might be thought of as teleological), the relevant values might not be ones that call for promotion. The relevant notion of the good here might be attributive goodness, for example. While it might be an important truth about belief that the good ones are suited for certain functional roles (and are so suited iff they constitute knowledge, say) we shouldn't say that we ought to have as many such beliefs as possible just like we shouldn't say that we ought to have as many good toasters or assassins as possible. The view that tries to account for epistemic norms in terms of values that call for promotion seem to face the trade-off problems that seem to make epistemic consequentialism implausible.

23 These matrices are misleading precisely because they don't capture the situation in cases where coming to believe some proposition necessitates believing or failing to believe others. When we take account of this complexity, we can start to see that, however probable $p$ might be, believing $p$ might fail to maximize expected epistemic value as the veritist conceives of it. This is why I said the approach sketched was naïve.

24 A fully developed view might want to limit assessment to questions that the thinker is or ought (in some sense to be specified) to be trying to settle and the attitudes that are the thinker's answers to these questions. Being able to answer questions that don't or needn't interest us shouldn't have a bearing on whether we ought PRO to believe things that we do know.

25 In general, I think that the knowledge-centred view is a more natural fit for the best views we have about the norms of suspension and the interaction between the considerations that determine when we ought to suspend and those that determine when we may believe. See Miracchi (forthcoming) and Raleigh (forthcoming) for helpful discussions of suspension and the role of reflection.

26 The importance of getting the lottery case right comes out clearly in discussions of the right kind of evidence for criminal trials. See Moss (2018) and Steele (n.d.) for two very different approaches to these issues.

27 For helpful discussions of how consequentializing a non-consequentialist theory and importing tools from decision-theory can help non-consequentialists handle uncertainty, see Lazar (forthcoming) and Olsen (2018). My crude recipe for consequentializing draws from their work on decision-theory for nonconsequentialists in ethics.

$28 \mathrm{My}$ hope is that this approach to derivative normative status addresses some of Brown's (2018) concerns about Williamson's (forthcoming a) approach to derivative normative status. It also might improve upon a suggestion of DeRose's (2002) where he suggests that we can characterize a kind of secondary normative status in terms of what we take to be proper in some primary sense. In many cases, we neither take something to be proper or to be improper but should think about the risk of the different kinds of norm violations to determine what is proper in this secondary sense.

29 Just as truth doesn't imply the high probability of truth, I don't think knowledge implies that it's particularly probable that we know. This account suggests that Lasonen-Aarnio (2010) is right that there can be unreasonable knowledge.

30 See Harman (1968).

31 Similar concerns might arise for truth-centred views that insist that evidential support only confers justification if a stability condition (e.g., Leitgeb 2017) or 
explanatory condition (e.g., Nelkin 2000) is met or if the supported beliefs don't contain any known falsehoods (e.g., Ryan 1991, 1996).

32 In Dutant and Littlejohn (forthcoming), we show how this view unifies various kinds of defeaters in a single framework. On our view, defeaters partially defeat the justification of belief by lowering the probability that we know and fully defeats it by lowering it below a threshold. This allows us to say that there is some single mechanism by which defeaters defeat and we think that this is preferable to a view that posits a multitude of different kinds of defeaters without any underlying explanation of their rational toxicity.

33 An interesting case study would be the evidentialist view. Suppose (with Conee and Feldman (2004) and McCain (2014)) that a thinker's evidence supervenes upon her internal mental states and determines what she ought (in some primary sense) believe. And suppose that while evidence of evidence might in some weak sense be evidence (see Feldman 2005), a rational thinker might be uncertain about what her evidence is and what it supports, rules out, etc. Given some very modest claims about the limitation of our access to our evidence, Dorst (forthcoming b) and Williamson (forthcoming b) argue that even very strong evidence of strong evidence might ensure only that we have very weak first-order evidence for our beliefs. In light of this, even the evidentialist might want to allow that there might be things that we ought not believe (in light of the first-order evidence) that we ought to think we ought to believe (in light of the higher-order evidence) and the approach sketched here might help us make sense of this.

34 Discussions of their gnostic utility theory with Julien Dutant and Branden Fitelson were incredibly helpful in thinking about the issues discussed here. I want to offer a special thanks to Kevin McCain for providing extensive feedback on a previous draft.

\section{References}

Ahlstrom-Vij, Kristoffer, and Dunn, Jeffrey. 2014. "A Defence of Epistemic Consequentialism.” Philosophical Quarterly 64: 541-551.

Brown, Jessica. 2018. Fallibilism: Evidence and Knowledge. Oxford: Oxford University Press.

Christensen, David. 2004. Putting Logic in its Place. Oxford: Oxford University Press.

Conee, Earl, and Feldman, Richard. 2004. Evidentialism. Oxford: Oxford University Press.

DeRose, Keith. 2002. “Assertion, Knowledge, and Context.” Philosophical Review 111: 167-203.

Dorst, Kevin. Forthcoming a. "Lockeans Maximize Expected Accuracy.” Mind.

Dorst, Kevin. Forthcoming b. "Evidence: A Guide for the Uncertain.” Philosophy and Phenomenological Research.

Dutant, Julien. Forthcoming. "Knowledge-First Evidentialism about Rationality.” In F. Dorsch and J. Dutant (eds), The New Evil Demon Problem. Oxford: Oxford University Press.

Dutant, Julien, and Fitelson, Branden. N.d. "Knowledge-Centered Epistemic Utility Theory." MS.

Dutant, Julien, and Littlejohn, Clayton. Forthcoming a. "Defeaters as Indicators of Ignorance." In J. Brown and M. Simion (eds), Reasons, Justification, and Defeat. Oxford: Oxford University Press. 
Dutant, Julien, and Littlejohn, Clayton. Forthcoming b. "Justification, Knowledge, and Normality.” Philosophical Studies.

Easwaran, Kenny. 2016. "Dr. Truthlove or: How I Learned to Stop Worrying and Love Bayesian Probabilities.” Nous 50: 816-33.

Easwaran, Kenny, and Fitelson, Branden. 2015. "Accuracy, Coherence, and Evidence." In T. Gendler and J. Hawthorne (eds), Oxford Studies in Epistemology. Oxford: Oxford University Press, vol. 5, 61-96.

Feldman, Richard. 2005. "Respecting the Evidence." Philosophical Perspectives 19: 95-119.

Firth, Roderick. 1981. "Epistemic Merit, Intrinsic and Instrumental.” Proceedings and Addresses of the American Philosophical Association 55: 5-23.

Foley, Richard. 2012. When is True Belief Knowledge? Princeton, NJ: Princeton University Press.

Foot, Philippa. 1985. "Utilitarianism and the Virtues." Mind 94: 196-209.

Goldman, Alvin. 1999. Knowledge in a Social World. Oxford: Oxford University Press.

Graham, Peter. 2010. "In Defense of Objectivism about Moral Obligation.” Ethics 121: 88-115.

Harman, Gilbert. 1968. “Knowledge, Inference, and Explanation.” American Philosophical Quarterly 5: 164-173.

Horowitz, Sophie. 2014. "Immoderately Rational.” Philosophical Studies 167: 41-56.

Hyman, John. 2015. Action, Knowledge, and Will. Oxford: Oxford University Press.

Jenkins, Carrie. 2007. "Entitlement and Rationality." Synthese 157: 25-45.

Joyce, James. 1998. “A Nonpragmatic Vindication of Probabilism.” Philosophy of Science 65: 575-603.

Lasonen-Aarnio, Maria. 2010. “Unreasonable Knowledge.” Philosophical Perspectives 24: 1-21.

Lazar, Seth. Forthcoming. "Deontological Decision Theory and the Grounds of Subjective Permissibility." Oxford Studies in Normative Ethics.

Leitgeb, Hannes. 2017. The Stability of Belief. Oxford: Oxford University Press.

Littlejohn, Clayton. 2012. Justification and the Truth-Connection. Cambridge: Cambridge University Press.

Littlejohn, Clayton. 2015. "What Cares What You Accurately Believe?” Philosophical Perspectives 2015: 217-248.

Littlejohn, Clayton. 2018. “The Right in the Good.” In J. Dunn and K. Ahlstrom-Vij (eds), Epistemic Consequentialism. Oxford: Oxford University Press.

Littlejohn, Clayton. Forthcoming. "Truth, Knowledge, and the Standard of Proof in Criminal Law." Synthese.

McCain, Kevin. 2014. Evidentialism and Epistemic Justification. Abingdon, Oxon: Routledge.

Makinson, David. 1965. "The Paradox of the Preface." Analysis 25: 205-207.

Miracchi, Lisa. Forthcoming. "When Evidence Isn’t Enough: Suspension, Evidentialism, and Knowledge-First Virtue Epistemology." Episteme.

Moss, Sarah. 2018. Probabilistic Knowledge. Oxford: Oxford University Press.

Nelkin, Dana. 2000. “The Lottery Paradox, Knowledge, and Rationality.” Philosophical Review 109: 373-409.

Oddie, Graham, and Milne, Peter. 1991. "Act and Value: Expectation and the Representability of Moral Theories.” Theoria 57: 42-76.

Olsen, Kristian. 2018. "Subjective Rightness and Minimizing Expected Objective Wrongness.” Pacific Philosophical Quarterly 99: 417-441.

Parfit, Derek. 1988. "What We Do Together." MS. 
Raleigh, Thomas. Forthcoming. "Suspending Is Believing." Synthese.

Regan, Don. 1980. Utilitarianism and Cooperation. Oxford: Oxford University Press. Ryan, Sharon. 1991. "The Preface Paradox." Philosophical Studies 64: 293-307.

Ryan, Sharon. 1996. "The Epistemic Virtues of Consistency.” Synthese 109: 121-141.

Sepielli, Andrew. 2018. "Subjective and Objective Reasons." In D. Star (ed.), The Oxford Handbook of Reasons and Normativity. Oxford: Oxford University Press, 784-800. Simion, Mona, Kelp, Christopher, and Ghijsen, Harmen. 2016. "Norms of Belief." Philosophical Issues 26: 374-392.

Singer, Daniel. 2018. "How to be an Epistemic Consequentialist." Philosophical Quarterly 68: 580-602.

Smith, Holly. 2011. "The 'Prospective View' of Obligation." Journal of Ethics and Social Philosophy 15: 1-9.

Smith, Martin. 2016. Between Probability and Certainty. Oxford: Oxford University Press.

Steele, Katie. N.d. “Crime, Punishment, and 'Individualized' Evidence.” MS.

Steinberger, Florian. 2019. “Three Ways in Which Logic Might Be Normative.” Journal of Philosophy 116: 5-31.

Steinberger, Florian. Forthcoming. "Accuracy and Epistemic Conservatism." Analysis.

Sturgeon, Scott. 2008. "Reason and the Grain of Belief.” Nous 42: 139-165.

Talbot, Brian. 2014. "Truth Promoting Non-Evidential Reasons for Belief." Philosophical Studies 168: 599-618.

Williamson, Timothy. 2000. Knowledge and its Limits. Oxford: Oxford University Press.

Williamson, Timothy. Forthcoming a. "Justifications, Excuses, and Sceptical Scenarios." In F. Dorsch and J. Dutant (eds), The New Evil Demon Problem. Oxford: Oxford University Press.

Williamson, Timothy. Forthcoming b. "Evidence of Evidence in Epistemic Logic." In M. Skipper-Rasmussen and A. Steglich-Petersen (eds), Higher-Order Evidence: New Essays. Oxford: Oxford University Press.

Worsnip, Alex. 2016. "Belief, Credence, and the Preface Paradox." Australasian Journal of Philosophy 94: 549-562.

Zimmerman, Michael. 2008. Living with Uncertainty. Cambridge: Cambridge University Press. 


\title{
13 The Normative Ground of the Evidential Ought
}

\author{
Anne Meylan
}

\section{The Evidential Ought: Instrumentalism vs. Intrinsicalism}

Besides being subject to certain obligations or permissions to act, we are also subject to certain duties and permissions to believe. More precisely, many philosophers have defended the view that we are subject to the following evidential ought:

One ought to believe in accordance with one's evidence. ${ }^{1}$

Take the case of a teenager observing a mother carrying her buggy on the metro staircase in clear daylight. The young man is not only compelled to help her. According to evidentialists-viz. the upholders of the evidentialist oughthe also ought to believe a certain number of things given the evidence he has, e.g. that there is a woman in the staircase, that she is carrying a buggy and not a bunch of flowers, etc. ${ }^{2}$

Although evidentialists agree on this, a more fundamental question keeps dividing them. It concerns the normative ground of the evidential ought: in virtue of what ought one to believe in accordance with the evidence? Or, to phrase the same question differently: from where does the evidential ought derive its normative force?

The philosophical literature contains two answers to this question, which correspond to two mutually exclusive conceptions of the normative ground of the evidential ought: instrumentalism, and what is often called intrinsicalism. Here are recent descriptions of these two conceptions.

Instrumentalism says that there is a reason to believe in accord with the evidence because doing so is an instrumentally rational way of achieving the ends, goals, or interests one has ... Intrinsicalism disagrees. According to intrinsicalists, the reason there is to believe in accord with the evidence is independent from any relationship doing so bears to one's ends, goals, or interests. Instead, says intrinsicalism, it's a brutely epistemic normative truth that there is a reason to believe in accord with the evidence.

(Sharadin, 2018, 3792) 
What is it about evidence that explains the existence of reasons-such as they are-to believe in accordance with it? Two rival explanations dominate the literature. The first explanation is, at bottom, practical. It is that there is reason to believe in accordance with one's evidence because this is an excellent means of fulfilling the goals that one has or should have. I'll call this instrumentalism. The second explanation is not instrumentalist. It states that there is reason to believe in accordance with one's evidence in virtue of a brutely epistemic normative truth relating belief to evidence (or to some other epistemic property such as truth, or epistemic rationality). I'll call this view intrinsicalism.

(Cowie 2014, 4003-4004)

To recapitulate, instrumentalism ${ }^{3}$ is the view that the normative force of the evidential ought is grounded in the epistemic purposes of the believer, for instance, in the aim of achieving knowledge or of getting a true belief about a particular topic. According to instrumentalism, it is in virtue of our epistemic goals that one ought to believe in accordance with one's evidence (the assumption here is that beliefs that satisfy the evidential ought contribute to the achievement of our epistemic goals). ${ }^{4}$

In contrast, intrinsicalism ${ }^{5}$ denies the instrumentalist claim that the evidential ought derives its normative force from the fact that its satisfaction contributes to achieving our epistemic purposes. What is the normative ground of the evidential ought, according to intrinsicalism, then? As we just saw, the usual answer is that:

There is a brute epistemic value in believing in accordance with one's evidence.

(Cowie 2014, 4005)

But what does this really mean? Intrinsicalists' negative claim is that the normative source of the evidential ought has nothing to do with the fulfilment of our epistemic purposes. But what is their positive claim exactly? What is the normative source of the evidential ought according to intrinsicalism? This chapter aims at improving our understanding of intrinsicalism by ruling out a natural answer that one might be tempted to give to this question.

\section{Intrinsic and Instrumental Rightness}

Bearing in mind that intrinsicalism and instrumentalism are considered to be mutually exclusive positions, a natural and immediate way of conceiving intrinsicalism is by invoking the classical opposition between intrinsic and instrumental rightness.

\section{The Natural Conception of Intrinsicalism}

Intrinsicalism, as the name suggests, is the view that believing in accordance with one's evidence is intrinsically right (as opposed to instrumentally right). 


\section{Anne Meylan}

According to this natural conception, the meaning of "there is a brute epistemic value in believing in accordance with one's evidence" is thus simply that believing in accordance with one's evidence is intrinsically right.

Now, what do philosophers-mainly ethicists-normally mean when they say that a thing is intrinsically right? An intrinsically right thing is right "in itself" in the sense that it derives its rightness from what it is and not from the rightness of something else. Typically, an intrinsically right thing does not derive its rightness from the rightness of its consequences. A pleasant experience is a classical—even though debated-example of an intrinsically right experience. A pleasant experience-some philosophers think-draws its rightness from what it is. In contrast, an instrumentally right thing is a thing that derives its rightness from the rightness of its consequences. For instance, punishing your dog is an instrumentally right action if it has some benefits, perhaps, on its social behaviour. The question whether such or such a thing-pleasant experience, punishment, etc.-is instrumentally or intrinsically right is one that frequently recurs in the domain of ethics.

Getting back to the disagreement between instrumentalism and intrinsicalism, given what I have just said is the most natural conception of intrinsicalism, the bone of contention between the two views is thus the following:

While instrumentalism takes my believing in accordance with my evidence to be instrumentally right, that is, to derive its normative force from its consequences, intrinsicalism takes my believing in accordance with my evidence to be intrinsically right, that is, to derive its normative force from what it is (and not from its consequences). According to intrinsicalism, to believe things in accordance with the evidence we have is right in itself.

According to this way of looking at things, the disagreement between instrumentalism and intrinsicalism constitutes a specific instantiation-in the field of beliefs-of the classical question whether a determinate entity is instrumentally or intrinsically right. Just as ethicists disagree about whether, say, a pleasant experience is instrumentally or intrinsically right, the debate between instrumentalists and intrinsicalists revolves around the question whether my believing in accordance with my evidence is instrumentally or intrinsically right.

If this were what the disagreement between intrinsicalism and instrumentalism amounted to, then we'd be on familiar territory. But this natural understanding of what constitutes the bone of contention between instrumentalism and intrinsicalism is incorrect. The antagonism between instrumentalism and intrinsicalism does not come down to a disagreement as to whether it is instrumentally or intrinsically right to believe things in accordance with the evidence. And this is because the fact that a belief is held in accordance with the evidence does not make beliefs intrinsically right. The "kind of rightness" that the fact that a belief is held in accordance with the evidence provides for this belief cannot be identified with the intrinsic rightness that is traditionally opposed to instrumental rightness. Or so, at least, I shall argue in section 3. 
Before this, I would like to address a subsidiary worry. The reader might wonder why I have moved from my original question that concerned the ground of the evidential ought to a discussion about the instrumental or intrinsic rightness of my believing in accordance with my evidence.

As the quotations above make clear, the disagreement between instrumentalism and intrinsicalism cuts across various normative notions that apply to beliefs: ought, value, rightness, etc. Nothing prevents me from formulating my original question-viz. the one that pertains to the normative ground of the evidential ought-in terms of other normative notions. Rather than asking in virtue of what one ought one to believe in accordance with the evidence, I could have asked:

In virtue of what is my belief epistemically valuable when my belief is in accordance with my evidence?

Or

In virtue of what is my believing (epistemically ${ }^{6}$ ) right when I believe in accordance with my evidence?

I will henceforth, for sake of simplicity, express the question that divides the instrumentalists and the intrinsicalists in these latter terms, that is, in the terms of what makes it right to hold beliefs in accordance with the evidence. But this does not reflect any commitment regarding, for instance, the primacy of the normative notion of rightness over other normative notions.

\section{Intrinsic Rightness Transfers from Actions to Purposes}

We have seen that the immediate and natural way of conceiving of intrinsicalism is by relying on the traditional ethical distinction between instrumental and intrinsic rightness and taking intrinsicalism to be the view that believing in accordance with one's evidence is intrinsically right, that is, right in itself. What I would like to show now is that this cannot be-on pain of being defeatedthe intrinsicalist view. Indeed, the view that believing in accordance with one's evidence is intrinsically right does not make sense.

To understand why this view is untenable I need, first, to recall a previously mentioned distinction. There are instrumentally right and intrinsically right actions. Suppose that having a healthy diet is intrinsically right. The action of buying your food at the organic market is, under this supposition, instrumentally right in that it promotes a healthy diet. Suppose now that having pleasure is another intrinsically right end and that jogging is pleasant. The action of jogging is under this supposition an intrinsically right action in that it is an action that achieves by itself the end of having pleasure. It does not help achieve this end. It achieves it.

The following argument also relies on the following hardly deniable claim: we often act for the sake of something we want or some purpose we have. ${ }^{7}$ Now, there are two different ways of acting for the sake of something we want 


\section{Anne Meylan}

or some purpose we have. The first way is when the action performed directly achieves our purpose. When this is so, we act for the sake of acting in this way and not for the sake of some other purpose we have. For instance, if I like jogging and want to go for a jog this morning, when I go for a jog this morning, I jog for the sake of jogging and not for the sake of some other purposes I would like to achieve by jogging (e.g. health). The second way to act for the sake of a purpose is when the action performed does not directly achieve the agent's purpose but is an action that is a means to achieving this purpose (at least in the agent's eyes). If I go to the organic market for the sake of having a healthy diet, I do not perform this action for the sake of performing it but for the sake of some other purpose I have, namely having a healthy diet.

Now, the following relation holds between, on one hand, the intrinsic and instrumental rightness of our actions and, on the other, the rightness of the purposes we have when we act:

When an action is intrinsically right, what makes this action intrinsically right is one and the same thing as what would make the agent's purpose

a right purpose (supposing the agent has such a purpose). ${ }^{8}$

For instance, the fact that makes jogging intrinsically right-the fact that it is pleasant for me-also makes it right to want to jog. Why should I want to jog? Because it is pleasant for me. In contrast, when an action is instrumentally right, what makes it instrumentally right is not one and the same thing as what would make the agent's purpose by acting in this way a right purpose (supposing the agent has such a purpose).

What makes the action of buying food at the organic market instrumentally right- the fact that it is a means to having a healthy diet—does not also make it right to want to have a healthy diet. Why should I want to have a healthy diet? The following answer: "because buying food at the organic market is a means to achieving a healthy diet" clearly does not make sense.

Put as a slogan:

Intrinsic rightness transfers from actions to purposes while instrumental rightness does not.

This is not a surprising result. Purposes for the sake of which we act cannot, by definition, be right means to ends since they are themselves the ends. But this result is, as we shall see now, revealing when one moves from actions to beliefs.

\section{Believing in Accordance with the Evidence: No Transfer of Rightness}

Recall that the point I am trying to make is that the view that believing in accordance with one's evidence is intrinsically right is not tenable. Now, the reason why it is not tenable is that the rightness of my believing in accordance with my evidence does not transfer to any plausible purposes for the sake of which I might believe things in accordance with my evidence. What are the 
plausible purposes or ends for the sake for which a subject might believe things in accordance with the evidence? Here are some possibilities:

- the believer might want to get the truth and only the truth and believe things in accordance with the evidence for the sake of this purpose;

- she might want to know and believe things in accordance with the evidence for the sake of this purpose;

- she might want to get the truth regarding a certain topic and believe things in accordance with the evidence for the sake of this purpose;

- she might want to know whether $p$ and believe things in accordance with the evidence concerning $p$ for the sake of this purpose; etc.

Even though the fact that such or such a belief is held in accordance with the evidence makes it right to hold it, this fact does not make any of the aforementioned potential purposes right too. The fact that the belief that $p$ is held in accordance with the evidence concerning $p$ makes it right to believe that $p$ but it does not also make wanting to know whether $p$ a right purpose to have. The rightness of this purpose has nothing to do with the fact that the belief that $p$ is held in accordance with the evidence concerning $p$. For instance, what makes it right to want to hold a true belief about whether the weather is going to be beautiful next weekend might be the fact that true beliefs are valuable states or the fact that a true belief about the weather will help you planning your hiking tour. But the fact that your belief about the weather is (supposedly) held in accordance with the evidence does not make your wanting to hold a true belief about the weather a right purpose to have. The evidential support of the belief that $p$ is a right making property of your belief that $p$ but it is not a right-making property of any of the purposes listed above. Searching for the truth about $p$ or aiming at knowledge about whether $p$ is not right in virtue of the (potential) evidential support of the belief that $p$. Note that the previous enumeration of our epistemic purposes does not include the "want to obtain the belief that $p$." Below, I consider whether the fact that the belief that $p$ is held in accordance with the evidence makes it right to want to obtain the belief that $p$. In this paragraph, to repeat, the point that I have tried to make is the following: the rightness that characterizes beliefs held in accordance with the evidence does not transfer to the various purposes for the sake of which a subject might end up believing things in accordance with the evidence.

But if the fact that the belief is held in accordance with the evidence is what makes beliefs intrinsically right-as suggested by the hypothesis under scrutiny-the same fact should also make the aforementioned potential purposes right. If the fact that the belief is held in accordance with the evidence is what makes the belief intrinsically right, rightness should transfer from the belief to the purposes because intrinsic rightness-as opposed to instrumental rightness-does transfer in this way (as the previous section taught us).

Thus, the kind of rightness provided by the fact that a belief is held in accordance with the evidence cannot be identified with the intrinsic rightness 


\section{Anne Meylan}

that is traditionally opposed to instrumental rightness. The reader might object that it is not this "classical" intrinsic rightness that most of the intrinsicalists have in mind when they claim that "there is a brute epistemic rightness in believing in accordance with one's evidence." What many intrinsicalists mean by this is that believing in accordance with the evidence is required by the nature of beliefs. ${ }^{9}$ The view that the ground of the evidential ought lies in what beliefs essentially are is often called "constitutivism." 10 I discuss this objection in the conclusion. Before this, let me address a less serious worry.

The previous argument relies on the following reasoning:

Since what makes it intrinsically right to perform a certain action $\Phi$ - e.g. the fact that it pleasant-makes it intrinsically right to want to $\Phi$, analogously, what makes it intrinsically right to hold the belief that $\mathrm{p}$ - the fact that it is held in accordance with the evidence-should also make one or the other of the aforementioned epistemic purposes (getting the truth, knowledge, etc.) intrinsically right.

The reader might object that the analogy between actions and beliefs is not precise enough. In the case of actions, what makes it intrinsically right to $\Phi$ makes it right to want to $\Phi$. There is a strict correspondence between the purpose (I want to $\Phi$ ) and the action itself (the action of $\Phi$-ing). But this correspondence is absent in the case of beliefs since the epistemic purposes that I am considering do not include wanting to believe that $p$. A more precise formulation of the analogy is the following:

Since what makes it intrinsically right to jog - the fact that it is pleasantmakes it intrinsically right to want to jog, analogously, what makes it intrinsically epistemically right to hold the belief that $p$-the fact that it is held in accordance with the evidence-should make it epistemically intrinsically right to want to believe that $p$.

Is this "should" satisfactory? Does the fact that the belief that $p$ is held in accordance with the evidence also makes it epistemically right to want to believe that $p$ ?

A positive answer to this question seems self-contradictory. The fact that the belief that $p$ is held in accordance with the evidence cannot make wanting to believe that $p$ epistemically right, since wanting to hold a specific belief wanting to believe that $p$-is not right from this point of view. The formulation is self-contradictory because aiming at holding a specific belief is precisely not aiming at acquiring a belief that is evidentially supported. When you aim at holding a specific belief you are ready to ignore the evidential support that speaks against the belief in question.

Note that things are different with a belief's practical rightness. Suppose pleasantness makes not only action but also certain beliefs intrinsically practically right and that the belief that $p$ is pleasant. What makes it intrinsically practically right to believe that $p$-the fact that it is pleasant-also makes it 
intrinsically practically right to want to believe that $p$. Quite unsurprisingly, beliefs' intrinsic practical rightness transfers in exactly the same way as actions' intrinsic rightness transfers.

\section{Conclusion}

One might think that, just as ethicists disagree about whether, say, a pleasant experience is instrumentally right or instrinsically right, the debate between instrumentalists and intrinsicalists comes down to a disagreement about whether the satisfaction of the evidential ought is instrumentally or intrinsically right. The purpose of this chapter has been to show that this is not the case. Intrinsicalism cannot be-on pain of being defeated-the view that believing in accordance with one's evidence is intrinsically right in the classical sense of the term, that is, the sense of intrinsic rightness on which it is opposed to instrumental rightness. If "there is a brute epistemic rightness in believing in accordance with one's evidence," as intrinsicalists hold, this brute epistemic rightness is not identical with intrinsic rightness.

As I have already said, the reader might object that intrinsic rightness is not what most intrinsicalists have in mind. Their claim is rather the following: beliefs are essentially such that they require that one ought to believe things in accordance with one's evidence. Beliefs are mental states such that one ought to hold them in accordance with the evidence. There are thus two ways of being an intrinsicalist. The first kind of intrinsicalism is the one that I have discussed at length and criticized in this chapter. Here I shall call it "intrinsic intrinsicalism" in order to distinguish it from the second kind.

Intrinsic intrinsicalism, to reiterate, states that believing in accordance with the evidence is intrinsically right, that is, right in itself just as a pleasant experience can be right in itself.

I shall dub the second kind of intrinsicalism "constitutive intrinsicalism."

According to constitutive intrinsicalism, believing in accordance with the evidence is constitutively right, that is, right in virtue of what beliefs essentially are.

How does intrinsic intrinsicalism differ from constitutive intrinsicalism? In contrast to constitutive intrinsicalism, the view criticized in this chapter does not imply that the evidential ought derives its normative force from what beliefs essentially are. Intrinsic and constitutive rightness are independent kinds of rightness, as made clear by the fact a property can make a thing intrinsically right without making it constitutively right. Suppose, once again, that pleasantness makes phenomenal experiences intrinsically right. Pleasantness is not also something that makes phenomenal experiences constitutively right. Experiences are not mental states such that they ought to be pleasant. Nothing in what experiences essentially are requires that they be pleasant. Unpleasant 


\section{Anne Meylan}

experiences are perfectly proper experiences that are intrinsically wrong. Analogously it is perfectly possible to claim-as intrinsic intrinsicalism doesthat beliefs held in accordance with the evidence are intrinsically right without claiming that they are constitutively right. Intrinsic intrinsicalism is thus clearly distinct from constitutive intrinsicalism and the criticism presented in section 3 targets only the former view. Constitutive intrinsicalism is left untouched by my objection. By clarifying why intrinsic intrinsicalism is not a tenable view, the present article has shown that there is only one possible way of being an intrinsicalist. Intrinsicalists need to be constitutivists.

\section{Notes}

1 The contemporary literature contains many distinct formulations of the evidentialist ought. Steglich-Petersen (2018), for instance, favors the following: One ought to believe that $p$ only if one has adequate evidence that $p$. I do not discuss these various different formulations since they do not matter for my purpose in this chapter. I shall also ignore the important question whether the possession of adequate evidence is sufficient to give rise to duties to believe or whether it is only sufficient for permissions.

2 Upholders of evidentialism are numerous. See e.g. Adler 2002; Conee and Feldman 2004; Kelly 2002; Nolfi 2018; Shah 2006; Skorupski 2011; Vahid 2010; Way 2016.

3 Instrumentalism has been extensively defended by Steglich-Petersen. See SteglichPetersen 2006a, 2006b, 2009, 2011, 2013, 2018.

4 Instrumentalism faces the objection (see e.g. Côté Bouchard 2015; Kelly 2003; Shah 2003; Owens 2003) that epistemic normativity does not seem to be hypothetical in the way it suggests. The fact that the temperature of the room has dropped is an epistemic reason to believe that there has been a transfer of air between outside and inside, and this is the case even if the believer does not aim at achieving knowledge about whether there has been a transfer of air. For various replies see e.g. Cowie 2014; Leite 2007; Steglich-Petersen 2009, 2018.

5 The vast majority of evidentialists are also upholders of a kind of intrinsicalistm. See, for instance, Adler 2002; Kelly 2003; Shah 2003, 2006; Engel 2004; Parfit 2011; Fassio 2011; Whiting 2013.

6 For sake of brevity, I won't use the qualifier "epistemic" in what follows, except on one occasion where it is required to differentiate epistemic from practical rightness.

7 For an enlightening discussion regarding how the purposes for the sake of which we act motivate, see Alvarez 2010, 95-97.

8 See Alvarez 2010, 107, for the claim that intrinsic rightness transfers from the purposes to the reasons for which we act.

9 See Velleman 2000; Shah 2003; Wedgwood 2007.

10 See Cowie 2014, 4010; Cowie and Greenberg 2018; Steglich-Petersen 2018, 5.

\section{References}

Adler J. 2002. Belief's Own Ethics. Cambridge, MA/London, MIT Press.

Alvarez, M. 2010. Kinds of Reasons: An Essay in the Philosophy of Action. Oxford: Oxford University Press.

Conee, E., and Feldman, R. 2004. Evidentialism. Oxford: Oxford University Press. 
Côté-Bouchard, C. 2015. "Epistemic Instrumentalism and the Too Few Reasons Objection." International Journal of Philosophical Studies 23: 337-355.

Cowie, C. 2014. "In Defence of Instrumentalism about Epistemic Normativity." Synthese 191 (16): 4003-4017.

Cowie, C., and Greenberg, A. 2018. "Constitutivism about Epistemic Normativity." In C. Kyriacou and R. McKenna (eds), Metaepistemology. Basingstoke: Palgrave Macmillan, 173-196.

Engel, P. 2004. "Truth and the Aim of Belief.” In D. Gillies (ed.), Laws and Models in Science. London: King's College Press, 77-97.

Fassio, D. 2011. "Belief, Correctness and Normativity." Logique et Analyse 54: 471.

Kelly, T. 2002. "The Rationality of Belief and Other Propositional Attitudes." Philosophical Studies 110 (2): 163-196.

Kelly, T. 2003. "Epistemic Rationality as Instrumental Rationality: A Critique." Philosophy and Phenomenological Research 66 (3): 612-640.

Leite, A. 2007. "Epistemic Instrumentalism and Reasons for Belief: A Reply to Tom Kelly's.” Philosophy and Phenomenological Research 75 (2): 456-464.

Nolfi, K. 2018. "Why Evidence (and Only Evidence) Can Justify Belief.” In C. McHugh, J. Way and D. Whiting (eds), Normativity: Epistemic and Practical. Oxford: Oxford University Press.

Owens, D. 2003. "Does Belief Have an Aim?” Philosophical Studies 115: 283-305.

Parfit, D. 2011. On What Matters, vol. 1. Oxford: Oxford University Press.

Shah, N. 2003. "How Truth Governs Deliberation." Philosophical Review 112, 447-482.

Shah, N. 2006. "A New Argument for Evidentialism.” Philosophical Quarterly 56 (225): 481-498.

Sharadin, N. 2018. "Epistemic Instrumentalism and the Reason to Believe in Accord with the Evidence." Synthese 195: 3791-3809.

Skorupski, J. 2011. The Domain of Reasons. Oxford: Oxford University Press.

Steglich-Petersen, A. 2006a. "No Norm Needed: On the Aim of Belief." Philosophical Quarterly 56 (225): 499-516.

Steglich-Petersen, A. 2006b. "Voluntarism and Transparent Deliberation." South African Journal of Philosophy 25 (2): 171-176.

Steglich-Petersen, A. 2009. "Weighing the Aim of Belief." Philosophical Studies 145 (3): 395-405.

Steglich-Petersen, A. 2011. "How to be a Teleologist about Epistemic Reasons." In A. Steglich-Petersen and A. Reisner (eds), Reasons for Belief. Cambridge: Cambridge University Press, 13-33.

Steglich-Petersen, A. 2013. "Transparency, Doxastic Norms, and the Aim of Belief." Teorema 32: 59-74.

Steglich-Petersen, A. 2018. "Epistemic Instrumentalism, Permissibility, and Reasons for Belief.” In C. McHugh, J. Way and D. Whiting (eds), Normativity: Epistemic and Practical. Oxford: Oxford University Press, 260-280.

Vahid, H. 2010. "Rationalizing Beliefs: Evidential vs. Pragmatic Reasons.” Synthese 176: 447-462.

Velleman, D. 2000. “On the Aim of Belief." In D. Velleman (ed.), The Possibility of Practical Reason. Oxford: Oxford University Press.

Way, J. 2016. “Two Arguments for Evidentialism.” Philosophical Quarterly 66 (265): 805-818.

Wedgwood, R. 2007. The Nature of Normativity. Oxford: Oxford University Press.

Whiting, D. 2013. "Truth: The Aim and Norm of Belief." Teorema 32: 121-136. 
$\because$ Taylor \& Francis Taylor \& Francis Group

http://taylorandfrancis.com 


\section{Part III}

Social Epistemic Duties 
$\because$ Taylor \& Francis Taylor \& Francis Group

http://taylorandfrancis.com 


\title{
14 Responsibility for Fundamentalist Belief
}

\author{
Rik Peels
}

\section{Introduction}

The ethics of belief is nowadays a flourishing field at the intersection of ethics and epistemology. In this chapter, I apply various ideas from the current ethics of belief literature to an important phenomenon in our society: fundamentalism. Fundamentalism is one of those cases in which belief formation or belief maintenance is much like we do not want it to be. I do not have enough space in this short chapter to develop a full-blown ethics and epistemology of fundamentalist belief, which is, after all, a largely novel field for philosophers. What I would rather like to do is show how an ethics and epistemology of fundamentalist belief are relevant to current models in fundamentalism studies that aim to understand and explain fundamentalism, sketch the main issues that such an ethics and epistemology of fundamentalist belief would have to cover, and make various positive suggestions about what my own preferred approach, the so-called Influence View, would imply for the ethics and epistemology of fundamentalist belief.

The chapter is structured as follows. In $\$ 2$, I sketch the state-of-the-art in fundamentalism studies. Most importantly, I explain how the main models of the field—such as the pathology model and the radicalization model—fail for two reasons: they cannot explain why some people turn to fundamentalism while others do not and they cannot do justice to the fact that we often hold fundamentalists responsible for fundamentalist actions and beliefs. I explain how a philosophical model that provides an ethics and epistemology of fundamentalist belief can help the field to overcome these two problems. After that, I sketch which issues such a model would have to address. First, what is needed is an account of fundamentalist belief $(\$ 3)$ : what is it to hold a fundamentalist belief? Second, we need a theory of what is wrong with fundamentalist belief $(\$ 4)$ : is it moral wrongness, epistemic wrongness, or both? Third, even if fundamentalists in coming to hold or in maintaining certain fundamentalist beliefs violated certain obligations pertaining to their beliefs, it does not follow that they are culpable or blameworthy for that $(\$ 5)$. Whether or not they are, depends on whether they are properly excused for violating such obligations and for holding such beliefs. What we also need, then, is an account of excuses for fundamentalist beliefs. I conclude by exploring where we can go from here. 


\section{Background: The Stagnating Field of Fundamentalism Studies}

Fundamentalism is an important, harmful phenomenon in contemporary society. It is harmful in a wide variety of ways. Fundamentalist groups avoid contact with what they consider evil, modern, and, in the case of religious fundamentalisms, secular developments. They treat certain texts as infallible, they are suspicious of various kinds of science, they deny the distinction between public and private, and sometimes commit terrorist attacks. ${ }^{1}$ Fundamentalism impedes access to education for members of fundamentalist groups. ${ }^{2}$ It limits the rights of minorities like members of the LGBT community ${ }^{3}$ and people from different faiths or races. ${ }^{4}$ It negatively influences the public image of religions, especially Islam, and it is sometimes taken to display a clash of civilizations. ${ }^{5}$ Such fundamentalism can, but need not, be religious; there are all sorts of secular extreme ideologies that qualify as varieties of fundamentalism-e.g., certain kinds of neo-Nazism, left-wing political extremism, certain kinds of communism, versions of nationalism, and so on. ${ }^{6}$ Moreover, according to a number of scholars, fundamentalism is on the rise. ${ }^{7}$ It is, therefore, not merely harmful but increasingly so.

Since fundamentalism is so harmful, it is not surprising that there has been a lot of academic research on it. The field of fundamentalism studies is a research area at the intersection of sociology, religious studies, theology, law, psychiatry, history, criminology, and psychology that has over the last few decades been studying different kinds of fundamentalism and various types of expressions of fundamentalism. However, scholarly attention has almost entirely focused on fundamentalist behaviour rather than beliefs. That is not all that surprising either. After all, it is the actions (and omissions) that are primarily harmful, such as maltreating minorities, biased treatment of people from other faiths, terrorist attacks, lack of scientific education, and so on. This focus on behaviour has naturally led to historical and empirical research on fundamentalism. For instance, the seminal five-volume series The Fundamentalism Project, edited by Martin Marty and Scott Appleby, ${ }^{8}$ asks such questions as how different fundamentalisms in religions arise and when they lead to violence.

The main models used to explain why and predict when people display fundamentalist behaviour do not treat fundamentalists as rational and responsible individuals. Here are two examples. The so-called Radicalization Model explains the turn to fundamentalist behaviour by appeal to a process of radicalization that involves various social and political factors, such as poverty and social isolation. ${ }^{9}$ Increasingly, though, scholars from fundamentalism studies are dissatisfied with this model, since it is often unable to explain why one individual turns to fundamentalism while another in similar conditions does not. ${ }^{10}$ Another model explains the turn to fundamentalist action in terms of personality pathology. Let us call this the Pathology Model. This is equally problematic, because there is good evidence to think that most fundamentalists are fairly normal people and do not suffer from psychiatric disorders. Some people in the field of fundamentalism studies still claim that terrorists and other fundamentalists suffer from some sort of mental disorder, ${ }^{11}$ but the majority 
view nowadays is that we should consider fundamentalists as non-pathological people who act and think at least in some sense rationally. ${ }^{12}$ Since the main models in the field fail to explain and predict fundamentalist behaviour, an increasing number of fundamentalism experts claim that research in this field has stagnated for the past dozen years. ${ }^{13}$

There is an additional problem with these models that has not received that much attention. If fundamentalism is explained in terms of pathological traits or in terms of social and economic forces, that, as such, does not explain how fundamentalists can be responsible for their fundamentalist actions and omissions. In fact, if fundamentalism is entirely explained in terms of pathology and social and economic factors, one might wonder how fundamentalists could ever be responsible for their fundamentalism. However, we clearly $d o$ hold fundamentalists (at least in many cases) responsible for their behaviour. We need models that do justice to this.

These two problems-the failure to truly explain fundamentalism and the failure to do justice to the fact that most fundamentalists are responsible for their fundamentalism-jointly call for a new model. I think such a model can be developed by studying how fundamentalists can be responsible for fundamentalist beliefs. After all, many fundamentalists act from sincere beliefs that they are doing the right thing, and the fundamentalism literature has come to acknowledge that fundamentalist beliefs are often in some sense rational. ${ }^{14}$ Not all fundamentalists hold such beliefs-some simply follow an authoritative leader or someone they admire-but those leading figures themselves are usually rather convinced of various ideas that lead them to fundamentalism. Now, the ethics of belief literature has extensively studied how people can be responsible for their beliefs, what obligations they have regarding their beliefs, when and how people are excused for holding certain beliefs, and so on. Moreover, over the last few decades social epistemology has developed various tools for better understanding an individual's beliefs in relation to those of the group(s) she belongs to and those of the group(s) she does not belong to. What I have in mind here are various theories and arguments concerning group belief, group justification, collective ignorance, disagreement, and testimony.

My suggestion is, therefore, that, in order to get a firmer grip on fundamentalism and be better able to normatively assess it, we need an epistemology and ethics of fundamentalism. More specifically, we need to better understand what makes these beliefs fundamentalist, how an individual's fundamentalist beliefs relate to those of the group he or she belongs to, what duties fundamentalists have regarding their beliefs, and when they are excused for violating them. This provides a more fine-grained normative-theoretical framework for understanding and assessing fundamentalism in all its facets. An epistemology of fundamentalist belief will tell us what fundamentalist belief is and how the individual's fundamentalist beliefs relate to those of the fundamentalist group. An ethics of fundamentalist belief will tell us when we can properly praise, blame, or neutrally appraise fundamentalists for their beliefs ${ }^{15}$ by giving an account of which epistemic and moral obligations regarding their beliefs fundamentalists violate and when they are properly excused for doing 


\section{Rik Peels}

so. A full-blown epistemology and ethics of fundamentalist belief will also lay out exactly how fundamentalist belief relates to fundamentalist action. Such a theory is exactly what the field of fundamentalism studies needs.

\section{What is a Fundamentalist Belief?}

The literature on fundamentalism provides detailed historical and empirical work on which beliefs fundamentalists hold. The influential five-volume series The Fundamentalism Project (1991-1995) starts with a volume that also explores fundamentalist beliefs in various religions and worldviews. ${ }^{16}$ A large number of studies have followed, both on factual and normative fundamentalist beliefs. ${ }^{17}$ Moreover, various scales with a variety of psychometric properties have been developed to measure the degree of someone's religious fundamentalism. ${ }^{18}$ However, a rigorous conceptual and epistemological analysis of the nature of fundamentalist belief is absent in the literature: should we think of them in terms of content, degree of certainty, centrality to one's belief system, or various other properties, such as that of being self-enforcing? ${ }^{19}$ Philosophy can contribute to the field of fundamentalism studies here, both by studying which beliefs of the fundamentalist should count as fundamentalist beliefs and by conceptualizing the notion of fundamentalist belief that would play such a crucial role in an alternative model meant to understand and explain fundamentalism.

Conceptualizing fundamentalist belief is a large-scale project. Here I would like to make one important point: something cannot count as a fundamentalist belief merely in virtue of its propositional content. This is important, for it is prima facie plausible to define 'fundamentalist belief' with reference to its content, since fundamentalism as a movement is often defined in terms of such stereotypical properties as treating certain texts as infallible, being sceptical of certain kinds of science, treating women as inferior, biased treatment of people from different faiths and races, unequal treatment of members of the LGBT community, embracing a narrative about the world in terms of a paradise, fall, and redemption, and so on. One might, therefore, be tempted to spell out fundamentalist beliefs in corresponding terms: the belief that women have fewer rights than men, the belief that, say, the Qur'an or Genesis read literally is infallible, and so on.

This, however, will not do for at least two reasons. First, the account of fundamentalism in terms of the properties just given is widely taken to be an account in terms of stereotypical properties. Fundamentalism is usually understood in terms of a family resemblance. Thus, something is a case of fundamentalism if it exemplifies enough of the stereotypical properties just mentioned. This means that satisfying, say, just one or two of them will not do. Thus, if one embraces a couple of beliefs along the lines just mentioned but rejects most of them, one is not a fundamentalist. Fundamentalist content, so to say, of a belief therefore cannot all by itself be sufficient for some belief to be a fundamentalist belief.

Second, imagine that someone believes that science ought to be treated with great scepticism. However, she does not believe this because of 
narrow-mindedness, commitment to a religious system that seems to conflict with science, or any such thing. Rather, she believes this on the basis of an indepth investigation of the track-record of science. The investigation is far from perfect, but it is the best she can possibly do. Would her belief count as a fundamentalist belief? It seems it would not. In fact, this is an important position among anti-realists in the philosophy of science and the debate is still going on. Now, imagine she paradoxically also believes that women are inferior to men in important ways-again, on the basis of thorough (even though misguided) empirical inquiry. Would her belief count as fundamentalist? Surely not. Just to be clear: that belief of hers would be false. But she has done the very best she could in inquiring into these issues and she has done so open-mindedly. What this strongly suggests is that beliefs are fundamentalist beliefs only if they come about in a certain way and if they have certain problematic sources.

If beliefs are fundamentalist not merely in virtue of their content, what does turn beliefs into fundamentalist beliefs? Here is a hypothesis: fundamentalist beliefs are beliefs with a particular content that have not been formed in the right sort of way. Here are at least two ways this might be fleshed out. First, one might think that fundamentalist beliefs are a specific kind of extreme beliefs that violate norms of moderation in belief formation. Thoughts along these lines can be found in medieval Islamic philosophy. ${ }^{20}$ Second, one might think that fundamentalist beliefs are always beliefs that are brought about by the operation of intellectual vices. The epistemology of intellectual virtues and vices has been flourishing over the last two decades. I take intellectual virtues, such as open-mindedness and thoroughness,$^{21}$ to be intellectual character traits that enhance effective and responsible inquiry. Intellectual vices are their opposites: intellectual character traits that impede effective and responsible inquiry. ${ }^{22}$ Among the many intellectual vices are carelessness, closed-mindedness, conformity, cowardice, dogmatism, gullibility, idleness, insensitivity to detail, intellectual pride, lack of thoroughness, negligence, obtuseness, prejudice, rigidity, and wishful thinking. ${ }^{23}$

Note that it does not follow from this hypothesis that fundamentalist beliefs are beliefs for which one is necessarily blameworthy. This is because fundamentalist beliefs are beliefs for which one can be excused, say, by indoctrination. Thus, even though the belief formation would always be misguidedeither because it results from the violation of certain intellectual or epistemic obligations, or because it necessarily involves the activation of certain intellectual vices-and in that sense wrong, the fundamentalist would not always be blameworthy. I take this to be an advantage of this view: it does justice to the fact that, when people form fundamentalist beliefs, something goes wrong epistemically and often, but not always, the cognitive subjects involved are blameworthy.

Let me stress that both conditions are not only jointly sufficient, but that they are also individually necessary. All of us, imperfect people, form beliefs as the result of the violation of certain epistemic norms and as a result of the exercise of intellectual vices, but that does not render those beliefs fundamentalist. Not even all of the fundamentalist's beliefs issuing from the violation of 


\section{Rik Peels}

epistemic norms or the exercise of intellectual vices count as fundamentalistif a fundamentalist sloppily reads the newspaper and comes to believe that the Germans won the World Cup in soccer as a result, that belief is blameworthy, but it is not a fundamentalist belief. Not even if, in fact, the Dutch won it. What also seems required, then, is that the propositional content of the belief in question is constitutional of the fundamentalism in question or is relevantly related to it. Thus, a belief is fundamentalist only if it has such contents as that women are inferior to men or that science regarding the origin of the cosmos ought to be treated with scepticism, and relevantly related beliefs, such as the belief that this person (a girl) should not have the same education as boys, or the belief that contact with that person should be avoided, because she works in the biology department where evolutionary theory reigns.

Before we turn to the normative dimension of fundamentalist belief, let me say one more thing. So far, I have focused entirely on beliefs on individuals. However, ever since the rise of social epistemology, ${ }^{24}$ it has become customary to also consider whether groups, such as courts, boards, governments, and research groups can hold beliefs, be epistemically justified in believing something, be ignorant of something, or know something. ${ }^{25}$ If this is right-and it seems to me that it is-it would be only natural for one to ask what it is for a group to hold a fundamentalist belief. If what I argued above is correct, then it cannot merely be explained in terms of standard analyses of group belief plus a qualifier about fundamentalist content; one should also consider the ways in which those beliefs came about. But how is this supposed to work in the case of a group? Moreover, it is widely acknowledged in fundamentalism studies that the group conditions heavily influence the beliefs of the individual that belongs to it. ${ }^{26}$ Finally, fundamentalist beliefs of individuals are often based on the authority of and trust in others in the group. ${ }^{27}$ Clearly, much more rigorous philosophical work is needed. In what follows, I confine myself to fundamentalist beliefs of individuals.

\section{The Wrongness of Fundamentalist Beliefs}

Exactly what obligations do fundamentalists violate in acquiring or maintaining fundamentalist beliefs?

The ethics of belief literature displays a wide variety of norms pertaining to our beliefs, including the obligation to avoid false belief, the obligation to believe only truth, the duty to believe in accordance with one's evidence, the obligation to gather sufficient evidence, the duty to hold only rational beliefs, and so on. This chapter focuses on responsibility for fundamentalist beliefs, so I will confine myself to full-blown deontological obligations: obligations that are such that if one violates them without being excused, one is thereby blameworthy or culpable.

This leaves us with two metaphysically different kinds of obligations that are relevant to doxastic responsibility. On the one hand, some philosophers have argued that there are doxastic norms, rules, obligations, or duties. These are duties to hold or not to hold specific beliefs. Among the philosophers who 
have fleshed out such obligations some believe that we have them in virtue of our volitional or voluntary or intentional control over our beliefs. Others have argued, in response to William Alston's famous argument from doxastic involuntarism against the deontological conception of justification, ${ }^{28}$ that we lack voluntary control over our beliefs. Instead, they surmise, we have doxastic obligations because we have compatibilist control over our beliefs. ${ }^{29}$ This is spelled out differently by different philosophers, but a common account is one in terms of beliefs that are sufficiently reason-responsive.

On the other hand, there are philosophers who believe that we lack volitional control over our beliefs and that compatibilist control over our beliefs does not render us responsible for them. They suggest that we are derivatively responsible for our beliefs: we are responsible for our beliefs because we control various actions that make a difference to what we believe. We lack control over our beliefs, but we do have influence on them. Anthony Booth, Sanford Goldberg, Anne Meylan, Nikolaj Nottelmann, I myself,, ${ }^{30}$ and others have defended an Influence View along these lines. The Influence View says that we generally lack doxastic obligations (there may be a few exceptional scenarios ${ }^{31}$ ), but we $d o$ have intellectual obligations, that is, obligations to perform belief-influencing actions. We are responsible-blameworthy, praiseworthy, neutrally appraisable-for our beliefs, because we bear derivative responsibility for our beliefs.

Since I have defended the Influence View in detail elsewhere, I will not repeat my criticisms of doxastic compatibilism here..$^{32}$ Rather, I will explore what responsibility for fundamentalist belief looks like on the Influence View. What I would like to suggest is that on the Influence View, the fundamentalist will generally violate both moral and epistemic intellectual obligations. Remember, intellectual obligations are obligations to perform belief-influencing actions or not to perform such actions. We have them in virtue of being human beings rather than in virtue of such contingent facts as specific tasks, commitments, and jobs (thus, the police have an obligation to investigate the murder, I have an obligation to check the train timetable if I promised to do so, and so on). Here is what I wrote on an earlier occasion about the moral intellectual obligations that we have:

A question that many philosophers will be interested in is whether there are any non-contingent intellectual obligations, obligations that we have, not in virtue of a voluntary commitment of some sort, but simply in virtue of being human. I think we do. For instance, Julia has a non-contingent moral intellectual obligation not to spy on her niece, for it is morally bad to acquire knowledge about such private matters and morally wrong (at least prima facie) to do so intentionally. If Julia violates this intellectual obligation, the moral badness involved is at least partly constituted by Julia's having certain knowledge (which entails certain beliefs) about her niece's private life that she should not have had. ${ }^{33}$

Do fundamentalists violate moral intellectual obligations? Well, if so, they will not be obligations like the obligation not to spy on your niece. After all, 


\section{Rik Peels}

violating such obligations leads to knowledge, true belief, justified belief, and beliefs with all sorts of other positive epistemic statuses. The moral wrongness in those cases of privacy violation is that of having access to and knowing certain things about another person that one should not know.

Someone might object that only the spying is morally wrong in this case; not so much having certain kinds of knowledge as a result of such spying. After all, there is nothing morally wrong about the knowledge as such: if Julia's niece freely shares her knowledge of her love affairs with Julia, there is nothing wrong with Julia's knowing these things. I agree that, in a situation like that, there is nothing morally wrong with Julia's knowing these things. It does not follow that there is nothing wrong with Julia's knowing these things once she finds them out by way of spying. Julia's niece, for instance, could rightly feel Julia has wronged her not merely by spying on her but also by coming to know certain things as a result of that. She may rightly think a situation in which Julia successfully spies—because it leads to knowledge-is even worse than a situation in which Julia unsuccessfully spies. She may feel wronged not only because of the intrusive act, but also by the very fact that Julia now knows something about her that she should not know. Apparently, things can be contingently wrong; not wrong if one freely brings it about, but wrong if the other person brings it about by way of the violation of an obligation.

Now, what about fundamentalist belief? Is fundamentalist belief a case of knowledge that came about in a wrong way? It seems not. With fundamentalist belief, things are crucially different: the relevant beliefs are widely considered to lack such positive statuses as being an instances of knowledge, being epistemically justified, being reliably formed, being true, and so on.

So, what is morally bad about these beliefs? I would like to suggest that there is not a single moral badness that they have in common. In fact, some may not be morally bad at all. Of course, to believe of homosexuals that they have fewer rights than heterosexuals is clearly morally wrong. It does not do justice to the rights that homosexuals have. To believe this about them wrongs them in some way. But it is not clear what the moral wrong is in believing that the world was literally created in six days some 6,000 years ago. Just to be clear: that belief is false and it seems epistemically wrong in a variety of ways. But it is not clear what is morally wrong with it (unless epistemic badness is a variety of moral badness, as Linda Zagzebski has suggested ${ }^{34}$ ).

What moral intellectual obligations do fundamentalists violate in coming to believe, say, that homosexuals have or should have fewer rights than heterosexuals or that women do not deserve the same sort of education that men deserve? Remember, if the Influence View is right, people do not really have a moral obligation to not believe these things. After all, they lack the sort of voluntary control over believing these things that having an obligation to not believe these things would require. Rather, they have an obligation (not) to perform various belief-influencing actions that make a difference to whether or not they believe these things. What such a belief-influencing action or various belief-influencing actions will look like may well differ from person to person: becoming more open-minded, reconsidering the evidence, talking to other 
people, and so on. These obligations are context-specific in that they depend on the particular wrong brought about by holding these fundamentalist beliefs. And, yet, these are also non-contingent or universal in the sense that they do not depend on any such contingent factors as having a particular role, job, task, or some such thing. The fundamentalist believer has these obligations simply in virtue of being a human being.

Now, could we say something similar about epistemic intellectual obligations and epistemic badness? If so, we would say something like this: in case a fundamentalist belief is epistemically wrong-it is false, it is unreliably formed, it is not in accordance with the evidence, or some such thing-one has an epistemic obligation to do one of those things that will rid one of the belief. The problem with this line of thinking is that it would give rise to way too many intellectual obligations. After all, we hold countless false beliefs, often where we have no clue to those beliefs being false. If the suggestion under consideration is correct, we would have numerous epistemic obligations to rid ourselves of all those false beliefs, unreliably formed beliefs, irrational beliefs, and so onobligations that we continually violate. That seems too strong a consequence.

So, what epistemic intellectual obligations do fundamentalists violate? Elsewhere, I have argued that we have a wide variety of subjective epistemic intellectual obligations. ${ }^{35}$ After all, we are not only sometimes blameworthy for doing that which is bad, but also for doing that which from our perspective is bad, whether or not it actually is. All things equal, we should not do what we believe to be bad. I prefer to cash out such subjective obligations in terms of what one believes rather than in terms of what one should believe. Elsewhere, I have explained why:

Thus, the suggestion is that subjective epistemic obligations should be understood in terms of what one believes. I prefer this to understanding subjective obligations in terms of what one should believe. I cannot defend this preference in detail here, but I would like to give at least one reason to prefer the former over the latter approach. I argued that doxastic responsibility should be understood in terms of intellectual obligations. It follows that if one should believe that $p$ [but one fails to do so; RP], then one has violated an intellectual obligation at some earlier time. But if subjective obligations are understood in terms of what one should believe rather than in terms of what one believes, then it seems that the chain of intellectual obligations would be endless. This is because an intellectual obligation would have to be explained in terms of what one should have believed at some earlier time and that would have to be explained in terms of what one should have believed at an even earlier time, and so forth. ${ }^{36}$

What would be examples of the violation of such subjective epistemic intellectual obligations be? Here are some examples: (a) One believes that one should really talk to that other person, but one does not do so because one does not want to do so (say, one is jealous of that person's achievements). Since one fails 


\section{Rik Peels}

to talk to that other person, one lacks crucial evidence that one would have had if one had talked to that person and that would have made a difference to what one believes. (b) One believes that one should investigate the trustworthiness of this pastor in more detail before accepting his views, but one fails to do so, again, thereby failing to have important evidence. (c) One believes that two beliefs that one holds are in tension with each other, that they cannot both be true, and that one should therefore further explore the contents of and evidential basis for each of them, but one fails to do so. It seems that all of us violate such epistemic (the badness is primarily epistemic rather than moral or prudential) intellectual obligations. Note that the fundamentalist need not violate an epistemic intellectual obligation that is more or less causally directly related to a specific belief in order for her to be blameworthy for that belief. She can also violate, say, a subjective epistemic intellectual obligation to work on her intellectual vice of narrow-mindedness. If she fails to do so on several occasions and, years later, she forms a fundamentalist belief that she would not have formed if she had met her obligation (or maybe even several of them), she can be blameworthy for that.

What if the fundamentalist does not violate any subjective epistemic intellectual obligations at all? This is hard to imagine. A scenario like that would look as follows. She believes it is perfectly fine not to listen to others, she believes it is fine to trust a source that, upon some further reflection, is clearly corrupt, she believes it is alright to disagree with the majority without any kind of argument, and so on. Such a fundamentalist is what we could call a second-order fundamentalist: she not only holds a wide variety of fundamentalist beliefs, but—on a second order-also believes it is perfectly fine to believe these things and believes that in coming to believe these things she did not violate any obligation whatsoever: at every point in coming to acquire these beliefs, she thought it was alright or even good to acquire those beliefs.

In assessing a scenario like this, we run into the debate about the so-called Origination Thesis, as defended by, for instance, Michael Zimmerman. ${ }^{37}$ The core idea of that thesis is that if someone is blameworthy for something, then she has at least at some point in time acted against her better judgment (akrasia). Elsewhere, I have fine-tuned that thesis: one can also be blameworthy if one acted from dormant and tacit beliefs (that would not count as akrasia) and in some cases if one acted even though one suspended judgment on, say, whether that was the right thing to do. I believe, though, that the basic idea of the Origination Thesis is true: one is blameworthy and the fundamentalist is blameworthy for acting as she does or believing something only if at some point her doxastic attitudes about her factual and normative situation did not match what she did. In other words, at some point, she acted against her beliefs, disbeliefs, and suspensions on what the right thing to do was. After all, it is hard to see how one could be blameworthy if one always acted in accordance with what one believed was the right thing. I will not delve into the debate about the Origination Thesis again here. Rather, let me point out that it levels an interesting hypothesis for the field of fundamentalism studies, a hypothesis that deserves further, rigorous empirical 
scrutiny. The hypothesis would be that the fundamentalist is blameworthy for holding certain fundamentalist beliefs and for acting on those beliefs only if in coming to hold those beliefs or forming those beliefs, she violated certain subjective intellectual obligations without any proper excuse for doing so, for instance by acting against her beliefs about what was the right thing to do. Investigating a thesis along these lines will not be easy. On the contrary, a fundamentalist is a fundamentalist and will, thus, normally believe that in believing the things she believes, she believes the right thing. Also believing that one violated various intellectual obligations in coming to hold those beliefs would, for a rational person, undermine holding those beliefs. Thus, it is unlikely that the fundamentalist will present such cases of violating intellectual obligations. Yet, it would be worthwhile to investigate her mental states or what she recalls about them at various stages that were crucial in coming to form and maintain the fundamentalist beliefs that she holds. After all, we might have good reasons to interpret some cases as cases of violating subjective epistemic intellectual obligations, even though the fundamentalist in her interpretation of those cases sees them in a different light (yet her presentation of them might give us enough reason to differ from her in our interpretation of them).

All this is not to deny that fundamentalist believers may also violate epistemic or professional or moral intellectual obligations regarding their beliefs that arise from such contingent factors as tasks, jobs, promises, and so on. That some intellectual obligations arise from these is often acknowledged in the literature ${ }^{38}$ and fundamentalist belief seems no different. Thus, a highschool teacher in biology may have an additional professional obligation to work on her beliefs regarding evolution and creation. All I have wanted to suggest here, though, is that even in the absence of such specific roles and tasks fundamentalists violate intellectual obligations, both moral and epistemic, that they have simply in virtue of being human beings.

\section{Excuses for Fundamentalist Belief}

It is one thing to violate an obligation with regard to one's beliefs, fundamentalist beliefs included. It is quite another thing to be blameworthy for the violation of such obligations. What bridges the gap is not being excused: one is blameworthy for violating an obligation only if one is not excused for doing so. ${ }^{39}$ Since it is widely taken that fundamentalists are often blameworthy for their beliefs, ${ }^{40}$ a viable ethics of fundamentalist belief should be able to explain when someone is excused for fundamentalist beliefs and when he or she is not.

Ethicists have studied the nature of excuses ${ }^{41}$ and various problems regarding excuses, such as whether moral ignorance can excuse. ${ }^{42}$ Ethicists have also paid considerable attention to specific excuses, such as the inability to act otherwise ${ }^{43}$ and ignorance. ${ }^{44}$ However, the focus has been on excuses for actions, not so much on excuses for beliefs. There have been a few studies on excuses for belief ${ }^{45}$ and one on indoctrination in particular, ${ }^{46}$ but these are exceptional. Moreover, what needs to be done is that this work should be taken 


\section{Rik Peels}

a step further by exploring when people are excused for violating obligations regarding fundamentalist beliefs.

From a more empirical perspective, we $d o$ find a large number of studies on excuses for belief, especially the excuses of brainwashing and indoctrination, or, as some scholars prefer to phrase it, "thought reform" or "thought persuasion" ${ }^{47}$ However, this work focuses on the context-specific social and political factors, rather than building an ethical theory of when specific excuses hold for fundamentalist beliefs. What fundamentalism studies as a field needs, in order to better understand and assess fundamentalism in all its facets, is a thorough analysis of (1) the various excuses that can hold with respect to fundamentalist beliefs, (2) how they relate to the obligations that fundamentalists are subject to, and (3) when excuses hold on an individual level and when they hold on a group level, as well as (4) a carefully developed theory that provides criteria for distinguishing which excuses fully or partially hold in specific circumstances.

The legal theorists and philosophers of law have also paid considerable attention to excuses for action and also for belief. ${ }^{48}$ Even though an ethics and epistemology can profit from the ideas covered in the philosophy of law, the existing work as such will not do. The reason for that is that the law does not merely work with what one is responsible for, but also the societal effects of (not) punishing someone, whether there has been a precedent or not, the likelihood of it happening again if someone is punished, and so on. Epistemology and ethics, however, focus on exactly which beliefs a person holds and whether that person is epistemically and morally responsible for those fundamentalist beliefs.

Now, one might of course explore the general doxastic excuses for fundamentalist belief, such as ignorance ${ }^{49}$ However, a substantial ethics of belief will also have to pay special attention to specific doxastic excuses that seem to occur more often in the case of fundamentalist belief than elsewhere. What I have in mind are such doxastic excuses as manipulation, cultural difference, peer pressure, social isolation, and indoctrination..$^{50}$

We should note that whether or not one of these factors excuses a person depends on whether or not she was in any way responsible for them. Indoctrination, for example, may excuse, but whether it does so depends on whether or not one was culpable for being indoctrinated. One might think, for instance, that an ISIS fighter voluntarily leaving the United Kingdom and ending up being indoctrinated in Syrian ISIS territory may be indoctrinated but not excused because she could and should have avoided being subject to such indoctrination. Or someone growing up in ISIS territory may go through a period of intense indoctrination but we might think that after she has lived in Germany for more than 20 years, she could and should have been able to rid herself of the most harmful effects of that indoctrination -it is at least not a full excuse for her fundamentalist beliefs (that is, that she is at least blameworthy to some degree for them). This means that there inevitably is an historical or, to use another term, diachronic dimension to these excuses; in order to know whether a certain state of affairs excuses a person, we need to know whether one was responsible for the actualization of that state of affairs in the first place. This squares well with the main tenets of the Influence View: we need to 
understand responsibility for beliefs not in terms of the reason-responsiveness of one's beliefs or at least not merely in those terms, but also at least partly in terms of the actions and omissions that in the course of time led to those beliefs.

Of course, unless the fundamentalist changes her mind and gives up various fundamentalist beliefs, she will normally not present various states of affairs as excusing circumstances. Yet, her description of those states of affairs might lead $u s$ to conclude that certain excusing circumstances obtain.

\section{Conclusion}

Let me draw the threads of this chapter together. I have argued that the current state of the art in fundamentalism studies is, to use a euphemism, sub-optional and that philosophers-ethicists and epistemologists in particular-can play an important role in helping us to understand why people make the turn towards fundamentalism. The main empirical models lack explanatory power and cannot do justice to the fact that most fundamentalists are responsible for what they believe and do. What is needed, then, is a philosophical model, based on thorough empirical inquiry, that can explain how normal, often rational people can make the turn to fundamentalism and how they are still responsible for doing so. Among other things, such a model will conceptually explore the nature of fundamentalist beliefs, study the relation between the beliefs of the individual fundamentalist and those of the group that he or she belongs to, lay out various contingent and necessary moral and epistemic obligations that fundamentalists violate, and spell out under which conditions fundamentalists are excused for doing so. ${ }^{51}$

\section{Notes}

1 See Marty and Appleby 1991a, 1991b; Ruthven 2004; Shupe 2011.

2 See Beyerlein 2004; West 2016.

3 See Cunningham and Melton 2013.

4 See Rose and Firmin 2016.

5 See Oudenampsen 2016.

6 See Hardin 2002.

7 Thus, Emerson and Hartman 2006.

8 Marty and Appleby 1991-1995.

9 HM Government 2009; Sageman 2016.

10 Cassam 2018; Sageman 2014; 2016.

11 E.g. Lankford 2013.

12 See Baurman 2007; Cassam 2018; Crenshaw 2011; Horgan 2005; Sageman 2004; 2014; 2016. In what follows, I am particularly inspired by the writings of Michael Baurman and Quassim Cassam.

13 E.g., Sageman 2014; 2016.

14 E.g., Baurman 2007; Cassam 2018; Sageman 2014.

15 For an account of responsibility in terms of such reactive attitudes as praise and blame, see Strawson 1974.

16 Mark and Appleby 1991. 


\section{Rik Peels}

17 E.g., Friedman and Rholes 2007; Hardin 2002; Yelderman et al. 2018.

18 E.g., Altemeyer and Hunsberger 2004.

19 Hardin 2002.

20 See Booth 2016; Winter 2006.

21 For an early exploration of the intellectual virtues, see Zagzebski 1996.

22 Thus also Cassam 2016.

23 For more on these, see Baehr 2011; Battaly 2010, 2016; Cassam 2016; Fricker 2007.

24 See, for instance, Goldman and Blanchard 2016.

25 See Brady and Fricker 2016; Klausen 2015; Mathiesen 2006; Peels and Lagewaard 2021; Tuomela 1995.

26 Hardin 2002.

27 Altemeyer and Hunsberger 1992; Hardin 2002.

28 See Alston 1989.

29 E.g. McHugh 2014.

30 Booth 2014; Goldberg 2018; Meylan 2013; Nottelmann 2007; Peels 2017a.

31 For some of those, see Peels 2015.

32 For such criticism, see Peels 2014a, 2017a.

33 Peels 2017a, 101.

34 See Zagzebski 1996. Here, I will assume with most other epistemologists that her argument for the idea that all epistemic badness is reducible to moral badness is not convincing.

35 See Peels 2017a, ch. 3.

36 Peels 2017a, 104-105.

37 See, for instance, Zimmerman 2008.

38 Goldberg 2018; McCormick 2015; Peels 2017a.

39 See Zimmerman 1988, 1996, 2008.

40 See, for instance, Cassam 2018; Shupe 2011.

41 Brandt 1969.

42 Rivera-López 2006.

43 Fischer and Ravizza 1998.

44 Harman 2011; Rosen 2003, 2004; Smith 2011; Zimmerman 1986, 1997.

45 Van Woudenberg 2009.

46 Yaffe 2003.

47 Pratkanis and Aronson 2001; Tan 2011; Taylor 2004.

48 E.g., Ginsburg and Richardson 1998.

49 See, for instance, Peels 2014b; 2017a, ch. 5; Peels 2017b.

50 See Yaffe 2003.

51 I would like to thank Kevin McCain for his astute and helpful comments on an earlier version of this chapter. Work on this chapter was made possible by the project EXTREME (Extreme Beliefs: The Epistemology and Ethics of Fundamentalism), which has received funding from the European Research Council (ERC) under the European Union's Horizon 2020 research and innovation programme (Grant agreement No. 851613). I would like to thank Imane Amara for carefully proofreading this chapter.

\section{References}

Alston, William P. 1989. “The Deontological Conception of Epistemic Justification.” In Epistemic Justification: Essays in the Theory of Knowledge. Ithaca, NY: Cornell University Press, 115-152. 
Altemeyer, Bob, and Hunsberger, Bruce. 1992. "Authoritarianism, Religious Fundamentalism, Quest, and Prejudice." International Journal for the Psychology of Religion 2: 113-133.

Altemeyer, Bob, and Hunsberger, Bruce 2004. "A Revised Religious Fundamentalism Scale: The Short and Sweet of it." International Journal for the Psychology of Religion 14: 47-54.

Baehr, Jason. 2011. The Inquiring Mind: On Intellectual Virtues and Virtue Epistemology. New York: Oxford University Press.

Battaly, Heather D. 2010. "Epistemic Self-Indulgence.” In Heather D. Battaly (ed.), Virtue and Vice, Moral and Epistemic. Oxford: Routledge, 215-236.

Battaly, Heather D. 2016 "Epistemic Virtue and Vice: Reliabilism, Responsibilism, and Personalism." In Chienkuo Mi, Michael Slote and Ernest Sosa (eds), Moral and Intellectual Virtues in Western and Chinese Philosophy. New York: Routledge, 99-120.

Baurman, Michael. 2007. "Rational Fundamentalism? An Explanatory Model of Fundamentalist Beliefs.” Episteme 4 (2): 150-166.

Beyerlein, K. 2004. "Specifying the Impact of Conservative Protestantism on Educational Attainment.” Journal for the Scientific Study of Religion 43 (4): 505-518.

Booth, Anthony R. 2014. "On Some Recent Moves in Defense of Doxastic Compatibilism.” Synthese 191 (8): 1867-1880.

Booth, Anthony R. 2016. Islamic Philosophy and the Ethics of Belief. London: Palgrave Macmillan.

Brady, Michael S., and Fricker, Miranda. 2016. The Epistemic Life of Groups: Essays in the Epistemology of Collectives Oxford: Oxford University Press.

Brandt, Richard B. 1969. "A Utilitarian Theory of Excuses.” Philosophical Review 78 (3): 337-361.

Cassam, Quassim. 2016. "Vice Epistemology.” The Monist 99: 159-180.

Cassam, Quassim. 2018. "The Epistemology of Terrorism and Counterterrorism." Philosophy, Supplementary Volume: Harms and Wrongs in Epistemic Practice, draft paper.

Crenshaw, Martha. 2011. Explaining Terrorism: Causes, Processes, and Consequences. London: Routledge.

Cunningham, George B., and Melton, E. Nicole. 2013. "The Moderating Effects of Contact with Lesbian and Gay Friends on the Relationships among Religious Fundamentalism, Sexism, and Sexual Prejudice." Journal of Sex Research 50 (3-4): 401-408.

Emerson, Michael O., and Hartman, David. 2006. "The Rise of Religious Fundamentalism.” Annual Review of Sociology 32: 127-144.

Fischer, John M., and Ravizza, Mark. 1998. Responsibility and Control: A Theory of Moral Responsibility. Cambridge: Cambridge University Press.

Friedman, Mike, and Rholes, W. Steven. 2007. "Successfully Challenging Fundamentalist Beliefs Results in Increased Death Awareness.” Journal of Experimental Social Psychology 43 (5): 794-801.

Fricker, Miranda. 2007. Epistemic Injustice: Power and the Ethics of Knowing. Oxford: Oxford University Press.

Ginsburg, Gerald, and Richardson, James T. 1998. “ Brainwashing' Evidence In Light of Daubert.” In Helen Reece (ed.), Law and Science. Oxford: Oxford University Press, $265-288$.

Goldberg, Sanford C. 2018. To the Best of Our Knowledge: Social Expectations and Epistemic Normativity. Oxford: Oxford University Press. 


\section{Rik Peels}

Goldman, Alvin, and Blanchard, Thomas. 2016. "Social Epistemology.” In Edward N. Zalta (ed.), The Stanford Encyclopedia of Philosophy. https://plato.stanford.edu/ archives/win2016/entries/epistemology-social/.

Hardin, Russell. 2002. "The Crippled Epistemology of Extremism.” In Albert Breton et al. (eds), Political Extremism and Rationality. Cambridge: Cambridge University Press, 3-22.

Harman, Elizabeth. 2011. “Does Moral Ignorance Exculpate?” Ratio 24 (4): 443-468.

HM Government. 2009. Pursue Prevent Protect Prepare: The United Kingdom's Strategy for Countering International Terrorism, https://assets.publishing.service. gov.uk/government/uploads/system/uploads/attachmentdata/file/228907/7833.pdf.

Horgan, John. 2005. The Psychology of Terrorism. Abingdon, Oxon: Routledge.

Klausen, Søren. 2015. “Group Knowledge: A Real-World Approach.” Synthese 192 (3): 813-839.

Lankford, Adam. 2013. The Myth of Martyrdom: What Really Drives Suicide Bombers, Rampage Shooters, and Other Self-Destructive Killers. New York: Palgrave Macmillan.

Marty, Martin E., and Appleby, R. Scott. 1991a. "Introduction: The Fundamentalism Project: A User's Guide." In Martin E. Marty and R. Scott Appleby (eds), Fundamentalisms Observed. The Fundamentalism Project, vol. 1. Chicago, IL: University of Chicago Press, pp. vii-xiii.

Marty, Martin E., and Appleby, R. Scott (eds). 1991b. "Conclusion: An Interim Report on A Hypothetical Family.” In Martin E. Marty and R. Scott Appleby (eds), Fundamentalisms Observed. The Fundamentalism Project, vol. 1. Chicago, IL: University of Chicago Press, 814-842.

Marty, Martin E., and Appleby, R. Scott (eds). 1991-5. The Fundamentalism Project. 5 vols. Chicago, IL: University of Chicago Press.

Mathiesen, Kay. 2006. "The Epistemic Features of Group Belief." Episteme 2 (3): 161-175.

McCormick, Miriam S. 2015. Believing Against the Evidence: Agency and the Ethics of Belief. New York: Routledge.

McHugh, Conor. 2014. "Exercising Doxastic Freedom." Philosophy and Phenomenological Research 88 (1): 1-37.

Meylan, Anne. 2013. Foundations of an Ethics of Belief. Berlin: Walter de Gruyter.

Nottelmann, Nikolaj. 2007. Blameworthy Belief: A Study in Epistemic Deontologism. Dordrecht: Springer.

Oudenampsen, Merijn. 2016. "Deconstructing Ayaan Hirsi Ali: On Islamism, Neoconservatism, and the Clash of Civilizations." Politics, Religion, and Ideology 17 (2-3): 227-248.

Peels, Rik. 2014a. “Against Doxastic Compatibilism.” Philosophy and Phenomenological Research 89 (3): 679-702.

Peels, Rik. 2014b. "What Kind of Ignorance Excuses? Two Neglected Issues." Philosophical Quarterly 64 (256): 478-496.

Peels, Rik. 2015. "Believing at Will Is Possible.” Australasian Journal of Philosophy 93 (3): 524-541.

Peels, Rik. 2017a. Responsible Belief: A Theory in Ethics and Epistemology. New York: Oxford University Press.

Peels, Rik. 2017b. Perspectives on Ignorance from Moral and Social Philosophy. London: Routledge.

Peels, Rik, and Thirza Lagewaard. 2021. "Group Ignorance: An Account Based on Case Studies of Fundamentalist and White Ignorance." In Jennifer Lackey and 
Aidan McGlynn (eds), Oxford Handbook of Social Epistemology. Oxford: Oxford University Press, forthcoming.

Pratkanis, Anthony, and Aronson, Elliot. 2001. Age of Propaganda: The Everyday Use and Abuse of Persuasion. New York: Henry Holt.

Rivera-López, Eduardo. 2006. "Can There Be Full Excuses for Morally Wrong Actions?” Philosophy and Phenomenological Research 73 (1): 124-142.

Rose, Stephanie Firebaugh, and Firmin, Michael W. 2016. "Racism in Interracial Dating: A Case Study in Southern Culture and Fundamentalism." Christian Higher Education 15 (3): 140-152.

Rosen, Gideon. 2003. "Culpability and Ignorance." Proceedings of the Aristotelian Society 103 (1): 61-84.

Rosen, Gideon. 2004. "Skepticism about Moral Responsibility." In Philosophical Perspectives: Ethics, vol. 18, ed. John Hawthorne. Malden, MA: Blackwell Publishing, 295-311.

Ruthven, Malise. 2004. Fundamentalism: The Search for Meaning. Oxford: Oxford University Press.

Sageman, Marc. 2004. Understanding Terror Networks. Philadelphia, PA: University of Pennsylvania Press.

Sageman, Marc. 2014. "The Stagnation in Terrorism Research.” Terrorism and Political Violence 26 (4): 565-580.

Sageman, Marc. 2016. Misunderstanding Terrorism. Philadelphia, PA: University of Pennsylvania Press.

Shupe, Anson. 2011. “Religious Fundamentalism.” In Peter B. Clarke (ed.), The Oxford Handbook of the Sociology of Religion. Oxford: Oxford University Press, 478-490.

Smith, Holly M. 2011. "Non-Tracing Cases of Culpable Ignorance." Criminal Law and Philosophy 5 (2): 115-146.

Strawson, Peter F. 1974. "Freedom and Resentment." In Freedom and Resentment and Other Essays. London: Methuen, 1-25.

Tan, Charlene. 2011. Islamic Education and Indoctrination: The Case of Indonesia. London: Routledge.

Taylor, Kathleen. 2004. Brainwashing: The Science of Thought Control. Oxford: Oxford University Press.

Tuomela, Raimo. 1995. The Importance of Us: A Study of Basic Social Notions. Stanford, CA: Stanford University Press.

Van Woudenberg, René. 2009. "Ignorance and Force: Two Excusing Conditions for False Beliefs.” American Philosophical Quarterly 46 (4): 373-386.

West, Linden. 2016. Distress in the City: Racism, Fundamentalism, and a Democratic Education. London: Trentham Books.

Winter, Timothy J. 2006. "The Poverty of Fanaticism.” In Joseph E. B. Lumbard (ed.), Islam, Fundamentalism, and the Betrayal of Tradition: Essays by Western Muslim Scholars. Bloomington, IN: World Wisdom, 301-314.

Yaffe, Gideon. 2003. "Indoctrination, Coercion, and Freedom of the Will." Philosophy and Phenomenological Research 67 (2): 335-356.

Yelderman, Logan A., West, Matthew P., and Miller, Monica K. 2018. "Death Penalty Decision-Making: Fundamentalist Beliefs and the Evaluation of Aggravating and Mitigating Circumstances." Legal and Criminological Psychology, DOI: https://doiorg.vu-nl.idm.oclc.org/10.1111/lcrp.12141.

Zagzebski, Linda T. 1996. Virtues of the Mind: An Inquiry into the Nature of Virtue and the Ethical Foundations of Knowledge. Cambridge: Cambridge University Press. 


\section{Rik Peels}

Zimmerman, Michael J. 1986. "Negligence and Moral Responsibility.” Nô̂s 20 (2): 199-218.

Zimmerman, Michael J.1988. An Essay on Moral Responsibility. Totowa, NJ: Rowman \& Littlefield.

Zimmerman, Michael J. 1996. The Concept of Moral Obligation. Cambridge: Cambridge University Press.

Zimmerman, Michael J. 1997, “Moral Responsibility and Ignorance.” Ethics 107 (3): $410-426$.

Zimmerman, Michael J. 2008. Living with Uncertainty: The Moral Significance of Ignorance. Cambridge: Cambridge University Press. 


\title{
15 Trust, Testimony, and Reasons for Belief
}

\author{
Rebecca Wallbank and Andrew Reisner
}

\section{Introduction}

Recent work on trust divides it into two broad categories that are sometimes thought to be relevant to determining what one has most epistemic reason to believe ${ }^{1}$ with respect to the testimony of trusted testifiers. One category is nonevidential trust, which is characterized by an affective attitude of optimism in an individual's good nature such that one forms the disposition to believe what she says and where this optimism is generated irrespective of evidential considerations. ${ }^{2}$ The other kind of trust, evidential trust, involves an attitude of some kind, ${ }^{3}$ one which also disposes one to believe what an individual says, yet which is generated because one takes it that there is sufficient evidence that that individual is reliable in general or in the relevant domain. ${ }^{4}$

Influential literature about duties and friendship suggests that non-evidential trust is an appropriate attitude that reflects one's genuine, but purely pragmatic, reasons for belief in the context of those relationships. ${ }^{5}$ Evidential trust, on the other hand, has a fundamentally epistemic character. However, at least at first blush, it seems ill suited to making a contribution to the epistemic status of beliefs acquired via testimony. This is because evidential trust seems to be, and we shall argue is, only epistemically justified if there are independent evidential reasons to believe what an individual is saying (i.e. that those individuals are reliably correct in their judgements in the relevant domain). Thus there is a challenge for those who wish to argue that testimonial trust in some way makes the trusted testimony contribute to what one has most epistemic reason to believe. Put succinctly, testimonial trust appears to be either epistemically impotent and perhaps even contraindicative, or epistemically redundant.

We believe that this conclusion may be hasty and propose a revised account of the role of testimonial trust on which there are sometimes non-evidential epistemic reasons to accept testimony from a trusted testifier, even when the underlying evidential support is not sufficiently strong to give one an equally strong reason to accept the testimony of a non-trusted testifier. We propose a novel kind of reason, a reason of epistemic facilitation, that is generated by non-evidential testimonial trust in certain contexts. Our tentative conclusion is that there are epistemic reasons for some beliefs arising from the testimony of trusted testifiers that does not depend on the evidential value of the testimony. 
The chapter is structured as follows. $\$ 1$ provides an overview of the notion of trust as it is understood in the current literature. $\$ 2$ explores a common class of theoretical assumptions about non-evidential trust, what we call 'attitude-liability assumptions', and argues that they should not be included in the correct account of non-evidential trust. In $\$ 3$ we offer a sketch of what we take to be the correct account of trust. $\$ 4$ discusses the kinds of reasons we can have for trusting and considers what sorts of reasons may and may not be provided by testimonial trust. In $\$ 5$ we develop the outlines of an account of a novel type of epistemic reason, a reason of epistemic facilitation, that we claim may be generated by having the attitude of non-evidential trust in certain circumstances. We offer some concluding thoughts in $\$ 6$.

\section{The Basics of Trust}

The term 'trust' is used in various different ways. For example, you might trust a clock to tell the time or politicians to fulfil their commitments. Sometimes we even speak of trusting certain people simpliciter. Our discussion is not intended to encompass all reasonable uses of the word 'trust' in English, but rather to consider a much smaller family of attitudes. Just what this family of attitudes is will become clearer presently, but we can begin by noting that the relevant kinds of attitude have two objects: person $\mathrm{X}$ trusts person $\mathrm{Y}$ to $\phi$. More specifically, since we are focused on testimonial trust, ' $\phi$ ' in these cases is to communicate about matters within a certain domain sincerely and competently. ${ }^{6}$ We distinguish two broad categories of testimonial trust: non-evidential and evidential. In order to explicate these two different kinds of trust, it will be helpful to begin by setting out what they have in common.

In its most general form, trust involves a certain type of interest, dependence, and expectation. The notion of interest captures the sense in which person $\mathrm{X}$ at the very least holds that the occurrence of $\phi$ is, or would be, in some sense positive. The notion of dependence captures the sense in which it is the case that for $\phi$ to occur individual $\mathrm{X}$ in some relevant way needs individual $\mathrm{Y}^{7}$ The notion of expectation at the very least captures the idea that trust involves a predictive expectation: $\mathrm{X}$ expects that $\mathrm{Y}$ will do $\phi .{ }^{8}$ What differentiates non-evidential and evidential trust lies mainly in what motivates this predictive expectation.

The distinguishing feature of evidential trust is that the expectation that $Y$ will $\phi$ arises as a result of believing that $\mathrm{Y}$ will $\phi$ on account of the evidence that $\mathrm{Y}$ will $\phi$, rather than from some non-evidentially dependent feature of the trust itself. In the case of evidential testimonial trust, X's expectation that $\mathrm{Y}$ will communicate $c$ within domain $d$ sincerely and competently is based on evidence derived from past experience used to make epistemically appropriate inferences about future behaviour. As a non-testimonial example, $\mathrm{X}$ might evidentially trust that the expert snooker player $\mathrm{Y}$ will pocket the red ball in a particular situation solely because she has never failed to do so in that situation in the past.

What we want to highlight is that $\mathrm{X}$ need not trust $\mathrm{Y}$ in consideration of Y's interests, nor need she expect that $\mathrm{Y}$ will show consideration or respect for her, 
or even know that she exists! This kind of trust can straightforwardly be given to inanimate objects as well as people. ${ }^{9}$ It arises out an evidential assessment. One could imagine a reductivist account of evidential trust that analysed evidential trust in terms of the combination of the presence of evidential considerations and (an) appropriate belief(s). We take it that this analysis of evidential trust would be unattractive to philosophers who wish to argue that evidential trust itself adds or constitutes a further epistemic reason to believe that to which a trusted testifier testifies. Thus we assume here that evidential trust should be understood as some sort of further attitude, the presence of which may be thought to add or constitute a further epistemic reason. We shall not speculate, however, about what sort of attitude this would be.

Non-evidential trust is different to evidential trust in structure and one might say spirit. Structurally it necessarily contains both a predictive expectation (like evidential trust) and a normative expectation (unlike evidential trust). It is this normative component, an expectation that the trusted ought or has reason to $\phi$ which motivates the predictive expectation that they will in fact $\phi$. This attitude can occur in the face of evidence suggesting that the trusted individual will not $\phi$. And strikingly the possession of supporting evidence that she will $\phi$ is not only unnecessary for this kind of trust to hold, but the act of searching for such evidence is constitutively a hindrance to forming and holding non-evidential trust.

\section{Some Problems about Attitude Liability Assumptions and a Solution}

There are several puzzles about non-evidential trust that arise for the leading accounts due, so we argue, to what may be called 'attitude-liability assumptions'. On several influential views about trust, there are attitudes that one is liable to form when one non-evidentially trusts someone. It is, for example, widely assumed that Y's non-evidentially trustworthy behaviour is something that X feels is owed to her, and Y's failure to behave trustworthily can prompt X to feel betrayed. ${ }^{10}$ The idea is that whilst we may be disappointed by the failure of shelves to support a vase or by the failure of clocks to tell the time, we would not be liable to feel betrayed by the shelves or the clocks. This, it is claimed, suggests that we don't trust inanimate objects in the richer, non-evidential, sense of trust. It is also widely assumed that, in circumstances where a trusted person does as expected, the truster should feel grateful. ${ }^{11}$

Both assumptions seem strange to us for reasons we articulate below, and they expose several points of ambiguity in the accounts that make use of them. First, it is not clear whether the claims in the literature are about the truster being betrayed or feeling betrayed. Most theorists seem to have both in mind. They capture the issue in terms of an appropriate liability for the truster to feel betrayed if the trusted person fails to act as expected. A second, connected point of ambiguity concerns whether theorists intend to claim that all cases of non-evidential trust appropriately generate a liability in $\mathrm{X}$ to feel betrayal if $\mathrm{Y}$ fails to meet X's expectations, or whether the claim is that in some cases 
the truster is liable to attitudes of betrayal (this differs from evidential trust in which there are no such cases). Our reading of many of the influential theorists (including Hawley, Holton, and Jones) is that they implicitly are making a claim about the attitudes which $\mathrm{X}$ is always liable to feel when $\mathrm{Y}$ fails to meet X's expectations. Thus violations of trust-based expectations always appropriately engender an attitude of betrayal. ${ }^{12}$

Yet this seems wrong. In order to appropriately engender an attitude of betrayal, it seems to us that: first, someone must have made a commitment to you; second, someone must have knowingly failed in their commitment, whilst aware that it will thwart your interests (out of either a lack of care or respect); and third, you must be aware of the commitment and their intentional failure to honour it. One does not feel betrayed by a mere failure of another to demonstrate competence. Rather one feels betrayed by another's insincere commitment where this commitment has been made specifically to you. Yet, as will become clearer in the following section, non-evidential trust does not always involve this specific kind of commitment.

Further, it is commonly assumed that being trusted in the relevant sense is an honour. Yet we are uncertain why being trusted is even prima facie an honour, given some other key assumptions in the literature. For example, it is commonly assumed that non-evidential trust is at least sometimes offered by people with self-interested motives and who do not offer their trust on the basis of a careful judgement about who is in fact trustworthy. Being trusted by someone because she regards trusting you as a good way to advance her interests does not seem to be much of an honour.

There is, of course, much to be said about strategies for deflecting each of the difficulties that arise from the inclusion of attitude-liability assumptions in an account of non-evidential trust. However, an advantage of our account of non-evidential trust is that we are able to avoid these difficulties altogether by dropping the attitude-liability assumptions. However, even assuming that our account avoids the difficulties raised by attitude-liability assumptions, we are still left with the epistemic puzzle that is the focus of this chapter.

A central thought in the literature about non-evidential trust is that there can be something of value about our evidentially unsupported, or undersupported, reliance on other people. More particularly, the thought is that there is a special kind of interpersonal value that cannot be achieved by, and is in fact thwarted by a sang froid evidential assessment. The value at issue is normally described as practical and in terms of advancing a relationship between $\mathrm{X}$ and $\mathrm{Y}$. Non-evidential trust captures the sense in which one might claim that trust in one's business partner is undermined if one proceeds to hire a private investigator to check on whether she is skimming money off of your joint enterprise. The act of trying to confirm trustworthiness is inconsistent with non-evidentially trusting. Accordingly, whilst arguments for the practical value of this kind of trust can be generated straightforwardly, the arguments currently on offer concerning its epistemic significance are more problematic.

The difficulty arises because it is not immediately clear how one can demonstrate the epistemic significance of non-evidential testimonial trust without 
searching for and relying on evidence, and one cannot appeal to evidence while still genuinely holding an attitude of interpersonal non-evidential trust. ${ }^{13}$ As Jennifer Lackey notes, 'either the view of testimony in question is genuinely interpersonal but epistemically impotent, or it is not epistemically impotent but neither is it genuinely interpersonal'. ${ }^{14}$ Lackey believes that this kind of dilemma is insurmountable. We disagree. We shall argue that non-evidential trust can be a valuable tool which facilitates our epistemic advancement in a way that is not properly characterized as purely pragmatic. In some circumstances, non-evidential testimonial trust generates a distinctive type of epistemic reason for belief.

\section{The Attitude of Trust}

Let's consider in more detail some of the standardly given reasons as to why a truster may non-evidentially trust an individual to $\phi$, if not due to evidence that she will $\phi$. Note that various accounts of trust offer differing reasons, and some of the accounts, such as those of Hawley and Jones, appear to be in tension. ${ }^{15}$ We propose that this tension can be eased once we recognize that there are in fact two kinds of non-evidential trust: dialogical and non-dialogical. Dialogical non-evidential trust postulates some kind of prior relationship/interaction between the truster and trusted person such that the trusted is aware of the truster's dependence. And importantly the acknowledgement of this relationship factors into at least part of the reason why the truster believes that the trusted will behave trustworthily. The acknowledgement of the relationship also belongs to the broader category of reasons why the truster regards the person she trusts as trustworthy. $\mathrm{X}$ expects $\mathrm{Y}$ to have made a commitment either directly or indirectly to $\mathrm{X}$ to $\phi$ (i.e. $\mathrm{Y}$ is aware, $\mathrm{X}$ is dependent upon $\mathrm{Y}$ to $\phi$, etc). And $\mathrm{X}$ expects $\mathrm{Y}$ to be responsive to her dependence on him. Nondialogical non-evidential trust, on the other hand, also operates on the basis of expectations that $\mathrm{X}$ holds towards $\mathrm{Y}$, but it doesn't require $\mathrm{Y}$ to be responsive to X's dependence. Nor does it require that $\mathrm{Y}$ is aware of $\mathrm{X}$ 's dependence on him as featuring in the motivation to trust. ${ }^{16}$

We shall describe X's non-evidential trust for $Y$ in terms of X's affective attitude of optimism towards Y's 'good-nature': where 'good-nature' means nothing more here than that $\mathrm{Y}$ has the disposition to communicate competently and sincerely, that $\mathrm{Y}$ thinks that communicating competently and sincerely is the right thing to do, and X agrees and regards Y's action as commendable. ${ }^{17}$

Within the literature one often finds objections to this kind of approach in the form of warnings against 'moralizing tendencies' within cases of nonevidential trust more generally. The proponents of these objections highlight that we can have non-evidential trust in 'bad' people to do 'bad' things. ${ }^{18}$ While true, this worry is beside the point. One need not expect those whom one affectively trusts to have general or even predominantly good character traits; one only need expect that they have a sufficient degree of the specific positive quality to meet one's present expectations in this context, as is perhaps illustrated by the idea of honour among thieves. 


\section{Rebecca Wallbank and Andrew Reisner}

We want to be careful to distinguish our account thus far from that of Jones, which is similar in some respects but importantly different in others. She argues that affective trust involves a sense of optimism towards another's 'goodwill'-which she analyses in terms of benevolence, compassion, integrity, and the like. However, she combines optimism about goodwill with a second component, namely an expectation that the person trusted is not motivated by something 'less honourable' such as selfishness, fear, or stupidity. ${ }^{19}$

Jones' second condition, although intuitively appealing, is too demanding. There are times when motivation from self-interest is compatible with motives arising from a more commendable character disposition. This can be helpfully illustrated with an example. Suppose that you have a sexist employer who has made a commitment to himself to treat women equally because he knows that he will suffer from a social backlash if he does not. You might have little care or respect for the employer; you may even actively dislike him. But suppose that you believe that honouring the commitments that one makes to oneself is a valuable quality in a person, and suppose you attribute this quality to him. We think it possible that you could non-evidentially trust him to keep his commitments to treating female employees equally. ${ }^{20}$

\section{Reasons for Trusting, Reasons from Trust}

As the discussion of evidential and non-evidential trust makes clear, there is a puzzle about how trust could give us epistemic reasons for belief or play any positive normative epistemic role. Here is the puzzle. Non-evidential trust seems to be epistemically irrelevant, as it is by definition not underpinned by evidence or other considerations capable of providing traditionally conceived epistemic reasons. If philosophers like Keller and Stroud ${ }^{21}$ are right, nonevidentially trusting someone may give us pragmatic reasons to believe her testimony, because doing so may be a constitutive norm of trusting someone.22 Even if they are right and having an attitude of affective trust towards another person does generate pragmatic reasons for believing her testimony, these pragmatic reasons, or the facts that constitute them, do not bear on the probability that the testimony of the trusted individual is true.

If the charge against non-evidential trust is that it is epistemically irrelevant, then the charge against evidential trust is that it is epistemically redundant. Recall that one holds an attitude of evidential trust towards an individual when, roughly, one takes it that there is evidence that that person's testimony in the relevant domain is reliable. This puts someone who evidentially trusts another individual in one of two epistemic situations: either the truster assigns the correct degree of evidential weight in accordance with the actual evidence to the trusted person's testimony, or the truster assigns the wrong degree of evidential weight given the actual evidence to the trusted person's testimony. In the latter case it is difficult to see how assigning the wrong degree of evidential weight to the trusted person's testimony can in any way ground or provide additional positive epistemic reasons for belief to the proposition that was the object of the testimony. In the case where one assigns the correct degree 
of evidential weight to testimony, a separate problem arises, namely that of redundancy. We shall take up this problem later in this section.

Our focus in the remainder of the chapter is to propose a novel, but qualified way in which non-evidential testimonial trust may provide epistemic reasons for belief over and above any evidential reasons that one may have for believing the contents of the testimony. Before taking on the main task, we shall briefly look at what kind of reasons there are for having an attitude of non-evidential and evidential trust, respectively.

Whatever sorts of normative reasons for belief we may or may not gain from having an attitude of (testimonial) trust towards another individual, there are normative reasons for having trust attitudes. As is generally the case for mental states and dispositions, there can be incentive-driven reasons. ${ }^{23} \mathrm{~A}$ mindreading eccentric billionaire can offer you all of her gold if you have an attitude of non-evidential trust towards another individual and likewise for the attitude of evidential trust. More mundanely, life is often easier and more pleasant in a number of respects if you trust what your friends, teachers, and family say about many things much of the time. The reasons for this can come from that fact that one will experience smoother social interactions and can gain diverse benefits such as distributing one's cognitive burdens to others (whether or not that turns out to be conducive to forming true or justified beliefs). In addition, non-evidential trust in particular may be accompanied by positive feelings towards the trusted individual, which may be valuable either intrinsically or instrumentally.

While there can be pragmatic reasons for having an attitude of nonevidential trust towards an individual, our understanding of non-evidential trust precludes there being anything more than weak evidential reasons for adopting an attitude of non-evidential trust. Although we shall argue in $\$ 6$ that non-evidential trust can provide a special kind of epistemic reason for belief, it is difficult to see how non-evidential trust is suited to provide evidential reasons for belief, as the reasons that count in favour of holding the attitude of non-evidential trust towards an individual must not be strong evidential reasons that the person being trusted is in fact reliable or an expert in the relevant domain.

On the other hand, one can have epistemic — and in particular evidentialreasons for standing in an attitude of evidential trust towards another individual. It may be helpful to consider an example, the coffee taster:

\section{The Coffee Taster}

In coffee brewing, extraction yield is measured as a percentage and is calculated by taking the product of the weight of brewed coffee in grams multiplied by the total dissolved solids and dividing it by the weight of ground coffee used (the 'dose'). Total dissolved solids are measured with a device called a 'refractometer'. Provided a refractometer is available and the relevant weights are known, it is possible to determine the extraction yield of a cup of coffee with great precision. 


\section{Rebecca Wallbank and Andrew Reisner}

Suppose someone claiming to be a highly skilled coffee taster says that she can reliably determine the extraction yield of a cup of coffee. Simply asserting that one is highly skilled at $\mathrm{X}$ is not evidence for being highly skilled at X. ${ }^{24}$ The assertion itself is not an epistemic reason to trust what the coffee taster says about the extraction yield of any particular cup of coffee.

But let us suppose now that we conduct a study to see whether the coffee taster is in fact a reliable and accurate judge of extraction yields. Armed with a refractometer and scale, we check her claims against our own careful measurements and discover that she is, in fact, a highly reliable and accurate judge of the extraction yield of any cup of coffee. Given this information, it appears that we have a reason to adopt an attitude of evidential trust towards the coffee taster, at least with respect to extraction yields, because we have excellent evidence that her judgements are accurate.

Of course, this is a rather minimalistic form of trust, rather like the kind of trust that we have in a piece of laboratory equipment because we have checked its calibration ourselves. Our reason for having this kind of trust extends only to judging the extraction yield of a cup of coffee. Were the same coffee taster to make another assertion about a cup of coffee's properties, for example its $\mathrm{pH}$ level, we would need some new evidence that she was competent to make $\mathrm{pH}$ level judgements. That evidence could come in more than one form: for example either direct evidence that she is a reliable and accurate judge of $\mathrm{pH}$ levels or indirect evidence that those who accurate judges of extraction yield are also reliable and accurate judges of $\mathrm{pH}$ levels. It is not difficult to extend the laboratory equipment analogy to a device with some form of multisensor.

This example points to an interesting feature of evidential trust. The normative reasons for adopting an attitude of evidential trust towards someone in a particular domain are often themselves evidence for the contents of her testimony. The reasons one has for evidentially trusting the coffee taster are also reasons for believing the contents of her testimony, independently of their being the contents of her testimony. It is worth explaining this observation in more detail.

Let us return to the coffee taster example. In that example, there was a strong evidential reason to believe that the coffee taster was a reliable and accurate judge of extraction yield. Suppose that she says of a particular cup of coffee that the extraction yield is $21 \%$. Is there an evidential reason to believe her testimony? That depends to some extent on what kind of principles one accepts with respect to the testimony of reliable individuals (or instruments).

It is not particularly controversial that the testimony of an expert about something within her domain of expertise counts as evidence. Let us suppose in that in the coffee taster example the evidential reasons for believing that the taster is reliable are the very facts that constitute her reliability (e.g. her demonstrated ability to correctly estimate the extraction yield of a cup of coffee). Suppose that the coffee taster testifies that a particular cup of coffee 
has a $21 \%$ extraction yield. We now have an evidential reason to believe that the cup coffee has a $21 \%$ extraction yield.

Our reason is made up of two parts. One comprises the facts that constitute the testifier's reliability. The other comprises the contents of the testimony. Put in a slightly more regimented form, we could say that the fact that individual I testifies to $\mathrm{T}$ and that individual $\mathrm{I}$ is reliable with respect to the domain under which $\mathrm{T}$ falls is a reason to believe $\mathrm{T}$.

Notice that in this case our reason to believe that the extraction yield is $21 \%$ partially comprises the same facts that are reasons to believe that the coffee taster is reliable. Reasons for believing that someone is reliable, or at least the facts that are or provide those reasons, are also part of the reason for believing the contents of a reliable individual's testimony. The reason to believe that the individual is reliable does not add a further reason to believe the reliable person's testimony. That would be double counting.

Consider a similar case. Suppose that we have a strong reason to believe (perhaps we in fact ought to believe) that the coffee taster is a reliable and accurate judge of extraction yield. However, in this version of the example, she is not in fact reliable. ${ }^{25}$ Against the odds, she guessed arbitrarily but accurately over a large number of trials. According to the principle that testimony in the relevant domain from reliable judges is evidence for the contents of their testimony, there is no reason to believe that a cup of coffee has a $21 \%$ extraction yield on the basis of the coffee taster's saying that there is.

One could try to adopt a weaker principle, one that says that there is reason to believe $\mathrm{X}$ if an individual whom we have reason to believe is reliable with respect to $\mathrm{X}$ testifies that $\mathrm{X}$. We are circumspect about this principle for reasons discussed in the literature, ${ }^{26}$ but we can set these concerns aside for the moment. We may note simply in this case that the reasons for believing what the coffee taster testified to, based on her testimony, are no stronger than our reasons for judging her as a reliable and accurate judge. Even if we treat believing that someone is reliable as a form of evidential trust, the trust itself adds no extra evidential reason for believing the content of the trusted individual's testimony.

Two points are of particular interest to us here. The first is that evidence for the reliability of an individual's testimony in a domain is evidence, directly or indirectly, for the contents of their testimony in that domain. This suggests that one lacks reasons to evidentially trust someone when one at least initially lacks testimony-independent evidential reasons to believe the contents of that person's testimony in the relevant domain.

The second point brings us back to the problem of redundancy mentioned in $\$ 4$. Once one has sufficient evidential reason to believe that an individual's testimony in a particular domain is reliable, that person's testimony, in the usual way that expert testimony does, provides evidential reasons for belief. This raises a dilemma for a proponent of the view that evidential trust itself provides reasons for belief. Either the attitude of evidential trust just is the disposition to accept testimony from actual experts, or it is a separate special attitude. If it is the former, evidential trust is not in any interesting sense trust; it is just a disposition to accept testimony that is evidence as evidence. If it is 


\section{Rebecca Wallbank and Andrew Reisner}

the latter, however, the attitude provides no additional reason to believe the expert testimony over and above that given by the evidence that the individual in question is an expert-by which we mean in this case 'gives reliable testimony'. Thus as far as we can see an attitude of evidential trust cannot provide additional epistemic reasons for believing the testimony of someone who is evidentially trusted.

Setting aside evidential trust, it is interesting, and we believe telling, that many of the central cases in which non-evidential (testimonial) trust is present are in a broad sense pedagogic. We take pedagogic situations to have a least four interesting features:

1. There is a presumed asymmetry in either domain specific or general competence.

2. The person who is trusted expects to be believed and the person who trusts expects the person whom they trust to testify accurately, either in the relevant domain or in general.

3. Beliefs are transmitted by testimony from the trusted person to the person who trusts on the mutual understanding that the (presumed) asymmetry in competence between them will thereby be reduced and possibly be eliminated over time. ${ }^{27}$

4. The person who trusts (usually) does not have evidential reasons to believe that the trusted person is an expert.

This describes familiar formal educational situations. Consider an adult literacy course. One is taught to read and write. It is presumed that the teacher knows more about reading and writing than the student. It is a presupposition of the teacher/student relation that the teacher expects to be believed and that the student expects the teacher to tell her the truth about how to read and write. Such education is undertaken with the aim of reducing the epistemic gap between the teacher and student; ideally the student will read at a higher level after studying with the teacher. And one may note that someone who is completely unable to read is not in a position to judge on the basis of evidence that a particular teacher is herself able to read well, since the student is not in a position to compare what the teacher claims a particular passage says to what it actually says.

In $\$ 5$ we shall explore the possibility that non-evidential trust at least sometimes provides reasons to believe in pedagogic situations.

\section{Trust as a Source of Epistemic, But Non-Evidential, Reasons for Belief}

Despite the apparent difficulties with doing so discussed thus far, we propose, albeit cautiously, that there are distinctive epistemic reasons for belief that arise from non-evidential trust, even in cases in which there is little evidence that the trusted individual is reliable in the domain in which she is testifying. Our idea is this. As a contingent matter, testimony facilitates learning. This 
is the case even under circumstances in which the testimony is false and the testifier(s) unreliable. Our claim is that there is a (qualified) standing epistemic reason to believe those whom we non-evidentially trust with respect to a particular domain up until the point where we have appropriate access to evidential reasons for belief in that domain. In short, trust provides reasons for belief until evidence becomes available in a particular sense of 'available'.

Let us return to the example of someone taking an adult literacy course. For the sake of the example, let us also assume that that individual cannot read at all and does not know the alphabet. The world that this individual inhabits is full of people reacting to what she recognizes as written speech. She notices that those who claim to be able to read are able to navigate certain tasks that she cannot. For example, they can follow written directions to arrive at their desired destinations. When they (appear to) have read a novel, they discuss a story having the same features and with the same dialogue as the one she encountered in an audio book with the same title, and so on. In short, she can see that there is a community of literate people who successfully interact with their environment and each other, apparently at least partially through the medium of written language.

These observations, we may assume, constitute some general evidence that individuals in the self-described 'literate' community are to some degree competent readers and writers. But which ones really know how to read and write well, are competent to expound on punctuation, or who have reliable, large vocabularies, is not something that she can yet judge.

At the first adult literacy class, the person in this example decides to trust her teacher to testify correctly about how to read and write. Her teacher claims to be a member of the community of literate people and seems to be accepted as such. By trusting her teacher, who is in fact competent with basic reading and writing, she is able to learn the alphabet and to start to read. Yet as her reading ability improves and she can read grammar books on her own, she comes to realize that her teacher is ignorant of grammar, has false beliefs about punctuation conventions, and has a limited and often inaccurately used vocabulary. In short, as she becomes more competent, she no longer needs to trust her teacher because she now can access the evidence in her environment.

Trusting her teacher was not a necessary condition for the student to learn to read; she could have trusted another teacher or perhaps cleverly figured things out for herself. Nor was it a sufficient condition for her to learn to read. But it was an effective means for her to learn to read. And it seems intuitively plausible to us that the student in this example had a good epistemic reason to believe the testimony of her teacher, at least in the early stages, because she non-evidentially trusted her teacher. But, once she had access to evidence about reading and her teacher's competence, non-evidential trust ceased to provide a reason for her to believe her teacher's testimony.

This epistemic reason is what we call a 'reason of epistemic facilitation'. It occurs in qualified cases of non-evidential trust, namely in pedagogic contexts in which one (a) lacks access to the kind of evidential reasons that would make the testimony redundant, (b) lacks access to the kind of evidential reasons 


\section{Rebecca Wallbank and Andrew Reisner}

required to make it the case that one ought to believe a testifier is an expert, and (c) has evidence that the trusted individual is regarded by the relevant community of individuals as being an expert.

Reasons of epistemic facilitation outstrip the accessible evidence for an individual who has them. They are in a sense fragile reasons. As one gains epistemic competence in a domain, one loses some of one's reasons of epistemic facilitation. As a secondary school student, if one trusts one's chemistry teacher, one has reason to believe what she says about chemistry. On reaching the same level of training as the teacher, one loses one's reasons of epistemic facilitation for believing her and also loses one's reason to non-evidentially trust her testimony about chemistry. But one may still have reasons of epistemic facilitation to believe the instructors in one's doctoral-level chemistry courses even before one has access to the relevant evidential reasons. And so on.

This is, of course, just a sketch of a view, and many important questions have been left unanswered. But we believe that it is worth taking the idea seriously that non-evidential trust provides epistemic, but non-evidential reasons for belief in a limited but important range of circumstances.

\section{Conclusion}

In this chapter we have sought to clarify the nature of trust and its contribution to determining what we have most epistemic reason to believe. We have offered reconceptualization of the nature of trust by diagnosing and exposing various problematic assumptions employed by popular current views and then offering a positive alternative account. We have also offered a sketch of an account of a novel kind of reason that may be generated in what we call 'pedagogic' situations, one which arises directly from having an attitude of non-evidential trust towards an individual.

Our aim in writing this chapter has been to provide a more promising approach to understanding what non-evidential trust in fact is and how it could play a positive epistemic role. Both the positive account of non-evidential trust and the details of the role it plays in generating epistemic reasons for belief require more fleshing out. We trust, however, that this chapter is at least an interesting start in developing an improved account of testimonial trust and its epistemic role. ${ }^{28}$

\section{Notes}

1 We do not mean 'most epistemic reason to believe' to be equivalent to ought, at least not as a conceptual matter. What one ought to believe all-in may be partially or completely determined by non-epistemological reasons. For more on this question, see Reisner (2018).

2 Or perhaps even knowingly against the evidence.

3 Of what kind is not clear in the literature.

4 These are our terms. Similar distinctions are often made in the literature labelled as a distinction between 'normative/predictive trust', 'affective/predictive trust', and 'trust/mere reliance'. 
5 See Hieronymi (2006), Keller (2004), and Stroud (2006).

6 It is a perhaps controversial assumption of the discussion in this chapter that sincere and competent testimony constitutes evidence under favourable conditions.

7 Within the literature on trust, the notions of dependence and interest are often captured in terms of vulnerability. Katherine Hawley (2014) has challenged the necessity of vulnerability in relation to what we call evidential trust. She gives an example of how one might trust a friend to bring enough food for the picnic but one might still bring some food anyway. This is not 'trust' in the sense that we are using the term but mere expectation.

8 We understand events as timed states of affairs. In some cases, it may be better to understand this relatum in the trust relation as an event type as opposed to events.

9 The general assumption is that evidential trust can be applied to inanimate objects whereas non-evidential trust cannot. However, we note that this assumption plays no role in our arguments.

10 Phillip Nickel (2007) has raised a similar worry. He objects to the prevalent and integral use of betrayal within the trust literature. However, his examples and arguments fail to capture correctly both the concept of trust and what is problematic about betrayal for it. He fails to acknowledge the above puzzles, and his concept of trust fails to recognize the necessity of interest, expectation, and dependence (as is apparent in his examples). He does nevertheless valuably acknowledge that accounting for trust in terms of attitudes that occur in response to it rather than attitudes involved in it is not an optimal methodology. See for example: Baier (1986), Hawley (2014), Holton (1994), Jones (1996, 2012), McLeod (2015) Mullin (2005), O’Neil (2012), Pettit (1995), Wanderer and Townsend (2013).

11 See Holton $(1994,4)$. He claims that 'you have a readiness to feel betrayal should [trust] be disappointed, and gratitude should it be upheld'.

12 Hawley (2017), Holton (1994), and Jones (1996, 2012).

13 While many authors eschew the claim that non-evidential trust has epistemic significance, there are some influential ones who do not such as Richard Moran (2005) and Paul Faulkner (2007).

14 Lackey $(2008,222)$.

15 Hawley (2014), Jones (1996).

16 Note that: non-diaological non-evidential trust might equally serve to develop an interpersonal relationship. The difference is that $\mathrm{X}$ need not expect $\mathrm{Y}$ to be aware of or responsive to X's specific dependence.

17 For dialogical non-evidential trust, we can add the condition that $\mathrm{Y}$ believes that communicating competently and sincerely is the right thing to do, directly or indirectly, at least in part because she is aware that $\mathrm{X}$ is dependent on her doing so. With respect to dialogical testimonial trust we think our account is broadly compatible with the account proposed by Katherine Hawley (2014). She holds that to trust someone is to simply expect that they have the will to fulfil whatever commitments they have made. Note that Hawley leaves it open as to whether the claim is that we expect them to have the will to fulfil whatever commitments they have made because they have independent, good reasons to fulfil these commitments or because they are aware of the commitments that they have made and have integrity and a sense of duty to fulfil them. We shall leave the issue as to whether Hawley's account's has broader applicability for non-dialogical trust open. Note that in some cases, it is not always clear what the commitment is, or who it has been made to. There is also a danger that the commitment is so indirect that the concept becomes empty, but we shall not pursue that here. 


\section{Rebecca Wallbank and Andrew Reisner}

18 See Nickel (2007).

19 Hardin (1996) comes closest to endorsing this approach. Speaking of 'trust' broadly, Hardin argues that A's trust for B simply involves A's expectation that B has purely self-interested motivations. The thought is that when we trust someone we simply expect the trusted person with whom we are interacting to want to preserve a relationship with us. On a Hardin-style account, we believe that they believe that it is in their best interests to keep us happy. This approach need not be normatively valanced and it is often understood in the context of evidential trust involving risk-assessment. Yet one could develop this account such that it were normatively valanced.

20 There are other aspects of Jones's (1996) account which are crucially different to ours, such as her later appeal to evidence and the claim that this kind of trust cannot be voluntary.

21 See Keller (2004) and Stroud (2006). Note that neither Keller nor Stroud discuss testimony directly, but one can easily imagine using a similar style of argument to support believing the testimony of trusted individuals or individuals to whom one stands in a trust-entailing relationship like friendship or romantic partnership.

22 Following Glüer and Wikforss (2013, 2018), McCormick (2015), and Reisner (2018), we are sceptical that there are constitutivist reasons of this kind, but here we are only concerned to point out that Keller and Stroud style arguments do not provide trust-based epistemic reasons for belief, whether or not they provide trustbased pragmatic reasons for belief.

23 See Howard (forthcoming) and Reisner (2009) for more discussion of incentivebased reasons.

24 It is empirically possible that there is a significant positive correlation between claiming that one is highly skilled at $\mathrm{x}$ and being highly skilled at $\mathrm{x}$. Perhaps it is better to say that we are assuming that there is no interesting positive or negative correlation between saying one is highly skilled at $\mathrm{x}$ and being highly skilled at $\mathrm{x}$.

25 We are assuming that there can be strong misleading evidence.

26 See Fitelson (2012) and Reisner (2016) for examples of why evidence of evidence of $x$ is not necessarily evidence for $x$.

27 We take it that this is one of the obvious purposes of teaching. We do not assume, however, that parties in pedagogic situations expect to achieve anything approaching epistemic equality in the relevant domain or generally, merely that the epistemic gap between them will become smaller.

28 The authors would like to thank audiences at the Uppsala Higher Seminar in Aesthetics and at a workshop associated with this volume at St Thomas University for valuable comments on drafts of this paper. We especially thank Miriam McCormick, Sharon Ryan, and Sophie Stammers for their in-depth feedback and the editors of this volume, Scott Stapleford and Kevin McCain for their feedback and support. In addition we would like to thank Jon Robson for his insight and comments on material that constitutes the background for this paper. Andrew Reisner wishes to express his gratitude to Vetenskapsrådet, whose generous support for the project Pragmatism, Pluralism, and Reasons for Belief has provided time and resources for writing this chapter.

\section{References}

Baier, A. 1986. "Trust and Antitrust." Ethics 96: 231-260.

Faulkner, P. 2007. “On Telling and Trusting.” Mind 116: 875-902. 
Fitelson, B. 2012. "Evidence of Evidence is Not (Necessarily) Evidence." Analysis 72: $85-88$.

Glüer, K., and Wikforss, Å. 2013. "Against Belief Normativity.” In Timothy Chan (ed.), The Aim of Belief. Oxford: Oxford University Press, 80-99.

Glüer, K., and Wikforss, Å. 2018. "Reasons for Belief and Normativity.” In Daniel Star (ed.), Oxford Handbook of Reasons and Normativity. Oxford: Oxford University Press, 575-599.

Hardin, R. 1996. "Trustworthiness.” Ethics 107: 26-42.

Hawley, K. 2014. “Trust, Distrust and Commitment.” Nous 48: 1-20.

Hawley, K. 2017. “Trustworthy Groups and Organisations.” In P. Faulkner and T. Simpson (eds), The Philosophy of Trust. Oxford: Oxford University Press, 230-250.

Hazlett, A. 2017. "On the Special Insult of Refusing Testimony." Philosophical Explorations 20: 37-51.

Hieronymi, P. 2006. "The Reasons of Trust." Australasian Journal of Philosophy 86: 213-236.

Holton, R. 1994. "Deciding to Trust, Coming to Believe." Australasian Journal of Philosophy 72: 63-76.

Howard, C. Forthcoming. "The Fundamentality of Fit.” In Russ Shafer-Landau (ed.), Oxford Studies in Metaethics, vol. 14. New York: Oxford University Press.

Jones, K. 1996. “Trust as an Affective Attitude.” Ethics 107: 4-25.

Jones, K. 2012. “Trustworthiness.” Ethics 123: 61-85.

Keller, Simon. 2004. "Friendship and Belief.” Philosophical Papers 33: 329-351.

Lackey, J. 2008. Learning from Words: Testimony as a Source of Knowledge, Oxford: Oxford University Press.

McCormick, M. S. 2015. Believing Against the Evidence: Agency and the Ethics of Belief. New York: Routledge.

McLeod, C. 2015. "Trust.” In Edward N. Zalta (ed.), The Stanford Encyclopedia of Philosophy. <https://plato.stanford.edu/archives/fall2015/entries/trust/>

Moran, R. 2005. “Getting Told and Being Believed.” Philosophers' Imprint 5: 1-29.

Mullin, A. 2005. “Trust, Social Norms, and Motherhood.” Journal of Social Philosophy 36: 316-330.

Nickel, P.J. 2007. “Trust and Obligation-Ascription." Ethical Theory and Moral Practice 10: 309-319.

O’Neil, C. 2012. "Lying, Trust, and Gratitude.” Philosophy and Public Affairs, 40: 301-333.

Pettit, P. 1995. “The Cunning of Trust.” Philosophy and Public Affairs 24: 202-225.

Reisner, A. 2009. "The Possibility of Pragmatic Reasons for Belief and the Wrong Kind of Reasons Problem.” Philosophical Studies 145 (2): 257-272.

Reisner, A. 2016. "Peer Disagreement, Rational Requirements, and Evidence of Evidence as Evidence Against.” In Pedro Schmechtig and Martin Grajner (eds), Epistemic Reasons, Norms and Goals. Berlin: De Gruyter, 95-114.

Reisner, A. 2018. "Pragmatic Reasons for Belief." In Daniel Star (ed.), The Oxford Handbook of Reasons and Normativity. Oxford: Oxford University Press (online).

Stroud, S. 2006. "Epistemic Partiality in Friendship.” Ethics 116: 498-524.

Wanderer, J., and Townsend, L. 2013. "Is it Rational to Trust?" Philosophy Compass 8: 1-14. 


\title{
16 When the Personal Becomes Political How do We Fulfil Our Epistemic Duties Relative to the Use of Autobiographical Stories in Public Debates?
}

\author{
Sophie Stammers and Lisa Bortolotti
}

\section{The Many Roles of Stories}

Autobiographical or personally significant stories (hereafter APS stories) are not typically objects of epistemic evaluation and agents who tell or share those stories do not typically attract judgements of epistemic blameworthiness or praiseworthiness for doing so. That is because APS stories are not always supposed to be, or valued for being, accurate descriptions of reality or ways of presenting evidence for or against a claim.

APS stories involve the recounting of an event that happened to the teller or to their friends, family, or colleagues, or that they are experiencing in their environment, such as their home town or place of work. In the context we are exploring here, the narrated event is taken by the teller to be relevant to a wider political issue, and is shared at least in part for the purpose of defending a particular claim central to that issue. APS stories used as evidence may be articulate narratives (e.g., memoirs) or very brief contributions (e.g., posts on Twitter), and constitute a distinctive way to engage in public debate, different from more readily recognized methods to debate wider political issues that make use of statistical claims or observations of general trends to make a point.

APS stories used as evidence are also different from so-called fake news. There is a sense in which fake news may take the form of APS stories: for instance, a presidential candidate claiming to have helped find survivors after 9/11 for the purposes of political propaganda may be telling an autobiographical story that is inaccurate to further their purposes-being admired for a good deed and gaining supporters. However, in the case of fake news the misinformation is deliberate (Radutzky 2017), and is often enacted on behalf of a larger organization with a particular political or economic motive, whereas in the phenomenon we describe here, neither the person telling the story nor the debate participant sharing the story need have any intention to deceive their audiences.

It is widely recognized that APS stories are used in different contexts and have a multiplicity of roles (see, e.g., Nash 2005). For instance, they have been found to have 'healing power', enabling one to cope with stress (Coles 1989); to facilitate the development of one's moral agency (Murdoch 1970); to contribute to one's identity by giving a sense of purpose to life (McAdams 1993); 
and to justify and explain one's earlier behaviour, as in instances of confabulation (Bortolotti 2018; Stammers 2019). This suggests that representing reality accurately is not the only role APS stories have, or even their dominant role. It has been argued that, even when their main role is to convey information, stories are always deemed fictional to some extent (Teske 2017, 886), because telling and sharing stories involves taking a perspective on events which entails the selection, fabrication, and construction of facts. Given that people may have different goals when they tell or share an APS story, we cannot determine the success conditions for telling or sharing APS stories without taking into account those goals.

Here we want to draw attention to a role of APS stories that has been so far neglected in the philosophical literature: stories are used as evidence in public debates. In section 2, we make some general observations about the use of APS stories in public debates. In section 3, we examine the debate on Brexit on social media, and reflect on how APS stories were used in the six months following the results of the referendum by groups campaigning for the UK to leave the EU and for the UK to stay in the EU. In section 4, we make a case for the need to think carefully about how APS stories support beliefs that may be central to a public debate if we want to fulfil our epistemic duties as debate participants.

\section{APS Stories in Public Debates}

Our observation of recent debates in the public sphere is that APS stories are often offered not as mere illustrations of a point, but as evidence in support of a belief the person wishes to defend from challenges. This raises some questions. What can debate participants learn from APS stories and in which circumstances, if any, do such stories qualify as evidence? In other words, an APS story may be intended to provide evidence by the teller or a debate participant who shares the story, but does the story genuinely support the claim the person wishes to defend? Does it play the relevant epistemic role? Further, admitting that an APS story plays the evidential role, how does the evidence presented in the form of an APS story compare with evidence presented in different ways in terms of weight, accessibility, and influence on debate participants' beliefs and behaviour? Such questions are motivated by the conviction that the use of APS stories as evidence has a considerable impact on the evolution of public debates and on the quality of the contributions to such debates. The precise nature of their impact is something that we think should be explored empirically. It is possible that the use of APS stories increases polarization within a debate. It is also possible that APS stories bring about empathetic responses and improve mutual understanding among debate participants by drawing attention to how personal circumstances shaped political views.

One thing that is well ascertained is that APS stories are incredibly powerful when they are used to influence people's views and motivate their actions because of their immediacy and vividness. There is an increasing body of work supporting the view that stories in general are more effective than other 


\section{Sophie Stammers and Lisa Bortolotti}

presentation strategies at conveying concepts to wider audiences in the context of science communication (Das et al. 2008). As a result, science communicators are advised to present their data in a narrative form. In the literature about charity fundraising and campaigning, stories with identifiable characters are more effective at moving people to donate to worthy causes than statistical evidence (Moore and Stilgoe 2009; Markovits and Schmeltzer 2007; Cubitt 2003; Bloom 2016).

To illustrate this, one might think that agents are more likely to give to charity when they learn that many people are in need rather when they hear about just one example of a person in need. However, it turns out that when agents are told about a real person in trouble, they tend to donate over twice as much as they would if they were given statistical information about a larger group of people in trouble (Small et al. 2007). This is called the 'identifiable victim effect'. It shows that focusing on one individual case, in which the suffering of a person is characterized and explored in narrative form, is more powerful at attracting the attention of potential donors and influencing their behaviour than information about many cases that is not conveyed in narrative form. In media training, potential interviewees are instructed to 'address the head' by mentioning facts in support of the point they are making; and 'address the heart' by providing a vivid example or story, possibly a story they are personally invested with, in support of the point they are making. This is based on the assumption that a message is driven home more effectively when the audience's emotions are engaged. Leaving aside the doubtful dichotomy between reason and emotion, the fact remains that stories are used as evidence and considered especially effective at getting people to both understand and appreciate the point being made.

The success of stories in engaging audiences, promoting understanding, and driving behaviour suggests that stories may be influential when they are used as evidence in public debates. ${ }^{1}$ In that context, APS stories have a special role to play in that they are well placed to express identity beliefs and create a sense of belonging that affects the dialectic. Belonging can track political and ideological affiliation (or alienation), national identity, and membership of (or exclusion from) other groups that have a stake in the debate at hand. Stories shape self-perceptions and create, challenge, and sometimes perpetuate either positive or negative stereotypes associated with groups of people (see Bortolotti and Jefferson 2019, for a defence of this claim as applied to mental health debates). Here we choose to focus on the social media debate about the UK's relationship with the European Union following the referendum on 23 June 2016.

\section{APS Stories in the Brexit Debate}

\subsection{Methodology}

We chose to focus on debates taking place on prominent pro-Leave and proRemain Facebook pages in the six months following the referendum on 23 June 
2016, a time period in which we might expect people to justify the way they voted, and how they think the UK as a whole should either reshape, preserve, or sever its relationship with the EU. We explored activity from Leave.EU and Get Britain Out on the Leave side, and from Scientists for EU and Britain for All on the Remain side. These are pages with high engagement following the referendum, and unlike groups which are often private, with codes of conduct that restrict sharing member-generated content outside of the group, pages are accessible to everyone and activity therein is in the public domain.

Whilst it is possible to manually click through page activity, we used the Netvizz application which enables researchers to extract page data in the form of a .csv file, exploring it on a more convenient platform (e.g. Microsoft Excel) for the purposes of identifying, systematizing, and evaluating relevant discussion. Facebook posts and comments can be downloaded through the application's search engine by specifying the page and time frame. The application automatically removes any identifying metadata about users, meaning that comments and posts extracted from Facebook are anonymized. The anonymity is preserved because Facebook comments are not visible to search engines (and individuals can only interact in the form of comments rather than original posts-the latter are reserved to the page-owner only). ${ }^{2}$

As we were assessing pages with high activity, we ended up with very large datasets (e.g., in excess of 300,000 comments on Leave.EU from the relevant time period) which are not practical to examine in their entirety. Because the content of APS stories may be diverse and idiosyncratic, there is no exhaustive set of search terms that identify all and only those comments in which such stories are shared. There are a number of existing methods for extracting insights from large conversation datasets such as these-e.g., membership category analysis (Sacks 1992) - but at this stage we did not want to make claims about trends in the data. Rather, we sought to provide some examples to illustrate our claim that people use APS stories to support points made in a political debate.

In order to do this, we first searched for phrases that might identify that a personal story is being shared, phrases such as 'my experience', 'my [family member]', 'my town', as well as searching for phrases indicative of someone justifying their own position on Brexit, e.g. 'I voted'. This delivered an assortment of examples of people using APS stories to support arguments about Brexit, in which we started to see a series of reoccurring themes, such as stories of the perceived benefits and costs of freedom of movement and EU immigration for UK public services and businesses; stories citing the right to travel freely within the EU; stories about EU regulations and trade agreements either helping or hindering the operation of UK businesses; and stories about family members involved in historical European conflicts.

From this, we could develop a series of debate-specific search terms. For instance, regarding stories about immigration, we could search directly for 'immigration' or 'immigrant', or 'freedom of movement'. We also saw that these stories tended to discuss local public services, enabling us to find further examples by searching for terms such as 'NHS', 'doctor', and 'school'. 


\section{Sophie Stammers and Lisa Bortolotti}

We acknowledge that this method will not extract all possible APS stories used as arguments from the datasets, but we reiterate that at this stage our intention was to establish that stories in fact are used as evidence (rather than to pronounce on, for example, the frequency at which this occurs in debates). As we will demonstrate in the next section, we discovered a number of APS story arguments using this method.

\subsection{Some Examples of APS Stories For and Against EU Immigration}

There are several arguments being put forward to defend the Leave and the Remain option in the debate about Brexit, or to defend key claims the truth of which would favour either Leave or Remain, as discussed in the previous section. For our purposes here, we will focus on just one issue, that of the costs and benefits of immigration and freedom of movement, but in future work, we intend to analyse story arguments on all other topics too. ${ }^{3}$

If we are to reconstruct the arguments to state the relevant implicit premises, then, in the Leave camp, the argument has the following general structure:

(a) Immigration from EU citizens is bad for the UK.

(b) Staying in the EU means that the UK cannot constrain/reduce/stop altogether immigration from EU citizens.

(c) We should avoid policies that are bad for the UK.

(d) So, the UK should leave the EU.

Premises (b) and (c) are often omitted but understood implicitly. Here are some examples of how people lent support to premise (a).

S1: [In response to a post citing research by Inside Housing that 'Twice as much land is used for golf courses in England than is used for housing' thus suggesting that Britain is not 'full'] I'm seeing and feeling it in all departments for real. Our town is well past bursting point!!!! GP's fully booked, massive waiting list in our hospitals, teachers and schools struggling, not just with lack of places but with the sheer number of non-British speaking immigrants, we have local British (again black, white, Asian ...) families waiting years on local housing lists and living in over crowded or poor accomidation while immigrants jump the queue into decent housing, i personally had to fight for five years to recieve the benefits i was entitled to after working $271 / 2$ years.

S2: [following a claim about EU citizen's entitlement to free healthcare] Why does this impact on me? I am a pensioner who worked and paid into the system for 45 years. I have to wait 2-3 weeks to see my GP whose surgery is full of foreigners, I was born British and resent being talked down to by the likes of Junkers, an unelected buffoon.

S3: [preceding claims about perceived benefits of Brexit] As for me insulting other races-Not really? I just get pissed off that my 75 year old 
mother cannot get a Doctors appointment due to strains on resources and massive immigration-when she has paid tax all of her life in the UK-

S4: Just a little story, my wife and I were shopping the other day in Sheldon Birmingham, as we walked thru a subway to cross the road there was a female busker playing an accordion, foreign and so on benefits and begging, call me cynical, my wife asked if she had a licence and she just laughed and carried on playing. This woman knew she had made it here and there was nothing we could do so she just laughed at us, that's why I voted leave!

S5: My small town now has two shops of bulgarian men hairdressing. They weren't needed, we already had british hairdressers trained in britain trying to raise families who are being undercut and being put out of business. If it was bulgarian scientists or engineers then fine, we need those. But brexit means there is no favouritism towards unskilled or unnecessary europeans but instead, necessary skilled workers are put on an equal footing as anyone else from around the world. Which includes workers for the nhs too. If anything i would say the current eu policy is more racist.

S6: In response to a post asking whether immigrants should learn English before they come to Britain] I would like those wishing to come to this country to be told that we are a nation of dog lovers. I am in my eighties, no longer drive, and can no longer travel with a small, friendly dog because most station taxi drivers are Moslem and refuse to take him. I was once left at Brighton station at eleven o'clock at night. If that is not bad enough this morning when walking in a local park with my dog on a lead a young woman ran behind a bench, and a man sitting at a pavement cafe looked at me in fury when I walked past and quickly moved. This occurred after an English toddler, with his parents, had exclaimed with delight on being permitted to stroke 'the nice doggie'. This may seem a trivial observation, but with more and more immigrants coming here surely they should be made aware that pets are valued in a great many British homes.

In the above examples, APS stories provide (putative) evidence to support negative attitudes towards immigration underlying premise (a). Stories in (S1), (S2), and (S5) talk about immigrants putting a strain on local services, jumping the queue, using local GP services so that British residents have longer waits or no available appointments, and taking jobs from British citizens (e.g., local Bulgarian hairdressing services are not needed). (S4) is about a foreign busker laughing when asked about her licence by a member of the public and (S6) is about taxi drivers (perceived to be Muslim) not picking up pets, even though pets are important in British culture. Such stories express negative attitudes towards how immigrants behave, but the observations are not directly aimed at EU immigrants and are not explicitly against immigration as such. Rather the idea seems to be that foreign immigrants should respect British laws and values. 
If we are to reconstruct the arguments to state the relevant implicit premises, then, in the Remain camp, the argument has the following general structure:

(a*) Immigration from EU citizens is good for the UK.

$\left(b^{*}\right)$ Leaving the EU means that the UK can no longer enjoy immigration from EU citizens.

$\left(c^{*}\right)$ We should enact policies that are good for the UK.

$\left(\mathrm{d}^{*}\right)$ So, the UK should stay in the EU.

Here are some examples of how people lent support to premise $\left(\mathrm{a}^{*}\right)$.

S7: I am very lucky to work with not only Muslims but amazing EU teachers who have brought so much to our school. [...] My school wouldn't be the rich place it is without this true diversity. They said it best on the last leg, these people are our doctors, nurses, teachers, friends, neighbours and valued members of our society. ${ }^{4}$

S8: I'm born in Germany married to a Brit. .living here since 17 years. I work alongside my husband running a charity for kids in recovery from cancer. I'd like to think I do my bit as good as I can. [...] As you all know Germany has its own disgraceful history with facism. My grandmother was in opposition to the Nazi regime and narrowly escaped being shot as traitor. So..believe you me when I smell the nasty odour of facism disguised as patriotism I know it's high time to stand up. Stand together for a just and open..and truly tolerant society.

S9: [On a post discussing the UK government cutting ties with Brussels] I'm an European migrant. I set up my business and hire 6 native British staff ... never claimed a penny off anyone and to be honest, personally I don't know any other immigrants who do ... we all work, pay taxes, I also volunteer in the community. Personally I feel very offended by comments like yours. I'm sure if you knew me personally you'd never say what you say in public. We brought skills with us that were funded by EU taxpayer.

S10: I am an undergrad student doing a placement year in a lab at a british university. I am unpaid, so reliant on the student loan system and my own paid job that i do on weekends. The other placement student is from Ghana, and has lived in the UK with her father since she was 16 , and studies at the same university. My supervisor is Italian, and he is doctorate-level educated and lectures at the uni. Also in the lab and under his supervision are $4 \mathrm{PhD}$ students, 2 of whom are from Libya (and hearing them talk about going home to a warzone for a month before coming back to study is equal parts fascinating and unnerving), and the other 2 are Italian, and had done their placement year where I am now a few years before. There is also a Masters student who again, is Italian. In any one day, between us in the lab and any visitors we get or people we are in contact with, there can be between 2 and 4 languages spoken, 
be it for business purposes (we use samples collected from around the world and sometimes emails need to be written in a language other than english), for casual conversations, or for fun/educational purposes-the native speakers help correct the non-native speakers on pronounciation and grammar, and we teach each other bits of language-I am learning a little italian, and I take great joy in introducing them all to some proper yorkshire slang they haven't come across before. A couple of the others also speak speak french and It's quite suprising to realise just how much I remember from high school. I still do not understand why any of these people are considered 'undesirable'. They are all very well educated, very intelligent and put into the UK economy as much, if not actually more, than I do as a British student.

S11: My focus is the next generation, not mine. I want my kids to have the widest possible opportunities. My children are Europeans and the EasyJet generation. My son has a Belgian girlfriend, his cousin a Lithuanian one. My daughter is in fashion and wants to work in Milan or Paris when she has finished university. She does not want to have to get a visa. If my Swedish mother in law gets old and infirm and wants to live with us I don't want to have to apply for a visa. We live in a free Europe and a flight to another EU country is a domestic flight far as I am concerned.

In the above examples, APS stories provide (putative) evidence to support a positive attitude towards immigration which underlies premise ( $\left.\mathrm{a}^{*}\right)$. In (S7)(S10), stories are about how EU27 citizens living in the UK can contribute to the common good, for instance they are teachers benefiting a school, run a charity for children with cancer, set up a business and provide jobs, work in a lab with educated and intelligent EU and non-EU immigrants who are net contributors to the UK economy. In (S11) we have a broader defence of freedom of movement within the EU, based on family members having benefited from travelling and being in relationships with EU27 citizens. ${ }^{5}$

From this brief snapshot, it is clear that APS stories can offer crucial perspectival information not always available at the level of articulating country-wide political trends and offer an insight into the lived experiences of constituents. However, we should be cautious about how they are used to defend or attack general claims, in this case about the costs and benefits of EU immigration in the UK.

Let us look at some examples: S1, S2, and S3 appeal to APS stories to support (a), intending to demonstrate that immigration puts considerable strain on UK services, particularly the health service. Leaving aside whether or not the tellers really do experience many immigrants in their GP surgeries, we wish to point to evidence stating that we should be cautious about the claim that immigrants are causing the significant strain. People consistently overrepresent the percentage of immigrants in the UK, as well as their impact on aspects of society such as employment and welfare (e.g. Policy Institute at King's 2018). 'Health tourism', defined by the King's Fund (2015) as 'where people come to the United Kingdom with the express intent of using health services to which 


\section{Sophie Stammers and Lisa Bortolotti}

they were not entitled', costs between $£ 60$ million and $£ 80$ million per year, less than $0.1 \%$ of the annual NHS budget of $£ 113$ billion (Prederi 2013). Indeed, policy researchers suggest that the political-ideological choice of austerity has put a greater strain on public services than the number of people (from any country) who need to use public services (Gietel-Basten 2016). So, personal experience of immigrants using public services are not in themselves sufficient to tell us about whether immigrants really are playing a significant causal role in the experienced strain on services.

In S4, the story of an interaction with a street busker is offered as an explanation for why the teller voted for Brexit. The teller states that the busker is "foreign" but does not include any information about whether the busker is from the EU and, either way, the story has dubious relevance to voting one way or another in the EU referendum. If the busker wasn't an EU citizen, she would be subject to non-EU visa requirements, but these are administered by the UK Home Office and are not to do with the EU (UK Home Office 2019). If the busker was an EU citizen, then she would be subject to EU immigration rules in which 'the right of residence depends on [her] having sufficient resources not to become a burden on the host Member State's social assistance system, and having sickness insurance' (European Parliament 2019,2) and so ought not to be on benefits without good reason. Charitably, there could be an implicitly understood premise here, claiming that the relevant immigration rules as stated above are not being enforced. But even including and assuming the truth of such a premise, it is not clear why leaving the EU is favoured, rather than, say, pressuring the UK government to properly enforce the relevant immigration policy.

Turning now to the examples of APS stories that aim to support ( $a *), S 10$ uses personal experience of a working in a research lab which employs a group of people who come from numerous different countries. The story contains details of sharing aspects of each other's cultures, speaking different languages and learning from one another, and intends to resist the conclusion that foreignborn people are undesirable, and support the conclusion that they have much to contribute to the UK. The force of the argument here seems at least in part dependent on the strong integration and social cohesion between people of different backgrounds in a particular lab. One might think that the intimacy and fondness for the new learning experiences are well conveyed. However, experience of social cohesion between the foreign-born population and the UK-born population is not universal across the country. Research suggests that income inequality and deprivation are likely to be important determinants of cohesion, with those in higher-income positions experiencing more cohesion (Gesthuizen et al. 2009, Demireva 2017). So, insofar as the thrust of the story depends on the cohesion and integration experienced in the lab, it tells us little about experiences of cohesion between different populations outside of that specific setting. In terms of its ability to persuade, this story may well not chime with other readers' experiences, serving to alienate and further entrench anti-immigrant sentiment, thus having the opposite effect to that intended by the teller. 
In both $S 8$ and $S 9$, the tellers identify themselves as EU27 migrants, and point out that they personally contribute something positive to the UK-running a cancer charity (S8) and creating jobs through setting up a business in the UK (S9). To preserve anonymity, we do not expand on the conversational context in which these stories are offered as arguments. If these stories are offered with the intention of supporting the claim that immigration is good for the UK, then one might think they fall short: single examples are not sufficient to get to the truth of the more general claim about the value of immigration to the UK as a whole. However, if these stories are offered as a means of countering an interlocutor's claim that immigration is bad, then, depending on exactly how the latter claim is spelled out, they may have argumentative force. If the latter claim is a universal (e.g., "all immigrants are a burden and bring nothing of value to the UK") then a single counter-example in which an immigrant does bring value is sufficient to defeat this claim. However, if the claim is a generic (understood as "some or most immigrants are a burden, and bring nothing of value to the UK") then a single example to the contrary does not defeat the generalization (Leslie 2017). ${ }^{6}$

Stories based on single examples (either of immigrants contributing to the UK, or of being a burden) are insufficient to support the general claims their tellers often intend to make. However, the power of (something like) the identifiable victim effect mentioned earlier means that the general claim defended by using a story is likely to be believed and to influence participants' views even if there is no good statistical evidence backing it.

\section{Fulfilling Epistemic Duties in Debate Participation}

As we saw in the previous section, APS stories play an important role in public debates as they offer some insight into direct experiences that are relevant to the debated issues, drawing attention to phenomena that may have been previously neglected and offering insights into the reasons why debate participants hold the views they defend. At the same time, APS stories are not always the best way to establish a general claim and do not always provide good reasons for adopting, revising, or abandoning a belief. This prompts a question: do we fulfil our epistemic duties as debate participants when we take APS stories as evidence and regulate our epistemic practices on the basis of such stories?

The literature on epistemic duties is divided as to which epistemic duties agents have and even whether agents have any epistemic duties (see for instance Alston 1988). According to Andrea Kruse, epistemic duties derive from epistemic norms that "serve to guide epistemic agents in their intellectual conduct” (Kruse 2013, 340). Typically, agents are thought to have epistemic duties about how they adopt and maintain their beliefs. Richard Feldman claims that agents have the epistemic duty to believe as the evidence dictates (Feldman 2002). Others argue that agents also have related epistemic duties. For instance, inspired by the writings of John Locke, Richard Hall and Charles Johnson argue that agents have an epistemic duty to seek more evidence about 


\section{Sophie Stammers and Lisa Bortolotti}

a proposition if they have not yet ascertained the truth of that proposition (Hall and Johnson 1998).

Also inspired by Locke, Scott Stapleford suggests that agents have no duties to hold any specific beliefs, because they may not be able to understand the connection between a belief and the evidence they have, but have an epistemic duty to proportion their beliefs to the evidence they have (Stapleford 2012). This is an indirect and imperfect duty. It is indirect because once agents understand the connection between the evidence they have and the belief, then they cannot but believe according to the evidence, but what they can do is perform actions that help them understand the connection better such as deliberate about the evidence (e.g., they can ask whether a testimony is reliable). It is an imperfect duty because it is not possible for agents like us to deliberate on the evidence for all of their beliefs, so the epistemic duty should be conceived of as a guiding principle for promoting an end, that of having beliefs that are proportionate to the evidence.

If Stapleford is right that epistemic duties are not about what agents believe, but about the connection between evidence and belief, and agents should aspire to deliberate about the evidence they have for their beliefs, then debate participants should strive to assess the relevance and weight of APS stories as evidence, especially when they are presented as evidence for a belief that is central to the debated issues.

This is challenging for several reasons. First, it is not always obvious when an APS story is used as evidence, given the other roles APS stories can play (as we saw in section 1). Second, compared to other forms of evidence such as statistical information, APS stories are often emotionally engaging and vivid, which makes them especially effective at influencing participants' beliefs and driving action (as we saw in section 2), compromising the capacity of the agent to understand the connection between evidence and belief. Third, it is easy to confuse the value of the APS story as a unique source of information about participants' experiences and perspectives in a debate with the role of the APS story as evidence in support of a belief that is central to the debate, such as 'EU immigration is harmful/beneficial to the UK' (as we also discussed in section 2).

Our suggestion is that we need a new framework of epistemic evaluation which applies to the use of APS stories in public debates and leads to effective strategies that debate participants can use to navigate the often overwhelming amount of information available to them. This would support their capacity to deliberate about the evidence they have, and enhance their potential to fulfil their epistemic duties.

\section{Conclusion}

It seems especially important in a debate to be able to regulate one's epistemic practices in accordance to the evidence, and this includes increasing or decreasing one's conviction in a belief, revising or abandoning a belief, suspending judgement, or adopting a new belief. In the case of APS stories, 
the vividness and immediacy of the information presented as evidence, in conjunction with phenomena akin to the identifiable victim effect, may contribute to debate participants' regulating their epistemic practices in accordance with stories that fail to provide support for the beliefs they alleged to support.

We argued that, if debate participants need to be able to deliberate about the evidence to fulfil their epistemic duties, then their task is especially challenging when the evidence is presented in the form of APS stories. Given the challenges that this task poses, we suggest that a new framework for the evaluation of APS stories as evidence should be put forward, preferably leading to the articulation of some strategies guiding participants' deliberation.

\section{Notes}

1 One question that deserves more attention than we can give it here is whether stories are influential in the sense that they directly affect behaviour, motivating agents to act in certain ways; or whether they lead people to adopt certain beliefs, where the beliefs then drive agents to act in certain ways. In practice, the distinction may be less easy to draw than in theory, though, as people will tend to be both motivated to act in ways that are consistent with their beliefs, and to adopt beliefs that are consistent with the way they act.

2 We received full ethical approval for this research activity from the Humanities and Social Sciences Ethical Review Committee of the University of Birmingham on 3 September 2018.

3 There are a number of features of debates on social media (particularly on the pages we investigated) that set it apart from, say, a live debate between two interlocutors who meet face to face. First, debate participants comment on posts published by the page-owner, meaning the original posts play a role in determining the topic of debate, and as such, comments often feature implicit content elucidated by knowing the content of the original post. Secondly, people debating on social media do not always explicitly state all of the premises required for the conclusion they specify to follow from the premise(s) they provide, yet they can still often be understood as producing a valid argument on account of assuming some implicit premises which are accepted by the target audience. This latter feature may not be peculiar to debate on social media, but to everyday arguments had by everyone (except, perhaps, philosophers and argument theorists) where some premises are understood implicitly through the community's knowledge, rather than stated explicitly by the arguer.

4 Comment authors sometimes use '...' for emphasis, and so we use '[...]' to signpost where we have abridged the comment for brevity.

5 We of course found examples in the data of people putting forward arguments in support of premise (a) and $\left(\mathrm{a}^{*}\right)$ which do not rely on recounting a personally experienced event, and use more readily recognized forms of argumentation, such as making statistical claims and claiming to identify broad sociological or economic trends. For example:

We don't haver labour shortages, we have greedy employers who won't pay enough for people to live on. We have at least 2 million people in the UK in need of work. They are ignored amidst a torrent of lies about laziness and stupidity, when the reality is it's just greed, pure and simple. Immigrants can be exploited far easier than indigenous workers. There shouldn't be any 
immigrants coming here for work unless there really is no one in the UK that can do the job (which is highly unlikely).

Wake up to what? The fact that a mere $5 \%$ of the population is from the EU and $41 \%$ of those came with a definite job (thus contributing to tax and NI)? That $80 \%$ of EU citizens in the UK of working age are in work, or that those looking for work are unable to claim benefits for three months? That there are 1.2 million British born people living and working in the EU? You sure it's me that needs to wake up? Or do you just have a general dislike of foreigners?

6 We, the authors, are committed to the truth of the claim that EU27 immigrants do bring net benefits to the UK, but we believe this largely on the basis of statistical evidence (Mulheirn 2018), suggesting that single examples alone are not sufficient to support this point.

\section{References}

Alston, W. 1988. “The Deontological Conception of Epistemic Justification.” Philosophical Perspectives 2: 257-299.

Bloom, P. 2016. Against Empathy: The Case for Rational Compassion. London Penguin.

Bortolotti, L. 2018. "Stranger than Fiction: Costs and Benefits of Everyday Confabulation.” Review of Philosophy and Psychology 9 (2), 227-249.

Bortolotti, L., and Jefferson, A. 2019. "The Power of Stories: Responsibility for the Use of Autobiographical Stories in Mental Health Debates.” Diametros 16 (60): 18-33.

Coles, R. 1989. The Call of Stories: Teaching and the Moral Imagination. Boston, MA: Houghton Mifflin.

Cubitt, S. 2003. "Anecdotal Evidence.” NECSUS: European Journal of Media Studies 2 (1): 5-18.

Das, E., Kerkhof, P., and Kuiper, J. 2008. “Improving the Effectiveness of Fundraising Messages: The Impact of Charity Goal Attainment, Message Framing, and Evidence on Persuasion." Journal of Applied Communication Research 36 (2): 161-175.

Demireva, N. 2017. "Immigration, Diversity and Social Cohesion." Migrant Observatory report). Available online at: https://migrationobservatory.ox.ac.uk/ resources/briefings/immigration-diversity-and-social-cohesion/

European Parliament. 2019. "Free Movement of Workers". Fact Sheet of the European Union. Available at: www.europarl.europa.eu/ftu/pdf/en/FTU_2.1.5.pdf

Feldman, R. 2002. “Epistemological Duties.” In P. K. Moser (ed.), Oxford Handbook of Epistemology. Oxford: Oxford University Press, 362-384.

Gesthuizen, M., Van Der Meer, T., and Scheepers, P. 2009. "Ethnic Diversity and Social Capital in Europe: Tests of Putnam's Thesis in European Countries." Scandinavian Political Studies 32 (2): 121-142.

Gietel-Basten, S. 2016. "Why Brexit? The Toxic Mix of Immigration and Austerity." Population and Development Review 42 (4): 673-680.

Hall, R. J., and Johnson, C. R. 1998. "The Epistemic Duty to Seek More Evidence.” American Philosophical Quarterly 35: 129-140.

Home Office. 2019. "Immigration Rules Part 1: Leave to Enter or Stay in the UK." Immigration Rules. Available at: www.gov.uk/guidance/immigration-rules/immigrationrules-part-1-leave-to-enter-or-stay-in-the-uk

Kruse, A. 2013. "What Are Epistemic Duties?” In M. Hoeltje, T. Spitzley, and W. Spohn (eds), What May We Believe? What Ought We to Do? Proceedings of GAP.8, the Eighth International Conference of the Society for Analytic Philosophy, 340-351. 
Leslie, S.-J. 2017. “The Original Sin of Cognition: Fear, Prejudice, and Generalization.” Journal of Philosophy 114 (8): 393-421.

Markovits, H., and Schmeltzer, C. 2007. "What Makes People Revise Their Beliefs Following Contradictory Anecdotal Evidence? The Role of Systemic Variability and Direct Experience." Cognitive Science 31 (3): 535-547.

McAdams, D. P. 1993. The Stories We Live By: Personal Myths and the Making of the Self. New York: Guilford Press.

Moore, A., and Stilgoe, J. 2009. "Experts and Anecdotes: The Role of 'Anecdotal Evidence' in Public Scientific Controversies." Science, Technology, and Human Values 34 (5): 654-677.

Mulheirn, I. 2018. The Fiscal Impact of Immigration to the UK: A Report for the Migration Advisory Committee. Oxford Economics. (). Available online at: https:// assets.publishing.service.gov.uk/government/uploads/system/uploads/attachment_ data/file/759376/The_Fiscal_Impact_of_Immigration_on_the_UK.pdf

Murdoch, I. [1970] 2001. The Sovereignty of Good. Oxford; New York: Routledge.

Nash, C. 2005. Narrative in Culture. London; New York: Routledge.

Policy Institute at King's. 2018. Brexit Misperceptions. Report,. Available online at: www.kcl.ac.uk/sspp/policy-institute/research-analysis/the-publics-brexit-mispercep tions.aspx

Prederi. 2013. Quantitative Assessment of Visitor and Migrant Use of the NHS in England: Exploring the Data. Available online at: https://assets.publishing.service.gov.uk/government/uploads/system/uploads/attachment_data/file/254200/ Quantitative_Assessment_of_Visitor_and_Migrant_Use_of_the_NHS_in_England_ -_Exploring_the_Data_-_SUMMARY._2_pdf.pdf

Radutzsky, M. 2017. “60 Minutes Overtime: What's 'Fake News'? 60 Minutes Producers Investigate.” CBS News, March 26.

Sacks, H. 1992. Lectures on Conversation, ed. G. Jefferson. Malden, MA; Oxford: Blackwell,.

Small, D., Loewenstein, G., and Slovic, P. 2007. "Sympathy and Callousness: The Impact of Deliberative Thought on Donations to Identifiable and Statistical Victims." Organizational Behavior and Human Decision Processes 102: 143-153.

Stammers, S. 2020. "Confabulation, Explanation, and the Pursuit of Resonant Meaning.” Topoi 39, 177-187. https://doi.org/10.1007/s11245-018-9616-7.

Stapleford, S. 2012. "Epistemic Duties and Failure to Understand One's Evidence." Principia 16 (1): 147-177.

Teske, J. 2017. “Knowing Ourselves by Telling Stories to Ourselves.” Zygon 52 (3): 880-902.

The King's Fund. 2015. What Do We Know about the Impact of Immigration on the NHS? Verdict report. Available online at: www.kingsfund.org.uk/projects/verdict/ what-do-we-know-about-impact-immigration-nhs

Tsipursky, G. 2017. The Truth-Seeker's Handbook: A Science-Based Guide. Columbus, $\mathrm{OH}$ : International Insights Press. 


\title{
17 Dialectical Responsibility and Regress Skepticism
}

\author{
Scott Aikin
}

Skeptics hold that we do not have the justification required for knowledge, and regress skeptics, in particular, hold that we fail this justification requirement because none of the options for the structure of justifying reasons can provide the requisite support. The locus classicus for regress skepticism is Sextus Empiricus' deployment of the Five Modes in his Outlines of Pyrrhonism. The Agrippan Trilemma (and other multivariable lemmas that followed in its spirit) is an argument from elimination for skepticism. According to the trilemma, reasons come in justifying chains, and those chains may come in three forms: either they may terminate with some reasons, they may go in circles, or they may run on to infinity. None of those options can yield justification, so skepticism follows. Call this the Agrippan argument.

If we believe that the conclusion of the Agrippan argument cannot be right, then we must explain where things go wrong. The Agrippan argument may seem intuitive, but it has assumptions that may be optional. Are there alternatives that do not yield skeptical conclusions? Is skepticism an acceptable conclusion, given the revisions we must make to avoid it? This rough set of questions comes together to constitute the epistemic regress problem.

One solution to the regress problem has been to hold that reason-giving in critical dialogue is our best model for justifying reasons. This is the dialectical model for justification, and given that there are regress-ending reasons in many critical dialogues, a form of dialectical foundationalism solves the regress problem. The Agrippan argument is, on this picture, just wrong about the modes. The dialectical structure of these foundational reasons is that, with them, the burden of proof is on those who challenge them, not on those who give them. Those who hold reasons as foundational (and with this dialectical structure), however, face a dilemma in being able to responsibly pose these reasons in exchange with a critical questioner-one either shifts the burden of proof with no given reason or with the promise of further reasons. The problem is that it is not clear how the former yields justification or how the latter effectively ends the regress of reasons. 
There are three questions central to the regress problem on which it is useful to focus. They are:

Q1: Do the norms of well-run verbal critical exchange provide a model for epistemic justification?

Q2: Are verbal critical exchanges vulnerable to a regress of reasons?

Q3: Does the fact that a theory of justifying reasons has skeptical consequences count against the theory? Do anti-skeptical consequences count for the theory?

Given that the questions are Yes/No, we have a limited variety of answers, and they each are indicators of particular views and methods in epistemology. To Q1, those who answer Yes are committed to the dialectical model of epistemic justification-that there is an isomorphism between the norms of justification and those of reason-exchange. For the dialecticalist, then, the act of justifying an assertion provides us with a model for what is simply what it takes for our beliefs and assertions to have the status of being justified. Adam Leite frames the view as follows:

Being justified ... is ordinarily a matter of being able to justify one's belief-that is, of being able to develop and provide an appropriate and adequate defense of one's belief when asked to do so under appropriate conditions

$(2004,220)$

On dialecticalism, the norms of well-run critical dialogue are the norms of justification, so the justificatory status of our beliefs depends on how we are able to defend them in the face of criticism. ${ }^{1}$

Those who reply No to Q1 are the non-dialecticalists, and they distinguish between the norms of critical verbal exchange and the structure of supporting epistemic reasons. William Alston is explicit about the importance of maintaining the difference:

We must clear out of the way a confusion of one's being justified in believing that $\mathrm{p}$, and one's justifying one's belief that $\mathrm{p}$...

(1986, 24-emphasis in original)

On the non-dialecticalist view, there is a difference between having evidence and being able to articulate and share it. ${ }^{2}$ Justification that tracks only the latter restricts not only what can count as a justifying reason (one that is shareable as a reason), but also restricts who can count as justified (those who can share reasons as reasons). This view of justification, it is thought by the nondialecticalist, is too restrictive, and consequently risks the skeptical conclusion. 


\section{Scott Aikin}

To the second question $(\mathrm{Q} 2)$, whether critical dialogue is open to regresses, there are those who hold that it is, the dialectical Pyrrhonists, and those who hold that the series of reasons given is finite, dialectical foundationalists. ${ }^{3}$ The dialectical Pyrrhonist holds that any assertion or reason given is open to challenge, and in particular, open to simple why?-question challenges. The dialectical foundationalist, however, holds that not all assertions can be challenged with a mere why?-question. Some challenges require that one provide a counter-argument or some evidence of a defeating reason. Call mere why?-questions or challenges without explicit reason-backing brute challenges (following Williams 2003: 133 and Rescorla 2009a: 88). Call challenges with some supporting reason backed challenges.

According to the dialectical Pyrrhonist, dialectical regresses occur within the context of reason-giving, wherein an assertor holds that $p$ and a questioner asks for the assertor's reasons. The regress ensues, according to the Pyrrhonist, because any assertion may be challenged by any kind of relevant request for reasons, brute or backed. The thought behind this is that, when one asserts, one takes on the burden of proof with regards to one's assertions, and so one either defends one's publicly stated commitments or retracts or revises them appropriately. ${ }^{4}$ That's just responsible assertion. The reason why is that, if one is asserting something, one is commending that commitment to others, one's listeners. One is suggesting to them that they take on that commitment, too; one commends the belief as something that they may make plans on the basis of, make inferences from, and take as a reason to reject contrary commitments. Consequently, dialectical Pyrrhonists hold, listening audiences are well within their rights to do due diligence on those commitments. So they may ask critical questions, and for them to properly understand the commitment, they should have a wide range of those questions available. That's just responsible listening. So they may ask questions about broader background assumptions, theoretical orientations, and even about values that make the commitment sufficiently well-supported. ${ }^{5}$ Brute challenges must, so it is thought, be within our rights as inquiring minds.

Dialectical foundationalists, in contrast, hold that critical questioning has bounds of cognitive propriety. With some matters around which there may be widespread doubt, brute challenges are appropriate; however, with other matters, there is room only for backed challenges. Consider the following exchange:

A: The movie starts at $6: 30$.

B: Are you sure it's 6:30?

A: Yep, I checked the theatre's website.

B: Are you sure you checked the website? ${ }^{6}$

In both cases, $\mathrm{B}$ has made a mere brute challenge, but only the first, by dialectical foundationalism, is an appropriately posed challenge. One poses the second challenge only if one has reason to doubt A's memory, internet access, or honesty. And so, such challenges would be properly framed, then, but as 
backed (and no longer as a brute) challenges. The dialectical foundationalist holds that few, if any, critical discussions yield infinite regresses, because they eventually end up with assertions for which there are no backed challenges and only brute challenges, but for which only backed challenges are appropriate. Call assertions of these reasons dialectically basic-for these assertions, the challenger must shoulder the burden of proof, and there are no reasons (currently) available to challengers. So for dialectically basic commitments, no brute challenges are appropriate and there's no (standing) evidence for backed challenges. ${ }^{7}$ Consequently, they end the regress of critical questions.

With the third question (Q3), whether the fact that a theory has skeptical consequences counts against it and anti-skeptical consequences count for it, there are the skeptically friendly and the anti-skeptical answers. There are many who hold that because we are analyzing a concept at the core of our commonsense conception of ourselves, that we are knowers and reasonable believers of many things, any view that eliminates this is (at least prima facie) absurd. ${ }^{8}$ These are the anti-skeptical takes on the regress problem.

Those who are skeptically friendly, on the other hand, hold that there should be a distinction of levels between our meta-epistemic theorizing and our normative epistemic judgments in practice. If our best meta-epistemic analysis has the result that there are no possible (or at least no actual) normatively justified commitments, then so be it. ${ }^{9}$ To hold that we must refigure our analysis of justification requisite for knowledge so that there is as much of it as we'd thought there was before we started theorizing is a stamp of the dogmatism of common sense.

\section{3}

My first observation is that the anti-skeptical views drive a good deal of discussion between, first, dialecticalists and non-dialecticalists about justification, and second, between dialectical foundationalists and Pyrrhonists. The operative premise behind these debates is that a powerful reason for one view is that the other, in both cases, is purported to have skeptical consequences.

Those who reject dialecticalism argue that because dialecticalism requires that supporting reasons be shareable in dialogue, and non-doxastic states, reliable (but not explicitly known to be reliable) belief-producing mechanisms, intuitions, and other private-but-not-shareable inputs, are not shareable, they are ruled out as reasons. Consequently, without these sources for backing, those who would otherwise be justified now no longer count as having justification. If one is an anti-skeptic, this is not an acceptable outcome.

Those who are dialecticalists hold that, contrary to the non-dialecticalists, the give-and-take of reason-giving in critical dialogue makes skepticism easier, rather than harder, to solve than the non-dialectical view of reasons. If the norms of reasoning track the way we attribute justification in light of actual critical dialogues, then the best hope for anti-skepticism is dialecticalism.

The lesson of the first observation, then, is that both sides of the dialecticalism/ anti-dialecticalism debate about justification are centrally motivated by what they see as the skeptical consequences of the other view and the anti-skeptical 
consequences of their own. At bottom, what drives the disagreement about models for justification, then, is a disagreement about whether dialectical norms are skeptically friendly or anti-skeptical. ${ }^{10}$

This brings us to a second observation-that how one views what the dialectical norms are determines whether one sees them as more or less open to skeptical regress. On the one hand, there is the purely descriptive program, perhaps best captured by Richard Rorty's epistemological behaviorism:

Explaining rationality and epistemic authority by reference to what society lets you say, rather than the latter by the former, is the essence of behaviorism when applied to human knowledge ...

Whatever norms there are, on the Rortian (naturalist/linguistic behaviorist) view, they arise out of actual practice. Our actual practices have widespread justification-attribution, so since these practices have such attributions, the norms are bound to capture those successful instances. If true to the phenomena, then, our analysis of justification should yield robust anti-skeptical outcomes.

On the other hand, there is the more idealist line wherein the target for analysis is a rational reconstruction that has in one eye our gritty practices of justification, but also another eye idealizing the rules of the practice, in order to keep the norms of critical discussion distinct from bullshitting, casual banter, and mere informational speechifying. To identify this, one must, as it were, set out rules of ideally structured critical exchange:

The normative approach sets out considerations regarding the norms of reasonableness that good argumentation must satisfy. However, normative rules and procedures, devised in a reflective Valhalla, where the peculiarities of argumentative practice can be discounted, can only have practical relevance if they do justice to the characteristics and properties inherent in discursive reality.

(van Eemeren and Grootendorst 2004, 10-11)

Consequently, of the dialecticalists, those who are more descriptive are less likely to think that vicious regresses occur for critical dialogue, because they don't occur in real life. But the more idealist dialecticalists are comparatively more likely to see the regresses arise out of the norms of reason-giving, and they will not be impressed by the fact that regresses don't happen in real life. Most regress-ending considerations, at least for the idealist, are taken to be irrelevant to the matter at hand, because they have arisen for non-epistemically salient reasons (time, etiquette, the fact of mere agreement, etc.).

\section{4}

A central motivation for dialecticalism (and in particular idealist dialecticalism) is anti-dogmatism. Let's start with a rough view of dogmatic belief and 
dogmatic comportments toward one's fellows-those who are dogmatic take themselves to be justified in believing something that others are not, and so they confidently assert or assent in light of this purported justification. Given this self-assurance of justification, dogmatists do not take critical questions from others seriously, and they continue to assert and act in light of this purported knowledge, even when others are on record rejecting it. I think that this yields a four-part analysis of dogmatic belief as follows:

$S$ dogmatically believes that $p$ iff:

(i) $S$ believes that $S$ knows or has sufficient reason to hold that $p$

(ii) $S$ holds objections to $p$ to be unfounded, and refuses to countenance them

(iii) $S$ believes that $p$ with more confidence than $S$ 's (publicly given) reasons warrant

(iv) $S$ asserts that and acts in light of $p$, even when there is standing disagreement

For sure, this analysis is rough and may be open to the odd counter-example (as perhaps one can be dogmatic about something one does not assert, or one can be dogmatic even if one does not possess the concept knowledge), but so long as dogmatism yields the core dialectical failures of challenge-responsiveness in (ii) and backing proportionality in (iii), we have reason to see the source of dialecticalism's appeal. ${ }^{11}$ One's assertions should be backed by sufficient reasons, and the test for those reasons is that of appropriate defense. The dialecticalist objective is to integrate our epistemic norms with our natural sociability-the dogmatist, as C. S. Peirce observed in "The Fixation of Belief," not only is cognitively pathological, but in being so tenacious, acts contrary to our social impulse (CP 5.378).

\section{5}

If we see the anti-dogmatic impulse behind the dialecticalist turn, then we see a problem arise for dialectical foundationalism. The dialectical foundationalist holds that there are dialectically basic reasons. A reason is dialectically basic if there is no standing evidence for a backed challenge and no brute challenges are appropriate. So for dialectical foundationalism, some commitments have, to use Brandomian (1994) terminology, default status, and we have entitlement to assert them until there are backed challenges. No brute challenge can rationally unseat these commitments. Michael Williams captures the program as follows:

In many contexts, and with respect to a wide range of beliefs, subjects possess and are properly granted default doxastic justification. Such default justification does not depend on the subject's doing or having done any specific evidential work, and does not require him to possess or seek 


\section{Scott Aikin}

for citable reasons for his believing as he does. In general, epistemically responsible believing does not require that one's belief be based on or supported by reasons.

The thought behind this program is, as Williams puts it, "there is a presumption of innocence" for many of our beliefs and assertions, and appropriate queries about them do not arise in an "epistemic vacuum" $(2014,233)$. Critical questions and arguments don't come out of nowhere-there's a background of other issues, worries, and things agreed upon that animates these exchanges. So there are some things that must stay in place in order for other things to be questioned.

The problem is that, if a central motive for dialecticalism is anti-dogmatism, then the dialecticalist should be wary of a view that allows speakers to identify a swath of challenges to their assertions as not appropriately framed and not in need of reply. That is, default justification cannot arise in an epistemic vacuum, either. Anti-dogmatism, in this vein, given the social elements of the view, and in particular, responsibilities of challenge-responsiveness, clearly connects with other social-epistemic worries about public reason-giving, as it shares the concern about marginalization of many groups who may not have standing to raise challenges, or who may not have the linguistic ability to raise any but brute challenges, because the language of critical discussion may not be their home language. And so in the same way testimonial injustices may occur in the form of speakers being blocked from providing information to a group (as noted in Fricker 2007, Dotson 2011, and Medina 2013), these injustices may occur in the form of reduced participation in reason-exchange (as noted by Hookway 2010, Bondy 2010, and Heikes 2017). That is, prohibitions on brute challenges to default reasons may restrict not only what counts as a relevant challenge, but who counts as a legitimate objector. ${ }^{12}$

For sure, there are epistemetric reasons why only a range of objections are appropriate for some conversations. Time and other resources are often in short supply, and so pragmatic constraints on inquiry play the role of bounding what counts as an objection worthy of complete reply and what is worth moving past. ${ }^{13}$ The question is whether those constraints on relevance are ones that make it so that one is justified in the relevant sense on the other side of ignoring an objection. It is worth, here, distinguishing between two ways this pragmatic restriction can be deployed.

One may, first, not reply to an objection only because it would take more time than allotted for the reply. But one could, were there time to do so. Call these curtailed replies. Alternately, there are brute objections to which one has no complete reply beyond the observation that one's regular use of the assertion hadn't needed defense before. All one can do is call attention to the default status of the assertion. Call these defaulted replies.

It seems that if one has a dialectically basic reason, and one is given a brute challenge, one has either a curtailed or defaulted reply. One, again, doesn't reply so long as the reason stays basic, but the matter is what one could do were one 
to make explicit what one is doing in not replying to the brute challenge. The question is whether these sorts of suppressed replies in the defense of a dialectically basic reason can play the role of what would confer justification, given the dialecticalist program. I believe they do not, and the reason why is that neither of the responses allow us to distinguish knowledge from dogmatism or knowledge from what just passes for knowledge. The result is a form of Pyrrhonism.

\section{6}

If one is a dialecticalist, one is committed to using the norms of critical reasonexchange as a model for the norms of epistemic justification. Justification is, then, a social status, one that is achieved in the game of giving and asking for reasons. In particular, the dialecticalist is committed to something along the lines of the Resolution and Defense Theses:

If $S$ is justified in holding that $p$, then $S$ can resolve disputes about $p$.

If $S$ can resolve disputes about $p, S$ can provide dialectically appropriate reasons for $p$.

Importantly, and again in anti-dogmatist spirit, these disputes for resolution should be widely flung, so that one does not just win arguments with one's lackeys and yes-men. Rather, one's reasons survive the scrutiny of public argument and the marketplace of ideas. ${ }^{14}$ Consequently, when we attribute justification to others, and particularly to ourselves, we put ourselves in a position of being able to address disputes, to handle critical questions. Knowing something differs from merely believing it, because justification comes on the basis of good grounding, understanding, and, presumably, what we can communicate comparatively as good grounding and understanding. Consequently, assertion is the social face of making a claim to this status, and the test for it is reason-giving and testing. Three phenomena arise from this intersection.

Endorsement: in assertion and justification-attribution, one endorses and commends a position to others.

Generality: in assertion and justification-attribution, one does not simply endorse the proposition, but also the reasons that purport to support the claim (and so a general endorsement/commendation).

Non-Defeasibility: in assertion and justification attribution, one holds that the proposition endorsed is well-founded and counter-considerations (defeaters) can be addressed.

How one establishes and lives in accord with these implications is that one displays one's reasons in critical dialogue. One lives up to those promises by following the Norm of Reply:

If $S$ asserts that $p$ and $p$ is challenged, then

$S$ must defend $p$ with dialectically appropriate reasons for $p$. 


\section{Scott Aikin}

In short, if you're challenged on an assertion, you should defend it or retract it, and defending $p$ requires reasons that actually support and are recognized to support $p$ and do not antecedently assume it. ${ }^{15}$

Now, again, dialectical foundationalists hold that there are exceptions to the Norm of Reply, that is, when the challenges are brute and the assertion is of a dialectically basic proposition. But the non-defense is still for a reason, as the default commitment is not defended either as a curtailed defense or as a defaulted defense.

The problem with dialectical foundationalism is that, once we have made these norms clear, it is built on an observation that there are dialectically basic commitments, but it does not mark out how speakers identify them to each other in disagreement. In particular, how do speakers mark them in cases of significant disagreement? Surely when there is broad agreement between speakers, premise-introduction is a simple task. However, in cases of deeper disagreement, identifying shared dialectically basic commitments is particularly difficult. And how one communicates this is not only interpersonally important, but epistemically significant, too. Again, as dialecticalism holds, the epistemic and dialectical norms are symmetric.

In the case of defaulted defenses of dialectically basic reasons (those for which all one has to say for it is that one hasn't received objections to it before), it is unclear how one communicates this to a listener, and in particular, to an objector. Perhaps one makes a quizzical face, chuckles, or just stares blankly back at the person. But here is the problem: this sort of behavior is indistinguishable from that of the dogmatist. One refuses to reply to an objection, treats it (and perhaps the objector) as impertinent, and presumably communicates this to the objector and to the onlooking audience. The problem is that the acts of justifying, on dialectical foundationalism, are indistinguishable from acts of refusing to justify. This is a curious result, and I believe what's proposed by dialecticalists cannot, if they are consistent, yield justification.

In the case of curtailed defenses of dialectically basic reasons (those for which there are reasons to be given but neither the time nor other resources are available), communicating the situation to the listener is much easier. We have all done this with good students-we don't use class time for all the deep questions, but invite the student to come by for office hours. The same goes in these cases-we can say that this question poses a different set of issues, which must be or have been discussed elsewhere, or we can say that, yes, things are more complicated than we'd framed it, but the case can still be made at another time. In this case, the curtailed defense of default commitments, when properly marked in conversation, is posited to stop critical discussion along the lines of the brute objection, but it promises cogent reasons under other conditions. So this particular critical conversation is over, but a broader conversation can still continue. The problem is that this ends the regress, but only locally and temporarily. It is less, really, a regress stopper, and more like a regress-pauser. Moreover, notice that the justification then comes not because of the default status of the commitment or the conversation, but on the basis of the cogent reasons promised later. This is no way to end the regress. 
Dialectical foundationalism is either dogmatic (with defaulted defenses of basic reasons) or merely a punt on further reasons (with curtailed defenses). Either way, dialectical foundationalism fails as a responsible solution to the dialectical regress problem, since a dialecticalist resolution to a regress of reasons should not be dogmatic (since it would not really resolve anything), or continues the regress (which is contrary to the foundationalist impulse). It is worth noting that the responsibilities here are those that arise from a view dialecticalists must share- that knowledge and our rational believing are commonable commodities, something we can share if prompted, and that shareability is the hallmark of the rationality of those commitments. Anti-dogmatism is not just a commitment to the truth of our views but the social elements of reason and argument. ${ }^{16}$ The result is that if one is a dialecticalist about justification, and in particular, if one is of an idealist stripe about dialectical norms, one is on the road to Pyrrhonism.

The Pyrrhonist view is that none of our commitments can survive a complete dialectical game of reason-giving and reason-testing, because if one rule of the game is avoidance of dogmatism, then one is in principle on the hook for answering even the brute questions to what seem our default assumptions. Anyone who has spent time with an inquisitive child knows this, and the children know this, too. For sure, why?-question-mongering 5 year olds are annoying, often obtuse, and perhaps even a little rude. But they aren't wrong, at least intellectually. And equally for sure, the children grow up and are eventually constrained by the norms of courtesy given to assertors and speakers. But who really thinks that such etiquette yields justification? It may yield plenty of justification-attributions (as one calls so many nincompoops "experts" in order to keep the peace), but the result of not being able to distinguish justification from what merely passes for "justification" is too high a price to pay. Better to say there is no justification at all than that. ${ }^{17}$

\section{Notes}

1 For other statements of the dialecticalist commitment, see Annis (1986: 208), Rorty (1991, 40), Brandom (1994, 130), Feldman (1994, 159), Williams (2003, 127), and Leite $(2005,409)$.

2 See also Audi (1993, 145), Bronner (2013), and Engelsma (2015).

3 Here, I am following Williams (2003), Lammenranta (2008 and 2011), and Rescorla (2009a and 2009b) for terminology. Exemplary cases of dialectical foundationalism are Annis (1986, 208), Brandom (1994, 213), Adler (2002, 159), Sellars (1997, 79), Leite $(2005,405)$. Rescorla characterizes the view as based on the thought that the foundationalists "shift the burden of proof to [their] interlocutor" (2009a, 88).

4 The intersection of intuitions here with the literature on the norm(s) of assertion is worth noting, and many of the cases supporting some positive epistemic status norm (be it knowledge-, warrant-, warrant-for-knowledge-, or other) runs from the thought that assertions are challengeable for backing, and should they fail this backing challenge, should be retracted. See, as exemplary, Williamson (2000, 243) and Turri $(2016,8)$. 


\section{Scott Aikin}

5 As Vazquez notes, "the skeptic is able to reapply his modes until one stops making assertions" $(2009,49)$.

6 I have modeled this exchange on Leite's two-stage conversation in 2005, 404.

7 See Rescorla $(2009 a, 94)$ for a detailed account of the distinction between dialectical foundationalism and what he calls "dialectical egalitarianism" (and what I've here called dialectical Pyrrhonism).

8 Exemplary is Rescorla, who takes it that dialectical skepticism is tolerable, because dialectical norms are not epistemic norms (2009b).

9 Exemplary of those holding this skeptical view are Fogelin $(1984,196)$, Fumerton $(1995,53)$, Klein $(2002,354)$, and Aikin $(2011,6)$.

10 This is a matter of no small import in argumentation theory regarding what Johnson (2000) calls the "dialectical tier" to argument, which is the requirement that a successful defense of a view must anticipate and answer likely challenges. Many think this requirement yields a vicious regress—see Govier (1999), Ohler (2003), and Adler (2004). Freeman (2003) and Johnson (2003) hold that the dialectical tier needn't yield a vicious regress.

11 Cf. Lammenranta, "the mistake of the dogmatist is a dialectical one" (2008).

12 Code notes that knowledge and justification are "commonable commodities," and this point means that we have social responsibilities to each other against a background of an "epistemic contract" $(1987,179)$.

13 As noted by Rescher $(2015,14)$.

14 Versions of this thought regarding the Resolution and Defense Theses can be found in Rorty (1985, 101), Brandom (1994, 189), Leite (2005, 402 and 2011, 162); Aikin $(2011,172)$, and Peregrin $(2014,110)$.

15 These features are highlighted by Williams (2003, 130) and Lammenranta (2011, 13).

16 See Code $(1987,154)$ for a case for the connection between the social elements of justification and anti-dogmatism.

17 Thanks go to audiences at the University of Alabama-Huntsville, UNLV, and the Society for Realism and Anti-Realism at the 2017 Pacific APA for feedback on earlier versions of this chapter. Personal thanks go to Andrew Cling, Deborah Heikes, Nicholaos Jones, Ian Dove, David Beisecker, James Woodbridge, Thomas Dabay, Jeffrey Tlumak, Robert Talisse, Jody Azzouni, Otavio Bueno, and Jeremy Dickinson for comments. Finally, thanks to Scott Stapleford and Kevin McCain for their careful comments and challenges.

\section{References}

Adler, Jonathan. 2002. Belief's Own Ethics. Cambridge, MA: MIT Press.

Adler, Jonathan. 2004. "Shedding Dialectical Tiers.” Argumentation 18: 279-293.

Aikin, Scott. 2011. Epistemology and the Regress Problem. New York: Routledge.

Alston, William. 1986. “Concepts of Epistemic Justification.” In Paul Moser (ed.), Empirical Justification. Lanham, MD: Rowman \& Littlefield, 23-53.

Annis, David. 1986. “A Contextualist Theory of Epistemic Justification.” In Paul Moser (ed.), Empirical Justification. Lanham: Rowman \& Littlefield, 203-211.

Audi, Robert. 1993. “The Foundationalism-Coherentism Controversy.” In The Structure of Justification. Cambridge: Cambridge University Press, 117-164.

Bondy, Patrick. 2010. “Argumentative Injustice.” Informal Logic 30: 263-278.

Brandom, Robert. 1994. Making it Explicit. Cambridge, MA: Harvard University Press. 
Bronner, Ben. 2013. “Assertions Only?” Thought 2: 44-52.

Code, Lorraine. 1987. Epistemic Responsibility. Providence, RI: Brown University Press. Dotson, Kristie. 2011. “Tracking Epistemic Violence.” Hypatia 26: 236-257.

Engelsma, Coos. 2015. "Arbitrary Foundations? On Klein's Objection to Foundationalism." Acta Analytica 30: 389-408.

Feldman, Richard. 1994. "Good Arguments.” In Frederick F. Schmitt (ed.), Socializing Epistemology. Lanham, MD: Rowman \& Littlefield, 159-188.

Fogelin, Robert. 1984. Pyrrhonian Reflections on Knowledge and Justification. Oxford: Oxford University Press.

Freeman, James. 2003. "Progress without Regress on the Dialectical Tier." Proceedings of the Ontario Society for the Study of Argumentation 5. Windsor, ON: OSSA Conference Archive, 1-13.

Fricker, Miranda. 2007. Epistemic Injustice. Oxford: Oxford University Press.

Fumerton, Richard. 1995. Metaepistemology and Skepticism. Lanham, MD: Rowman \& Littlefield.

Govier, Trudy. 1999. The Philosophy of Argument. Newport News: Vale Press.

Heikes, Deborah. 2017. “On Being Reasonably Different.” Southwest Philosophy Review 33: 53-61.

Hookway, Christopher. 2010. "Some Varieties of Epistemic Injustice." Episteme 7: 151-163.

Johnson, Ralph. 2000. Manifest Rationality. Mahwah, NJ: Lawrence Erlbaum.

Johnson, Ralph. 2003. “The Dialectical Tier Revisited.” In F. H. van Eemeren, J. A. Blair, C. A. Willard, and F. A. Snoeck Henkemans (eds), Anyone with a View. Dordrecht: Springer, 41-52.

Klein, Peter. 2002. "Skepticism." In Paul Moser (ed.), The Oxford Handbook to Epistemology. Oxford: Oxford University Press, 336-361.

Lammenranta, Markus. 2008. “The Pyrrhonian Problematic.” In John Greco (ed.), The Oxford Handbook of Skepticism. Oxford: Oxford University Press, 9-33.

Lammenranta, Markus. 2011. "Disagreement, Skepticism, and the Dialectical Conception of Justificaiton." International Journal for the Study of Skepticism 1: 3-17.

Leite, Adam. 2004. “On Justifying and Being Justified." Philosophical Issues 14: 219-253.

Leite, Adam. 2005. "A Localist Solution to the Regress of Justification." Australasian Journal of Philosophy 83: 395-421.

Leite, Adam. 2011. "Immediate Warrant, Epistemic Responsibility, and Moorean Dogmatism.” In A. Reisner and A. Stegligh-Petersen (eds), Reasons for Belief. Cambridge: Cambridge University Press.

Medina, Jose. 2013. The Epistemology of Resistance. Oxford: Oxford University Press. Ohler, Amy. 2003. “A Dialectical Tier within Reason.” Informal Logic 23: 65-75.

Peirce, Charles Sanders. 1965. The Collected Papers of Charles Sanders Peirce, ed. Charles Hartshorne and Paul Weiss. Cambridge, MA: Harvard University Press. Referenced as CP.

Peregrin, Jaroslav. 2014. Inferentialism: Why Rules Matter. New York: Palgrave.

Rescher, Nicholas. 2015. Cognitive Complications: Epistemology in Pragmatic Perspective. Lanham, MD: Lexington Books.

Rescorla, Michael. 2009a. "Shifting the Burden of Proof?" Philosophical Quarterly 59: 86-109.

Rescorla, Michael. 2009b. "Epistemic and Dialectical Regresses.” Australasian Journal of Philosophy 87: 43-60. 
Rorty, Richard. 1985. "Epistemological Behaviorism and the De-Transcendentalization of Analytic Philosophy.” In Robert Hollinger (ed.), Hermeneutics and Praxis. Notre Dame, IN: Notre Dame University Press, 89-121.

Rorty, Richard. 1991. "Science as Solidarity." In Objectivity, Relativism, and Truth: Philosophical Papers, vol. 1. Cambridge: Cambridge University Press, 35-45.

Sellars, Wilfrid. 1997[1956]. Empiricism and the Philosophy of Mind. Cambridge, MA: Harvard University Press.

Turri, John. 2016. Knowledge and the Norms of Assertion. Cambridge: Open Book Publishers.

Van Eemeren, Frans, and Grootendorst, Rob. 2004. A Systematic Theory of Argumentation. Cambridge: Cambridge University Press.

Vazquez, Daniel. 2009. "Reason in Check: The Skepticism of Sextus Empiricus." Hermathena 186: 43-57.

Williams, Michael. 2003. “The Agrippan Argument and Two Forms of Skepticism.” In Walter Sinnott-Armstrong (ed.), Pyrrhonian Skepticism. Oxford: Oxford University Press, 121-145.

Williams, Michael. 2014. "Avoiding the Regress.” In John Turri and Peter Klein, (eds), Ad Infinitum. Oxford: Oxford University Press, 227-241.

Williamson, Timothy. 2000. Knowledge and its Limits. Oxford: Oxford University Press. 


\title{
18 Epistemic Duties Regarding Others
}

\author{
Jennifer Lackey
}

In this chapter, I argue that we have distinctively epistemic duties regarding others, where others include both individuals and communities. In particular, I clam that we have both positive interpersonal epistemic duties-which involve promoting the epistemic flourishing of others, such as their true beliefs, access to evidence, possession of knowledge, and so on-and negative oneswhich involve preventing members of our communities from being the victims of epistemic wrongs or harms, such as being victims of epistemic oppression. I conclude that epistemology is not only far more social than has previously been recognized, but also that it bears deep and important similarities to ethics.

\section{The Doxastic Thesis}

The standard view of epistemic duties includes at least two theses. The first is what I call the doxastic thesis: epistemic duties concern only what we ought to believe, and thus their domain is strictly doxastic. For instance, Chase Wrenn says that "Epistemic duties are doxastic duties that are grounded in purely epistemic considerations, such as what evidence one has" (Wrenn 2007, 117). Given this, the typical strategy for arguing that there are no epistemic duties is to show that there are no propositions that we ought to believe. Wrenn makes this point clear when, in summarizing arguments against epistemic duties put forth by William Alston and Alvin Plantinga, he writes:

if it is truly one's duty to X, one must have voluntary control over whether or not one X-es. People do not have voluntary control over whether or not they believe something. Therefore, it is never one's duty (not) to believe something. Epistemic duties pertain to what one believes, and so there are no epistemic duties (Alston 1985, 1988; Plantinga 1988).

(Wrenn 2007, 116)

In a similar spirit, Mark Nelson states the plan for his (2010) paper as follows: "I think that we have negative epistemic duties, but no positive epistemic duties. There are things that we ought not to believe, but there is nothing that we ought to believe, on purely epistemic grounds" (Nelson 2010, 83). 


\section{Jennifer Lackey}

The thesis that epistemic duties concern only what we ought to believe is so widely accepted that it is frequently presented without any direct argument on its behalf. A central assumption at work here is that the realm of action is governed by moral duties, and so any normative pressure to do something is ultimately moral rather than epistemic. Support for this can be found in the classic characterization of evidentialism from Conee and Feldman (1985), according to which:

EJ Doxastic attitude $D$ toward proposition $p$ is epistemically justified for $S$ at $t$ if and only if having $D$ toward $p$ fits the evidence $S$ has at $t$.

(Conee and Feldman 1985, 15)

Evidentialism is a paradigmatic instance of what Sarah Moss calls "time-slice epistemology," where the core thesis of such a view is that "what is rationally permissible or obligatory for you at some time is entirely determined by what mental states you are in at that time. This supervenience claim governs facts about the rationality of your actions, as well as the rationality of your full beliefs and your degreed belief states" (Moss 2015, 172). Moreover, according to Moss, there is an important connection between time-slice epistemology and the view that "all fundamental norms of rationality are temporally local" (Moss 2015, 172). This is clearly true of the evidentialism of Conee and Feldman, which endorses a temporally local version of epistemic duties where one's epistemic obligations are exhausted by temporally local facts.

But this view is challenged by even some of the most ordinary epistemic demands. Consider the following: suppose that a racist claims to have epistemically justified racist beliefs on the grounds that the very limited amount of cherrypicked information he is exposed to supports them. This is because he actively insulates himself from conflicting evidence, surrounds himself with like-minded racists, carefully curates his news consumption so that it reflects his already existing views, and so on. Surely, the racist's beliefs here are not only false but unjustified.

To develop this point in greater detail, note that it is standardly agreed across even deep epistemological differences that justification ${ }^{1}$ is incompatible with the presence of undefeated defeaters. The first kind is what we might call psychological defeaters, which can be either rebutting or undercutting. A psychological defeater is a doubt or belief that is had by $S$ and indicates that $S$ 's belief that $p$ is either false (i.e., rebutting) or unreliably formed or sustained (i.e., undercutting). Defeaters in this sense function by virtue of being had by $S$, regardless of their truth-value or epistemic status. ${ }^{2}$ But what cases like the selfinsulating racist show is that psychological defeaters aren't enough because you cannot get off the epistemic hook by simply failing to expose yourself to evidence you should be aware of. This would have the consequence that the person whose racism is so pernicious that he won't even put himself in situations where his beliefs might be challenged ends up epistemically in the clear precisely because of this insulation. Here is another example: a police detective has enough evidence to justifiedly believe that the innocent suspect in question 
is guilty of the murder, but only because he fails to follow up on leads that he knows might challenge his theory. Again, this is overtly epistemically problematic behavior.

This is why, in addition to psychological defeaters, normative defeaters are also incompatible with justified belief. Whereas psychological defeaters are concerned with counterevidence you in fact possess, their normative counterpart focus on counterevidence you ought to have. More precisely, a normative defeater, which can also be either rebutting or undercutting, is a doubt or belief that $S$ ought to have and indicates that $S$ 's belief that $p$ is either false (i.e., rebutting) or unreliably formed or sustained (i.e., undercutting). ${ }^{3}$ Defeaters in this sense function by virtue of being doubts or beliefs that $S$ should have (whether or not $S$ does have them). ${ }^{4}$ Normative defeaters fly in the face of time-slice epistemology by virtue of making epistemic justification a matter, not only of one's mental states at a given time, but also of the mental states one should have at a time. The epistemic duties in question here go beyond the evidence that is represented in the hearer's present psychology, and thus are temporally non-local. ${ }^{5}$

Now, it might be objected that the evidentialist can accommodate these sorts of cases by arguing that the subjects in fact have relevant evidence that can capture the epistemic deficiencies in question. In particular, they have evidence that there is evidence that should have been gathered, and this provides them with a defeater for the target beliefs without needing to invoke the concept of normative defeat. For instance, it might be said that the reason the racist is still on the epistemic hook in the above case is that he has evidence that there is evidence that he should have acquired; namely, despite the fact that he holds racist beliefs, he knows that there is counterevidence that he is ignoring. In this way, he has evidence that he should have more evidence concerning his views about the members of underrepresented groups. ${ }^{6}$

But this response does not work when people make life choices that severely restrict the evidence in their possession and, thus, aren't aware of all of the relevant consequences that follow from their choices. When white supremacists are surrounded by only sources that support their preferred racist views, they might be so insulated that they are unaware that there is in fact specific evidence that they have failed to gather. Of course, in a broad sense they might be aware that there is evidence "out there" that conflicts with their beliefs. But surely this isn't sufficient for their having evidence that there is evidence that they should have since this is arguably true of each one of us. I know right now that there is evidence "out there" that conflicts with many of my beliefs, yet this by itself doesn't prevent them from being justified. If it did, there would be very little knowledge of any kind. What we think is the problem with the racist beliefs of the white supremacists is that there is evidence they should gather, regardless of whether they are aware that it exists. When the white supremacist says, "I had no idea that there was evidence that challenged my beliefs of white supremacy," this might mean that he lacked the higher-order evidence, but it does not render his beliefs free from normative defeat. This is why evidence that one should have cannot be fully captured by evidence that one in fact has, even when higher-order evidence of the sort considered here is factored in. 


\section{Jennifer Lackey}

What all of this shows is that, even at the most basic level of appropriate sensitivity to evidence, epistemic duties go beyond what we believe to include what we do. Normative defeat doesn't just capture a failure to believe in accordance with the evidence; it also extends to a failure to collect, or expose ourselves to, evidence that we ought to have. The police detective who comfortably sits with his belief in the guilt of his suspect is not disregarding evidence that he has but, rather, is failing to follow up on leads. This involves actions, not beliefs. He ought to interview potential witnesses, pursue other suspects, consult with experts, and so on. Moreover, including a condition ruling out the compatibility of epistemic justification and normative defeat is not something that only evidentialists or internalists do. Even those with strong externalist leanings recognize that gross epistemic negligence and irrationality cannot be what leads to epistemically justified beliefs. This is a commitment that cuts across otherwise deep disagreements in epistemology.

My aim thus far has been to show that the doxastic thesis, while widely accepted, is neither plausible nor compatible with other nearly universally accepted commitments regarding normative defeat. Thus, even very traditional epistemological views grant that there are epistemic duties concerning actions.

Once we see this, it is not difficult to identify other types of actions that are demanded by epistemology. If one includes intellectual or epistemic virtues in one's view, for instance, then the cultivation of such character traits crucially involves doing things. We must identify epistemic exemplars in our community and then try to emulate their behavior, such as by practicing intellectual humility or open-mindedness. Another example concerns epistemic norms governing assertion and action. If, for instance, knowledge is the norm of assertion and action, then in order to avoid epistemic criticism, we need to assert and act only when we have the relevant knowledge. Again, there are epistemic oughts here that overtly target actions.

Once we admit epistemic oughts that govern actions into our normative framework, then how do we distinguish epistemic duties from moral ones? At least one helpful rule of thumb here is to look to what the aim is of the ought—very roughly, is it the promotion of the true or the good? ${ }^{7}$ In the case of gathering evidence relevant to normative defeat, for instance, there clearly seems to be both a truth-oriented aim and a goodness-oriented one. If the police detective ignores other suspects and leads, then he is not engaging in belief-forming practices that are truth-conducive, but he is also perpetrating moral wrongs by detaining an innocent person without sufficient grounds. Thus, there clearly seem to be both epistemic and moral duties here. Having true beliefs about suspects is valuable, and avoiding wrongful convictions is valuable. Another useful method here is to assess the nature of the criticism that agents are subject to for violating the obligations in question. If one acts on the basis of a lucky guess, then at least one dimension of the criticism is that she lacks the appropriate epistemic basis or grounds for doing so. A natural response to you heading to the airport an hour late because you merely suspected the flight was delayed is to object to your epistemic position: "you had no reason to think the flight wasn't on time!" This supports the conclusion 
that the ought at work here regarding the norm of action is epistemic, rather than moral, in nature.

\section{The Intrapersonal Thesis}

We have seen that the doxastic thesis of the standard view of epistemic duties should be rejected. What I want to do in this section is to provide a sustained challenge to the second dimension of the standard view, which I call the intrapersonal thesis: epistemic duties concern only one's own doxastic life, and thus their domain is importantly intrapersonal. According to this standard view, if, for instance, there is an epistemic duty to believe in accordance with the evidence, then this applies to me and my beliefs. Otherwise put, I have the duty to manage my own doxastic life, not that of others. This point is supported, in part, by the doxastic thesis. If epistemic duties concern only beliefs, then it seems to follow fairly naturally that my epistemic duties do not extend to others. This is especially clear if duties require voluntary control, as I rarely have voluntary control over what those around me believe.

But as was the case with the doxastic thesis, there are good reasons to reject this. To see this, notice, first, that it is undeniable that we have obligations to others and to our communities. This is so obvious in the moral case that it hardly needs to be noted. If I am walking past a very shallow pond where a toddler is drowning, and I would barely need to get my shoes wet in order to save her, I clearly have a moral obligation to do so. Failure to do so would render me subject to moral criticism-indeed, people would rightly regard me as morally callous or depraved for walking past a dying child and failing to provide assistance when it would be extremely easy for me to do so. But now consider: if I know that through very little effort on my part, I could save you from a false belief, why do I not similarly have an epistemic duty to intervene? Why should I care only about wrongness or harm when others are at issue, but not truth or knowledge? Otherwise put, whatever we take to be of epistemic value - truth, knowledge, understanding, evidence, and so on-there is simply no reason why we would have obligations to promote these ends only in ourselves. If it is valuable for me to believe truly, then it is also valuable for you to believe truly. If I have obligations to ensure this end in myself, why would I not, at least sometimes, have duties to assist others in this end? ${ }^{8}$

One may argue that while caring about, say, the truth or grounding of my own beliefs is epistemic, any responsibility that I have regarding the beliefs of others is moral. But, why? If there is a distinctively epistemic ought governing me and my doxastic life that is not ultimately reducible to the moral, it is unmotivated to say that an ought that is identical in all respects except that it concerns another person becomes moral by this very fact. I'm going to thus put forward what I call the parity thesis: if it is an epistemic duty to promote an aim in myself, then a duty that is identical except that it regards others is also epistemic. Accordingly, if it is an epistemic duty to promote true beliefs in myself or to believe in accordance with the evidence, then if I have the duty to promote true beliefs in others or to assist them in believing in accordance with 


\section{Jennifer Lackey}

the evidence, it is also epistemic. Of course, one who believes that, in general, all epistemic oughts are ultimately moral oughts is not violating the parity thesis; instead, one who believes that epistemic oughts are ultimately moral oughts only when others are at issue is.

This point may be made clearer by distinguishing my view from an importantly different one. On this alternative picture, there is a general moral duty to promote the good, and knowledge is just one of the goods that this moral duty covers. In contrast, my view holds that the source of the normativity found in epistemic duties is epistemic in the first order, not derivative from a more general moral duty. In other words, the end of the duty in question is distinctively epistemic in nature, where the end in question may be truth, knowledge, evidence-enriching, and so on. In this way, epistemic duties aim to promote, say, knowledge, in their own right, rather than goodness through the promotion of knowledge.

A related point that is frequently assumed, often tacitly so, is that if having a true belief or knowledge matters, say, practically or morally, then this shows that the duty at work cannot be epistemic. For instance, consider, again, a police detective who falsely believes that his suspect is guilty of murder. If I have evidence that would put pressure on the detective's false belief, it seems that I have a duty to share this with him. What is the nature of the duty? Clearly, a suspect being wrongfully accused or convicted of a violent crime is a serious moral wrong that causes a great deal of harm, and so there is undoubtedly moral pressure to do so. But surely this doesn't rule out there also being an epistemic duty to share the evidence. It matters, not only that the detective pursue the right suspect, but also that he have true beliefs and knowledge about the situation. The moral value of avoiding perpetrating a moral wrong or harm does not need to swamp or rule out the epistemic value of him having a true belief or knowledge about the murder. Consider the intrapersonal case: if I am the police detective in question, I have moral duties to pursue the right suspect and also epistemic duties to have true beliefs about the matter. We would not say that the pressure to believe in accordance with the evidence in the intrapersonal case is moral when the stakes are high. In other words, my epistemic duties do not become moral ones simply because their truth value bears on moral matters or has practical urgency. As the parity thesis makes clear, we should say the same thing in the interpersonal case. Given this, it is not an objection to the claim that there are interpersonal epistemic duties to point out that, in many of the most compelling cases, there are moral and practical stakes involved that can explain the intuition that we should intervene. Yes, there are moral and practical stakes in such cases, as there are with most of our own beliefs. But none of this shows that there are not epistemic duties in either the intrapersonal or interpersonal cases.

\section{Epistemic Duties Regarding Others}

I have been discussing there being an epistemic duty to "intervene" in the lives of others. Some examples I have offered include correcting a false belief and 
sharing relevant evidence. Following discussions in ethics, we might propose the following as an umbrella principle ${ }^{9}$ for such epistemic duties regarding others:

\section{Interpersonal Epistemic Duties (IED)}

If it is in our power to prevent something epistemically bad from happening through very little effort on our part, we ought, epistemically, to do it.

Note two features about IED: first, it emphasizes the prevention of epistemic badness, which distinguishes it from the moral version; and, second, it makes the ought dependent on its satisfaction requiring very little effort. This is to satisfy the over-demandingness constraint-just as there is said to be a "limit to how great a sacrifice morality ... can legitimately demand of agents," ${ }^{10}$ so, too, there is a limit to how great a sacrifice epistemology can legitimately demand of agents.

Inow want to highlight two broad categories of epistemic badness concerning other members of our communities that the IED captures. First, there are what we might call positive epistemic interpersonal duties. These involve promoting the epistemic flourishing of others, such as their true beliefs, access to evidence, possession of knowledge, the cultivation of epistemic virtues, understanding, wisdom, and so on. I am endorsing a pluralist view here, according to which there are many epistemic ends or aims that need not be reducible to others. In this way, it may be important to promote, say, the truth in some contexts, epistemic virtues in others, and wisdom in still others. Moreover, positive epistemic interpersonal duties might be understood as subsumed under the IED by preventing the epistemic badness of false beliefs, inadequate evidence, ignorance, the cultivation of epistemic vices, and so on. Thus, if it is in my power to prevent, say, a false belief or ignorance in you through very little effort on my part, I ought, epistemically, to do it.

We might promote these positive aims, or prevent the badness of their absence, through — very broadly speaking — two sorts of actions: objecting and informing/ educating. In other work, ${ }^{11}$ I have provided an account of the epistemic duty to object according to which this is an imperfect epistemic duty to object to assertions that one takes to be false or unwarranted. I understand objections as assertions that are added to a conversational context with the aim of adding to the communal pool of evidence. ${ }^{12}$ Objections here do not require the likelihood of acceptance. I might discharge my duty to object even if I know in advance that acceptance will be very unlikely, perhaps because the views of the other members of the conversation are settled and strong. In this way, objecting need only require the intention to have your dissenting voice noted. Moreover, adding to the communal pool of evidence need not involve the contribution of new information. One can add to the communal pool by strengthening the body of evidence, deepening it, and so on, simply through a new voice of dissent.

Objecting generally involves assertions with negative content-your suspect is not the person who committed the murder, climate change is not the result of entirely natural factors, and so on. In contrast, informing or educating typically 
includes assertions with positive content-the eyewitnesses at the scene of the crime point to this other suspect, the recent warming of the Earth is connected to rising $\mathrm{CO} 2$ emissions that are the result of burning carbon-based materials, and so on. Of course, it need not be the case that only one or the other is demanded at any given time, as some contexts might call for both objecting and educating. If I have evidence that proves that the suspect the police detective has in custody is innocent, I might be epistemically obligated both to correct his false beliefs and to inform him about the relevant evidence. In response to a climate change denier, there might be the epistemic duty both to object to her ignorance on the matter and also to educate her about the support for there being dangerous anthropogenic interference with the climate system.

I am focusing specifically on objecting and informing that target the propositional content of an assertion. It might be the case that what I say here applies not only to what is said, but also to how it is said, who it is said by, and so on. For instance, I might have the duty to object to what you're doing, and the normative pressure can be either moral or epistemic. For instance, I have the moral duty to object, both if you make a racist remark and if you make a non-racist remark, but in blackface. Similarly, I have the epistemic duty to object both if you say that Whole Foods is to the left and if you don't say this, but you put your left-hand directional on in the car. In such cases, it is clear that the moral and epistemic duties to object can apply not only to the propositional content of our assertions, but also to our actions. For the sake of clarity, however, I will restrict my attention to duties to object and educate with respect to the content of assertions. ${ }^{13}$

Second, there are what we might call negative epistemic interpersonal duties. While their positive counterpart involves promoting the epistemic flourishing of others, these involve preventing members of our communities from being the victims of epistemic wrongs or harms. Testimonial injustice, for instance, is standardly understood as giving a speaker less credibility than the evidence supports because of a bias that targets her social identity. ${ }^{14} \mathrm{~A}$ woman who reports a sexual assault and is not believed by the detective simply because he believes that women lie about these sorts of things is the victim of testimonial injustice: she is given less credibility than the evidence supports in virtue of the detective's sexism targeting her gender identity. In such a context, it might be an epistemic duty to prevent the sexual assault victim from suffering the harm of testimonial injustice, in addition to the obvious moral duties involved in such a situation. Similar considerations apply to other epistemic wrongs that can harm members of our community. For instance, Kristie Dotson develops an account of epistemic oppression, which "refers to persistent epistemic exclusion that hinders one's contribution to knowledge production" (Dotson 2014, 115). According to Nora Berenstain:

Epistemic exploitation occurs when privileged persons compel marginalized persons to produce an education or explanation about the nature of the oppression they face. Epistemic exploitation is a variety of epistemic oppression marked by unrecognized, uncompensated, emotionally taxing, 
coerced epistemic labor. It maintains structures of oppression by centering the needs and desires of dominant groups and exploiting the emotional and cognitive labor of members of marginalized groups who are required to do the unpaid and often unacknowledged work of providing information, resources, and evidence of oppression to privileged persons who demand it-and who benefit from those very oppressive systems about which they demand to be educated.

(Berenstain 2016, 570, emphasis added)

Emmalon Davis understands epistemic appropriation as follows:

Call th[e] first harm epistemic detachment. When epistemic detachment occurs, the intercommunal pool is expanded to incorporate new epistemic resources (e.g., concepts, interpretations, stories, and meanings), but the participatory role of marginalized contributors in the process of knowledge production is obscured. While epistemic detachment may occur independently from other epistemic harms, it is often compounded by a second harm, namely, epistemic misdirection. Epistemic misdirection occurs when epistemic resources developed within, but detached from, the margins are utilized in dominant discourses in ways that disproportionately benefit the powerful. That is to say, the benefits associated with the epistemic contributions of the marginalized are misdirected toward the comparatively privileged. Taken together, epistemic detachment and epistemic misdirection constitute what I am calling epistemic appropriation.

(Davis 2018, 705)

In Lackey (2020), I provide an account of agential testimonial injustice, which occurs when a speaker's testimony has been obtained in a way that denies or bypasses her epistemic agency and is then afforded an unwarranted credibility excess. A paradigmatic instance of this occurs when a false confession is given a massive amount of credibility in the criminal justice system even when the confession was extracted via coercion, manipulation, or deception. And Lauren Leydon-Hardy identifies epistemic infringement as "a category of epistemic misconduct that works through the systematic contravention of interpersonal social and epistemic norms in a manner that subverts the epistemic agency of targeted individuals" (Leydon-Hardy forthcoming). For instance, predatory grooming and gaslighting contravenes norms of trust, often in close relationships, in a way that leads the targeted individuals to doubt their own experiences and cognitive faculties.

I don't intend for this list of epistemic wrongs to be exhaustive. Instead, my aim is to highlight a selection of the negative epistemic interpersonal duties that have been identified. According to the IED, then, if it is in our power to prevent someone from being the victim of, say, epistemic oppression, epistemic exploitation, or agential testimonial injustice through very little effort on our part, we ought, epistemically, to do it. 
One question that may be raised with respect to both positive and negative interpersonal duties is: why are we on the normative hook when it comes to the epistemic lives of others? By way of response, I will note three points. First, as was suggested earlier, the alternative position found in the intrapersonal thesis seems to be grounded in nothing more than a bias in favor of our own doxastic lives. If I have other-regarding duties in general, why do they cease when it comes to the epistemic? Second, the IED has intuitive force. Just as I seem to have moral duties to help others if it would take very little effort on my part, so, too, does it seem that I have epistemic duties to share evidence with them, help them promote intellectual open-mindedness when needed, prevent them from being victims of epistemic oppression, and so on. Finally, promoting the epistemic flourishing of others, and preventing them from suffering epistemic wrongs, increases the overall epistemic success and well-being of our communities. Living in a world with more true beliefs, fewer false ones, greater depths of wisdom, less epistemic oppression and exploitation, and so on is a win-win for everyone. Consider the epistemic chaos being wreaked on our lives by the intentional spread of fake news online. Indeed, the damage has been so severe that democracies across the globe have been threatened in unimaginable ways. Thus, not only do we all benefit when we maximize epistemic goods, and minimize epistemic wrongs, but we all suffer when we fail to do so. This makes clear that we ought to care about the epistemic well-being of our communities and information systems.

Related to this last point, our epistemic duties regarding others, both positive and negative, apply to both individuals and groups, as well as in-person and virtual interactions. If I am part of an online discussion and there is a loud group of climate-change deniers espousing their views, I may have the epistemic duty to present contrary evidence. If I see that the trans community is being targeted for systematic acts of epistemic oppression on Twitter, I may have the epistemic duty to jump into the discussion to make space for their voices. Indeed, with the increased use and power of social media, much of our interaction is with online groups or communities, such as our Facebook "friends" and our Twitter followers.

As emphasized earlier, these obligations are almost always also moral in nature. I have the duty to make space for the voices of members of the trans community because there are both good moral and epistemic reasons to do so. I should care about their flourishing as both humans and as epistemic agents; I should prevent the exclusion of their views both because it is morally and epistemically harmful to them and to the community; I should promote the visibility of their perspectives because doing so helps spread truth and knowledge and understanding. But for those who cannot see epistemic force when moral force is also at issue, consider this: just as we correct our own beliefs, even when they are practically and morally irrelevant, the corrections we offer to others need not be tied to any practical or moral question they currently face. In other words, our objections can be grounded in strong epistemic reasons, even in the absence of moral or practical considerations. Suppose, for instance, that I know that a dataset that a colleague in the social sciences 
believes is inaccurate, though it is unlikely that there will be any practical or moral repercussions from this belief. There is still normative pressure to correct this colleague's belief, especially if doing so requires very little effort on my part. Upon learning that I knew the dataset was false and yet failed to say anything, we would regard my colleague's anger or disappointment with me as perfectly justified. Moreover, this assessment would persist, even if I were to emphasize that I was aware that nothing practically or morally important depended on her belief being true. This highlights the distinctively epistemic dimension of the duty to object.

One final point I would like to address is this: do I have an obligation to intervene whenever I see someone in epistemic need? If so, doesn't this have the consequence that I would be spending all day every day either correcting people's false beliefs or helping them avoid epistemic wrongs? Consider how much information we come across in our daily lives via Facebook, Twitter, news outlets, op-eds, meetings, conversations, and so on. Now consider how many times in this process we encounter false beliefs or inadequate evidence or voices being drowned out because of biases. Doesn't my view have the consequence that we need to step in with all of these cases and thus that epistemology is too demanding - that it is asking each of us to make unreasonable contributions to our communities? I have addressed this question in detail elsewhere, ${ }^{15}$ so I will simply gesture at a response here: epistemic duties regarding others can be understood as imperfect in nature. While there is disagreement over some of the details, at the heart of the notion of an imperfect duty-paradigmatically including charity, mercy, gratitude, beneficence, and the like-is the idea that discretion and latitude are allowed in their fulfillment. ${ }^{16}$ Charity, for instance, might require that I donate to the poor, but it doesn't specify to whom or how much. I may fulfill this duty by sending $\$ 200$ to Oxfam every month or by sending $\$ 500$ to Habitat for Humanity twice per year. Contrast this with the classic perfect duty of promise-keeping, where there is no discretion or latitude regarding how I satisfy it. If I promise to visit Rose in the hospital on Tuesday, then I have a duty to do just this. It won't do to instead visit George in the hospital on Tuesday, or to visit Rose at home on Thursday. ${ }^{17}$ Indeed, this leads some to understand imperfect duties as being disjunctive in nature. Unlike my duty to keep my promise, which has the form of the duty to do act X, my duty to donate to the poor has the form of the duty to do act $<\mathrm{X}$ or $\mathrm{Y}$ or $\mathrm{Z}>.^{18}$ But regardless of whether imperfect duties admit of such a disjunctive explanation, the key point is that there is latitude in their satisfaction.

If epistemic duties to others are imperfect in nature, ${ }^{19}$ then there is latitude allowed in their fulfillment. Just as I might discharge my duty to engage in charitable giving by donating $\$ 200$ to Oxfam every month or by sending $\$ 500$ to Habitat for Humanity twice per year, so, too, I might discharge my epistemic duty to object by correcting some friends on Facebook or by writing an op-ed calling out Trump's lies or by engaging with my neighbor about climate change. It is not necessary for me to do all of these, nor is it required that I do them all of the time. Understanding our epistemic duties to others as imperfect 
in nature thus provides a first step toward addressing the worry that the view espoused here is far too epistemically demanding.

\section{Conclusion}

I have argued that we have other-regarding epistemic duties, just as we have other-regarding moral duties. If, through very little effort on my part, I could promote your epistemic flourishing, or prevent you from being the victim of epistemic wrongs, then, epistemically, I ought to do so. Such duties can be helpfully understood as imperfect in nature, which enables the view defended here to avoid worries about overdemandingness. Thus, not only is epistemology far more social than has previously been recognized, but it also bears deep and important similarities to ethics.

\section{Notes}

1 I'm focusing on justification here, but what I say can apply equally to knowledge.

2 For various views of what I call psychological defeaters see, for example, BonJour (1980 and 1985), Nozick (1981), Pollock (1986), Goldman (1986), Plantinga (1993), Lackey (2008), Bergmann (1997), and Reed (2006).

3 It should be noted that a defeater may itself be either defeated or undefeated. Suppose, for instance, that Harold believes that there is a bobcat in his backyard because he saw it there this morning, but Rosemary tells him, and he thereby comes to believe, that the animal is instead a lynx. In such a case, the justification that Harold had for believing that there is a bobcat in his backyard has been defeated by the rebutting belief that he acquires on the basis of Rosemary's testimony. But since psychological defeaters can themselves be beliefs, they, too, are candidates for defeat. For instance, suppose that Harold consults a North American wildlife book and discovers that the white tip of the animal's tail confirms that it was indeed a bobcat, thereby providing him with a defeater-defeater for his original belief that there is a bobcat in his backyard. And, as should be suspected, defeater-defeaters can also be defeated by further doubts and beliefs, which, in turn, can be defeated by further doubts and beliefs, and so on. Similar considerations involving evidence, rather than doubts and beliefs, apply in the case of normative defeaters. When one has a defeater for one's belief that $p$ that is not itself defeated, one has what is called an undefeated defeater for one's belief that $p$. It is the presence of undefeated defeaters, not merely of defeaters, that is incompatible with justification and, thus, knowledge.

4 For discussions involving what I call normative defeaters, approached in a number of different ways, see BonJour (1980 and 1985), Goldman (1986), Fricker (1987 and 1994), Chisholm (1989), Burge (1993 and 1997), McDowell (1994), Audi (1997 and 1998), Williams (1999), Lackey (2008), BonJour and Sosa (2003), Hawthorne (2004), and Reed (2006). What all of these discussions have in common is simply the idea that evidence can defeat knowledge (justification) even when the subject does not form any corresponding doubts or beliefs from the evidence in question.

5 See also Goldberg (2017).

6 I'm grateful to Kevin McCain for pressing this objection.

7 As will be clear later, I am assuming a pluralist view in this chapter according to which there are many epistemic ends, but I focus only on truth here for the sake of simplicity. 
8 Perhaps unsurprisingly, there is virtually no work in the epistemological literature devoted specifically to understanding our epistemic duties to others. The literature on testimony focuses on our obligations as speakers, but rarely is this framed in terms of responsibilities that involve the epistemic needs of those around us. A rare exception is Jason Kawall's (2002). As I will discuss later in this chapter, there is an explosion of interest in social epistemology regarding the sorts of epistemic harms that we can inflict on one another, such as acts of epistemic injustice. To the extent that it is tacitly assumed that we ought not inflict such acts on others, then this work might be construed as involving interpersonal epistemic duties. I will flesh this out in more detail in the next section.

9 Principles of this sort are found throughout discussions in ethics, but one of the most well-known is in Singer $(1972,231)$.

10 See Murphy $(1993,268)$.

11 See Lackey (2018a, 2018b, 2020, forthcoming).

12 In my (2018b), I actually say that objections are assertions that are added to a conversational context with the aim of correcting the record. Since one can object even when one knows that there is no chance of successfully correcting the record, I think it is better to emphasize adding to the communal pool of evidence.

13 I'm grateful to Karen Bennett for this point.

14 See Fricker (2007).

15 See Lackey (2018b and forthcoming).

16 See, for instance, Schroeder (2013).

17 Of course, latitude might be built directly into the content of a promise. I might, for instance, promise to Rose that someone in my family will visit her in the hospital this week, which might be fulfilled by my visiting her on Monday, or my daughter visiting her on Tuesday, and so on. But this is a separate point than latitude being tied to the fulfillment of the duty itself.

18 See, for instance, Price (1974). See Stocker (1967) for an argument that virtually all duties are infinitely disjunctive, and hence this cannot adequately capture imperfect ones.

19 For another account of imperfect epistemic duties, see Stapleford (2013).

\section{References}

Audi, Robert. 1997. "The Place of Testimony in the Fabric of Knowledge and Justification.” American Philosophical Quarterly 34: 405-422.

Audi, Robert. 1998. Epistemology: A Contemporary Introduction to the Theory of Knowledge. London: Routledge.

Berenstain, Nora. 2016. “Epistemic Exploitation.” Ergo 3: 569-590.

Bergmann, Michael. 1997. "Internalism, Externalism and the No-Defeater Condition." Synthese 110: 399-417.

BonJour, Laurence. 1980. "Externalist Theories of Epistemic Justification.” Midwest Studies in Philosophy 5: 53-73.

BonJour, Laurence. 1985. The Structure of Empirical Knowledge. Cambridge, MA: Harvard University Press.

BonJour, Laurence, and Sosa, Ernest. 2003. Epistemic Justification: Internalism vs. Externalism, Foundations vs. Virtues. Oxford: Blackwell Publishing.

Burge, Tyler. 1993. "Content Preservation.” Philosophical Review 102: 457-488.

Burge, Tyler. 1997. "Interlocution, Perception, and Memory." Philosophical Studies 86: $21-47$. 


\section{Jennifer Lackey}

Chisholm, Roderick M. 1989. Theory of Knowledge, 3rd edition. Englewood Cliffs, NJ: Prentice-Hall.

Conee, Earl, and Feldman, Richard. 1985. "Evidentialism.” Philosophical Studies 48: $15-34$.

Davis, Emmalon. 2018. “On Epistemic Appropriation.” Ethics 128: 702-727.

Dotson, Kristie. 2014. “Conceptualizing Epistemic Oppression.” Social Epistemology 28: $115-138$.

Fricker, Elizabeth. 1987. "The Epistemology of Testimony." Proceedings of the Aristotelian Society, supp. vol. 61: 57-83.

Fricker, Elizabeth. 1994. "Against Gullibility.” In Bimal Krishna Matilal and Arindam Chakrabarti (eds), Knowing from Words. Dordrecht: Kluwer Academic Publishers, 125-161.

Fricker, Miranda. 2007. Epistemic Injustice: Power and the Ethics of Knowing. Oxford: Oxford University Press.

Goldberg, Sanford. 2017. "Should Have Known.” Synthese 194: 2863-2894.

Goldman, Alvin I. 1986. Epistemology and Cognition. Cambridge, MA: Harvard University Press.

Hawthorne, John. 2004. Knowledge and Lotteries. Oxford: Oxford University Press.

Hawthorne, John, and Stanley, Jason. 2008. "Knowledge and Action." Journal of Philosophy 105: 571-590.

Kawall, Jason. 2002. “Other-Regarding Epistemic Virtues.” Ratio 15: 257-275.

Lackey, Jennifer. 2008. Learning from Words: Testimony as a Source of Knowledge. Oxford: Oxford University Press.

Lackey, Jennifer. 2018a. "Silence and Objecting." In Casey Johnson (ed.), Voicing Dissent: The Ethics and Epistemology of Making Disagreement Public. Abingdon, Oxon: Routledge: 82-96.

Lackey, Jennifer. 2018b. "The Duty to Object." Philosophy and Phenomenological Research: doi: 10.1111/phpr.12563.

Lackey, Jennifer. Forthcoming. "When Should We Disagree about Politics?” In Elizabeth Edenberg and Michael Hannon (eds), Political Epistemology.

Lackey, Jennifer. 2020. "False Confessions and Testimonial Knowledge," Journal of Criminal Law and Criminology 110: 43-63.

Leydon-Hardy, Lauren. Forthcoming. "Predatory Grooming and Epistemic Infringement.” In Jennifer Lackey (ed.), Applied Epistemology. Oxford: Oxford University Press.

McDowell, John. 1994. "Knowledge by Hearsay.” In Bimal Krishna Matilal and Arindam Chakrabarti (eds), Knowing from Words. Dordrecht: Kluwer Academic Publishers, 195-224.

Moss, Sarah. 2015. “Time-Slice Epistemology and Action under Indeterminacy.” Oxford Studies in Epistemology 5: 172-194.

Murphy, Liam B. 1993. "The Demands of Beneficence." Philosophy and Public Affairs 22: 267-292.

Nelson, Mark T. 2010. “We Have No Positive Epistemic Duties.” Mind 119: 83-102.

Nozick, Robert. 1981. Philosophical Explanations. Cambridge, MA: Belknap Press.

Plantinga, Alvin. 1993. Warrant and Proper Function. Oxford: Oxford University Press.

Pollock, John. 1986. Contemporary Theories of Knowledge. Totowa, NJ: Rowman \& Littlefield.

Price, Richard. 1974. A Review of the Principal Questions in Morals, 2nd revised edition. Oxford: Oxford University Press. 
Reed, Baron. 2006. "Epistemic Circularity Squared? Skepticism about Common Sense." Philosophy and Phenomenological Research 73: 186-197.

Schroeder, S. Andrew. 2013. "Imperfect Duties, Group Obligations, and Beneficence." Journal of Moral Philosophy 11: 557-584.

Singer, Peter. 1972. "Famine, Affluence, and Morality." Philosophy and Public Affairs 1: 229-243.

Stapleford, Scott. 2013. "Imperfect Epistemic Duties and the Justificational Fecundity of Evidence." Synthese 190: 4065-4075.

Stocker, Michael. 1967. “Acts, Perfect Duties, and Imperfect Duties." Review of Metaphysics 20: 507-517.

Williams, Michael. 1999. Groundless Belief: An Essay on the Possibility of Epistemology, 2nd edition. Princeton, NJ: Princeton University Press.

Williamson, Timothy. 2000. Knowledge and its Limits. Oxford: Oxford University Press.

Williamson, Timothy. 2005. "Contextualism, Subject-Sensitive Invariantism and Knowledge of Knowledge.” Philosophical Quarterly 55: 213-235.

Wrenn, Chase B. 2007. "Why There Are No Epistemic Duties.” Dialogue 46: 115-136. 


\section{Index}

Adler, J. 188-189, 216, 277-278

Aglioti, S.M. 144

Ahlstrom-Vij, K. 202, 205-206

Aikin, S. 42, 278

aim of belief 116, 118-119

Alston, W. 7, 16, 19-21, 23-25, 44, 57-58, 76, 94, 134, 141, 161-164, 167-168, 172, 234, 263, 269, 281

Altemeyer, B. 234

alternative possibilities 81,166

Alvarez, M. 216

Amir, Y. 141

Amodio, D.M. 136

Annis, D. 277

Appleby, R.S. 222, 233-234

APS (autobiographical or personally significant) stories 254-259, 261-265

Archer, S. 108

Argument from Suspension 13

Aronson, E. 234

Ashburn-Nardo, L. 139

Ashmore, R.D. 141

Audi, R. 76, 277, 292

Axtell, G. 121

Ayer, A.J. 156, 159

Azar, B. 139

Baehr, J. 113, 117, 149-151, 181-182, 189,234

Baier, A. 251

Baker, L.R. 188

Bales, R.E. 76

Ballantyne, N. 140, 157

Banaji, M.R. 140

Barnes-Holmes, D. 139

Basu, R. 33, 35, 37

Battaly, H. 181, 234

Baurman, M. 233

Beddor, B. 157

Berenstain, N. 288-289

Bergmann, M. 169, 292
Berto, F. 75

Bertrand, M. 139

Beyerlein, K. 233

bias: explicit 127, 138; implicit 125-141, 162,164

Bird, A. 107

Blair, I.V. 139

blame 7, 20-22, 25, 29-41, 58-59, 103, 122, 128-129, 132-135, 137-141, 149, 161-164, 167-172, 184-186, $188,221,223,225-127,229-233,254$

Blanchard, T. 234

Bloom, P. 256

Bodenhausen, G.V. 139

Bondy, P. 274

BonJour, L. 292

Booth, A. 26, 95, 227, 234

Bortolotti, L. 255-256

Brady, M.S. 234

Brandom, R. 277-278

Brandt, R.B. 234

Brewer, M.B. 141

Briñol, P. 135

Brogaard, B. 176

Bronner, B. 277

Brown, J. 40-41, 204

Burge, T. 292

Bykvist, K. 96-97

Carney, D.R. 139

Caroll, L. 122

Cassam, Q. 233-234

Chisholm, R. 76, 92, 94, 128, 292

Chrisman, M. 48-49, 51, 57, 59, 162

Christensen, D. 186, 203

Chuard, P. 58

Clifford, W.K. 1, 26, 35-36, 39, 156, 159,185

Cloos, C.M. 149-151, 158

Coates, J. 41, 59

Code, L. 278 
Coles, R. 254

Conee, E. 25, 92, 114, 121-122, 146-147, 202, 205, 216, 282

Cook, S. 141

Corlett, J.A. 139

Côté-Bouchard, C. 49-50, 56, 59

Cowie, C. 209, 216

Crenshaw, M. 233

Cubitt, S. 256

Cunningham, G.B. 233

Dancy, J. 75

Das, E. 256

Dascal, M. 76

Dasgupta, N. 141

David, M. 139

Davis, E. 289

De Houwer, J. 139

Demireva, N. 262

DePaul, M. 139

DeRose, K. 113, 117, 157-158, 204

Descartes, R. 1

Devine, P.C. 136

DiPaolo, J. 58

Dorst, K. 202-203, 205

Dotson, K. 274, 288

Dougherty, T. 113, 158

Dovidio, J.F. 141

doxastic: control 84, 162-163, 167, 172, 184; involuntarism 22-25, 45, 58, 227; omission 11-12, 14; self-control 82-89, 91; voluntarism 58, 82, 86, 92 , 94, 106, 115, 157, 171-172, 184, 187,

Doxastic Puzzle 45-46, 50-52, 55, 59

DTR (Duty to Reflect) 114, 116, 118-121

Dunn, J. 202

Dutant, J. 202-203, 205

duty: to believe $8-12,14,19,32,97$, 108, 113-114; doxastic 29, 37, 121-122, 128, 134, 139-140, 162, $168,170-171,185,226,263,281$, 285; moral 30, 33, 38-40, 95-96, 127-130, 134, 139, 189, 282, 284, 286, 288, 290, 292

Easwaran, K. 202-203

Elgin, C. 188

Emerson, M.O. 233

Engel, P. 216

Engelsma, C. 277

epistemic irresponsibility 147-151, 155

European Parliament 262

evasive strategy $1,46,50-52,54-57,59$ evidentialism 8-14, 17-19, 25-26, 59, 76, 103, 113-114, 117-118, 120-122, 146-155, 157-158, 282; C-constrained 9, 19; CF-constrained 11-12, 14, 18; F-Constrained 19; moderate 11-13, 18; unconstrained $8,11,19$

Fassio, D. 216

Faulkner, P. 251

Fazio, R.H. 139

Feldman, R. 16-18, 25-26, 31, 38, 51-52, 92, 94, 96, 98, 113-115, 117, 122, 139, 146-147, 158, 202, 205, $216,263,277,282$

Finlay, S. 59

Fischer, J.M. 234

Firmin, M.W. 233

Firth, R. 139, 202

Fitelson, B. 202-203, 252

Flowerree, A. 27

Fogelin, R. 278

Foley, R. 202

Follenfant, A. 140

Foot, P. 58

Frankish, K. 139

Freeman, J. 278

Fricker, E. 292

Fricker, M. 34-35, 234, 274, 293

Friedman, J. 58

Friedman, M. 234

Fumerton, R. 75, 122, 278

Gardiner, G. 33, 35

Gary, M.L. 48

Gawronski, B. 139

Gendler, T.S. 139

Gesthuizen, M. 262

Ghijsen, H. 203

Gietel-Basten, S. 262

Ginsburg, G. 234

Glaser, J. 139

Glüer, K. 252

Goldberg, S. 36, 157, 227, 234, 292

Goldman, A. 158, 203, 234, 292

Govier, T. 278

Graham, P. 58, 203

Greco, D. 31, 168

Greco, J. 93

Gregg, A.P. 140

Grice, P. 9-10, 25

Grimm, S. 47-48, 175-176, 187-188

Grootendorst, R. 272

Haack, S. 139

Hall, R.J. 263-264 
Hardin, C.D. 139

Hardin, R. 233-234, 252

Harman, E. 234

Harman, G. 200, 204

Harmon-Jones, E. 136

Hartman, D. 233

Hasan, A. 75

Hattiangadi, A. 96-97

Hawley, K. 242-243, 251

Hawthorne, J. 292

Hazlett, A. 58

Heikes, D. 274, 278

Heil, J. 94

Heller, M. 94

Herman, B. 41

Hess, M.P. 139

Hieronymi, P. 140-141, 251

Higgins, E.T. 141

HM Government 233

Holroyd, J. 127, 136-137, 139-141

Holton, R. 242, 251

Hookway, C. 274

Horgan, J. 233

Horowitz, S. 200-201

Houwer, J.D. 139

Howard, C. 252

Howard-Snyder, D. 181

Huebner, B. 140

Huemer, M. 122

Hughes, S. 139

Hume, D. 67, 75, 90, 93

Hunsberger, B. 234

Hunter, D. 34

Hyman, J. 203

inference to the best explanation 94, 99-102, 106

infinity problem $8-9,25$

instrumentalism 2, 208-211, 216

intellectual humility 90, 180-182, 188,284

intellectual virtue $37,87-89,174,179$, $185,225,234$

intentionality 22

intrinsicalism 2, 208-211, 215-216

Inzlicht, M. 141

Jackson, E. 59, 92

Jefferson, A. 256

Jenkins, C. 202

Jetten, J. 140

Johnson, C.R. 139, 263-264

Johnson, R. 278

Jones, K. 242-244, 251-252

Jost, J.T. 139
Joyce, J. 203

Joyce, R. 58, 105, 108

justification: deontological 7-8, 16, 19, 20, 22, 24, 44, 172, 184-185, 187, 227; epistemic 1-3, 7, 15-17, 19-20, $25,44,64,66,68,71-72,74$, 113-114, 117, 146-147, 150-1151, 154-57, 172, 184, 187, 269, 275, 283-284; non-deontological 7-8, 20; robust $2,146,154-159$

Kant, I. 47, 66, 92

Kawakami, K. 141

Kawall, J. 293

Keller, S. 244, 251-252

Kelly, D. 131, 140-141

Kelly, T. 18-19, 26-27, 216

Kelp, C. 203

Kerkhof, P. 256

King's Fund, The 261

Kirwan Institute for Race and Ethnicity 125,139

Klausen, S. 234

Klein, P. 278

Kornblith, H. 51, 57, 157-158

Kratzer, A. 48

Kruse, A. 263

Kuiper, J. 256

Kvanvig, J. 139, 188

Kwong, J. 188

Lackey, J. 3, 95, 139, 157, 243, 251, 289, 292-293

Lammenranta, M. 277-278

Lankford, A. 233

Lasonen-Aarnio, M. 204

Lazar, S. 203-204

Leary, S. 169

Leite, A. 56, 216, 269, 277-278

Leitgeb, H. 204

Lenman, J. 76

Leslie, S.J. 263

Levy, N. 95, 139-141

Leydon-Hardy, L. 289

Littlejohn, C. 2, 41, 49-50, 56, 59, 202-205

Locke, J. 1, 76, 172, 199-200, 202, 263-264

Loewenstein, G. 256

Lovibond, P.F. 139

Mackie, J.L. 47

Macrae, C.N. 140

Madva, A. 139, 141

Maffie, J. 95, 98, 107-108 
Maguire, B. 26, 57-58

Makinson, D. 203

Mandelbaum, E. 139, 141

Markovits, H. 256

Marty, M.E. 222, 233

Marušić, B. 37, 103

Matheson, J. 2, 122, 157-158

Mathiesen, K. 234

McAdams, D.P. 254

McCain, K. 118, 120-123, 157-159, $172,202,205,292$

McCaslin, M.J. 135

McConnell, A.R. 139

McDowell, J. 292

McHugh, C. 58, 108, 168-169, 172, 234

McKenna, M. 140

McLeod, C. 251

McPherson, T. 47, 53, 59

McRae, E. 188

Medina, J. 274

Meiland, J. 108

Mele, A.R. 93

Melton, E.N. 233

Meylan, A. 2, 227, 234

Miller, M.K. 234

Miller, N. 141

Milne, A.B. 188

Milne, P. 198

Miracchi, L. 114, 117, 156, 158, 204

Mitchell, C. 139

Monteith, M. 139

Moore, A. 256

Moran, R. 251

Moss, S. 204, 282

Mulheirn, I. 266

Mullianathan, S. 139

Mullin, A. 251

Murdoch, I. 254

Murphy, L.B. 293

Nadolny, D. 141

Nagel, T. 59

NAP (Not All Propositions) 114-116

Nash, C. 254

NDI (No Duty to Inquire) 114 , 118-121

Nelkin, D. 205

Nelson, M.T. 2, 12-14, 25-26, 75-76, $95,121,281$

Nickel, P.J. 251-252

Nolfi, K. 58, 216

Noordhof, P. 97, 103

No Reasons Argument 55, 57

normative reason 46, 52-57, 59, 68, 108, 245-246 norms: knowledge 192, 194, 197; truth 197, 199

Nottelmann, N. 92, 162, 227, 234

Nozick, R. 292

O’Brien, L. 99

Oddie, G. 198

O'Grady, P. 175-176, 188

Ohler, A. 278

Oliveira, L.R. 1-2, 59

Olsen, K. 203-204

Olson, D. 94

O’Neil, C. 251

open-minded 2, 37, 114, 128, 174, 179-188, 225, 228, 284, 290

Oudenampsen, M. 233

ought implies can 45, 106, 115, 161, 167

Owens, D. 216

Pandora's Box Argument 14, 16

Papineau, D. 58

Parfit, D. 53, 59, 203, 216

parsimony $94,102,105-106$

Peck, T.C. 141

Peels, R. 3, 162, 167, 172, 234

peer disagreement 81, 89-91, 93, 153, 158, 174, 184, 186-187, 192, 223

Peirce, C.S. 273

Pereboom, D. 27

Peregrin, J. 278

permissivism 12-19, 26-27, 59, 75

Perrine, T. 59

Peters, U. 130, 132

Pettit, P. 251

Petty, R.E. 135

Phillips, D. 59

Phills, C.E. 141

Pickard, H. 41

Plant, E.A. 136

Plantinga, A. 281, 292

Policy Institute at King's 261

Pollock, J. 170, 292

Poston, T. 159

Pratkanis, A. 234

Prederi 262

Price, R. 293

Priest, G. 75

Pritchard, D. 176-177, 188

Radutzsky, M. 254

Raleigh, T. 204

Ravizza, M. 234

Raz, J. 59

Reed, B. 292

reflective equilibrium $87-88,91$ 
Regan, D. 203

Reisner, A. 3, 250, 252

Rescher, N. 278

Rescorla, M. 270, 277-278

Rettler, L. 2, 135, 140-141

Rholes, W.S. 234

Ric, F. 140

Richardson, J.T. 234

Rinard, S. 26, 169

Rivera-López, E. 234

Roeber, B. 27, 92, 162

Roedder, E. 131, 140-141

Rorty, R. 272, 277-278

Rose, S.F. 233

Rosen, G. 234

Ross, W.D. 59, 68-76

Rudman, L.A. 141

Ruse, M. 108

Russell, B. 94

Ruthven, M. 233

Ryan, Shane 176-177, 188

Ryan, Sharon 2, 27, 58, 94-95, 108, 128, 141, 175, 187, 203, 205

Rydell, R.J. 139

Sacks, H. 257

Sageman, M. 233

Santelli, A.G. 141

Saul, J. 130-131, 133, 136-137, 139-141

Scanlon, T.M. 59, 140

Scheepers, P. 262

Schleifer McCormick, M. 1, 26, 42, 108, 234, 252

Schmeltzer, C. 256

Schroeder, S.A. 293

Schwitzgebel, E. 131, 139-140

Seibt, B. 140

Seinfeld, S. 141

Sellars, W. 277

Sepielli, A. 194

Shah, N. 103, 116, 141, 169, 216

Sharadin, N. 208

Shupe, A. 233-234

Simion, M. 203

Singer, D. 202

Singer, P. 293

skepticism 23, 71, 76, 89, 93, 180-181, 268-269, 271-272, 278

Skorupski, J. 59, 216

Skyrms, B. 68, 75

Slater, M. 141

Sliwa, P. 177, 188

Slovic, P. 256

Small, D. 256
Smith, A.M. 140-141

Smith, H. 172, 203, 234

Smith, M. 200

Smithies, D. 122

Snedegar, J. 59

Sosa, E. 46, 56, 58-59, 80, 92, 292

Southwood, N. 51, 58-59

Stafford, T. 139

Stammers, S. 3, 255

Stapleford, S. 2, 25-26, 39-40, 75, 94-95, 98-99, 101-105, 108, 120-122, 139-140, 158, 172, 264, 293

Steele, J.R. 141

Steele, K. 202, 204

Steglich-Petersen, A. 97, 103, 107, 216

Steinberger, F. 203

Steup, M. 1, 27, 58, 92, 94, 141, 172

Stilgoe, J. 256

Stocker, M. 293

Strawson, P.F. 29, 140, 233

Street, S. 47, 108

Stroud, S. 34, 244, 251-252

Struthers, C.W. 141

Sturgeon, S. 202

Sullivan-Bissett, E. 2, 97, 100, 103, 107-108, 121, 131, 189

suspended judgment 12-13, 15, 85-86, 92, 114-115, 117, 121, 153-154, 161, 163, 186-187, 198-199, 204

Sweetman, J. 139

Sylvan, K. 59

Tabi, E. 141

Talbot, B. 202, 204

Tan, C. 234

Taylor, K. 234

Teske, J. 255

testimony 3, 34-35, 67, 70-71, 73, 76, $78,80,83,130,151,153,158,176$, 183-184, 186, 200, 223, 239-240, 242-252, 264, 274, 288-289, 292-293

Thomson, J. 47

Timmons, M. 93

Tognazzini, N. 41

Townsend, L. 251

Tuomela, R. 234

Turnbull, M.G. 59

Turri, J. 277

UK Home Office 262

unintentional behavior 22-23

Unjustified Belief Argument 15-17, 19

Vahid, H. 216

Vance, S.L. 136 
Van Der Meer, T. 262

Van Eemeren, F. 272

van Woudenberg, R. 172, 234

Vazquez, D. 278

Velleman, D. 216

Voils, C. 139

Wallace, R.J. 140

Walzer, M. 64-66, 75

Wanderer, J. 251

Weatherson, B. 58, 141, 162

Wedgwood, R. 59, 76, 116, 216

West, L. 233

West, M.P. 234

Westlund, A. 41

Whitcomb, D. 181, 188

White, R. 26, 75

White, S. 34, 37
Whiting, D. 216

Wikforss, A. 252

Williams, B. 71, 76, 96

Williams, M. 270, 273-274, 277-278, 292

Williamson, T. 93, 122, 203-205, 277

Winter, T.J. 234

Wodak, D. 59

Wolf, S. 140

Worsnip, A. 203

Wrenn, C. 25, 95, 281

Yaffe, G. 234

Yelderman, L.A. 234

Zagzebski, L. 188, 228, 234

Zimmerman, M.J. 203, 230, 234 


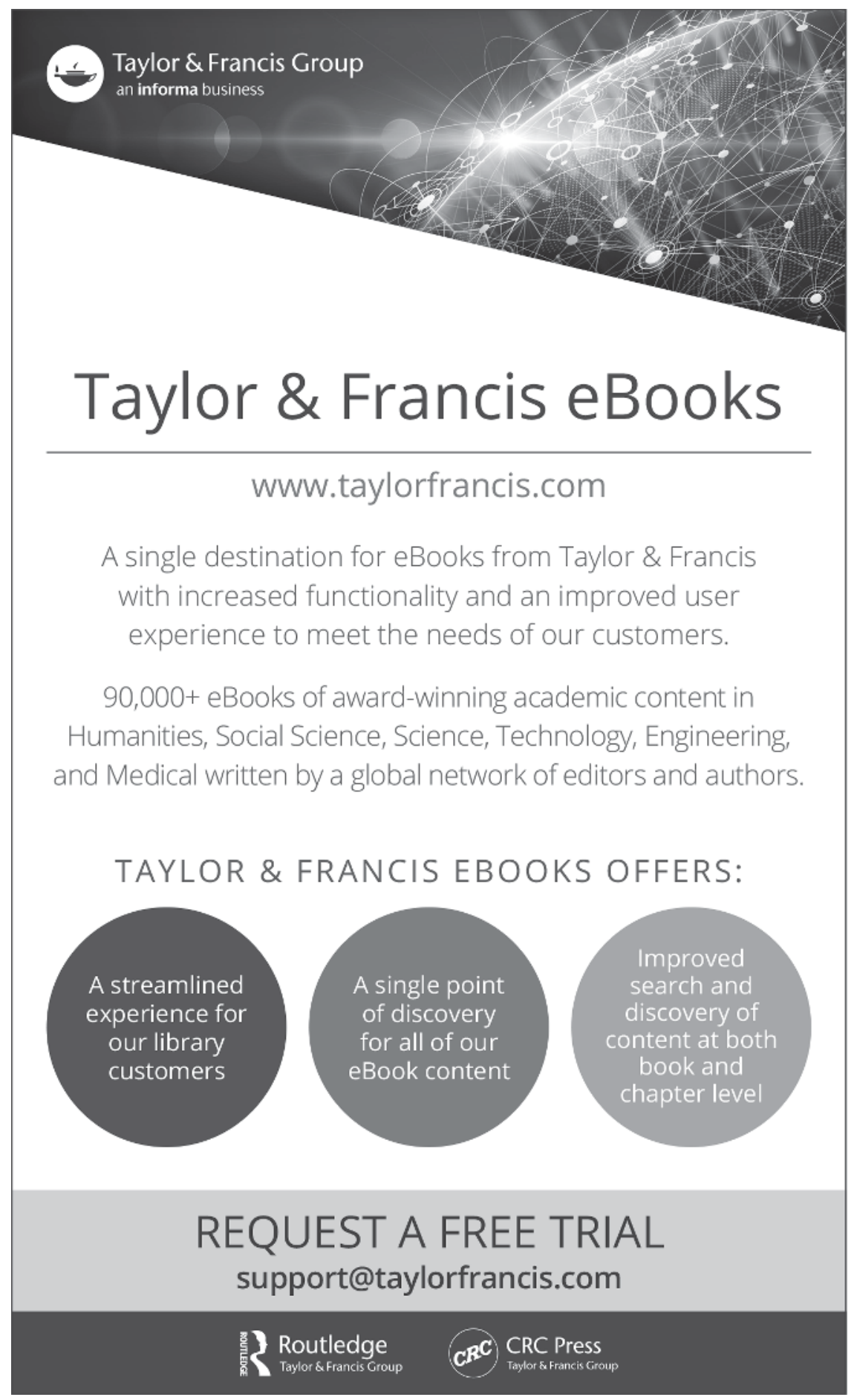

